\title{
Saúde e desenvolvimento humano
}

\author{
Tânia Gracy Martins do Valle \\ Lígia Ebner Melchiori \\ (orgs.)
}

VALLE, TGM., and MELCHIORI, LE., orgs. Saúde e desenvolvimento humano [online]. São Paulo: Editora UNESP; São Paulo: Cultura Acadêmica, 2010. 257 p. ISBN 978-85-7983-119-5. Available from SciELO Books <http://books.scielo.org>.

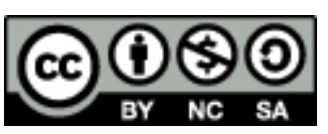

All the contents of this work, except where otherwise noted, is licensed under a Creative Commons Attribution-Non Commercial-ShareAlike 3.0 Unported.

Todo o conteúdo deste trabalho, exceto quando houver ressalva, é publicado sob a licença Creative Commons Atribuição Uso Não Comercial - Partilha nos Mesmos Termos 3.0 Não adaptada.

Todo el contenido de esta obra, excepto donde se indique lo contrario, está bajo licencia de la licencia Creative Commons Reconocimento-NoComercial-CompartirIgual 3.0 Unported. 


\section{SAÚde E DESENVOLVIMENTO HUMANO}


CONSELHO EDITORIAL ACADÊMICO

Responsável pela publicação desta obra

Ana Cláudia Bortolozzi Maia

Carmen Maria Bueno Neme

Lígia Ebner Melchiori

Olga Maria Piazentin Rolim Rodrigues

Sandro Caramaschi 
TÂNIA GRACY MARTINS DO VALLE LÍGIA EBNER MELCHIORI (ORGS.)

\section{SAÚDE E DESENVOLVIMENTO HUMANO}

CULTURA $\frac{\text { ACADÊMICA }}{\varepsilon d i t o n a}$ 
(C) 2010 Editora UNESP

\section{Cultura Acadêmica}

Praça da Sé, 108

01001-900 - São Paulo - SP

Tel.: (0xx11) 3242-7171

Fax: (0xx11) 3242-7172

www.editoraunesp.com.br

feu@editora.unesp.br

CIP - Brasil. Catalogação na fonte

Sindicato Nacional dos Editores de Livros, RJ

\section{S272}

Saúde e desenvolvimento humano / Tânia Gracy Martins do Valle, Lígia Ebner Melchiori (orgs.). - São Paulo : Cultura Acadêmica, 2010.

Inclui bibliografia

ISBN 978-85-7983-119-5

1. Psicologia clínica da saúde. 2. Psicologia do desenvolvimento.

3. Crianças - Desenvolvimento. 4. Psicologia infantil. 5. Adolescentes Conduta. 6. Psicologia do adolescente. 7. Sexo (Psicologia). I. Valle, Tânia Gracy Martins do. II. Melchiori, Lígia Ebner.

$11-0144$.

CDD: 155

CDU: 159.92

Este livro é publicado pelo Programa de Publicações Digitais da Pró-Reitoria de Pós-Graduação da Universidade Estadual Paulista "Júlio de Mesquita Filho" (UNESP)

Editora afiliada:

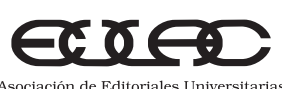

Asociación de Editoriales Universitarias de América Latina y el Caribe

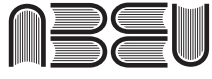

Associação Brasileira de Editoras Universitárias 


\section{Agradecimentos}

Agradecemos aos pareceristas, professores do programa de pósgraduação em Psicologia do Desenvolvimento e da Aprendizagem da Faculdade de Ciências da Unesp Bauru, que leram e contribuíram com sugestões para o aperfeiçoamento dos capítulos deste livro. Também agradecemos, em especial, a colaboração preciosa de Gethiely Silva Gasparini, secretária do referido programa, na preparação dos materiais iniciais e na organização dos documentos necessários para a conclusão desta obra. 



\section{SUMÁRIO}

Apresentação 9

\section{Parte 1 - Sexualidade e corporeidade}

1 Corporeidade e gênero: relações entre homens e mulheres com os cuidados com a saúde 17

2 Imagem corporal em mulheres com depressão 33

3 Sexualidade e vulnerabilidade: reflexão sobre a política de redução de danos 51

\section{Parte 2 - Intercorrências no desenvolvimento infantil}

4 Efeitos do chumbo e da escolaridade no desenvolvimento infantil 69

5 Habilidades sociais de irmãos de crianças com Transtorno do Espectro Autístico 91

6 Estresse e bullying em crianças em condição de sobrepeso e obesidade 113 


\section{Parte 3 - Adolescentes: maternidade, riscos e}

proteção

7 Gravidez e maternidade na adolescência 133

8 Mães adolescentes desenhando e falando sobre suas interações familiares 155

9 Fatores de risco e mecanismos de proteção em adolescentes do sexo feminino com transtorno mental 177

\section{Parte 4 - Manejo de estresse e outros fatores em diferentes populações adultas}

10 Estresse, habilidades sociais e desordens temporomandibulares em universitários 199

11 Manejo de estresse, coping e resiliência em motoristas de ônibus urbano 217

12 Pacientes com líquen oral: avaliação de eficácia adaptativa em estudo longitudinal $\quad 237$ 


\section{ApresentaÇÃo}

Lígia Ebner Melchiori

Este livro representa o esforço de muitas pessoas e é dirigido principalmente aos estudantes de graduação e pós-graduação em Psicologia e áreas afins. Também se destina a pesquisadores que compartilham dos mesmos interesses. Seu objetivo é apresentar contribuições da Psicologia da Saúde e de sua inter-relação com a Psicologia do Desenvolvimento Humano. Ele contém trabalhos extraídos de dissertações elaboradas por alunos do programa de pós-graduação em Psicologia do Desenvolvimento e da Aprendizagem da Unesp, campus de Bauru.

O livro está dividido em quatro seções. Na primeira, "Sexualidade e corporeidade", encontram-se três capítulos. No Capítulo 1, "Corporeidade e gênero: relações entre homens e mulheres com os cuidados com a saúde", Florêncio Mariano da Costa-Junior e Ana Cláudia Bortolozzi Maia abordam, além do conceito de corporeidade, elementos que levam à compreensão de que os cuidados com o corpo variam em função do gênero e, consequentemente, na busca de serviços de saúde e na adesão aos tratamentos. A "Imagem corporal em mulheres com depressão" é abordada no Capítulo 2, no qual Gislaine Lima da Silva e Sandro Caramaschi investigam a percepção da imagem corporal em dois grupos de mulheres, com depressão e sem tratamento para depressão, utilizando escala, ques- 
tionário e avaliando seu peso e índice de massa corporal. Os autores trazem contribuições para a compreensão de múltiplos aspectos envolvidos na percepção corporal de mulheres e uma reflexão sobre a importância de aprofundar-se as investigações dessa área. O Capítulo 3, "Sexualidade e vulnerabilidade: reflexão sobre a política de redução de danos", de autoria de Aline Ariana Alcântara Anacleto e Ana Cláudia Bortolozzi Maia, é um trabalho teórico que aborda um tema polêmico e ainda recente no Brasil. As autoras refletem a respeito da necessidade de se respeitar indivíduos que optem por utilizar drogas e/ou vivenciar práticas sexuais de risco com a implantação de políticas públicas que tratem, previnam e reduzam os possíveis danos causados por tais práticas.

$\mathrm{Na}$ segunda seção, "Intercorrências no desenvolvimento infantil", encontram-se três capítulos. No Capítulo 4, "Efeitos do chumbo e da escolaridade no desenvolvimento infantil", Maria Alice Ferraz Troijo e Olga Maria Piazentin Rolim Rodrigues analisam os efeitos da contaminação por chumbo sobre o desenvolvimento infantil, considerando a frequência ou não à escola, em dois grupos de crianças contaminadas, de quatro a cinco anos, um com concentração de chumbo no sangue acima do nível preconizado pela Organização Mundial de Saúde e outro com concentração abaixo do índice julgado como sendo de risco. As autoras destacam a importância da escola como fator protetivo, uma vez que proporciona apoio e estimulação. No Capítulo 5, "Habilidades sociais de irmãos de crianças com transtorno do espectro autístico", Aline Beatriz Feltrin e Olga Maria Piazentin Rolim Rodrigues apresentam um estudo descritivo e comparativo das habilidades sociais de dez crianças, sendo cinco com irmãos com transtorno de espectro autístico (TEA) e cinco com irmãos com desenvolvimento típico. Foi refutada a hipótese de que irmãos de indivíduos com TEA apresentam menos comportamentos socialmente habilidosos do que irmãos de indivíduos com desenvolvimento dentro do esperado para a faixa etária. Há necessidade de mais estudos que enfatizem a importância de sólidas e satisfatórias relações familiares visando contribuir para o desenvolvimento de diferentes habilidades nas crianças. O Capítulo 6, intitulado 
"Estresse e bullying em crianças em condição de sobrepeso e obesidade", de Lucinéia Crepaldi de Mello e Sandro Caramaschi, apresenta um estudo realizado com 15 crianças acima do peso e suas mães. O objetivo foi avaliar as condições psicossociais de crianças com sobrepeso e obesas, bem como avaliar níveis de estresse e a ocorrência de bullying. Os autores destacam a importância da elaboração de programas de prevenção e intervenção, em nível familiar e escolar, com a finalidade de melhorar a qualidade da saúde física e psicológica das crianças, minimizando situações de estresse e aumentando a habilidade de enfrentamento de situações, tanto das crianças quanto dos educadores, evitando sofrimento emocional daquelas que fogem ao padrão corporal e também situações de bullying.

A terceira seção, intitulada "Adolescentes: maternidade, fatores de risco e de proteção", é composta por três capítulos, todos a respeito da adolescente do gênero feminino. No Capítulo 7, "Gravidez e maternidade na adolescência”, Mariane da Silva Fonseca e Lígia Ebner Melchiori apresentam uma pesquisa que incluiu, além das mães adolescentes, seus companheiros ou genitoras, com o objetivo de investigar as implicações da gravidez e da maternidade nessa fase e as mudanças advindas dessa experiência. A análise quantitativaqualitativa dos dados facilita a percepção da multiplicidade de fatores e visões relativas à maternidade da adolescente na fase do curso de vida de cada um dos participantes. O Capítulo 8, "Mães adolescentes desenhando e falando sobre suas interações familiares", de autoria de Verônica Lima dos Reis, Tânia Gracy Martins do Valle e Ana Cláudia Bortolozzi Maia, procurou compreender as dimensões interacionais que regem a dinâmica familiar de dez mães adolescentes: comunicação, regras, papéis, liderança, conflitos, afeição, integração e autoestima. O desenvolvimento de programas de apoio a famílias com mães adolescentes é novamente discutido, com o objetivo de construir parâmetros norteadores que facilitem a reestruturação familiar e a definição de papéis dos membros envolvidos, ajudando a construir claras fronteiras de relacionamento. No Capítulo 9, "Fatores de risco e mecanismos de proteção a adolescentes do sexo feminino com transtorno mental", as autoras, Cristiane Araújo 
Dameto e Carmen Maria Bueno Neme, apresentam um estudo qualitativo realizado com 16 adolescentes que apresentavam algum tipo de transtorno mental, com o objetivo de investigar fatores de risco e mecanismos de proteção em suas histórias de vida. Os resultados surpreendem e indicam mecanismos protetivos nas categorias pessoal, familiar e social, conforme apontado na literatura.

A quarta seção, intitulada "Manejo de estresse e outros fatores em diferentes populações adultas”, apresenta três capítulos. No Capítulo 10, "Estresse, habilidades sociais e desordens temporomandibulares em universitários", Tânia Gracy Martins do Valle, Rui Mateus Joaquim e Alessandra Turini Bolsoni-Silva verificam a correlação entre o índice de estresse e de habilidades sociais em 57 estudantes universitários distribuídos em dois grupos, com e sem diagnóstico de desordens temporomandibulares. Os autores também verificam se há diferença estatística em função do gênero. Os resultados fornecem importantes subsídios para a prática educativa e para a clínica psicológica. O Capítulo 11, "Manejo de estresse, coping e resiliência em motoristas de ônibus urbano”, foi elaborado por Luciana Silva Zanelato e Sandra Leal Calais. As autoras trabalharam com um grupo experimental e controle e realizaram intervenção com o objetivo de proporcionar aos motoristas atitudes mais adequadas e eficazes no enfrentamento do estresse, visando ações que promovam a saúde. São feitas importantes reflexões para a elaboração de estratégias preventivas em nível individual e coletivo, além de ações de caráter contínuo, contribuindo para uma melhor qualidade de vida dos motoristas, dos serviços prestados aos passageiros, além da prevenção de possíveis acidentes de trânsito. $\mathrm{O}$ Capítulo 12, "Pacientes com líquen oral: avaliação de eficácia adaptativa em estudo longitudinal”, é de autoria de Mirella Martins Justi e Carmen Maria Bueno Neme. As autoras apresentam um estudo realizado com dez pacientes diagnosticados com líquen plano oral, uma desordem mesocutânea que aparece e é agravada por situações de estresse e ansiedade, verificando a eficácia da psicoterapia breve operacionalizada grupal. O estudo permitiu constatar a relevância da colaboração multidisciplinar na investigação científica e os efei- 
tos, ao longo do tempo, da psicoterapia realizada, tanto no manejo do estresse como na adaptabilidade e na redução das lesões orais. Sugere-se a realização de outros estudos longitudinais com interface entre a Psicologia e outras especialidades em saúde.

Espera-se que este livro possa ser útil, estimulando os leitores a envidar esforços na realização de novas pesquisas e construir, junto a outras áreas de investigação, um conhecimento relevante do ponto de vista social e científico. 

Parte 1

SeXualidade e corporeidade 



\title{
1 \\ CORPOREIDADE E GÊNERO: RELAÇÕES ENTRE HOMENS E MULHERES COM OS CUIDADOS COM A SAÚDE ${ }^{1}$
}

\author{
Florêncio Mariano da Costa-Junior ${ }^{2}$ \\ Ana Cláudia Bortolozzi Maia ${ }^{3}$
}

\section{Introdução}

Este texto apresenta uma retomada teórica fundamentada na revisão da literatura de um estudo mais amplo que investigou a concepção de profissionais da saúde - seis enfermeiros/as e cinco médicos/as - sobre questões de gênero e cuidados com a saúde. Neste estudo, os dados revelaram elementos que levam ao entendimento dos cuidados em saúde como um produtor e produto das concepções de corpo e de gênero. Tais cuidados e concepções foram apreendidas ao longo das experiências interpessoais e também pela socialização vivenciada ao longo do ciclo vital. Aquilo que se aprende quanto ao corpo e aos cuidados a ele prestados varia em relação ao gênero e influencia diretamente nas condições e nos cuidados pres-

1 Baseado na dissertação de mestrado Concepções de médicos/as e enfermeiros/as sobre questões de gênero na saúde, de autoria do primeiro autor sob orientação da segunda autora.

2 Programa de pós-graduação em Psicologia do Desenvolvimento e da Aprendizagem da Faculdade de Ciências da Unesp, campus de Bauru.

3 Programa de pós-graduação em Psicologia do Desenvolvimento e da Aprendizagem da Faculdade de Ciências da Unesp, campus de Bauru. 
tados à saúde de homens e mulheres. Alguns fragmentos das falas dos participantes deste estudo ilustrarão a teoria apresentada.

\section{Corporeidade e gênero: controle e normatização do corpo}

O corpo é a primeira evidência incontestável da diferença humana, e em todas as sociedades os seres humanos são confrontados com um fato idêntico: a diferença corporal relativa à diferença sexual. Ao longo do processo de civilização, cada cultura construiu uma forma particular de simbolizar e conceber essa diferença, produzindo múltiplas versões sobre a dicotomia homem-mulher. Essas formulações simbólicas das diferenças sexuais ganham forma nos conjuntos de práticas subjetivas, representações sociais que influenciam e condicionam a conduta objetiva e subjetiva dos indivíduos em função do seu sexo (Lamas, 2007; Menezes \& Heilborn, 2007).

A palavra "corpo", usualmente utilizada em nossa língua para definir a entidade orgânica da qual os seres humanos são constituídos, pouco descreve seu papel diante do funcionamento coletivo e individual em nossa atual sociedade. Durante séculos, as ciências analisaram o corpo humano somente em seu aspecto físico e funcional. A partir dos anos 30 do século passado, novos atributos são adicionados à noção de "corpo" e é nesse cenário social que o corpo e a corporeidade ultrapassam os debates restritos ao viés biológico (Giffin, 1991; Martins, 2001).

No debate acadêmico acerca do corpo humano passa a ser analisado como uma construção histórica e subjetiva. Seguindo essa compreensão, o corpo é uma condição humana contingente à construção histórica e cultural que de modo incisivo fundamenta a constituição da subjetividade, sendo essa última composta, entre outros fatores, pela identidade de gênero e pelas relações de gênero. ${ }^{4}$ Tal como nos

4 Segundo Joan Scott (1995), o termo "relações de gênero" refere-se ao modo como as culturas organizam a hierarquia entre as pessoas em função do sexo. 
apontam Rohden (2001; 2003), Mosse (1998) e Martins (2004), as intervenções e os estudos sobre o corpo masculino e feminino são distintas, e ao longo da história os desdobramentos dessa diferenciação fortaleceram o estabelecimento de padrões normativos socialmente considerados "adequados", referentes a um ou outro sexo biológico, que respaldaram a discriminação dos "desviantes".

O corpo humano é historicamente objeto de interesse de várias ciências e, por variados motivos, configurou-se como cenário no qual atuam os instrumentos de normatização e de adequação dos indivíduos segundo as normas e valores vigentes nos diferentes períodos da história da humanidade. Ao classificar as diferenças corporais existentes entre os sexos, as ciências formataram as concepções naturalizadas dos papéis sociais atribuídos aos homens e às mulheres e, consequentemente, a forma como os indivíduos lidam com seus corpos. As classificações culturais fundamentam os dispositivos, ${ }^{5}$ as obrigações sociais de cada sexo e também uma série de proibições que asseguram a manutenção da dicotomia entre masculino e feminino. E o gênero marca a percepção e a relação humana nas esferas sociais, políticas e religiosas, bem como enviesa a produção de conhecimento de modo a legitimar os mecanismos de exclusão e dominação (Butler, 2008; Bourdieu, 2003; Lamas, 2000; 2007).

O corpo é, portanto, um dos instrumentos no qual operam tanto os caracteres genéticos como os dispositivos sociais. É, sobretudo, o objeto no qual atuam as intervenções em saúde. Baseando-se nas denominações de "saudável" ou "doente", as ciências da saúde focam no corpo sua maior atenção, pois é nele que se manifestam as doenças e é nele que se deve promover a saúde. Desde a fecundação, o corpo

Tal hierarquia é mediada pelas relações de poder existentes nos diversificados contextos sociais.

5 Dispositivo, segundo Foucault (2005, p.244), é "um conjunto decididamente heterogêneo que engloba discursos, instituições, organizações arquitetônicas, decisões regulamentares, leis, medidas administrativas, enunciados científicos, proposições filosóficas, morais, filantrópicas. Em suma, o dito e o não dito são os elementos do dispositivo. O dispositivo é a rede que se pode estabelecer entre esses elementos". 
inicia seu processo de transformação, e durante as etapas de desenvolvimento psicológico, todos nós somos formados e formadores dessas normas, conduzidos por significados sobre o corpo, pois o processo de socialização é predominantemente pautado em normas de conduta e valores (Giffin, 1991; Martin, 2006; Rohden, 2001; 2003).

As formas, os atos e os padrões estéticos de utilização do corpo configuram aquilo que Marcel Mauss (1974) conceituou como "Técnicas corporais", sendo tal conceito amplamente utilizado nas ciências humanas. Desse modo, as formas de utilização do corpo por meio de técnicas corporais são provenientes das experiências vividas pelos indivíduos e é a partir da relação entre o homem e a sociedade que são configurados o seu modo de ser, sentir ou de agir (Mauss, 1974; Sarti, 2001).

Segundo Sarti (2001), o processo de socialização implica dois momentos indissociáveis: o contato do indivíduo com a sociedade, ou seja, com a realidade objetiva, e a interiorização desta como realidade subjetiva. Seguindo esse raciocínio, os indivíduos só irão construir suas experiências e concepções mediante as referências coletivas iniciadas logo ao nascer e renovadas ao longo de seu desenvolvimento.

Autores como Sarti (idem) e Mauss (1974) defendem que o corpo, para além de seu caráter anatomofisiológico, é produto de processos culturais inerentes a uma dada sociedade. Portanto, o corpo, seus significados, seu uso e o cuidado que lhe é prestado de modo individual ou coletivo são fruto de uma aprendizagem social que resulta na construção de uma condição psicológica em cada indivíduo. Os autores compartilham a ideia de corpo como linguagem adquirida culturalmente, sendo os costumes um tipo de ordem dessa linguagem sobre a qual os sujeitos não têm total clareza. Segundo Sarti (2001, p.6), "tal como a gramática da língua não é plenamente conhecida pelos falantes, a ordem da linguagem simbólica do corpo não é amplamente conhecida pelos seus agentes".

O corpo não é apenas um instrumento técnico resultante da interação cultural. É, sobretudo, um lugar prático no qual o controle social exerce seu poder (Foucault, 1981). É por meio da organização e regulamentação do tempo, do espaço e das convenções cotidianas 
que os corpos são disciplinados segundo a forma histórica dominante de individualidades, desejos, masculinidade ou feminilidade, e, dessa forma, o controle social fundamenta e homogeneíza o habitus, o modus operandi das condutas e práticas sociais típicas de uma classe, de um grupo social, do gênero, entre outros (Mauss, 1974; Sarti, 2001; Bordo, 1997). Mauss (1974, p.214) define habitus como as práticas sociais e os hábitos que "não variam simplesmente com os indivíduos e suas imitações, mas, sobretudo, com as sociedades, as educações, as conveniências e as modas, com os prestígios".

Os modos de vida ou as práticas sociais são, de todo modo, transmitidas pelas instituições formadoras, as quais podem ser agrupadas em dois conjuntos: as instituições que cuidam, como a família, os sistemas de saúde, e as instituições que ensinam, como escolas, organizações e centros de saúde. Sarti (2001) discorre sobre o controle coercitivo inerente às práticas coletivas, nas quais a coerção aparece quando se tenta sair da regra, ou seja, quando os indivíduos buscam resistir ou transformar práticas consolidadas e normativas existentes dentro das instituições sociais. Então o corpo, tal como a formação de subjetividade, constitui-se a partir de uma tensão constante entre o sujeito, com suas particularidades, e o coletivo, com suas regras de conduta rigidamente estabelecidas.

Sarti (idem), referindo-se aos estudos desenvolvidos junto à comunidade indígena, aponta que nessas comunidades havia um ideal no qual a sociedade submetia o corpo a periódicos processos de fabricação. Tais processos eram distintos daquilo que nas sociedades civilizadas chama-se de intervenção médica, pois essas práticas, como advoga Foucault (1981), são práticas de poder que ferem a autonomia do sujeito em relação a seu próprio corpo. Isso não ocorre no contexto indígena. Nas sociedades tribais o apoderamento do corpo é um processo pedagógico no qual lhe é atribuido um código. A sociedade imprime sua marca no corpo e com isso os indivíduos passam a ser reconhecidos pela fidelidade à lei, a vontade de ser e a de pertencer a um grupo. Nesse sentido, os tribais conhecem claramente os motivos pelos quais e para os quais o corpo é fabricado e as etapas que pressupõem os momentos de intervenção social (Sarti, 2001). Os significa- 
dos sociais marcam claramente as formas como a experiência corpórea será vivida nos momentos de rituais de fabricação do corpo.

Nos ambientes modernos, o corpo também sofre intervenções, sejam elas físicas ou sociais. Nesses momentos, as clivagens do gênero instituem modos distintos de lidar com a experiência corpórea. Assim, suportar a dor em silêncio pode ser sinal de virilidade em algumas culturas que, em contrapartida, permitem e valorizam a expressão explícita do sofrimento nas mulheres (idem, ibidem). Os relatos abaixo exemplificam essa questão.

[...] homem é durão, homem não fica doente. "Magina! Você vai no médico pra quê? Tá tudo bem, você tá forte aî". (Enfermeira, 26a)

Mulher, qualquer coisinha vai ao médico. Uma dor de cabeça, se tá tensa. Mulher se queixa mais, se preocupa mais. (Médica, 37a)

[...] a mulher aceita as condições de tratamento. A mulher, se ela tem uma orientação médica, ela vai seguir. A mulher, embora tenha isso também, ela é um pouco mais receptiva nisso. Ela aceita melhor essa condição de ter que se sentir manipulada, de ter que tomar medicação. (Enfermeira, 31a)

[...] culturalmente, foi desenvolvida essa preocupação maior com a mulher. Até porque é maior a quantidade de doença, ela acabou sendo mais cuidadosa. (Enfermeiro, 30a)

O papel antes desempenhado pelo líder religioso da comunidade indígena, agora é assumido por profissionais da saúde que irão interferir decisivamente na significação do corpo do paciente (Foucault, 1981; Sarti, 2001). Desse modo, a forma como o profissional reage diante dos comportamentos do doente influencia na própria reação do paciente diante do tratamento - ambos qualificando a experiência com o corpo e seus aspectos subjetivos (Sarti, 2001). Segundo Montanger (2006), nesse cenário operam as representações, e tais representações são manifestações de um habitus que, objetivas por si mesmas, exercem sua coerção sobre os indivíduos. 
A aprendizagem decorrente dos processos de instrução sobre o corpo produz relações distintas entre a função, a necessidade e o manejo do corpo de acordo com o sexo biológico. Nesse sentido, homens e mulheres aprendem a perceber e a lidar de maneira diferente com seu corpo, pois aqueles são socialmente representados na cultura segundo a norma: prescritiva de um masculino saudável, ativo e resistente, em contraste com um feminino frágil, instável e sensível a doenças.

Os relatos abaixo exemplificam a forma como o corpo feminino é representado. As mulheres estariam mais vulneráveis a doenças devido a um desgaste físico maior ou devido a sua composição física. A interação entre o corpo feminino, os remédios comumente utilizados por algumas mulheres e determinados hábitos de vida resultaria em vulnerabilidade:

Ela é mais vulnerável assim, em termos de imunidade, ela acaba se tornando uma pessoa mais vulnerável: imunidade, psicológico, hormonal. Tem muita alteração hormonal na mulher. (Enfermeiro, 30a)

A mulher está mais predisposta [a doenças] [...] eu acho que até mesmo pelo desgaste físico dela, que é maior, entendeu? E assim, tem os anticoncepcionais, tudo isso. (Enfermeira, 31a)

Além disso, os relatos apresentados também ilustram a crença de que as mulheres cuidam mais da saúde, previnem-se mais e aderem ao tratamento. Embora tenham medo e receio, as mulheres procuram mais os serviços de saúde, são mais dedicadas e interessadas no diagnóstico e no tratamento, aceitam mais os exames que possam ser invasivos, pois estão acostumadas com isso, e, principalmente, têm mais atitudes preventivas:

A mulher, ela tem essa coisa de perceber essas coisas menores, ela está mais atenta ao detalhes, entendeu? Com isso ela acaba percebendo os primeiros sintomas, ela vai acabar indo atrás no começo, ela vai atrás, ela se preocupa mais, ela tem esse tempo. (Médica, 35a) 
A mulher, principalmente na prevenção, ela previne muito mais do que o homem. Lógico, é uma coisa desde menina. A mulher, na maioria das famílias, ela já é criada para ter determinados cuidados com ela mesma. (Enfermeira, 35a)

Preventivamente, ela se preocupa mais, faz mais exames preventivos do que os homens [...] a mulher adere melhor ao tratamento. Ela consegue assimilar melhor a doença e consegue administrar melhor esse tratamento também. (Enfermeiro, 30a)

As diferenças sociais que em nossa cultura caracterizam os sexos irão delimitar determinados percursos para o desenvolvimento social e psicológico de homens e mulheres. Isso pode ter relação quanto aos cuidados com o corpo e com a saúde. Os escritos de Graciano (1978), Afonso (1995), Reis (2008) e Maia \& Maia (2009) têm mostrado como a educação familiar e institucional são importantes para "ensinar" modelos comportamentais de masculinidade e feminilidade por meio da socialização. Quando internalizadas ou aprendidas pelos sujeitos, as normas do que é masculino e feminino ou do que é ser homem ou ser mulher são reproduzidas no dia a dia e, com isto, mantêm as desigualdades de socialização e educação.

\section{Gênero e desenvolvimento humano}

Durante o desenvolvimento, homens e mulheres são educados em função das naturezas distintas: vivem e são conduzidos por motivações e interesses distintos, como fazendo parte de papéis predefinidos atribuídos aos sexos. A sociedade modela as "diferenças" a partir de crenças que são fundamentadas em estereótipos de gênero sociais e culturais (Graciano, 1978; Lamas, 2007).

Nossa percepção acerca do mundo desde o início está condicionada pela forma já estabelecida na cultura em que habitamos, dessa maneira, no caso de gênero, a constituição individual e psicológica é desde sempre influenciada pelo discurso social dominante no que se refere ao "ser homem" ou "ser mulher" (idem, ibidem). 
Nos seres humanos, a identidade de gênero se estabelece junto à aquisição da linguagem e é anterior ao conhecimento da diferença anatômica entre os sexos. Nessa etapa do desenvolvimento, a criança estrutura suas experiências com o gênero ao qual pertence e identifica suas manifestações (Graciano, 1978; Hidalgo \& Palácios, 2004). A experiência da criança com seu sexo biológico e com as primeiras abstrações e prescrições sociais de padrões hegemônicos culmina na formação de gênero (Lamas, 2000; Moro, 2001).

As relações de gênero são estabelecidas e aprendidas de modo gradual por meio de processos de socialização que se iniciam logo após o nascimento e, nesse sentido, a família tem grande responsabilidade na educação sexista (Graciano, 1978; Maia \& Maia, 2009; Parker, 2000; Rocha, 2000; Whitaker, 1995). Estudos mostram que os membros da família reproduzem uma educação sexual e moral diferenciada em relação ao gênero de seus filhos/as, evidenciando vantagens e desvantagens na infância justificadas pelo gênero a que pertencem (Belotti, 1979; Moreno, 1999; Maia \& Maia, 2009; Navarro, 2005; Reis, 2008; Whitaker, 1995).

A educação sexista nas instituições familiares e escolares, comum na infância e na adolescência, procura adequar o sujeito para que ele corresponda o mais coerentemente possível aos modelos de masculino e feminino que são considerados "normais" na sociedade, e isso, segundo Maia \& Maia (2009, p.50), representa um "custo emocional para todos - tanto para as mulheres quanto para o homem - em reproduzir o modelo de gênero existente, pois há sempre punições para aqueles que não se adaptam”.

O relato abaixo exemplifica uma concepção na qual se define a influência de traços genéticos como determinantes para o desenvolvimento de características tidas como tipicamente masculinas e femininas.

Existe um ponto de vista assim, educacional... "Ah, é porque criou as meninas desse jeito e os meninos daquele jeito". Mas eu acho que tem uma coisa um pouco antes, até mesmo genética [...] tenho uma paciente de hemodiálise que tem três anos de idade e veio de uma família 
cultural extremamente pobre, que não tem acesso a nada e ela tava há dois anos aqui dentro internada. Então, ela não tem um convívio familiar. Ela é extremamente feminina, gosta de batom, de esmalte, ela quer pentear os cabelos de um jeito, ela adora as bonecas. E isso é interessante porque é só médico, técnico de enfermagem que tem que estimular. Ela cuida, ela quer dar de mamar, então ela tem toda uma coisa que já vem na própria natureza. (Médica, 37a)

O contexto de cuidado hospitalar e as interações nele presentes segundo a concepção do relato acima parecem pouco influentes no desenvolvimento e na aprendizagem de condutas tidas como características do sexo feminino. No entanto, as expectativas sociais produzem por si mesmas a necessidade de tipificação e adequação do gênero ao sexo biológico. A prática profissional baseada na naturalização da masculinidade e da feminilidade exime a própria atuação como um elemento que ratifica a desigualdade de gênero. Ou seja, ao naturalizar aquilo que é vantajoso ou desvantajoso na conduta de homens e mulheres, retira-se a responsabilidade do contexto sobre a aprendizagem do que atualmente consideramos como tipicamente "de homem" ou "de mulher".

Nas últimas décadas, a relação entre gênero e desenvolvimento humano foi objeto de estudo de pesquisadores de diferentes áreas das ciências, como a Educação e a Psicologia. Graciano (1978) e Hidalgo \& Palácios (2004) defendem que as expectativas parentais são fundamentais para a configuração do ambiente familiar no qual o recém-nascido será recebido.

A relação entre contexto ambiental, composto por práticas parentais, cultura, normas e valores, é notavelmente distinta em relação ao sexo biológico. Graciano (1978), Whitaker (1995) e Belotti (1975) comentam que os processos sociais responsáveis pela construção dos papéis sexuais são iniciados a partir da gestação, quando já existem expectativas sobre o sexo do bebê. O tratamento diferenciado que meninos e meninas recebem ao longo de sua socialização, além de estimular ou inibir o acesso a determinados contextos, produz o desenvolvimento de determinadas habilidades e característi- 
cas pessoais diferenciadas e isto é interpretado em nossa sociedade como natural, determinado pelo sexo biológico e não pela cultura (Graciano, 1978; Hidalgo \& Palácios, 2004; Whitaker, 1995). Contrapondo esse conhecimento compartilhado por vários pesquisadores da área, temos o seguinte relato:

[...] a gente vê toda uma diferença do gênero feminino mais voltado, desde a infância, pra questão da procriação. $O$ gênero masculino já não é tão voltado pra esse lado [...] a pessoa se encaixa naquilo que anatomicamente ela nasceu pra ser: ser uma mulher ou ser um homem. Algumas coisas a gente vê de bebê, você fala que o bebê é uma menina: o olhar, o jeitinho. Outras coisas você percebe já no primeiro ano de vida [...] A maneira como as meninas olham a boneca, pegam a boneca, é diferente. E os meninos, não. A menina tem o jeito mais delicado. Então, a menina, quando pega o carro pra brincar, ela brinca de maneira mais delicada. Ela anda com o carro, coloca o bebê no carro, cuida do carro. O menino, quando pega o carro, ele quer brincar, quer correr, quer ver o quanto que ele derruba. (Médica, 37a)

Porém, há também quem se baseie na crença de que a origem das diferenças está na história de socialização, na educação e na cultura, a partir de certas características "históricas", tais como o homem ser "provedor" e "forte" e a mulher ser "submissa" e "dona de casa". Os argumentos também se relacionam com a educação familiar e intergeracional e também com a escolar, como podemos ver nos relatos.

É a própria história do homem. Ele sempre foi colocado como o ser mais forte, e a mulher como o sexo mais frágil. O homem foi colocado como o responsável, pai de família, que trabalha e que tem que ter atitude. A mulher já é colocada naquela posição de ser mais mansa, mais humilde e mais dona de casa, cuidar de filhos, essas coisas. (Enfermeira, 40a)

Eu acredito que pela sociedade machista que a gente vive, vem de gerações em gerações. (Médico, 36a) 
Eu acho que é o que é passado pra gente desde que a genteé criança. O que você aprende na escola, na verdade desde que você entra, começa a crescer e se entender por gente, é colocado pra você que menina é corde-rosa e que menino é azul. Que menina é delicada e que menino é agressivo, que menino é rude. Então, você cresce com essas características. (Médica, 35a)

Os estudos de Graciano (1978), Silva et al. (1976) e Karraker et al. (1995) demonstram que os pais consideram as meninas mais prestativas, delicadas e interessadas pela vida doméstica e pela vida privada. Os meninos, por sua vez, são vistos como menos prestativos, mais agressivos e competitivos, voltados para as atividades públicas. Traços mais delicados são atribuídos aos bebês femininos mesmo quando estes não apresentam diferenças estéticas comportamentais perceptíveis (Graciano, 1978; Karraker et al., 1995). Já as mães tendem a demonstrar melhores expectativas profissionais pelos filhos, sendo que profissões de maior reconhecimento social e financeiro são também atribuídas a crianças do sexo masculino (Karraker et al., 1995; Reis, 2008).

$\mathrm{O}$ ambiente de educação formal não foge às normatizações do gênero e, segundo dados analisados por Afonso (1995), as educadoras tendem a considerar meninas mais carinhosas e mais fáceis de lidar, o que atua na formação do autoconceito das crianças. A crença de que as meninas são dóceis, atenciosas e carinhosas, e de que aos meninos correspondem os adjetivos antônimos irá repercurtir na formação da identidade desses indivíduos (Afonso, 1995, Graciano, 1978, Hidalgo \& Palácios, 2004).

De acordo com Moro (2001), os professores tendem a considerar de maneira mais positiva as produções acadêmicas de meninos em detrimento das meninas, e isso claramente resulta em um maior engajamento dos meninos nas atividades de pesquisa e na produção científica. Esses educadores legitimam a desigualdade de oportunidades, pois provavelmente compartilham da concepção na qual as distintas constituições cerebrais resultariam em diferentes capacidades em meninos e meninas, e assim seus desempenhos seriam 
recebidos e avaliados de forma diferente (Moro, 2001; Navarro, 2005). Possivelmente, essa mesma legitimação da desigualdade nos contextos de ensino referida pelos autores ocorra nas instituições que prestam cuidados em saúde e que também são contextos de ensino. Neste caso, nos referimos ao ensino dos conhecimentos sobre o corpo, aos cuidados a ele prestados e, sobretudo, ao ensino da expressão daquilo que se sente e vivência pelo corpo.

Ainda que entendamos a biologia como uma variável que influencia diretamente no produto final das características masculinas e femininas, essas características não existem independentemente da cultura em que os sujeitos desenvolvem-se. Segundo Graciano (1978), por meio de uma complexa interação, a influência biológica define-se pela atuação dos hormônios, e a influência cultural, pela atuação do meio social na modelagem de comportamentos.

As concepções construídas sobre a biologia fundamentam, e muito, as concepções discriminatórias e a facilidade ou dificuldade em lidar com a condição corporal. A diferença presente na anatomia e nas funções sexuais e reprodutivas de homens e mulheres não parece ser capaz de induzir condutas distintas de cuidados com o corpo (Magalhães \& Ribeiro, 2009).

\section{Considerações finais}

O corpo como uma construção social não é somente produto dos fatores biológicos que o constituem, mas, sobretudo, uma expressão de humanidade, pois traz em sua formação inúmeros valores e normas vigentes na cultura. Esse corpo cultural e histórico deve ser compreendido e atendido em suas diferentes especificidades, especialmente quando se tratam das questões de gênero sobre as quais se assenta a maneira como homens e mulheres aprendem a lidar com o corpo.

Os avanços nos serviços de saúde ao longo dos anos aprimoraram as técnicas de intervenção sobre o corpo biológico sem considerar seus constituintes culturais e dos cuidados a ele prestado. Uma 
vez que é por meio da socialização e também da interação entre os profissionais e seus pacientes que se estabelecem os processos educativos quanto aos cuidados com a saúde, parece evidente que a eficácia dos cuidados preventivos e terapêuticos depende do entendimento sobre o corpo e do cuidado em sua total complexidade.

\section{Referências bibliográficas}

AFONSO, L. Gênero e processo de socialização em creches comunitárias. Cadernos de Pesquisa. São Paulo, n.93, p.12-21, maio 1995.

BELOTTI, E. G. Educar para a submissão: o descondicionamento da mulher. Petrópolis: Vozes, 1975.

BORDO, S. R.. O corpo e a reprodução da feminilidade: uma apropriação feminista de Foucault. In: JAGGAR, A. M.; BORDO, S. R. Gênero, corpo, conhecimento. Rio de Janeiro: Rosa dos Tempos, 1997, p.21-41.

BOURDIEU, P. A dominação masculina. Rio de Janeiro: Bertrand Brasil, 2003.

BUTLER, J. Problemas de gênero: feminismo e subversão da identidade. 2.ed. Rio de Janeiro: Civilização Brasileira, 2008.

CONNELL, R. W. Políticas da masculinidade. Educação e Realidade. v.20, n.2, p.185-206, 1995.

COSTA-JUNIOR, F. M. Concepções de médicos/as e enfermeiros/as sobre questões de gênero na saúde. Dissertação (mestrado em Psicologia do Desenvolvimento e da Aprendizagem). Faculdade de Ciências, Universidade Estadual Paulista, Bauru, 2010.

FOUCAULT, M. Microfísica do poder. 2ed. Rio de Janeiro: Graal, 1981.

História da sexualidade I: a vontade de saber. São Paulo: Graal, 2005.

GIFFIN, K. M. Nosso corpo nos pertence: a dialética do biológico e do social. Cad. Saúde Pública. v.7, n.2, p.190-200, 1991.

A inserção dos homens nos estudos de gênero: contribuições de um sujeito histórico. Ciência e saúde coletiva. Ano 10, n.1, p.47$57,2005$. 
GRACIANO, M. Aquisição de papéis sexuais na infância. Cadernos de Pesquisa. São Paulo, n.25, p.29-44, jun. 1978.

HIDALGO, V.; PALÁCIOS, J. Desenvolvimento da personalidade entre os dois e sete anos. In: COLL. C.; MARCHESI, A.; PALÁCIOS, J. (Orgs.) Desenvolvimento psicológico e educação. Tradução de Deisy Vaz de Moraes. Porto Alegre: Artmed, 2004.

KARRAKER, K. H.; VOGEL D. A; LAKE, A. Parents' genderstereotyped perceptions of Newborns: The Eye of the Beholder revisited. Sex Roles. v.33, p.687-701, 1995.

LAMAS, M. Gênero: os conflitos e desafios do novo paradigma. Proposta. Rio de Janeiro, n.84/85, p.12-25, 2000.

O Gênero é cultura? In: V Campus euroamericano de cooperação cultural. Almada: 2007.

MAGALHÃES, J. C.; RIBEIRO, P. R. C. As neurociências ensinando modos de ser homem e mulher em revistas de divulgação científica. Revista eletrônica de Enseñanza de lãs Ciências. ano 8, n.2, p.692710, 2009.

MAIA, A. C. B.; MAIA, A. F. Educação para as questões de gênero e diversidade sexual. In: MORAES, M. S. S.; MARANHE E. A. (Orgs.). Educação na diversidade e cidadania. v.4. Bauru: Unesp; Brasília: MEC/Secad, 2009.

MARTIN, E. A mulher no corpo: uma análise cultural da reprodução. Rio de Janeiro: Garamond, 2006.

MARTINS, A. P. V. Visões do feminino: a medicina da mulher nos séculos XIX e XX. Rio de Janeiro: Fiocruz, 2004.

MAUSS, M. Sociologia e Antropologia. São Paulo: Epu/Edusp, 1974.

MENEZES, R. A.; HEILBORN, M. L. A inflexão de gênero na construção de uma nova especialidade médica. Revista Estudos Feministas. v.15, n.3, p.563-80, dez. 2007.

MORENO, M. Como se ensina a ser menina: o sexismo na escola. Tradução de Ana Venite Fuzatto. São Paulo: Moderna; Campinas: Unicamp, 1999.

MORO, C. G. A questão de gênero no ensino de ciências. Chapecó: ARGOS, 2001.

MOSSE, G. L. Masculinidade e decadência. In: PORTER, R.; TEICH, M. (Orgs.). Conhecimento sexual, ciência sexual: a história das atitudes em relação à sexualidade. São Paulo: Fundação Editora Unesp, 1998. 
NAVARRO, C. Z. Questões de gênero no contexto escolar. Monografia. Trabalho de Conclusão de Curso (curso de Pedagogia). Faculdade de Ciências, Universidade Estadual Paulista, Bauru, 2005.

PARKER, R. G. Corpos, prazeres e paixões: a cultura sexual no Brasil contemporâneo. Tradução de Maria Therezinha Cavallari. São Paulo: Best Seller, 2000.

REIS, K. C. F. Infância, gênero e estereótipos sexuais: análise do relato de mães de crianças de 4 a 6 anos. Dissertação (mestrado em Psicologia do Desenvolvimento e Aprendizagem), Faculdade de Ciências, Universidade Estadual Paulista, Bauru, 2008.

ROCHA, C. M. F. Desconstruções edificantes: uma análise da ordenação do espaço como elemento do currículo. Dissertação. Porto Alegre, UFRGS/FACED/PPGEDU, 2000.

ROHDEN, F. Uma ciência da diferença: sexo e gênero na medicina da mulher. Rio de Janeiro: Fiocruz, 2001.

Ginecologia, gênero e sexualidade na ciência do século XIX. Horizontes Antropológicos. Porto Alegre, ano 8, n.17, p.101-25, 2002. A construção da diferença sexual na medicina. Cad. Saúde Pública. Rio de Janeiro, ano 19, n.2, p.201-12, 2003.

SARTI, C. A. A dor, o indivíduo e a cultura. Saúde soc. v.10, n.1, p.313, 2001.

SCOTT, J. Gênero: uma categoria útil de análise histórica. Educação E Realidade. v.20, n.2, p.71-99, 1995.

SILVA, T. R. N.; GRACIANO, M.; GUARIDO, E. L. Estudo sobre estereótipos sexuais nas percepções dos pais em relação a comportamentos e atitudes de seus filhos. Cadernos de Pesquisa. São Paulo, n.21, p.15-40, 1976.

WHITAKER, D. C. A. Menino - menina: sexo ou gênero? In: SERBINO, R. V.; GRANDE, M. A. R. L. (Orgs.), A escola e seus alunos: o problema da diversidade cultural. São Paulo: Fundação Editora Unesp, 1995, p.31-52. 


\section{2 \\ IMAGEM CORPORAL EM MULHERES COM DEPRESSÃO}

Gislaine Lima da Silva Sandro Caramaschi

\section{Introdução}

A imagem corporal é um aspecto considerado importante pelos indivíduos desde os povos primitivos. Na sociedade atual, sua importância está diretamente relacionada a transtornos alimentares, na sua percepção e distorção, interferindo na autoestima e promovendo o adoecimento psíquico quando há obsessão pela magreza estimulada pela mídia, pelas relações sociais e pela família. $\mathrm{Na}$ maioria dos casos, alterações na percepção corporal estão associadas à depressão e a outros aspectos psicopatológicos (Tavares, 2003).

Schilder (1999) apresentou contribuições que englobam aspectos fisiológicos, psicanalíticos e sociológicos na análise da imagem corporal. As sensações e a experiência visual participam da formação da imagem corporal, que pode sofrer modificações continuamente, considerando-se as emoções e as mudanças sociais possibilitadas pela moda, pela dança e pela ginástica.

Do ponto de vista antropológico, Assumpção Jr. (2004) faz um levantamento detalhado considerando diferentes momentos históricos que demonstram a preocupação com a imagem corporal, de aspectos físicos e de dimensões corporais até o uso de pinturas e aces- 
sórios. Ao longo desses momentos, existiu uma alternância da valorização entre mulheres magras e aquelas de formas arredondadas.

Hopwood (1993) desenvolveu uma escala para avaliar a imagem corporal de mulheres com câncer, considerando um valor atribuído ao corpo no geral, doente ou não, e um valor atribuído ao corpo doente. Observou que a perturbação da imagem corporal pode ser severa e, às vezes, aparentemente desproporcional à deformação observada.

No Brasil, alguns trabalhos sobre imagem corporal podem ser citados, porém pesquisas realizadas associando imagem corporal ao tema depressão são relativamente escassas. As investigações, muitas vezes, restringem-se a grupos específicos, como funcionários de uma universidade entre 22 e 59 anos (Veggi et al., 2004), mulheres entre vinte e sessenta anos atendidas por diferentes serviços de saúde ambulatoriais (Almeida et al., 2005), praticantes de caminhadas (Damasceno et al., 2005) e estudantes universitários, de ambos os sexos (Kakeshita \& Almeida, 2006), ou apenas universitárias (Secchi et al., 2009).

Considerando os aspectos antropológicos, os trabalhos de pesquisadores brasileiros indicam que avaliar a imagem corporal em termos de satisfação/insatisfação, percepção/alterações e desejos de mudança é avaliar o modo como as pessoas percebem-se, valorizamse, o conceito que possuem de si, ou seja, sua autoestima.

Autoestima é um conceito intimamente ligado à percepção da imagem corporal, à satisfação ou insatisfação, e interfere nas relações sociais. O termo autoestima sofreu modificações ao longo da história da humanidade. Ele foi associado ao autoconhecimento por Sócrates. No senso comum, recebeu conotações individualistas e por décadas foi desconsiderado pela ciência. Atualmente, apresenta conotações de responsabilidade do indivíduo por si mesmo e de sua relação consigo e com os demais (Assis, 2004).

A percepção da imagem corporal pode estar profundamente alterada quando aspectos da autoestima e a valorização de si estão perturbados, tanto por transtornos alimentares (anorexia, bulimia) quanto do humor (depressão, ansiedade). 
A depressão é um transtorno de humor grave e frequente. $\mathrm{O}$ humor tem uma função adaptativa para a sobrevivência dos seres humanos. No humor normal, as reações a determinados eventos são adequadas aos estímulos ambientais. No transtorno de humor, a pessoa interpreta o ambiente de forma distorcida (Nardi, 2006).

A depressão pode ser considerada como a mais comum das doenças tratadas pela psiquiatria na atualidade. É muito possível que as pessoas confundam estados normais de tristeza, a partir da experiência diária, com depressão, assim como acreditam na depressão como uma doença incurável, quando na verdade ela pode ser um estado momentâneo que, tratado adequadamente, pode ser revertido.

A depressão pode ser analisada por meio de referenciais médicos e psicológicos. O referencial médico é descrito pela CID-10 (Classificação de Transtornos Mentais e de Comportamento - OMS, 1993), e o referencial psicológico é descrito por Seligman (1977)e Beck (1997).

Seligman (1977) apresenta seis sintomas de desamparo aprendido que tem seu correspondente na depressão: dificuldade na iniciação de respostas voluntárias, tendência cognitiva negativa, curso temporal, redução da agressividade, perda de apetite e alterações fisiológicas.

Beck (1997) cita o conceito de tríade cognitiva para explicar a depressão. $\mathrm{O}$ primeiro componente da tríade gira em torno da visão negativa que o paciente tem de si mesmo. Ele vê a si próprio como defeituoso, inadequado, doente ou carente. O segundo é a tendência da pessoa deprimida a interpretar suas experiências atuais de forma negativa. Ele vê o mundo como fazendo exigências exorbitantes sobre ele e/ou apresentando obstáculos insuperáveis para atingir suas metas de vida. O terceiro componente consiste em uma visão negativa de futuro. Geralmente, a pessoa faz projeções antecipando seu sofrimento ou dificuldades, espera frustrações e privações incessantes.

Os tratamentos farmacológicos para depressão devem ser utilizados como complementares às diversas formas de psicoterapia. $\mathrm{O}$ medicamento proporciona recuperação inicial para que o paciente adquira condições de submeter-se à psicoterapia que irá ampliar seu autoconhecimento e ajudá-lo na reintegração social e na retomada 
de sua individualidade. O tratamento psicoterápico é indispensável para a compreensão da depressão (Nardi, 2006).

Os distúrbios alimentares podem apresentar comorbidades psicológicas ou psiquiátricas, como a depressão, a esquizofrenia, ou distúrbios obsessivos compulsivos. Pacientes com depressão podem estar tão deprimidos que não querem comer, outros excedem na alimentação em virtude da depressão e adquirem peso (Tannenhaus, 1994). Os transtornos alimentares mais evidentes são a anorexia nervosa, a bulimia nervosa e a obesidade, tanto pelo aumento do número de casos, quanto pela maior divulgação e informação sobre o problema, além de maior exposição por meio de figuras públicas que narram seu drama (Nakamura, 2004).

Os sintomas comuns dos principais distúrbios alimentares são: preocupação extrema com a aparência, a imagem ou o tamanho do corpo; medo exagerado de ficar gorda; exagero do tamanho e dos defeitos do corpo; e cada vez maior rigidez de pensamento e afastamento das atividades normais (Tannenhaus, 1994).

A insatisfação com a imagem corporal pode estar presente em outros quadros psiquiátricos, como transtorno dismórfico corporal, delírios somáticos, transexualismo, depressão, esquizofrenia e obesidade. É nos transtornos alimentares que seu papel sintomatológico e prognóstico é mais relevante (Saikili et al., 2004).

Também estão associados à obesidade o transtorno alimentar sem especificação e o transtorno de compulsão periódica. Outros transtornos podem estar associados à compulsão periódica, como o transtorno obsessivo compulsivo e o transtorno de ansiedade generalizada (Mattos et al., 2003).

O obeso é objeto de grave discriminação. A baixa autoestima pode levar a um círculo vicioso, causando depressão, superalimentação como fuga, vergonha e falta de ânimo para a prática de atividades físicas, aumento de peso, rejeição social e diminuição da autoestima (Cunha, 1999).

Mello (2008), em um trabalho de intervenção com crianças em condição de sobrepeso e obesidade, observou que situações de bullying (caracterizadas por atitudes agressivas e preconceituosas) 
constituem fator de estresse para elas. Os relatos das crianças refletiam um autoconceito negativo mensurado pelo peso e pela estrutura corpórea fora dos padrões culturais estéticos, segundo elas, e um desejo de "fugir" das contrariedades sociais ocorrentes em forma de zombarias e insultos, por exemplo.

Para avaliar se o indivíduo é obeso utiliza-se o Índice de Massa Corporal (IMC), dividindo-se o peso (em quilos) pelo quadrado da altura (em metros). Esse método é utilizado por ter fácil aplicação e demonstrar forte correlação desse índice com o risco de morbiletalidade em diversas populações avaliadas. O método falha em não diferenciar massa gorda e massa magra (Burd, 2004).

O aumento de peso pode ocorrer na depressão branda. Já na depressão grave pode ocorrer tanto o emagrecimento quanto o aumento de peso. Por outro lado, alterações de massa corporal podem deixar a pessoa deprimida. $\mathrm{O}$ aumento de peso pode ser provocado por hipotireoidismo, que causa depressão, porém geralmente é causado pelo exagero na ingestão de alimentos (Gillett, 1996).

Sintomas depressivos e ansiosos são comuns em obesos. A síndrome depressiva parece ser frequente nos gravemente obesos. $\mathrm{Pa}$ cientes obesos emocionalmente instáveis podem vivenciar um aumento de ansiedade e depressão quando fazem dietas. Os aspectos emocionais e psicológicos podem ser identificados como consequências e como mantenedores da condição do obeso, concomitante a uma condição clínica e alimentar alterada (Cordás \& Azevedo, 2005).

Stunkard \& Wadden (1992) estudaram pessoas que apresentavam obesidade severa antes de cirurgia bariátrica e observaram que não há um tipo específico de personalidade que caracteriza o obeso severo, não apresentam níveis de psicopatologia maiores do que os das pessoas que controlam o peso, entretanto as complicações específicas da obesidade severa incluem depreciação da imagem corporal e o comer compulsivo. Estudos realizados com indivíduos depois de tratamento cirúrgico e de perda de peso indicaram aumento do amor próprio e das emoções positivas e diminuição das depreciações com a imagem corporal. O aumento na satisfação matrimonial ocorreu apenas quando já havia uma medida de satisfação antes da 
cirurgia, e o comportamento de comer com melhor qualidade nutricional melhora dramaticamente.

Depressão, imagem corporal e transtornos alimentares são dimensões da experiência pessoal que podem estar intimamente interligadas. A depressão pode estar associada à ansiedade e, com isso, promover o aumento de peso, sem esquecer que o aumento de peso apresenta multideterminações associadas: aspectos genéticos, uso de medicamentos antidepressivos, hábitos alimentares inadequados, sedentarismo, entre outros.

Baptista et al. (2008) avaliaram 82 pacientes obesos mórbidos, de ambos os sexos, maiores de 18 anos. Destes, 43 eram pacientes candidatos à cirurgia de obesidade (Grupo A) e 39 participantes eram pacientes pós-cirúrgicos (Grupo B), ambos os grupos com predominância de mulheres. No Grupo A, aproximadamente 40\% apresentou sintomatologia moderada e severa de depressão. No Grupo B, apenas $10 \%$.

A presente investigação foi realizada com mulheres que realizavam tratamento para depressão em um CAPs III de uma cidade do interior de São Paulo e faziam uso de antidepressivos. O objetivo do trabalho foi o de investigar a percepção da imagem corporal por meio da Figure Rating Scale (FRS) e do Body Shape Questionnaire (BSQ) em mulheres em tratamento para depressão com uso de antidepressivos (Grupo com Depressão) e em mulheres que não fazem uso de antidepressivos (Grupo de Comparação).

\section{Método}

\section{Participantes}

Participaram sessenta mulheres divididas em dois grupos, o Grupo com Depressão $(n=30)$, com idades variando entre 21 e 58 anos, com escolaridade mínima de nível fundamental, e o Grupo de Comparação ( $n=30)$, com idades variando de 25 a 63 anos, com escolaridade mínima de nível médio. 
Foram excluídas do Grupo com Depressão mulheres com diagnóstico de esquizofrenia (F-20 e variantes de acordo com CID-10), por apresentarem disfunção da percepção característica da doença. Do Grupo de Comparação foram excluídas mulheres com queixa de depressão ou em tratamento com antidepressivos. Excluíram-se também indivíduos do sexo masculino por apresentarem número reduzido na população em tratamento no período.

Encontra-se na Tabela 1 a caracterização das participantes deste estudo em função de idade e IMC (baixo peso: IMC < 18,5 kg/m²; peso normal ou eutrófico: IMC de 18,6 a $24,9 \mathrm{~kg} / \mathrm{m}^{2}$; sobrepeso: IMC de 25 a 29,9 kg/m² e obesidade: IMC $\left.>30 \mathrm{~kg} / \mathrm{m}^{2}\right)$. O teste de qui-quadrado aplicado à amostra não demonstrou diferença significativa entre os grupos tanto em relação à idade $\left(X^{2}=4,667 ; g l=4 \mathrm{e}\right.$ $p=0,3231)$ como ao diagnóstico nutricional $\left(X^{2}=4,67 ; g l=3\right.$ e $p=$ 0,1976).

Tabela 1 - Caracterização da amostra $(n=60)$ em função da idade e do Índice de massa Corporal (IMC).

\begin{tabular}{llccccc}
\hline \multicolumn{2}{c}{ Participantes } & \multicolumn{5}{c}{ Diagnóstico } \\
Idade & Grupos & Baixo peso & Normal & Sobrepeso & Obesidade & Total \\
\hline \multirow{2}{*}{$1-30$} & Depressão & 2 & 3 & 1 & 1 & 7 \\
& Comparação & 1 & 1 & 0 & 1 & 3 \\
\multirow{3}{*}{$1-40$} & Depressão & 1 & 0 & 4 & 3 & 8 \\
& Comparação & 0 & 4 & 4 & 1 & 9 \\
\multirow{2}{*}{ 1-50 } & Depressão & 0 & 4 & 4 & 0 & 8 \\
& Comparação & 0 & 7 & 2 & 4 & 13 \\
\multirow{2}{*}{$51-60$} & Depressão & 0 & 2 & 4 & 1 & 7 \\
& Comparação & 0 & 0 & 1 & 3 & 4 \\
$>60$ & Depressão & 0 & 0 & 0 & 0 & 0 \\
& Comparação & 0 & 1 & 0 & 0 & 1 \\
\hline \multirow{2}{*}{ Parcial } & Depressão & 3 & 9 & 13 & 5 & 30 \\
& Comparação & 1 & 13 & 7 & 9 & 30 \\
\hline \multirow{2}{*}{ Total } & & 4 & 22 & 20 & 14 & 60 \\
\hline
\end{tabular}




\section{Materiais e instrumentos}

Além de um formulário para assinatura do consentimento livree esclarecido para a participação nesta pesquisa, foi utilizado um roteiro semiestruturado de entrevista para levantamento de dados sociodemográficos (nome, idade, estado civil, escolaridade, número de filhos e questões sobre hábitos em relação à alimentação, exercícios físicos e mudanças corporais desejadas) e anotação de medidas antropométricas (peso e altura) das participantes.

A FRS foi utilizada para verificação da imagem corporal atual e ideal das mulheres participantes. Foi proposta originalmente por Stunkard et al. (1983) e adaptada para o português por Scagliusi \& cols. (2005). A escala é composta por nove cartões com figuras com silhuetas corporais, que podem ser relacionadas aos diferentes índices de massa corporal (Almeida et al., 2005). Uma figura representa baixo peso; duas, a eutrofia; duas, o sobrepeso; e duas, a obesidade.

O BSQ, de Cooper \& cols. (1987), traduzido por Di Pietro et al. (2003), foi utilizado para verificar a distorção da imagem corporal das participantes. O BSQé um questionário autoaplicativo que apresenta 34 perguntas. Cada questão apresenta seis possibilidades de resposta: (1) Nunca, (2) Raramente, (3) Às vezes, (4) Frequentemente, (5) Muito Frequentemente e (6) Sempre.

\section{Análise de dados}

A análise quantitativa consistiu na avaliação do IMC, caracterizando a porcentagem de indivíduos obesos, com sobrepeso, eutróficos e abaixo do peso ideal, descritos na caracterização das participantes. Foram tabulados os resultados obtidos no BSQ com relação ao grau de distorção da imagem corporal, se leve, moderada ou intensa. O mesmo foi feito com relação ao FRS, caracterizando o grau de distorção entre a imagem corporal dada pelo IMC (Real), a percebida pelas participantes (Atual) e a imaginada como desejável (Ideal) pelas participantes. A discrepância foi verificada por meio da comparação correlacional entre a escolha ideal e a atual. 
A distorção da imagem corporal pode ser considerada como um estado subjetivo no qual se verifica alteração na percepção da imagem corporal, resultante direta da discrepância nos valores numéricos relativos à autoavaliação. Ou seja, quanto maior a discrepância, maior a distorção.

No nosso caso específico, a distorção da imagem corporal foi medida pela diferença entre a imagem escolhida por meio do FRS como atual e o IMC como valor real.

\section{Resultados}

\section{Imagem corporal}

Na Tabela 2, encontram-se os dados obtidos a partir da aplicação do BSQ nos dois grupos envolvidos na pesquisa.

O teste qui-quadrado calculado entre os grupos foi de $X^{2}=$ 14,103; $g l=3$ e $p=0,0028$, indicando que há diferença significativa entre os dois grupos com relação à insatisfação com a imagem corporal.

Observando-se os resultados, é possível considerar que diante do adoecimento há um aumento significativo no grau de exigência em relação a aspectos da imagem corporal relacionado à diminuição da autoestima, característica da depressão.

$\mathrm{Na}$ Tabela 3, pode-se verificar a satisfação ou insatisfação com a imagem corporal das mulheres dos dois grupos. Considerou-se como insatisfação quando a imagem escolhida como atual era diferente da ideal, obtida no FRS. 
Tabela 2 - Comparação dos diagnósticos nos dois grupos, com Depressão e de Comparação.

\begin{tabular}{lcccccccc}
\hline Grupos & \multicolumn{9}{c}{ Depressão } & \multicolumn{5}{c}{ Comparação } \\
\hline \multicolumn{1}{c}{ (BSQ) } & Sem & Leve & Moder. & Grave & Sem & Leve & Moder. & Grave \\
\hline Obeso & - & - & $3,3 \%(1)$ & $13,3 \%(4)$ & $20 \%(6)$ & $6,7 \%(2)$ & $3,3 \%(1)$ & - \\
Sobrepeso & $16,7 \%(5)$ & $3,3 \%(1)$ & $6,7 \%(2)$ & $16,7 \%(5)$ & $10 \%(3)$ & $10 \%(3)$ & $3,3 \%(1)$ & - \\
Eutrofia & $13,3 \%(4)$ & $13,3 \%(4)$ & - & $3,3 \%(1)$ & $36,7 \%(11)$ & $6,7 \%(2)$ & - & - \\
Baixo peso & $3,3 \%(1)$ & $6,7 \%(2)$ & - & - & $3,3 \%(1)$ & - & - & - \\
Total & $\mathbf{3 3 , 3 \% ( 1 0 )}$ & $\mathbf{2 3 , 3 \% ( 7 )}$ & $\mathbf{1 0 \% ( 3 )}$ & $\mathbf{3 3 , 3 \% ( 1 0 )}$ & $\mathbf{7 0 \% ( 2 1 )}$ & $\mathbf{2 3 , 3 \% ( 7 )}$ & $\mathbf{6 , 7 \% ( 2 )}$ & - \\
\hline
\end{tabular}


Tabela 3 - Satisfação ou não com a imagem corporal em mulheres dos dois grupos (com e sem depressão).

\begin{tabular}{|c|c|c|c|c|}
\hline \multirow{2}{*}{$\frac{\text { Grupos }}{\text { (FRS) }}$} & \multicolumn{2}{|c|}{ Depressão } & \multicolumn{2}{|c|}{ Comparação } \\
\hline & Satisfação & Insatisfação & Satisfação & Insatisfação \\
\hline Obeso & - . - - & $16,7 \%(5)$ & $6,7 \%(2)$ & $23,3 \%(7)$ \\
\hline Sobrepeso & $\ldots$ & $43,3 \%(13)$ & - . . - & $23,3 \%(7)$ \\
\hline Eutrofia & $10 \%(3)$ & $20 \%(6)$ & $13,3 \%(4)$ & $30 \%(9)$ \\
\hline Baixo Peso & $\cdots$ & $10 \%(3)$ & - - - - & $3,3 \%(1)$ \\
\hline Total & $10 \%(3)$ & $90 \%(27)$ & $20 \%(6)$ & $80 \%(24)$ \\
\hline
\end{tabular}

O teste qui-quadrado calculado foi de $X^{2}=3,569, \mathrm{gl}=3$ e $p=$ 0,3119 , indicando que não houve diferença significativa entre os dois grupos com relação à insatisfação com a imagem corporal.

Tabela 4 - Comparação dos resultados por meio do teste de correlação de Spearmann para os dados obtidos mediante o IMC (Real) e o BSQ. Valores significativos indicados por * para $p<0,05$.

\begin{tabular}{lcccc}
\hline Grupos & \multicolumn{2}{c}{ Depressão } & \multicolumn{2}{c}{ Comparação } \\
\hline Correlação & $R s$ & $p$ & $R s$ & $p$ \\
Real/Atual & 0,7230 & $0,0001^{*}$ & 0,7167 & $0,0001^{*}$ \\
Real/Ideal & 0,4002 & $0,0283^{*}$ & 0,5553 & $0,0014^{*}$ \\
Atual/Ideal & 0,4270 & $0,0189^{*}$ & 0,6444 & $0,0001^{*}$ \\
\hline
\end{tabular}

Foi realizada outra análise para verificar se havia diferença entre os grupos utilizando-se o Teste de Correlação de Spearmann a partir dos dados brutos. Os resultados são apresentados na Tabela 4.

Constatou-se com os resultados do Teste de Spearmann que existem correlações positivas significativas em todas as análises efetuadas. Verifica-se, entretanto, que as correlações entre a imagem real (IMC) e a atual (autoimagem) foram de maior magnitude nos dois grupos, indicando que todas as participantes apresentam uma percepção corporal bastante próxima da realidade. 
As correlações que envolveram a dimensão referente à imagem desejada (Ideal) apresentaram valores numéricos bem menores, principalmente no grupo com Depressão ( $r s=0,4002$ e $r s=0,4270)$, indicando uma maior distância entre a imagem corporal (Real e Atual) com a idealizada (Ideal). Cabe ressaltar que no Grupo com Depressão tais correlações foram menores do que no Grupo de Comparação, refletindo uma maior insatisfação com o próprio corpo e menor autoestima.

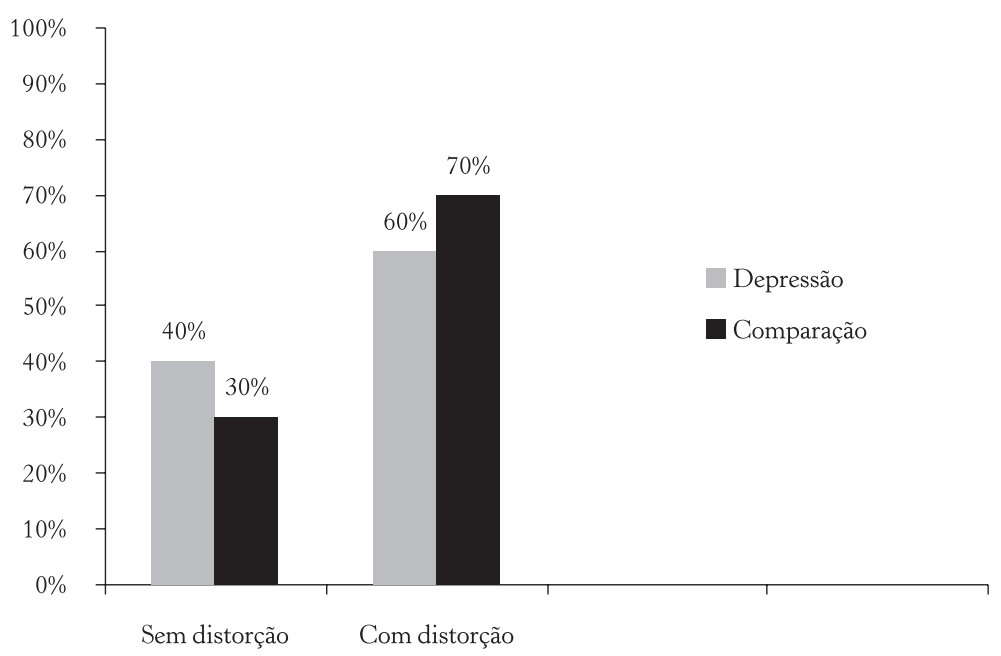

Figura 1 - Comparação da distorção da imagem corporal encontrada nos dois grupos (Real e Atual).

Os resultados obtidos acerca da distorção de imagem corporal nos dois grupos são apresentados na Figura 1.

O teste qui-quadrado calculado foi de $X^{2}=0,662, g l=2$ e $p=$ 0,7181 , indicando que não há diferença significativa entre os dois grupos em relação à distorção da imagem corporal.

Verificou-se que 40\% (12) das participantes do Grupo com Depressão apresentaram escolhas sem distorção. Considerando-se as $60 \%$ (18) que apresentaram distorção, 40\% (13) subestimaram o peso e $20 \%$ (5) superestimaram. 
No Grupo de Comparação, 30\% das participantes apresentaram escolhas sem distorção. Das $70 \%$ das mulheres que apresentaram distorção, 50\% subestimaram o peso (30\% eram mulheres obesas, $10 \%$ apresentavam sobrepeso e $10 \%$, eutrofia) e $20 \%$ superestimaram o peso (todas com eutrofia).

Constata-se que escolhas com distorção apareceram com alto índice nos dois grupos. No Grupo com Depressão deste estudo, observou-se que grande parte das mulheres com sobrepeso e obesas subestimou o peso, enquanto as eutróficas superestimaram. O mesmo verificou-se no Grupo de Comparação.

Uma das formas de minimizar a dissonância entre a imagem atual e a ideal seria a realização de cirurgias estéticas. No geral, ambos os grupos relataram não ter dinheiro para fazer cirurgia ou não fariam por medo. Apenas $0,3 \%$ em ambos os grupos relatou que vai fazer cirurgia bariátrica por apresentar obesidade Grau 3.

Nesse estudo, o Grupo de Comparação apresentou índice maior de risco genético para obesidade porque apresentou um maior número em que um dos genitores ou ambos tiveram diagnóstico de obesidade ou sobrepeso ao longo da vida. Esse grupo apresentou também maior número de participantes obesos em relação ao grupo com depressão. Porém, na somatória de obesos/sobrepeso não há diferença entre os grupos. Deve-se lembrar que a genética está sempre associada a fatores ambientais na determinação da obesidade, assim como de outros transtornos. Nos grupos avaliados, aos fatores genéticos podem ser acrescentados a inadequação alimentar e o sedentarismo.

Algumas doenças tipicamente encontradas em pacientes obesos foram encontradas no grupo com depressão, como hipertensão, diabetes, hipotireoidismo, alta taxa de colesterol e hiperlipidemia. No Grupo de Comparação, foram encontradas doenças vasculares e hipertensão com menor incidência. 


\section{Discussão}

Os dados encontrados por meio da aplicação do BSQ revelam que as pacientes em tratamento para depressão e as participantes do Grupo de Comparação estão insatisfeitas com sua imagem corporal, verificando-se diferenças significativas entre os dois grupos. Diante do adoecimento há um aumento significativo no grau de exigência com relação à imagem corporal, considerando os resultados do BSQ.

Observou-se que, de forma geral, o IMC apresenta uma relação direta com a insatisfação. Assim, quanto maior o IMC, maior a insatisfação, embora o índice de insatisfação tenha sido maior no grupo com sobrepeso do que no grupo de obesos, nas pacientes com depressão. Esses resultados também foram diferentes no Grupo de Comparação, com insatisfação tanto em obesos como naquelas com sobrepeso, sendo menor em comparação ao Grupo com Depressão.

Considerando-se os dados obtidos por meio da FRS, no geral constatou-se insatisfação em ambos os grupos e independente do IMC. Esses dados coincidem com os de diversos autores, como Almeida (2003) e Almeida et al. (2005), Kakeshita \& Almeida (2006), que obtiveram resultados indicando que a insatisfação independe do IMC, porque a percepção subjetiva que uma pessoa tem de seu corpo pode ser mais importante do que a realidade objetiva.

A distorção da imagem corporal, uma medida subjetiva da percepção que a participante tem de sua imagem corporal, revelou grau de distorção significativo em ambos os grupos. Embora houvesse uma diferença numérica maior no Grupo de Comparação, não se verificou diferença estatisticamente significativa entre os grupos.

\section{Considerações finais}

A imagem corporal constitui um tema amplo, suas possibilidades de distorção apresentam aspectos multifatoriais e pode ser indicativo de diversas patologias. Constitui tema de grande impor- 
tância para a sociedade contemporânea e notadamente para pacientes depressivos.

O presente trabalho teve o objetivo de investigar aspectos da imagem corporal e o diagnóstico nutricional de dois grupos, um em tratamento com antidepressivos e outro que não faz uso de tais medicamentos. Foram investigados os hábitos de vida em relação à prática de atividades físicas, a dieta e a mudanças corporais para avaliar a relevância de algum aspecto no aumento do peso na concepção das participantes.

Os resultados do diagnóstico nutricional com essa amostra indicaram tendência ao aumento do contingente de obesos/sobrepeso no Brasil, como relataram Cordás \& Azevedo (2005). A obesidade é considerada, atualmente, um problema de saúde pública e vem aumentando alarmantemente (Cunha, 1999).

A equivalência de obesidade/sobrepeso nos dois grupos desmistifica a relevância da medicação no aumento de peso, embora seja um aspecto interveniente. A alimentação inadequada e a ausência de prática de exercícios físicos parecem ser fatores importantes. Podemos constatar que, diante desses resultados, o trabalho contribuiu para desmistificar o medicamento como único aspecto interferindo no aumento de peso.

Mattos \& cols (2003) consideram a interação de fatores na determinação da obesidade. Burd (2004) considera a herança genética relevante, mas acrescenta fatores culturais como participativos. Sichieri \& Souza (2006) destacam o consumo de alimentos calóricos e o baixo encorajamento para a prática de atividades físicas. Kaplan \& Sadock (2007) salientam a redução da atividade física.

Os dois grupos caracterizaram-se por apresentarem insatisfação com a imagem corporal, evidenciando dados em conformidade com a literatura. Para Queiroz \& Otta (2000), a beleza é tão importante para as mulheres que a insatisfação com o peso apresenta impacto negativo sobre sua autoestima.

Diferenças significativas entre os grupos foram encontradas nos aspectos insatisfação e distorção da imagem corporal. O grupo com 
depressão apresentou maior número de representantes com distorção da imagem corporal.

Nesta pesquisa, tanto no Grupo com Depressão quanto no Grupo de Comparação, as mulheres com sobrepeso e obesas subestimaram o peso, e as eutróficas, superestimaram. Constatou-se uma participante com diagnóstico de anorexia apresentando escolha de figura com distorção característica do diagnóstico sugerido. Kakeshita \& Almeida (2006) observaram que mulheres eutróficas e com sobrepeso tendem a superestimar seus pesos, ao contrário das obesas, que subestimam o peso. Resultados semelhantes foram encontrados nos dois grupos.

A pesquisa realizada caracterizou-se como uma contribuição para a compreensão dos aspectos envolvidos na percepção corporal de mulheres com depressão. Investigações mais aprofundadas poderão envolver outros aspectos da comunicação não verbal envolvidos no contexto dessa psicopatologia.

\section{Referências bibliográficas}

ALMEIDA, G. A. N. et al. Percepção de tamanho e forma corporal de mulheres: estudo exploratório. Psicologia em Estudo. v.10, n.1, p.2735, 2005.

ASSIS, S. G. Labirinto de espelhos: formação da autoestima na infância e na adolescência. Rio de Janeiro: Fiocruz, 2004.

ASSUMPÇÃO JR., F. B. A questão da beleza ao longo do tempo. In:

BUSSE, S. R.(Org.). Anorexia, bulimia e obesidade. São Paulo: Manole, 2004.

BAPTISTA, M. N.; VARGAS, J. F.; DAHER BAPTISTA, A. S. Depressão e qualidade de vida em uma amostra brasileira de obesos mórbidos. Avaliação Psicológica. v.7, n.2, p.235-47, 2008.

BECK, A. Terapia cognitiva da depressão. Porto Alegre: Artes Médicas, 1997.

BURD, M. Obesidade e família. In: MELLO F., J. E.; BURD, D. (Orgs.) Doença e família. São Paulo: Casa do Psicólogo, 2004. 
CORDÁS, T. A.; AZEVEDO, A. P. Contra os estigmas da balança. Revista Mente Cérebro. v.152, n.13, p.56-61, 2005.

CUNHA, L. N. Dietbook. São Paulo: Mandarim, 1999.

DAMASCENO, V. et al. Tipo físico ideal e satisfação com a imagem corporal de praticantes de caminhada. Revista Brasileira de Medicina do Esporte. v.11, n.3, p.181-86, 2005.

FREITAS, S. R. Instrumentos para avaliação dos transtornos alimentares. In: NUNES, M. A. et al. Transtornos alimentares e obesidade. Porto Alegre: Artmed, 2006.

GILLETT, R. Superando a depressão: um prático de autoajuda. São Paulo: Nova Cultural, 1996.

HOPWOOD, P. The assessment of body image in cancer patients. European Journal of Cancer. v.29, n.2, p.276-81, 1993.

KAKESHITA, I. S.; ALMEIDA, S. S. Relação entre Índice de Massa Corporal e a percepção da autoimagem em universitários. Revista de Saúde Pública. v.40, n.3, p.497-504, 2006.

KAPLAN, B. J.; SADOCK, V. A. Compêndio de Psiquiatria: Ciências do Comportamento e Psiquiatria Clínica. Tradução de Claudia Dornelles et al. 9.ed. Porto Alegre: Artmed, 2007.

MATTOS, D. G. et al. Estudo de transtornos alimentares em pacientes com obesidade mórbida no pré-operatório. In: NEME, C. M. B.; RODRIGUES, O. P. R. (Orgs.) Psicologia da Saúde: perspectivas interdisciplinares. São Carlos: Rima, 2003.

MELLO, L. C. Avaliação e intervenção psicossocial e nutricional com crianças em condição de sobrepeso e obesidade. Dissertação (mestrado). Universidade Estadual Paulista, Bauru, 2008.

NAKAMURA, E. Representações sobre o corpo e hábitos alimentares: o olhar antropológico sobre aspectos relacionados aos transtornos alimentares. In: BUSSE, S. R.(Org.). Anorexia, bulimia e obesidade. São Paulo: Manole, 2004.

NARDI, A. E. Questões atuais sobre depressão. São Paulo: Lemos Editorial, 2006.

OMS. Classificação de transtornos mentais e de comportamento da CID-10: descrições clínicas e diretrizes diagnósticas. Tradução de Dorgival Caetano. Porto Alegre: Artes Médicas, 1993.

QUEIROZ, R. S. (Org.). O corpo do brasileiro: estudos de estética e beleza. São Paulo: Senac, 2000. 
SAIKILI, C. J. et al. Imagem corporal nos transtornos alimentares. Revista de Psiquiatria Clínica. v.31, n.4, p.164-6, 2004.

SECCHI, K., CAMARGO, B. V.; BERTOLDO, R. B. Percepção da imagem corporal e representações sociais do corpo. Psicologia: Teoria e Pesquisa. v.25, n.2, p.229-36, 2009.

SELIGMAN, M. E. P. Desamparo: sobre depressão, desenvolvimento e morte. São Paulo: Hucitec, 1977.

SCHILDER, P. A imagem do corpo: as energias construtivas da psique. Tradução de Roseane Wertman. 3.ed. São Paulo: Martins Fontes, 1999.

SICHIERI, R.; SOUZA, R. A. G. Epidemiologia da obesidade. In: NUNES, M. A. et al. Transtornos alimentares e obesidade. 2.ed. Porto Alegre: Artmed, 2006.

STUNKARD, A. J.;WADDEN, T. A. Psychological aspects of severe obesity. American Journal of Clinical Nutrition. v.55, p.524-32, 1992. TAVARES, M. C. G. C. Imagem corporal. São Paulo: Manole, 2003.

TANNENHAUS, N. Distúrbios alimentares: como tratar e evitar. Tradução de Paulo Fróes. Rio de Janeiro: Ediouro, 1994.

VEGGI, A. B. et al. Índice de Massa Corporal, percepção do peso corporal e transtornos mentais comuns entre funcionários de uma universidade no Rio de Janeiro. Revista Brasileira de Psiquiatria. v.26, n.4, p.242-7, 2004. 


\title{
3 \\ Sexualidade e VUlNerabilidade: REFLEXÕES SOBRE A POLÍTICA DE REDUÇÃO DE DANOS ${ }^{1}$
}

\author{
Aline Ariana Alcântara Anacleto ${ }^{2}$ \\ Ana Cláudia Bortolozzi Maia ${ }^{3}$
}

\section{Introdução}

Este texto pretende apresentar algumas reflexões envolvendo o conceito de redução de danos e a relação entre sexualidade e vulnerabilidade. Entendendo a vulnerabilidade social como uma condição que aumenta o risco de engajamento em práticas sexuais que levam ao contágio de doenças sexualmente transmissíveis associadas ao uso de drogas em geral, a política de redução de danos poderia ser útil para favorecer o exercício autônomo da sexualidade. Essa relação ainda é recente nas práticas sociais e a Psicologia ainda não apresenta pesquisas sólidas nessa área. Dessa forma, baseamo-nos em reflexões iniciais, tendo como parâmetro a literatura recente sobre a redução de danos e a compreensão da sexualidade e da vulnerabilidade como construções sociais e políticas.

1 Este texto apresenta parte teórica da dissertação de mestrado da primeira autora sob orientação da segunda autora.

2 Programa de pós-graduação em Psicologia do Desenvolvimento e da Aprendizagem. Faculdade de Ciências da Unesp, campus de Bauru.

3 Programa de pós-graduação em Psicologia do Desenvolvimento e da Aprendizagem. Faculdade de Ciências da Unesp, campus de Bauru. 


\section{Política de redução de danos}

Uma nova modalidade de atendimento para enfrentar a problemática de pessoas que possuem comportamentos de risco e suas consequências psicossociais refere-se a uma Proposta de Redução de Danos (PRD) já realizada em outros países e recentemente defendida pelo governo brasileiro. Ainda desconhecida por muitos e polêmica entre diferentes profissionais, essa proposta representa um novo olhar sobre as populações vulneráveis e procura garantir a saúde pública por meio de ações de esclarecimentos, ao invés de ações proibitivas e punitivas que tentam reduzir os danos causados pelo consumo de drogas lícitas e ilícitas, bem como de práticas sexuais de risco ao contágio de doenças sexualmente transmissíveis (DST) e Aids.

A política de redução de danos é uma proposta internacional que se originou para responder à grande epidemia de Aids da década de 1980, "quando muitos países reconheceram a necessidade de desenvolver estratégias mais práticas e adaptativas para reduzir o risco de transmissão de HIV entre usuários de drogas injetáveis" (Fligie et al., 2004, p.421). Dessa maneira, seu objetivo principal é o de "abordar usuários de drogas e educá-los para o uso seguro, visando o controle epidemiológico da Aids, da hepatite e de outras doenças" (Oliveira \& Paes, 2004, p.1).

Brites (2006, p.89) explica:

Claramente contextualizada no direito constitucional (art.196), a redução de danos à saúde pelo uso indevido de drogas promove a integração a programas de saúde de uma parcela importante de cidadãos com pouca visibilidade social e sem força de pressão para reivindicar as medidas de proteção específicas aplicáveis àquele período de suas vidas em que seus hábitos deixam-nas vulneráveis a muitas formas de violência. As infecções e doenças são apenas uma face dessa questão com forte e determinante repercussão sanitária e socioeconômica.

A PRD fundamenta-se visando garantir a saúde pública por meio de ações que tentam reduzir os danos causados pelo consumo de drogas lícitas e ilícitas, bem como por práticas sexuais de risco para 
DST/Aids, compreendendo, com isso, que atuar com o usuário de drogas significa respeitar sua individualidade, garantindo-lhe os direitos humanos e o exercício da cidadania, possibilitando a ele a reinserção social e não sua exclusão. Isto evidencia que a política de redução de danos tem uma preocupação humanista e ampliada, e procura "tratar" e "prevenir" considerando as relações do sujeito e seu entorno. Não é possível tratar apenas o sujeito desconsiderado das condições sociais que o mantêm nas práticas de risco, por isso, diferentes áreas, como a médica, a psicológica, a educacional e a legal devem atuar conjuntamente.

A PRD, então, caracteriza-se como um conjunto de estratégias, do ponto de vista da saúde, que tenta diminuir as consequências adversas do consumo de drogas e das práticas sexuais de risco, sem necessariamente levar o usuário à redução da prática/consumo ou a sua abstinência (Mesquita \& Bastos, 1994). Essas estratégias, de acordo com Almeida (2003), podem estar no campo da prevenção primária, pois dificultam a contaminação dos usuários por patologias, promovendo, assim, a saúde.

Essa proposta de redução de danos diverge das políticas proibicionistas de saúde pública existentes no trato com a questão das drogas e das práticas de risco. Visa atitudes mais acolhedoras, proporcionando relações de escuta e de diálogo no lugar de atitudes de julgamento, a fim de estreitar as relações com os sujeitos envolvidos nesse contexto de vulnerabilidade. Dessa forma, como afirma Fonseca (2005), seria possível ampliar a possibilidade de ajuda e de prevenção aos riscos e agravos decorrentes das práticas exercidas por entender que não raras são às vezes em que esses sujeitos possuem certa vontade, explícita ou não, de mudança de comportamento, porém encontram uma série de barreiras ou dificuldades, que não contribuem para a efetiva resolução de seus conflitos. Almejando superar essas barreiras, a PRD aproxima-se da realidade da vida cotidiana dos sujeitos usuários e abre uma discussão que envolve os valores sociais e políticos de cada pessoa, ressaltando a liberdade individual, bem como o direito de dispor do próprio corpo, afirmando os direitos e deveres de qualquer sujeito como cidadão. 
Sendo assim, a proposta de redução de danos não considera o usuário como marginal à sociedade e tem como propósito eliminar o estigma de "usuário problema", que é doente e que precisa de tratamento. Como uma proposta de tratamento humanizado, visa considerar o sujeito usuário na condição "regular" e "estável”, isto é, que mantém seu hábito de consumir drogas e/ou práticas sexuais de risco, já que eliminar esse hábito parece-lhe inviável. Esse processo deve ocorrer com orientações sobre práticas de consumo e de comportamento seguros, o que poderia minimizar os prejuízos causados pela droga e pelo sexo desprotegido com o auxílio constante de profissionais envolvidos na PRD (Rodrigues, 2003).

É preciso reconhecer que o indivíduo que possui práticas de risco é marcado e estigmatizado (Goffman, 1988) por sua condição marginal, o que prejudica os tratamentos e as intervenções preventivas. Ele é visto como “doente", "marginal”, e é ainda marcado pela representação social de que ele é "culpado” pelo hábito que não consegue deixar de ter. Por isso, mais importante do que o ato de usar drogas ou de praticar sexo não seguro, a PRD preocupa-se com o sujeito como pessoa, tentando compreender as condições subjetivas e objetivas que o levaram a tal situação.

Delbon et al. (2006, p.34) comentam que:

No caso específico da redução de danos, quando uma sociedade não reconhece os direitos de uma pessoa que faz uso de uma droga ilícita, significa que essa sociedade, do ponto de vista ético, está afirmando que umas pessoas são mais cidadãs que outras. Portanto, a condição de cidadão passa a ser secundária em relação à de usuário de drogas, ou seja, primeiro a pessoa é julgada por fazer uso de droga e, em decorrência disso, perde o reconhecimento de sua condição de cidadão.

Algumas questões que direcionam esse modo de pensar seriam as seguintes:

Quem é a pessoa que faz isso? Como respeitar a singularidade e particularidade que constituem o sujeito como ser único?

Como e por que ela faz isso? Que mecanismos subjetivos e objetivos mantêm seu comportamento? Em quais condições e riscos? 
Quão exposta é essa pessoa à vulnerabilidade social que produz seu comportamento? Em que condições econômicas e sociais ela está inserida?

De que modo ela pode fazer isso com mais segurança e menos riscos à sua saúde e à de outros? Como colaborar para que se minimizem os riscos de suas práticas?

Esse novo paradigma sugere uma forma alternativa aos modelos tradicionais de encarar o tratamento e a prevenção das práticas de risco, levando em consideração a pessoa que exerce a prática e não somente o comportamento de risco, ganhando expressividade a partir dos anos 80 devido ao grande aumento da epidemia de Aids nos países europeus (Queiroz, 2007).

A Síndrome de Imunodeficiência Adquirida Humana (Aids), desde seu surgimento, nos anos 80 , vem provocando grandes discussões em diversos cenários. Dessas discussões emergiu uma gama de informações, conceitos e teorias que tentam orientar e até mesmo regular a conduta das pessoas, no sentido de evitar a contaminação pelo vírus HIV. Isso evidencia que o surgimento da Aids representou um dos acontecimentos marcantes da história do século XX, fazendo emergir uma demanda da sociedade por respostas efetivas sobre a epidemia que se instalava nos famosos grupos de risco (Vidal et al., 2009). A responsabilidade sobre a infecção e a transmissão da doença foi direcionada ao indivíduo, o que contribuiu para o aumento da culpabilização dos sujeitos atingidos, obscurecendo ainda mais as determinações e influências sociais, históricas e culturais que envolveram o advento da Aids e das sexualidades (Bozon, 2004; Brites, 2006; Russo, 2009).

Com o avanço das pesquisas e do conhecimento sobre a doença, divulgou-se que não havia grupos de risco e o contágio ao HIV poderia atingir toda a população e não apenas um determinado grupo, os homossexuais, como foi divulgado antes (Lima \& Moreira, 2008). Essas novas informações contribuíram para diminuir a estigmatização e a exclusão dos anteriores "grupos de riscos", mas também ampliaram as preocupações sobre como garantir o envolvimento maior de todos nos hábitos de prevenção (Ayres, 1997). 
Passou-se, então, a se pensar em práticas de risco e vulnerabilidade, o que revelou, antes de tudo, o aspecto ardiloso de uma tentativa de controle da epidemia que definia como promíscuo e perigoso o estilo de vida dos gays, dos usuários de drogas, dos travestis e dos profissionais do sexo (Souza, 2007). Além disso, criou-se a ideia de que a sociedade atual precisa controlar os riscos e diminuir as vulnerabilidades, gerenciando tanto os comportamentos individuais quanto os coletivos (Lima \& Moreira, 2008).

Pensar o risco e a vulnerabilidade implica compreender que os princípios normativos que criminalizam ou não determinadas práticas, mesmo sendo estas danosas à saúde do sujeito e à integridade de seu contexto social, devem ser analisados de acordo com as consequências de tais práticas, a responsabilidade e a intencionalidade envolvida nelas e as alternativas concretas para superação e prevenção de determinada prática, articulando tudo isso com os direitos e deveres socialmente reconhecidos para cada cidadão (Brites, 2006).

\section{Sexualidade e vulnerabilidade}

O conceito de sexualidade é destacado aqui como um fenômeno social e cultural. A sexualidade envolve os desejos, os sentimentos, as atitudes, os valores e os comportamentos que dizem respeito ao erotismo humano, mas suas manifestações dependem das representações sociais em diferentes contextos culturais e momentos históricos (Bozon, 2004; Louro, 1999; Maia, 2001; 2006; Mottier, 2008; Ribeiro, 1990). Bozon (2004) explica:

Como construção social, a sexualidade humana implica, de maneira inevitável, a coordenação de uma atividade mental com uma atividade corporal, aprendidas ambas através da cultura. A sexualidade humana não é um dado da natureza. Construída socialmente pelo contexto cultural em que está inscrita, essa sexualidade extrai sua importância política daquilo que contribui, em retorno, para estruturar as relações culturais das quais depende, na medida em que 'incorpora' e representa. 
[...] A sexualidade é uma esfera específica, mas não autônoma do comportamento humano, que compreende atos, relacionamentos e significados [...]. A sexualidade não se explica pela própria sexualidade, nem pela biologia. A sociologia da sexualidade é um trabalho infinito de contextualização social e cultural que visa estabelecer relações múltiplas, e por vezes, desconhecidas, dos fenômenos sexuais com outros processos sociais, o que se pode chamar de construção social da sexualidade.

Michel Foucault, em seus livros sobre a história da sexualidade (1976/1984, p.62), constrói uma hipótese acerca da sexualidade humana, argumentando que ela não deve ser concebida como um dado apenas da natureza e sim como um produto do encadeamento da estimulação dos corpos, da intensificação dos prazeres, da incitação ao discurso, da formação dos conhecimentos, do reforço dos controles e das resistências.

Não se deve descrever a sexualidade como um ímpeto rebelde, estranha por natureza e indócil por necessidade a um poder que, por sua vez, esgota-se na tentativa de sujeitá-la e, muitas vezes, fracassa em dominála inteiramente. Ela aparece mais como um ponto de passagem particularmente denso pelas relações de poder: entre homens e mulheres, entre jovens e velhos, entre pais e filhos, entre educadores e alunos, entre padres e leigos, entre administração e população. Nas relações de poder, a sexualidade não é o elemento mais rígido, mas um dos dotados de maior instrumentalidade, utilizável no maior número de manobras e podendo servir de ponto de apoio, de articulação às mais variadas estratégias.

As sexualidades são, portanto, socialmente construídas a partir de discursos sociais que se tornam, no pensamento foucaultiano, "dispositivos de poder", uma vez que as instituições sociais, culturais e históricas seriam mediadas pela relação saber-poder. Ao se falar sobre as práticas sexuais e o que elas representam nas sociedades, geram-se normas, controles, vigílias, regras que implicam na repressão que ocorre nas relações de poder (Britzman, 1999; Chauí, 1985; Louro, 1999). Na mesma direção, Maia (2009, p.16) afirma que a sexualidade é "um conjunto de valores e concepções sobre as ques- 
tões relacionadas ao corpo, às funções do sexo, à construção de gêneros, à normatização de vínculos amorosos e aos padrões definidores de normalidade que configuram o erotismo humano".

Aparentemente, a sociedade permite práticas sexuais diversas, mas isso não implica dizer que a relação que os sujeitos estabelecem com o sexual esteja de uma maneira mais simplificada (Lima \& Moreira, 2008) ou fora de regras e controles. Embora as sociedades sempre mostrassem preocupações morais e valorativas sobre sexo e sexualidade, o controle sobre elas aparece de modo mais evidente pelo controle do corpo, com uma visão médico-profilática, visando à saúde sexual (Maia, 2004).

É comum, por exemplo, que as políticas públicas brasileiras direcionadas à sexualidade, seja no âmbito da saúde ou da educação, priorizem o esclarecimento de aspectos higiênicos e fisiológicos ligados ao sexo e às suas patologias e não lidem com o enfretamento das discussões sociais que realmente possuem implicações nas práticas sexuais. Além disso, o desejo e o prazer envolvidos na sexualidade de maneira singular para cada sujeito também devem ser considerados como subjetividades que refletem questões sociais mais amplas (Altmann, 2003; Lima \& Moreira, 2008; Maia, 2004). Nesse sentido, Lima \& Moreira (2008, p.114) afirmam que é preciso reconhecer que as manifestações da sexualidade podem ser múltiplas, mas elas traduzem uma pessoa única e particular. Os autores alertam, ainda, que é preciso

lembrar que o aspecto mais notável dos seres humanos é a singularidade psíquica de cada um. Portanto, é necessário refletirmos sobre as práticas sexuais, a sexualidade e o gozo sexual, retirando a ênfase das discussões sobre a aids dos fluidos, humores, bactérias e vírus que eventualmente estão presentes num ato sexual e direcionarmos nossas atenções para o prazer que todos os seres humanos, de um modo ou de outro, buscam em suas práticas sexuais.

Partindo desse enfoque, cria-se a necessidade de pensar sobre vulnerabilidade e risco, uma vez que a construção desse campo conceitual na área da saúde é relativamente recente, sendo encontrado 
em uma estreita relação com a epidemia de HIV/Aids e a tentativa de superação de práticas preventivas nesse contexto (Seed, 2008).

Entende-se o conceito de vulnerabilidade, tal como apresenta Ayres (1997), como os diferentes graus e naturezas de suscetibilidade dos sujeitos e da coletividade a uma exposição a algum risco, seguindo particularidades de cada situação integradas aos aspectos sociais, programáticos e individuais.

A vulnerabilidade tem relação direta com a dimensão social, permeada pelas representações que tiveram a epidemia de Aids no sujeito e no seu contexto histórico-social. A vulnerabilidade considera que os agravos ou a própria epidemia de Aids estão incorporados por dimensões da realidade de cada sujeito, relacionados aos grupos e segmentos sociais aos quais ele pertence, deixando de individualizar o risco ou a própria vulnerabilidade de cada um (Brites, 2006).

$\mathrm{O}$ aspecto social da vulnerabilidade possui relação com o acesso dos sujeitos às informações, às possibilidades de compreendê-las e de incorporá-las, a fim de promover uma mudança significativa nas práticas cotidianas. Nesse sentido, os aspectos programáticos para diminuir as situações de vulnerabilidade devem envolver o compromisso das instituições nacionais, regionais ou locais na promoção da prevenção e do cuidado, identificando as necessidades dos sujeitos que se encontram em situações de vulnerabilidade (Seed, 2008). Ou seja, as pessoas não são em si mesmas vulneráveis, mas podem (ou não) encontrar-se em situações vulneráveis diante de alguns agravos e não de outros, sob determinadas condições e em diferentes momentos de sua vida.

Portanto, a compreensão de que há pessoas que se encontram em situação vulnerável articula-se bem com a perspectiva da política de redução de danos que requer pensar em elementos que avaliem as chances que os sujeitos possuem, no caso de contaminação pelo vírus HIV, considerando as características sociais e individuais que perpassam por sua vida cotidiana e que são definidas como relevantes para uma maior exposição ao HIV, ou uma menor possibilidade de proteção. 
Portanto, ser estatisticamente parte de grupos de riscos é diferente de ser vulnerável aos riscos. $\mathrm{O}$ conceito de risco pode ser considerado, de acordo com Ayres (1997), parte integrante do campo conceitual abrangente da vulnerabilidade, uma vez que o risco é a probabilidade de ocorrência de um determinado agravo a qualquer sujeito, em qualquer circunstância, e a vulnerabilidade vem julgar essa probabilidade de ocorrência, visando à suscetibilidade do agravo em um conjunto de condições intervenientes.

Risco, historicamente, conformou-se como um instrumento preditivo de quantificação das possibilidades de indivíduos ou populações virem a sofrer determinados agravos, em sentido lato, a partir da identificação de associações entre eventos ou condições insalubres, do ponto de vista biológico, social ou moral, e outros eventos e condições saudáveis, do mesmo ponto de vista, e que seriam causalmente relacionáveis. Vulnerabilidade, por sua vez, é um conceito muito mais amplo e complexo que implica o movimento de considerar a chance de exposição das pessoas ao adoecimento [e a outros agravos sociais] como a resultante de um conjunto de aspectos não apenas individuais, mas também coletivos [e] contextuais que estão relacionados com a sua maior suscetibilidade a esses agravos e, concomitantemente, com sua maior ou menor disponibilidade de recursos de proteção. (Ayres \& cols., 2003, p.127)

\section{Sexualidade e redução de danos}

A implantação das PRD é uma tentativa de diminuir os riscos, e não eliminar a prática, utilizando estratégias de controle sobre os comportamentos de riscos que não estigmatizem os sujeitos que as pratiquem. Oferece, então, um suporte ao sujeito, procurando escutar suas necessidades, descarregado de preconceitos, respeitando as escolhas do outro e observando estratégias de diminuição de riscos possíveis para o momento, sugerindo que cada sujeito vivencie sua realidade (Almeida, 2003).

Ou seja, a PRD visa reduzir os efeitos nocivos na vida dos sujeitos que praticam comportamentos de risco, dando-lhes o direito de 
escolha do que é possível para sua vida neste momento, sendo o responsável por ela, o que leva à compreensão de que o foco dessa política não é extinguir as práticas, mas sim conviver com os riscos dentro de uma possibilidade de qualidade de vida, respeitando a singularidade, considerando as diferenças com ações não rígidas e nem estanques (idem, ibidem).

Essa proposta oferece um conjunto de ações alternativas aos modelos de tratamento e prevenção tradicionais, que integram os sujeitos em uma nova perspectiva, na qual a abstinência a qualquer custo não é a única saída, mas sim a convivência não danosa com o uso de drogas e as práticas sexuais de risco. Assim, as ações de redução de danos direcionam-se para sujeitos que não querem, não podem ou não conseguem abandonar os comportamentos de risco. Tais ações representam uma promoção de saúde em sentido amplo, que se aproxima da realidade vulnerável em que vivem os usuários de drogas e as pessoas com práticas sexuais de risco (Campos et al., 2001).

Não se pretende, com isso, deixar de investir em prevenção contra o hábito de práticas arriscadas, mas essas medidas preventivas estariam relacionadas às políticas que investissem na identificação e na erradicação de situações de vulnerabilidade. A redução de danos procura oferecer, tal como prevê a Organização das Nações Unidas (ONU, 2000; Rodrigues, 2003), estratégias que fortaleçam estilos de vida que sejam promotores de saúde, enfraquecendo os prejudiciais, por meio de uma combinação de programas comunitários, econômicos, educacionais e organizacionais.

A PRD atua no sentido de oferecer orientações sobre as práticas sexuais que são arriscadas para o contágio de doenças sexualmente transmissíveis e, nesse sentido, essas práticas articulam-se com as questões da sexualidade humana, sendo possível pensar na PRD como um conjunto de ações que também objetivam tratar e prevenir os danos causados por práticas sexuais não seguras, sejam tais práticas exercidas por usuários de drogas, profissionais do sexo ou outras pessoas vulneráveis.

A PRD enfatiza sua preocupação com a relação existente entre a sexualidade e o risco, que levanta uma discussão entre o perigo, a 
doença e a culpa envolvidos nas práticas e um silêncio em torno da relação entre sexualidade e prazer. Pensar essas práticas como constituintes da vida do sujeito, como algo que precisa ser prevenido e não apenas eliminado, implica pensar a sexualidade humana como um conceito complexo, multideterminado, sendo parte da expressão da personalidade, que envolve a relação de pessoas em um contexto social (Maia, 2001).

\section{Considerações finais}

A proposta da PRD não é proibir ou punir o comportamento de risco, mas sim aceitá-lo de uma forma segura, minimizando riscos e possibilitando qualidade de vida a quem o exerce. Pensar a sexualidade das pessoas que possuem práticas sexuais de risco à luz da PRD nos parece um modo de respeitar o exercício autônomo da sexualidade individual, pois a vulnerabilidade do sujeito é, antes de tudo, social.

Acredita-se que os profissionais envolvidos nas intervenções de redução de danos devam estar despidos de preconceitos diante das pessoas que se encontram vulneráveis aos diversos comportamentos de risco, pautando-se, em última instância, nos direitos humanos, em que se respeitariam as diferenças culturais, sociais e históricas, independentemente de origem, sexo, cor da pele, credo, orientação sexual, faixa etária (Seed, 2008) e também de seus comportamentos sexuais.

Diante disso, é possível dizer que a perspectiva da PRD propõese a trabalhar a partir do conceito de alteridade, uma vez que se investe na pessoa e não no comportamento de risco que ela exerce, respeitando as várias escolhas por estilos de vida e a diversidade existente dentro de um contexto social amplo? É possível dizer que essa proposta seria adequada se entendermos, como diz Britzman (1999, p.89), que "a sexualidade não segue as regras da cultura, mesmo quando a cultura tenta domesticar a sexualidade"? 
Acredita-se, por fim, que a política de redução de danos pode ser uma proposta favorável no oferecimento de subsídios que fundamentam a prática de aceitar o sujeito de acordo com as escolhas que ele fez e faz, dando-lhe a possibilidade de minimizar os riscos envolvidos nessa escolha, por valorizar a diversidade existente. E, nesse sentido, seria um modo de respeitar o outro pela sua história e pelas suas condições subjetivas e objetivas, evitando a discriminação e a estigmatização individual daqueles que rompem com um modelo de sexualidade controlado pelo discurso médico e patológico.

\section{Referências bibliográficas}

ALMEIDA, C. B. Conceito de redução de danos: uma apreciação crítica. Boletim da Saúde. v.17, n.1, 2003.

ALTMANN, H. Orientação sexual em uma escola: recortes de corpos e gêneros. Cadernos Pagu. n.21, p.281-315, 2003.

AYRES, J. R. C. M. Sobre o risco: para compreender a epidemiologia. São Paulo: Hucitec, 1997.

et al. O conceito de vulnerabilidade e as práticas de saúde: novas perspectivas e desafios. In: CZERESNIA, D. (Org.). Promoção da saúde: conceitos, reflexões, tendências. Rio de Janeiro: Fiocruz, 2003.

BOZON, M. Sociologia da sexualidade. Tradução de Maria de Lourdes Menezes. Rio de Janeiro: FGV, 2004.

BRITES, C. M. Ética e uso de drogas: uma contribuição da Ontologia Social para o campo da saúde pública e da redução de danos. Tese (doutorado). Programa de estudos pós-graduados em Serviço Social. Pontifícia Universidade Católica de São Paulo, São Paulo, 2006. BRITZMAN, D. Curiosidade, sexualidade e currículo. In: LOURO, G. L. (Org.). O corpo educado: pedagogias da sexualidade. Belo Horizonte: Autêntica, 1999.

CAMPOS, M. A.; SIQUEIRA, D. J. R.; BASTOS, F. I. Drogas e redução de danos: abordagens para pessoas vivendo com HIV e Aids. In: PINHEIRO, R. M.; SILVEIRA, C.; GUERRA, E. (Orgs.) Drogas e Aids: prevenção e tratamento. Belo Horizonte: Fundação do Estado de Minas Gerais, 2001. 
CHAUÍ, M. Repressão sexual: essa nossa (des)conhecida. São Paulo: Brasiliense, 1985.

DELBON, F.; Da ROS, V.; FERREIRA, E. M. A. Avaliação da disponibilização de kits de redução de danos. Saúde e Sociedade. v.15, n.1, p.37-48, 2006.

FIGLIE, N. B.; BORDIN, S.; LARANJEIRA, R. Aconselhamento em dependência química. São Paulo: Roca, 2004.

FONSECA, E. M. Políticas de redução de danos ao uso indevido de drogas: o contexto internacional e uma análise preliminar dos programas brasileiros, escola nacional de saúde pública. s. 1.: Fundação Oswaldo Cruz, 2005.

FOUCAULT, M. História da sexualidade I: a vontade de saber. 17.ed. Rio de Janeiro: Edições Graal, 1984.

GOFFMAN, E. Estigma: notas sobre a manipulação da identidade deteriorada. 4.ed. Rio de Janeiro: Editora Guanabara, 1988.

LIMA, M. L. C.; MOREIRA, A. C. G. Aids e feminização: os contornos da sexualidade. Revista Mal-Estar e Subjetividade. Fortaleza, v. 8, n.1, p.103-18, 2008.

LOURO, G. L.; Pedagogias da sexualidade. In: (Org.). O corpo educado: pedagogias da sexualidade. Belo Horizonte: Autêntica, 1999, p.9-34.

MAIA, A. C. B.; Sexualidade: reflexões sobre um conceito amplo. SBPN - Scientific Journal. v.5(1), 2001.

. Orientação sexual na escola. In: RIBEIRO, P. R. M. (Org.). Sexualidade e educação: aproximações necessárias. São Paulo: Arte e Ciência, 2004, p.153-79.

Sexualidade e deficiências. São Paulo: Fundação Editora Unesp, 2006.

Inclusão e sexualidade: questões afetivo-sexuais em pessoas com deficiências físicas. Relatório de pesquisa de pós-doutorado. Brasília: CNPq, 2009.

MESQUITA, F.; BASTOS, F. I. Drogas e Aids: estratégias de redução de danos. São Paulo: Hucitec, 1994.

MOTTIER, V. Sexuality: a very short introduction. New York: Oxford university press, 2008.

OLIVEIRA, M. W.; PAES, P. C. D. Educação no Programa de Redução de Danos: alienação ou práxis educativa. Revista Brasileira de Educação. n.6, 2004. 
ONU. Posição Oficial do Sistema das Nações Unidas: prevenção da transmissão do HIV entre usuários de drogas. Anexo do Relatório da $8^{\circ}$ sessão do sub-comitê sobre controle de drogas da ACC, 2000. Disponível em: <www.aids.gov.br/final/prevencao/ udi_nações_unidas.doc $>$.

QUEIROZ, I. S. Adoção de ações de redução de danos direcionadas aos usuários de drogas: concepções e valores de equipes do PSF. Pesquisas e Práticas Psicossociais. São João Del Rei, v.2, n.1, mar.-ago, 2007.

RIBEIRO, P. R. M. Educação sexual: além da informação. São Paulo: EPU, 1990.

RODRIGUES, T. Política de drogas e a lógica de danos. Revista Verve. São Paulo, Nu-Sol/PUC-SP, n.3, 2003.

RUSSO, J. A. A sexologia na era dos direitos sexuais: aproximações possíveis. In: VELHO, G.; DUARTE, L. F. D. (Orgs.). Gerações, família e sexualidade. Rio de Janeiro: 7 Letras, 2009, p.63-76.

SEED-PARANÁ. Secretaria de Estado da Educação. Superintendência da Educação. Diretoria de políticas e programas educacionais. Coordenação de Desafios Educacionais Contemporâneos. Sexualidade, Curitiba, Seed - PR, 2008.

SOUZA, T. P. Redução de danos no Brasil: a clínica e a política em movimento. Dissertação (mestrado). Universidade Federal Fluminense, Niterói, 2007.

VIDAL, E. C. F. et al. Políticas públicas para pessoas com HIV: discutindo direitos sexuais e reprodutivos. Revista Rene. Fortaleza, v.10, n.2, p.166-74, abr.-jun. 2009. 

PARTe 2

\author{
INTERCORRÊNCIAS NO \\ DESENVOLVIMENTO INFANTIL
}





\title{
4 \\ EFEITOS DO CHUMBO E DA ESCOLARIDADE NO DESENVOLVIMENTO INFANTIL ${ }^{1}$
}

\author{
Maria Alice Ferraz Troijo ${ }^{2}$ \\ Olga Maria Piazentin Rolim Rodrigues ${ }^{3}$
}

\section{Introdução}

A partir do uso indiscriminado do chumbo pelo homem, muitas são as fontes de contaminação identificadas (Kim, 2002; Gonzáles et al., 2002; Klaassen, 1996; Bornschein et al., 2002). Alguns pesquisadores (Cunha, 2003; Sharma \& Reutergardh, 2000) desenvolveram estudos sobre os efeitos do chumbo na gasolina, resultando em emissões atmosféricas danosas à saúde pública e contribuindo para o aumento dos teores de chumbo no solo, principalmente em áreas próximas a autoestradas. Autores como Rojas et al. (2003), Pino et al. (2001), Luo et al. (2003) e Leroyer (2000) encontraram níveis de chumbo no sangue da população infantil relacionados à gasolina e às emissões industriais em cidades com grande densidade populacional urbana e grande número de veículos.

1 O estudo é parte integrante da dissertação de mestrado da primeira autora sob orientação da segunda autora.

2 Programa de pós-graduação em Psicologia do Desenvolvimento e da Aprendizagem da Unesp, campus de Bauru.

3 Programa de pós-graduação em Psicologia do Desenvolvimento e da Aprendizagem da Unesp, campus de Bauru. 
Carvalho et al. (2003), Cunha (2003) e Albalak (2003) identificaram contaminação infantil em populações próximas a fundições de chumbo, ainda que em alguns casos estas estivessem desativadas. Em estudos conduzidos por Paoliello \& Chasin (2003), o chumbo encontrado em peitoris de janelas, no chão e em brinquedos e o hábito de levar a mão à boca foram indicados como preditores significativos de níveis de chumbo no sangue de crianças contaminadas que moram próximo a uma fundição de baterias.

O chumbo absorvido por qualquer via, em decorrência das várias formas de exposição citadas anteriormente, entra na circulação sanguínea, sendo a determinação de sua quantidade no sangue um biomarcador da exposição ao metal, norteando investigações científicas. O diagnóstico de intoxicação por chumbo pode ser também constatado por exames de sangue e urina, técnicas de raio-fluorescência, tomografia computadorizada, entre outros. A eliminação desse metal pelo organismo é extremamente lenta (até dez anos para sua total eliminação), mesmo com a ausência de chumbo no ambiente e tratamento específico (Malta et al., 2000).

As crianças, principalmente as oriundas das zonas urbanas de países em desenvolvimento, estão mais propensas ao envenenamento por chumbo devido a sua vulnerabilidade orgânica e por entrarem em contato com diferentes fontes do metal. Em 1994, calculou-se que $80 \%$ das crianças de três a cinco anos de idade e 100\% dos menores de dois anos teriam níveis de saturnismo superiores a $10 \mu \mathrm{g} / \mathrm{dl}$, segundo o Center of Disease Control and Prevention (CVE, 2002). A incidência é maior na população mais desfavorecida do ponto de vista econômico, pois a pobreza causa desnutrição e complicações físicas que têm como consequência a intensificação das incapacidades devido à absorção do chumbo. Cada vez mais têm-se indícios de que quando o corpo da criança contém chumbo, ainda que seja em pequenas quantidades, as primeiras etapas de seu crescimento físico e mental podem sofrer transtornos, assim como em etapas posteriores, interferindo em sua capacidade intelectual e em seu rendimento acadêmico; além disso, a presença desse metal no organismo está altamente associada a comportamentamentos como agressividade e 
delinquência. Desse modo, a contaminação por chumbo não é apenas um problema ambiental, mas constitui também um problema social (Mello-da-Silva \& Fruchtengarten, 2005).

Os efeitos do chumbo para a população em geral e para aquela exposta ocupacionalmente são os mesmos para adultos e crianças, mas a suscetibilidade é diferente entre os dois grupos. As crianças e as gestantes são mais vulneráveis aos efeitos do chumbo por razões neurológicas, metabólicas e comportamentais, absorvendo mais de 50\%, enquanto os adultos absorvem de $10 \%$ a $15 \%$ da quantidade ingerida. Por terem barreira hematoencefálica ainda em desenvolvimento, as crianças intoxicadas nas fases iniciais de seu desenvolvimento podem apresentar importantes distúrbios biológicos e neurológicos. A maior vulnerabilidade para a contaminação do chumbo pelas crianças se deve ao fato de: a) o consumo por quilo de peso ser maior do que nos adultos; b) com maior frequência, as crianças colocam na boca objetos que estão no chão; c) a absorção do chumbo pelo organismo da criança ser maior do que a do adulto; ed) as crianças pequenas, pelo desenvolvimento rápido e constante, tornam-se mais vulneráveis aos efeitos do chumbo (Yule \& Lannsdown, 1993).

A Organização Mundial de Saúde (OMS) considera aceitável a concentração de chumbo no sangue inferior a $10 \mu \mathrm{g} / \mathrm{dl}$ para mulheres grávidas e crianças (CVE, 2002; Moreira \& Moreira, 2004). Os referenciais de avaliação utilizados foram os índices propostos pelo Center for Disease Control - CDC (1992), indicando que níveis menores que $9,9 \mu \mathrm{g} / \mathrm{dl}$ são considerados seguros e as crianças não são consideradas intoxicadas. Com níveis de chumbo no sangue acima de $10 \mu \mathrm{g} / \mathrm{dl}$, a criança é considerada contaminada. Indicam-se reavaliações frequentes e programas de estimulação ambiental. Acima de $20 \mu \mathrm{g} / \mathrm{dl}$, a criança deve passar por procedimentos de desintoxicação, incluindo a quelação (Lidsky \& Schneider, 2006).

As consequências do efeito do chumbo sérico sobre o QI de crianças pequenas têm sido estimada como uma perda média de dois a três pontos para nível de chumbo no sangue em torno de $20 \mu \mathrm{g} / \mathrm{dl}$, comparativamente com níveis até $10 \mu \mathrm{g} / \mathrm{dl}$ (CDC, 2004). Tong et al. (2000) investigaram os efeitos do chumbo sobre o desempenho 
intelectual de crianças contaminadas. Os resultados mostraram que a relação é inversa entre o QI das crianças e a média de concentração de chumbo no sangue $(\mathrm{PbB})$ e diverge entre os gêneros, sendo mais pronunciada em meninas do que em meninos na idade avaliada, mas não é estatisticamente significativa.

O efeito adverso da intoxicação por chumbo na infância, analisado sob uma perspectiva neuropsicológica clínica, comprova que tal intoxicação acarreta, em longo prazo, efeitos negativos experienciados pelos pacientes, como rebaixamento e prejuízo neurocognitivo no desenvolvimento (Lidsky \& Schneider, 2006; Bellinger, 2000).

No Brasil, a partir da identificação de uma população infantil contaminada acidentalmente por chumbo, alguns estudos foram realizados com o objetivo de avaliar possíveis efeitos dessa contaminação. Os resultados apontaram para uma relação entre a presença de chumbo no sangue e variáveis como: atraso no desenvolvimento (Alves et al., 2003; Rodrigues et al., 2003; Troijo et al., 2004; Troijo, 2007; Rodrigues \& Carnier, 2007), dificuldade de atenção e discriminação de estímulos (Dascânio et al., 2004), baixo desempenho intelectual (Correia et al., 2005; Amaral, 2005; Ribeiro, 2007), fracasso escolar (Rodrigues et al., 2004; Capellini et al., 2008) com comprometimento emocional (Neme et al., 2009) e associado a variáveis demográficas (Dascânio \& Valle, 2009; Melchiori et al., 2010). Diante disso, diferentes autores enfatizaram a importância da avaliação do desenvolvimento infantil como um todo e do ambiente que cerca a criança, fatores que podem acelerar ou retardar esse processo (Bee, 1997; Papalia et al., 2006).

O desenvolvimento infantil é um processo contínuo e as mudanças qualitativas e quantitativas pelas quais as crianças passam no decorrer do tempo não acontecem isoladamente. Certos princípios do desenvolvimento aplicam-se a todas as crianças e proporcionam parâmetros de orientação na interpretação de comportamentos, como as diferenças individuais e os períodos críticos e de desenvolvimento ordenado. Assim, diferentes tipos de comportamento são importantes no ciclo vital. À medida que a criança cresce, podemos observar mudanças em alguns aspectos do desenvolvimento, mais do que 
em outros que, muitas vezes, se sobrepõem e interagem entre si durante toda a vida, uma vez que o desenvolvimento de uma área afeta o desenvolvimento de outra (idem, ibidem).

O desenvolvimento se dá em sua relação com o ambiente, sem desconsiderar os limites biológicos, sendo o comportamento moldado por diferentes processos de aprendizagem. Entre os aspectos que podem promover o desenvolvimento da criança, a escola pode ser considerada um fator protetivo. Poletto \& Koller (2008), estudando aspectos protetivos e de risco para o desenvolvimento humano, analisaram contextos ecológicos diversos. Entre eles, identificaram, nos estudos revisados, a escola como fator de proteção ao desenvolvimento infantil. Para Lisboa (2005), a escola, além de possibilitar o desenvolvimento cognitivo, pode promover a autoestima e autoeficácia dos estudantes e suas habilidades sociais, influenciando o relacionamento entre o grupo. Silva et al. (2008), em um estudo sobre varáveis que têm impacto sobre o desenvolvimento infantil, revisaram pesquisas que indicam que desde os primeiros anos escolares o desempenho escolar está associado com o envolvimento da família.

D'Avila-Bacarji et al. (2005) desenvolveram um estudo que aponta também que o envolvimento dos pais, analisado em termos de interesse em participar ativamente da vida escolar dos filhos, foi positivamente associado com o bom desempenho escolar. Vendrúsculo \& Matsukura (2007) também analisaram a participação do suporte familiar como fator protetivo para o desenvolvimento infantil comparando crianças de escolas públicas e privadas.

A utilização de escalas para avaliar o desenvolvimento de crianças tem se mostrado útil na medida em que dá parâmetros para comparação com seus pares de mesma idade cronológica. Dentre as várias escalas de desenvolvimento utilizadas para detecção de distúrbios do desenvolvimento infantil, destaca-se o Inventário Portage Operacionalizado (IPO), descrito por Williams \& Aiello (2001). O IPO fornece uma visão global do desenvolvimento da criança dividindo-o em cinco grandes áreas: cognição, desenvolvimento motor, linguagem, socialização e autocuidado, possibilitando a detecção de áreas que devem ser objeto de intervenção. Prevê, inclusive, avaliações sequen- 
ciais como forma de monitorar o desenvolvimento da criança a partir da introdução de procedimentos de intervenção (idem, ibidem).

Observar se a contaminação por chumbo está afetando o desempenho cognitivo associado à possibilidade de frequência à escola permitiria avaliar se a estimulação ambiental sistemática, especialmente a oferecida pela educação infantil, diminuiria os possíveis danos de desenvolvimento atribuídos ao chumbo pela literatura da área. Nesse sentido, o objetivo do estudo foi analisar os efeitos do chumbo e os da frequência à escola sobre o desenvolvimento geral e em áreas específicas de crianças de quatro a cinco anos de idade com nível de chumbo acima de $10 \mu \mathrm{g} / \mathrm{dl}$, comparando-os com crianças com nível de chumbo abaixo de $5 \mu \mathrm{g} / \mathrm{dl}$, frequentando a escola, oriundas de condições socioeconômicas semelhantes.

\section{Método}

Os procedimentos metodológicos deste estudo atendem às normas éticas em pesquisa com seres humanos e foi realizada mediante aprovação do Comitê de Ética da Faculdade de Ciências da Unesp, campus de Bauru. Os pais e responsáveis receberam informações sobre a participação das crianças e assinaram termo de autorização e participação voluntária.

\section{Participantes}

O estudo foi realizado com 49 crianças, entre quatro a cinco anos de idade, com história de exposição ambiental ao chumbo e contaminação comprovada ou não por exames de sangue, divididas em dois grupos: Grupo 1: Grupo de Crianças Contaminadas (GCC), composto por 33 crianças com nível de chumbo no sangue acima de $10 \mu \mathrm{g} / \mathrm{dl}$, de ambos os sexos, subdividido em dois subgrupos quanto à frequência à escola - 19 (39\%) crianças contaminadas por chumbo que frequentavam a pré-escola (GCC1) e 14 (29\%) crianças con- 
taminadas por chumbo que não estavam frequentando a pré-escola (GCC2). Grupo 2: Grupo de Crianças Não Contaminadas (GCNC), com nível de chumbo no sangue abaixo de $5 \mu \mathrm{g} / \mathrm{d}$, composto por 16 (32\%) crianças que frequentam a pré-escola e também residentes na área de contaminação. No GCC, nove crianças eram meninas (27\%) e 24, meninos (73\%). Quanto à escolaridade dos participantes do GCC, 58\% frequentam a escola, o GCC1, sendo cinco meninas (15\%) e 14 (43\%) meninos, e 42\% não frequentam a escola, o GCC2, sendo quatro meninas (12\%) e dez meninos (30\%). O GCNC era formado por 16 crianças consideradas não contaminadas por apresentarem nível de chumbo abaixo de $5 \mu \mathrm{g} / \mathrm{dl}$ no sangue, expostas às mesmas condições ambientais e de nível socioeconômico semelhante às crianças do GCC. Considerando a distribuição por gênero, a maioria é do sexo masculino $(62,5 \%)$ nesse grupo.

Os participantes foram selecionados a partir de uma demanda já identificada de 832 crianças de zero a 12 anos, de ambos os sexos, que foram avaliadas a partir do acidente ambiental ocorrido em Bauru, estado de São Paulo. Todos os integrantes dos grupos residiam no mesmo bairro, oriundos, portanto, de condições socioeconômicas semelhantes.

\section{Materiais}

Utilizou-se para a avaliação do desenvolvimento o IPO (Williams \& Aiello, 2001). Foram utilizados protocolos para anotação dos comportamentos e folhas de registro resumo das respectivas áreas específicas do desenvolvimento. Os protocolos para anotação dos comportamentos avaliados pelo IPO permitem obter dados nas cinco áreas: socialização, linguagem, desenvolvimento motor, cognição e autocuidado. São utilizados nas idades correspondentes à idade cronológica da criança e das idades próximas, até que o critério preestabelecido pelo instrumento seja alcançado. Para a aplicação do IPO foram utilizados brinquedos específicos e materiais pedagógicos (folhas, tesoura, lápis preto e colorido, massa de modelar, giz de cera, 
livros de história, gravuras, jogos, entre outros), organizados e acondicionados em caixas para cada faixa etária, permitindo o transporte de todo o material de acordo com o local de aplicação. Também foram utilizadas folhas de registro para cada uma das cinco áreas do IPO: cognição, que avalia a linguagem receptiva e o estabelecimento de relação de semelhanças e diferenças; socialização, que avalia habilidades relevantes na interação com as pessoas; autocuidados, que avalia a independência para o alimentar-se, vestir-se, banhar-se etc; linguagem, que avalia o comportamento verbal expressivo; e desenvolvimento motor, que avalia os movimentos coordenados por pequenos e grandes músculos.

\section{Procedimento}

O procedimento de coleta foi o mesmo para os dois grupos (GCC e GCNC). Para a aplicação do IPO, inicialmente, o aplicador promovia diálogos e ações facilitadoras para a interação positiva e de confiança com a criança a ser avaliada. A presença dos responsáveis foi indispensável durante a aplicação, uma vez que estes, além de confortarem a criança, dando segurança a ela em um ambiente estranho ou com pessoas estranhas, serviam também como informantes. A aplicação era encerrada quando a criança cumpria todos os itens previstos ou mostrava-se cansada, irritada e/ou com sono. Se necessário, um novo horário era agendado para a continuidade da avaliação. Os acertos e os erros foram contabilizados nos protocolos de cada uma das áreas avaliadas, possibilitando a organização do que seria feito na próxima sessão, de forma a contemplar o critério para o encerramento da avaliação, que incluía a aplicação de protocolos em idades acima e abaixo da idade da criança até que 15 acertos consecutivos tivessem sido observados nas idades anteriores, e 15 erros, nas idades posteriores.

A avaliação das respostas dadas pela criança e a elaboração do resultado final foram realizadas segundo as diretrizes propostas no manual, para posterior descrição e análise conjunta. Os dados foram 
descritos a partir dos pontos obtidos pela média das crianças de cada grupo e organizados a partir das variáveis, como frequência à escola, nível de chumbo etc., e analisados estatisticamente utilizando-se a prova estatística de Mann-Whitney, com índice de significância no nível de $5 \%$. Os resultados do IPO foram avaliados também por meio da análise de cada uma das áreas e do resultado total e correlacionados (Kruskal-Wallis Test) com a frequência ou não à pré-escola. A análise estatística foi realizada com o auxílio do Statstical Software Minitab, versão 13 .

\section{Resultados}

Pela vulnerabilidade das crianças à contaminação do chumbo, este estudo foi proposto objetivando avaliar possíveis efeitos desse metal no desenvolvimento geral e em cinco áreas específicas - desenvolvimento motor, linguagem, autocuidado, cognição e socialização - de dois grupos de crianças expostas aos efeitos desse metal no sangue, de crianças contaminadas $(\mathrm{PbB}>10 \mu \mathrm{g} / \mathrm{dl})$ frequentando ou não a pré-escola, e outro da mesma faixa etária, mas com outro nível de chumbo $(\mathrm{PbB}<5 \mu \mathrm{g} / \mathrm{dl})$, frequentando a escola. Optou-se por destacar o desempenho dos grupos avaliados em cognição, por tratar-se da área de desenvolvimento que está diretamente ligada aos conteúdos acadêmicos.

\section{A influência da escola no GCC}

O desenvolvimento geral, obtido a partir da somatória de todas as áreas, de crianças do GCC1 (com nível de chumbo acima de 10 $\mu \mathrm{g} / \mathrm{dl}$ e que frequentam a pré-escola) foi comparado com o das que não frequentam (GCC2). Foi também comparado com o desempenho esperado para essa faixa etária. Os resultados mostraram que o GCC1 apresentou, como média do desempenho obtido, 451,4 pontos, e o GCC2, 398,9 pontos, sendo que o total de pontos esperado 
no IPO era de 444 pontos para a idade avaliada. Análise estatística apontou que a diferença entre o GCC1 (com escola) e o GCC2 (sem escola) foi significativa $(0,025)$.

Encontramos diferenças também ao comparar o desenvolvimento do grupo de crianças contaminadas por chumbo com escolaridade (GCC1) com as sem escolaridade (GCC2) nas cinco áreas avaliadas pelo IPO, conforme mostra a Figura 1.

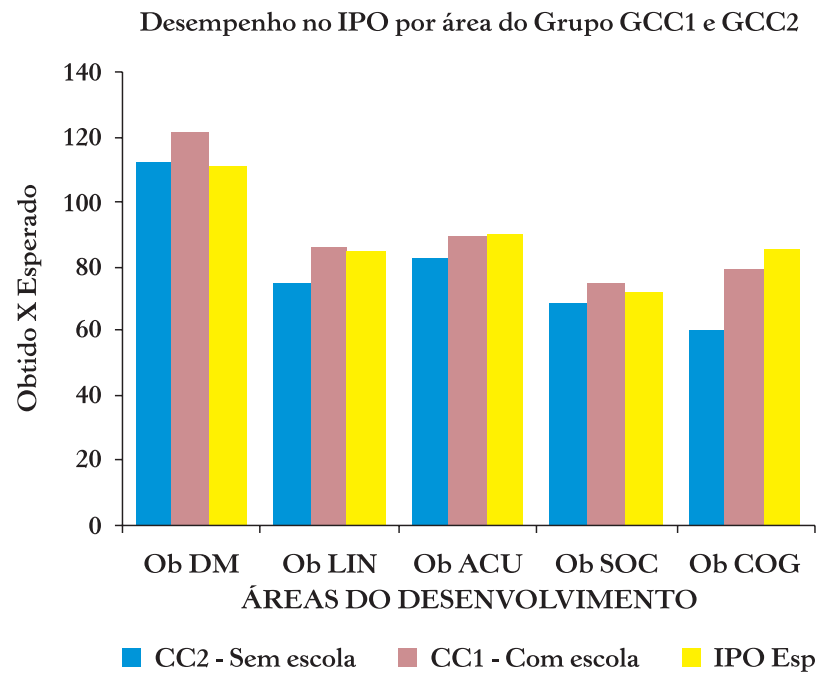

Figura 1 - Desempenho no IPO por áreas do desenvolvimento do GCC1 (com escola)e do GCC2 (sem escola).

Há diferenças significativas $(\mathrm{P}<0,05)$ entre os desempenhos nas seguintes áreas de desenvolvimento: desenvolvimento motor, linguagem, socialização, cognição, como também na média geral entre os dois grupos, segundo o Mann-Whitney Test (Tabela 1).

Destacando o desempenho na área de cognição das crianças do GCC1, para o grupo contaminado com escola o valor obtido foi de 79,1, enquanto do GCC2, sem escola, o obtido foi de 60,1, sendo que para essa faixa etária o esperado é 86. O GCC2, com escola, apresentou um decréscimo de 6,9 pontos na média, e o GCC1, sem escola, 25,9 pontos na média, abaixo do esperado. 
Tabela 1 - Análise estatística comparando os participantes do GCC com escola (GCC1) e sem escola (GCC2).

\begin{tabular}{|c|c|c|c|c|c|c|}
\hline & 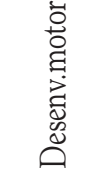 & 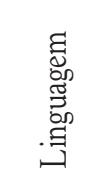 & 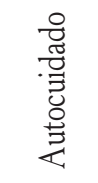 & 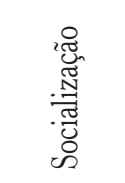 & 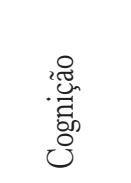 & 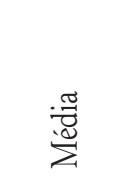 \\
\hline GCC1 & 121,4 & 86,3 & 89,3 & 75,3 & 79,1 & 451,4 \\
\hline GCC2 & 112,6 & 74,9 & 82,7 & 68,4 & 60,1 & 398,9 \\
\hline Valor P & 0,025 & 0,006 & 0,152 & 0,0014 & 0,0001 & 0,0025 \\
\hline
\end{tabular}

Outra análise possível dos efeitos do chumbo no desenvolvimento infantil é a comparação de seu desempenho considerando o nível de plumbemia. Para a análise foram considerados a média do grupo, e as crianças foram divididas em abaixo $(<17,1)$ e acima $(>17,1)$ da média. Considerando o desempenho no IPO do GCC1 e do GCC2 com nível de chumbo $<17,1 \mu \mathrm{g} / \mathrm{dl}$, observa-se na Tabela 2 que a diferença só foi significativa para linguagem $(0,0405)$. Todavia, podemos considerar significativa também em cognição $(0,067)$, ainda que com valor maior que 0,05 .

Tabela 2 - Análise estatística comparando nível de plumbemia < $17,1 \mu \mathrm{g} / \mathrm{dl}$ dos participantes do GCC1 (com escola) e do GCC2 (sem escola) e o desempenho por áreas no IPO.

\begin{tabular}{|c|c|c|c|c|c|c|}
\hline 总 & 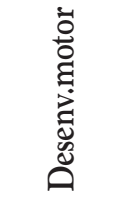 & 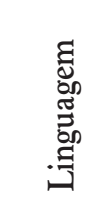 & 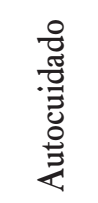 & 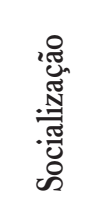 & 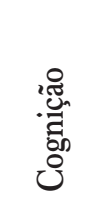 & స్త్రేౖ \\
\hline $2(\mathrm{~N}=07)$ & 113,8 & 76,6 & 84,7 & 69,71 & 63,4 & 408 \\
\hline $1(\mathrm{~N}=13)$ & 117,2 & 84,3 & 88,3 & 73,46 & 70,8 & 433 \\
\hline D* & 0.3495 & 0.0405 & 0.155 & 0.155 & 0.067 & 0.067 \\
\hline
\end{tabular}


A Tabela 3 mostra o desempenho no IPO do GCC1 e do GCC2 com nível de chumbo $>17,1 \mu \mathrm{g} / \mathrm{dl}$. Observou-se que houve diferença significativa entre as crianças contaminadas com escola e sem escola em desenvolvimento motor, socialização, cognição e no desempenho geral.

Tabela 3 - Análise estatística comparando nível de plumbemia > $17,1 \mu \mathrm{g} / \mathrm{dl}$ dos participantes do grupo GCC1 (com escola) e do GCC2 (sem escola) e o desempenho por áreas no IPO.

\begin{tabular}{|c|c|c|c|c|c|c|}
\hline 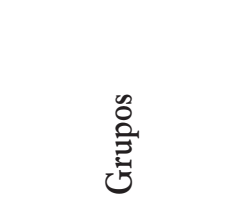 & 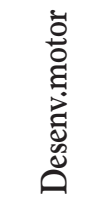 & 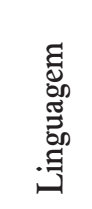 & 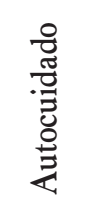 & 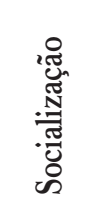 & 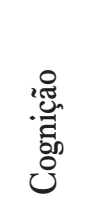 & 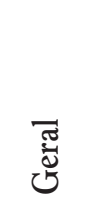 \\
\hline GCC $2(\mathrm{~N}=07)$ & 111,4 & 73,29 & 80,71 & 67,14 & 56,86 & 389,4 \\
\hline GCC $1(N=13)$ & 130,5 & 90,67 & 91,33 & 79,17 & 80,33 & 472 \\
\hline Valor P* & 0,01 & 0,11 & 0,117 & 0,025 & 0,005 & 0,004 \\
\hline
\end{tabular}

\section{Comparando o desempenho do GCC1 com o GCNC}

Os Grupos GCC1 e GCNC têm como característica comum a ida à escola. Comparando o desenvolvimento geral, observa-se que o GCC1, de crianças contaminadas com escola, apresentou desempenho acima do esperado e ligeiramente superior ao GCNC, sem contaminação e com escola. Porém, a diferença observada não foi estatisticamente significante (Figura 2).

Quando comparamos por áreas de desenvolvimento avaliadas pelo IPO, os dois grupos também não apresentaram diferenças estatisticamente significativas $(\mathrm{P}>0,05)$, segundo o Mann-Whitney Test.

A Figura 3 mostra o desempenho do GCC1 e do GCNC, quando comparados pelas áreas de desenvolvimento avaliadas pelo IPO: autocuidado, cognição, desenvolvimento motor, linguagem e socia- 
lização. Nas áreas de desenvolvimento motor e socialização, o desempenho de ambos os grupos está acima do esperado. Em linguagem, o GCNC está abaixo, e o GCC1, acima. Em autocuidado apresentam os mesmos escores, muito próximos do esperado.

Desempenho Geral no IPO do GCC1 e GCNC

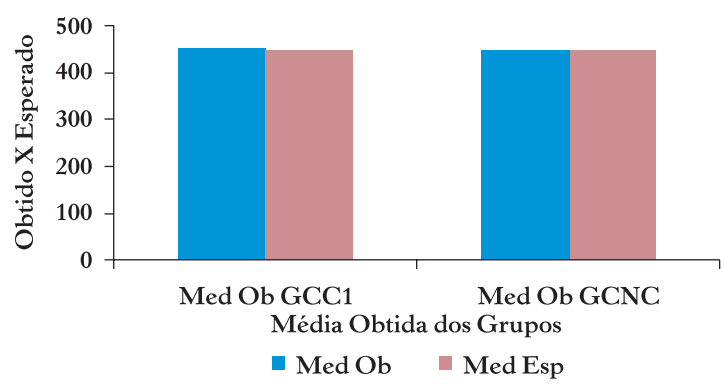

Figura 2 - Desempenho geral no IPO do GCC1 e do GCNC.

Desempenho nas áreas do IPO dos grupos GCC1 e do GCNC

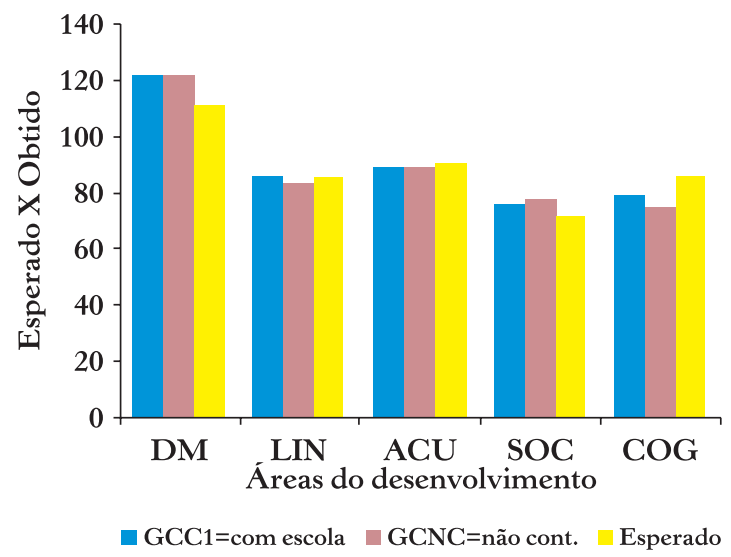

Figura 3 - Desempenho nas áreas do IPO do GCC1 e do GCNC.

Destacando a área de cognição, observamos que ambos estão abaixo do esperado. Porém o GCC1 apresentou 6,9 pontos de de- 
créscimo em relação ao esperado, enquanto o GCNC, 11,9. Todavia, comparando o GCC1 e o GCNC observa-se que a média dos grupos não é estatisticamente significativa $(\mathrm{P}>0,05)$, segundo o Mann-Whitney Test.

\section{Comparando o desempenho do GCC2 com o GCNC}

Comparando o desenvolvimento geral do CCC2 com o GCNC, encontramos a média obtida pelo GCC2 $(398,9)$ abaixo do esperado em relação à média do $\operatorname{GCNC}(446,8)$, sendo que este último está acima do esperado (444).

Analisando o desenvolvimento por área, observamos que o GCC2 apresenta desempenho inferior ao GCNC em todas as áreas avaliadas, conforme mostra a Figura 4. Análises estatísticas mostraram que o desempenho do GCC2 na média geral e nas áreas de desenvolvimento motor, socialização e cognição foi estatisticamente significativo ( $\mathrm{P}>0,05)$, segundo o Mann-Whitney Test. Considerando que a linguagem tem relevância na análise do desenvolvimento infantil, influenciando as demais aquisições, é possível considerar a diferença observada $(0,07)$ como também estatisticamente significante (Tabela 4).

Desempenho no IPO por área dos grupos

GCC2 e GCNC

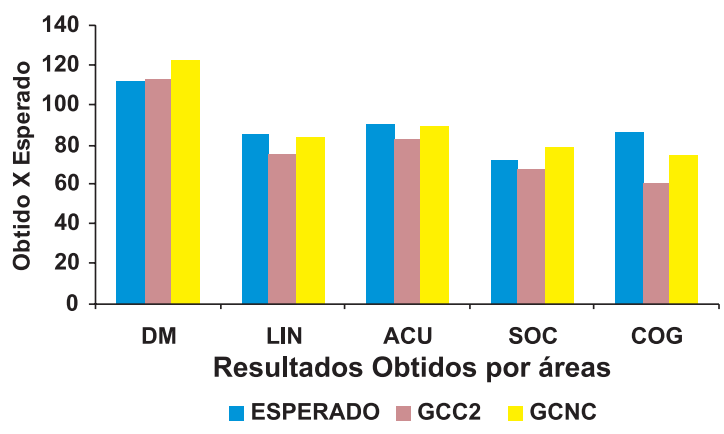

Figura 4 - Desempenho nas áreas do IPO do GCC2 e do GCNC. 
Destacando a área de cognição, quando comparados o GCC2 e o GCNC, observa-se que a diferença entre os grupos é estatisticamente significativa (Tabela 4). Quando comparamos o desempenho do GCC2 (60,1 pontos), observa-se uma diferença de 25,9 pontos em relação ao esperado (86), e o GCNC (74,1 pontos) apresenta uma diferença de 11,9 pontos. Os dois grupos estão abaixo do esperado na área de cognição, mas a defasagem maior do GCC2 deve ser enfatizada.

Tabela 4 - Análise estatística comparando os participantes do GCC2 com os do GCNC.

\begin{tabular}{|c|c|c|c|c|c|c|}
\hline 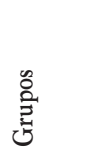 & 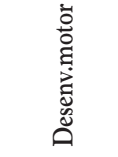 & 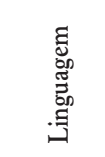 & $\begin{array}{l}\frac{8}{\pi} \\
\frac{\pi}{3} \\
\frac{0}{0} \\
\frac{3}{2}\end{array}$ & 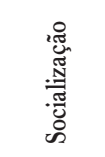 & 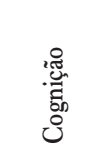 & 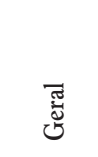 \\
\hline $\mathrm{C} 2$ & 112,64 & 74,93 & 82,71 & 75,26 & 74,10 & 451,4 \\
\hline $\mathrm{NC}$ & 121,56 & 83,75 & 89,50 & 78,44 & 60,10 & 446,9 \\
\hline or P* & 0,034 & 0,070 & 0,142 & 0,002 & 0,004 & 0,003 \\
\hline
\end{tabular}

Confirmando as comparações anteriores entre os dois grupos de crianças expostas ao chumbo (GCC1 e GCC2) com o grupo daquelas consideradas não contaminadas (GCNC) por meio do KruskalWallis Test, comprovamos os dados anteriormente citados como estatisticamente significativos, conforme mostra a Tabela 5.

Tabela 5-Análise estatística utilizando o Kruskal-Wallis Test, comparando os participantes do GCC1 e do GCC2 com os do GCNC.

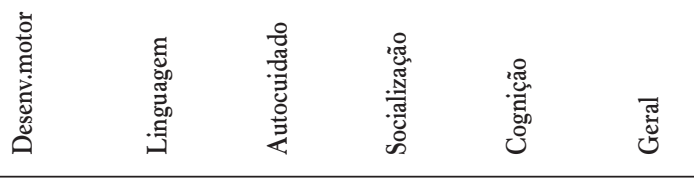

$\begin{array}{lllllll}\text { Qui-quadrado } & 5,377 & 6,935 & 2,847 & 9,900 & 10,671 & 10,671\end{array}$ $\begin{array}{lllllll}\text { Asymp.Sign } & 0,068 & 0,031 & 0,241 & 0,007 & 0,005 & 0,006\end{array}$ $\begin{array}{lllllll}\text { Valor P* } & 0,034 & 0,015 & 0,12 & 0,003 & 0,002 & 0,003\end{array}$ 


\section{Discussão}

As crianças do GCC foram divididas em dois grupos: GCC1, que frequentavam a escola, e GCC2, que não frequentavam a escola. Considerando que todas as crianças estavam contaminadas por chumbo, as diferenças de desempenho poderiam ser atribuídas à escola. Tais diferenças foram observadas em todas as áreas, com exceção de autocuidado. Em uma análise mais refinada, comparando as crianças com níveis de chumbo mais alto e mais baixo, frequentando ou não a escola, os resultados indicaram que as crianças sem escola e com nível de chumbo mais alto apresentaram diferenças significativas em desenvolvimento motor, socialização e cognição, e que as crianças com nível de chumbo mais baixo também apresentaram diferenças significativas em linguagem e cognição, reforçando a probabilidade de efeitos nefastos do chumbo no desenvolvimento infantil mesmo em níveis próximos ao considerado como aceitável para crianças. Pode-se afirmar que a frequência à escola minimiza os efeitos do chumbo, confirmando as críticas de alguns autores sobre a importância de se considerar variáveis específicas relacionadas à educação da criança, entre outras, pela importância do impacto social exercido pelos níveis de chumbo no organismo e por este afetar negativamente o funcionamento intelectual das crianças em diversas dimensões (Kaufman, 2001).

Alguns estudos têm mostrado que o progresso escolar está diretamente associado à participação dos pais nas atividades escolares (Marturano, 1999; Silva et al., 2008; D’Avila-Bacarji et al., 2005). O presente estudo não avaliou como os pais participam da vida escolar dos filhos, porém colocá-los na escola pode significar interesse daqueles pelo desenvolvimento dos filhos, considerando o número de crianças do mesmo bairro, da mesma faixa etária, mas ainda fora da escola. É importante considerar que a escola é distante do bairro e implica atravessar uma rodovia de pista dupla sem passagem para pedestres.

Ainda analisando os efeitos da escola, comparando os desempenhos no IPO do GCG1 e do GCNC, ainda que os dois apre- 
sentassem desempenho abaixo do esperado em cognição, observou-se que o GCC1 foi melhor em pelo menos duas das áreas avaliadas, apontando para o papel da escola no desenvolvimento geral das crianças. Isso foi confirmado quando se comparou o desempenho do GCC2 com o do GCNC, em que as diferenças foram maiores e estatisticamente significativas nas áreas de desenvolvimento motor, socialização, cognição e na média geral. A escola pode representar um importante suporte social na superação de déficits cognitivos encontrados em crianças com exposição excessiva ao chumbo. Alguns estudos relacionaram indiretamente esses déficits a características socioeconômicas e demográficas, mas outros sugerem que crianças com baixo nível socioeconômico familiar estariam mais vulneráveis aos efeitos desse metal, já que seu desenvolvimento neuropsicológico estaria comprometido pelas desvantagens sociais. Todavia, esses resultados não foram consistentes, gerando uma preocupação metodológica maior ao analisar essas variáveis (Tong et al., 1998; Koller et al., 2004; Lidsky \& Schneider, 2006).

\section{Considerações finais}

Os efeitos adversos da exposição ao chumbo na infância e suas consequências no desenvolvimento cognitivo e comportamental têm sido observados em algumas pesquisas recentes realizadas no exterior e no Brasil, mas identificamos poucas pesquisas focadas na repercussão da contaminação para a população infantil e voltadas para os diferentes aspectos do desenvolvimento e os efeitos de variáveis ambientais, como, por exemplo, a escola.

As análises permitiram identificar o desenvolvimento global e o desempenho do grupo de crianças contaminadas e não contaminadas, e as comparações feitas apontaram a importância da escola, como ambiente de apoio que proporciona qualidade e quantidade de estímulos para uma população que vive em condições socioeconômicas precárias, somadas a poluição ambiental e a baixa quali- 
dade do ambiente, fatores que colocam em risco o desenvolvimento dessas crianças.

\section{Referências bibliográficas}

AGENCYFORTOXICSUBSTANCES ANDDISEASE REGISTRY (CDC). Case studies in environmental medicine: lead toxicity. October 1992. Disponível em: <http://www.atsdr.cdc.gov/HEC/CSEM/ lead.htm>. Acesso em: 10 dez. 2004.

ALBALAK, R. et al. Blood lead levels and risk factors for lead poisoning among children in a Mexican smelting community. Archives of Environmental. v.58, n.3, p.172-83, 2003.

ALVES, C. O.; RODRIGUES, O. M. P. R.; MANFRINATO, J. W. Exposição ambiental ao chumbo: efeitos sobre o desenvolvimento de meninos e meninas. Anais do XII SIMPEP. Bauru, São Paulo, Brasil, 2003.

AMARAL, J. N. Avaliação intelectual de crianças contaminadas por chumbo: um estudo comparativo. Dissertação (mestrado em Educação). Faculdade de Filosofia e Ciências, Universidade Estadual Paulista, Marília, 2005.

BEE, H. O ciclo vital. Porto Alegre: Artes Médicas, 1997.

BELLINGER, D. C. Effect modification in epidemiologic studies of low-level neurotoxicant exposures and health outcomes. Neurotoxicology e Teratology. v.22, n.1, p.133-400, 2000.

BORNSCHEIN, R. L. et al. Assessment of cleaning to control lead dust in homes of children with moderate lead poisoning: treatment of lead-exposed children trial. Environmental Health Perspectives. v.110, 2002. Disponível em: < http://www.ncbi.nlm.nih.gov/pmc/ articles/PMC1241131/pdf/ehp0110-a00773.pdf>. Acesso em: 21 jun. 2010.

CAPELLINI, V. L. M. F. et al. Crianças contaminadas por chumbo: estudo comparativo sobre desempenho escolar. Avaliação Educacional. v.19, n.39, p.155-80, 2008.

CARVALHO, F. M. et al. Chumbo no sangue de crianças e passivo ambiental de uma fundição de chumbo no Brasil. Rev. Panm Salud Publica/Pan Am J Public Health. v.13, n.1, p.19-24, 2003. 
CENTRO DE VIGILÂNCIA EPIDEMIOLÓGICA (CVE). Estratégias de abordagem para a exposição ambiental ao chumbo no Estado de São Paulo. Disponível em: <http: //www.cve.saude.sp.gov.br/ htm/chumbo.htm>. Acesso em: 10 dez. 2004.

CORREIA, M. R. G. et al. Avaliação do desempenho intelectual de crianças de 4 anos a 6 anos e 11 meses contaminadas por chumbo. Anais da Reunião Anual de Psicologia [resumo de comunicação científica], 2004. Disponível em: <http://www.sbponline.org.br>. Acesso em: 5 maio 2005.

CUNHA, F. G. Contaminação humana e ambiental por chumbo no Vale do Ribeira, nos estados de São Paulo e Paraná, Brasil. Tese (doutorado). Instituto de Geociências, Unicamp, 2003.

DASCÂNIO, D. et. al. Emergência de relações equivalentes por crianças com índices de contaminação por chumbo. Anais da Reunião Anual de Psicologia [resumo de comunicação científica], 2004. Disponível em: < http://www.sbponline.org.br>. Acesso em: 5 maio 2005.

; VALLE, T. G. M. A associação entre variáveis sociodemográficas e plumbemia em crianças. Paideia (USP. Ribeirao Preto. Impresso), v.18, p.541-53, 2009.

D'AVILA-BACARJI, K. M. G.; MARTURANO, E. M.; ELIAS, L. C. S. Recursos e adversidades no ambiente familiar de crianças com desempenho escolar pobre. Paideia, v.15, p.43-55, 2005.

GONZÁLEZ, E. J. et al. Tijuana childhood lead risk assessment revisited: validating a GIS model with environmental data. Journal Environmental Management. v.4, n.29, p.559-65, 2002.

JONES, R. L. Blood lead levels: United States, 1999-2002. US Environmental Protection Agency. Washington, DC, USA. v.54, n.20; p.513-6, 2005.

KAUFMAN, A. S. Do low levels of lead produce QI loss in children? A careful examination of the literature. Archives of clinical Neuropsychological. v.16, p.303-41, 2001.

KIM, D. Y.; STALEY, F.; BUCHANA, S. Relation between housing age, housing value, and childhood blood lead levels in children in Jefferson County. Am J Public Health. v.92, n.5, p.769-72, 2002.

KLAASSEN, C. D. Metais pesados e antagonista de metais pesados. In: GOODMAN; GILMAN. As bases farmacológicas da terapêutica. Rio de Janeiro: McGraw Hill, 1996. 
KOLLER, K. et al. Recent developments in low-level lead exposure and intellectual impairment in children. Environmental Health Perspectives. v.12, n.9, p.987-94, 2004.

LEROYER, A. et al. Environmental lead exposure in a population of children in northern France: factors affecting lead burden. American journal of industrial medicine. v.3, n.38, p.21-28, 2000.

LIDSKY, T. L.; SCHNEIDER, J. S. Adverse effects of childhood lead poisoning: clinical neuropsychological perspective. Environmental Research. v.100, n.2, p.284-93, 2006.

LISBOA, C. Comportamento agressivo, vitimização e relações de amizade de crianças em idade escolar: fatores de risco e proteção. Tese (doutorado). Pós-graduação em Psicologia do Desenvolvimento. Universidade Federal do Rio Grande do Sul, Porto Alegre, 2005.

LUO, W.; ZHANG, Y.; LI, H. Children's blood lead levels after the phasing out of leaded gasoline in Shantou. Arch Environmental Health. 2003. Disponível em: <http://findarticles.com/p/articles/ mi_m0907/is_3_58/ai_109023561 >. Acesso em: 4 maio 2007.

MALTA, C. G. T.; TRIGO, L. A. S. C.; CUNHA, L. S. Saturnismo. 2000. Disponível em: <http://www.geocities.com/HotSprings/ Resort/4486/chumbo1.htm>. Acesso em: 7 ago. 2002.

MELCHIORI, L. E. et al. Percepção de risco de pessoas envolvidas com intoxicação por chumbo. Paideia (USP. Ribeirao Preto. Impresso). v.20, p.63-72, 2010.

MELLO-DA-SILVA, C. A.; FRUTCHTENGARTEN, L. Riscos químicos ambientais à saúde da criança. Jornal de Pediatria. v.81, n.5, p.205-11, 2005.

MOREIRA, F. R.; MOREIRA, J. C. Os efeitos do chumbo sobre o organismo humano e seu significado para a saúde. Rev. Panam. Salud Publica. v.15, n.2, p.119-29, 2004.

NEME, C. M. B. et al. Indicadores de comprometimento emocional em crianças contaminadas e não contaminadas por chumbo. Arquivos de Ciências da Saúde (Famerp). v.16, p.15-20, 2009.

PAOLIELLO, M. M. B.; CHASIN, A. A. M. Ecotoxicologia do chumbo e seus compostos. Cadernos de Referência Ambiental. v.3, n.4, 2001. Disponível em: <http://intertox.com.br/index.php?option= com_docman\&task>. Acesso em: 21 junho 2010.

PAPALIA, D. E.; OLDS, S. W.; FELDMAN, R. D. Desenvolvimento humano. Porto Alegre: Artmed, 2006. 
PINO, P. et al. Rapid drop in infant blood lead levels during the transition to unleaded gasoline use in Santiago, Chile, 2001. Disponível em: <http://www.findarticles.com/p/articles/mi_m0907/is_4_59/ ai_n15727540>. Acesso em: 04 maio 2007.

POLETTO, M.; KOLLER, S. H. Contextos ecológicos: promotores de resiliência, fatores de risco e de proteção. Estud. psicol. (Campinas). v.25, n.3. p.405-16, 2008.

RIBEIRO, T. M. Análise comparativa de teste e reteste de crianças expostas ao chumbo. Dissertação (mestrado em Psicologia do Desenvolvimento e da Aprendizagem). Universidade Estadual Paulista Júlio de Mesquita Filho, Bauru/SP, 2007.

RODRIGUES, O. M. P. R. et al. Avaliação do desenvolvimento de crianças de 1 a 3 anos de idade contaminadas por chumbo. In: NEME, C. M. B.; RODRIGUES, O. M. P. R. Psicologia da Saúde. São Carlos: Rima, 2003, p.73-92.

; CARNIER, L. E. Avaliação do desenvolvimento geral de crianças de um a cinco anos de idade contaminadas por chumbo. Interação (Curitiba). v.11, n.2, p.269-79, 2007.

ROJAS, M.; ESPINOSA, C.; SEIJAS, D. Associación entre plomo em sangre y parâmetros sociodemográficos em populacion infantil. Rev. Saúde Pública. v.37, n.4, p.503-9, 2003.

SHARMA, K.; REUTERGARDH, L. B. Exposure of preschoolers to lead in the Makati area of Metro Manila, the Philippines. Environ Res. v.83, n.3, p.322-32, 2000.

SILVA, N. C. B. et al. Variáveis da família e seu impacto sobre o desenvolvimento infantil. Temas em Psicologia. v.16, n.2, p.215-29, 2008. TONG, S. et al. Declining blood lead level and changes in cognitive function during childhood: the Port Pirie Cohort Study. Jama. v.280, n.22, p.1915-19, 1998.

; McMICHAEL, A. J.; BAGHURST, P. Interactions between environmental lead exposure and sociodemographic factors on cognitive development. Arch Environ Health. v.55, n.5, p.330-5, 2000.

TROIJO, M. A. F.; RODRIGUES, O. M. P.; RIBEIRO, T. M. Avaliação de desenvolvimento infantil: efeitos do chumbo ou da falta de escola? Anais da XXXIV Reunião Anual da Sociedade Brasileira de Psicologia. Ribeirão Preto, 2004. 
A influência da escolaridade no desenvolvimento de crianças contaminadas por chumbo. Dissertação (mestrado em Psicologia do Desenvolvimento e da Aprendizagem). Universidade Estadual Paulista Júlio de Mesquita Filho, 2007.

VENDRÚSCULO, L. M.; MATSUKURA, T. S. Desempenho escolar satisfatório de crianças de diferentes realidades socioeconômicas: Identificando fatores protetivos. Cadernos de Terapia Ocupacional da UFSCar. v.15, n.1, 2007.

WILliAMS, L. C. A.; AIELLO, A. L. R. O Inventário Portage Operacionalizado: intervenção com famílias. São Paulo: Memnon, 2001. YULE, W.; LANNSDOWN, R. G. Blood lead concentrations in school age children, intelligence and attainment in a school population: a pilot study. Devpm. Med. Child Neurol. v.23, p.56776, 1993. 


\title{
5 \\ HABILIDADES SOCIAIS DE IRMÃOS DE CRIANÇAS COM TRANSTORNO DO ESPECTRO AUTÍSTICO ${ }^{1}$
}

\author{
Aline Beatriz Feltrin ${ }^{2}$ \\ Olga Maria Piazentin Rolim Rodrigues ${ }^{3}$
}

\section{Introdução}

O Transtorno do Espectro Autístico (TEA) é um transtorno de desenvolvimento que se inicia na infância e tem como características clínicas principais a dificuldade de interação social recíproca, a de se comunicar com o outro, o pobre contato visual, a indiferença afetiva ou demonstrações inapropriadas de afeto, bem como manifestações de comportamentos estereotipados e repetitivos (Leboyer, 2003; Schwartzman, 2003).

Essa forma peculiar de comportar-se interfere nos relacionamentos intrafamiliares em geral e, em especial, com os irmãos. Estes, pela proximidade etária, compartilham um único e importante relacionamento dentro da unidade familiar, o qual tem sido considerado como altamente relevante para o desenvolvimento de habilidades sociais na infância, já que um aprende constantemente com o outro

1 O estudo é parte integrante da dissertação de mestrado da primeira autora sob orientação da segunda autora.

2 Programa de pós-graduação em Psicologia do Desenvolvimento e da Aprendizagem da Unesp, campus de Bauru.

3 Programa de pós-graduação em Psicologia do Desenvolvimento e da Aprendizagem da Unesp, campus de Bauru. 
em função do convívio (Gadia et al., 2004; Gomes \& Bosa, 2004; Kaminsky \& Dewey, 2002; Powel \& Ogle, 1992).

Investigar a interação entre irmãos possibilita entender o papel daquela na aquisição de determinadas habilidades, como a social. O estudo envolvendo irmãos com TEA inclui o pressuposto de que esse tipo de relação pode apresentar algumas diferenças daquelas encontradas em irmãos com desenvolvimento normal, tendo em vista que as variáveis presentes nesses ambientes podem diferir daquelas existentes em famílias de crianças com desenvolvimento normal, tais como: a) a ausência constante da mãe que tem de acompanhar o filho com deficiência nos atendimentos especializados; b) a presença de um membro que encontra maiores dificuldades para aprender determinados comportamentos e habilidades, o que muitas vezes faz com que a família não frequente junta determinados ambientes; c) a presença de uma pessoa que não apresenta um desenvolvimento típico e requer atenção excessiva (Pereira-Silva \& Dessen, 2001).

O sistema familiar é dinâmico e, portanto, qualquer circunstância que esteja relacionada com a vida das pessoas que compõem aquela família afeta o sistema como um todo (Ajuriaguerra, 1990). Assim, o nascimento de um filho pode gerar tensão e estresse tanto para o filho quanto para os pais, principalmente se uma das crianças tem algum tipo de deficiência.

A literatura referente aos benefícios/prejuízos que um irmão deficiente pode proporcionar ao irmão com desenvolvimento típico é controversa, posto que estudos demonstram que ter um irmão com uma incapacidade não está necessariamente associado ao aparecimento de vulnerabilidades e de dificuldades (Verte et al., 2003; Pilowsky et al., 2004), enquanto outros destacam que a presença de um irmão especial traz alguns prejuízos para os irmãos com desenvolvimento típico (Kaminsky \& Dewey, 2001; Rivers \& Stoneman, 2003). Todavia, é possível que tal contradição esteja relacionada a questões de ordem metodológica, como a falta de um grupo controle com equiparações adequadas e utilização somente de medidas indiretas, via relato dos pais (Mulvany, 2000; Rossiter \& Sharpe, 2001; Verte et al., 2003). 
Gomes \& Bosa (2004) não encontraram indicadores de estresse em irmãos de crianças com Transtornos Globais do Desenvolvimento (TGD), comparando com irmãos de crianças sem deficiência. Marciano \& Scheuer (2005) pesquisaram a qualidade de vida de irmãos de autistas e os resultados indicaram que havia prejuízos naquela, quando comparada à dos irmãos do grupo controle. Dimov (2006) buscou identificar a presença de problemas de comportamento e a competência social em irmãos de crianças com autismo e os resultados de seu estudo apontaram que os irmãos de autistas apresentaram mais problemas de comportamento e baixos índices de competência social quando comparados ao grupo controle, sendo que esses escores eram piores nos irmãos mais jovens. Pilowsky et al. (2004) examinaram as habilidades de socialização e problemas de comportamento em irmãos de crianças com TEA e concluíram que a maioria dos irmãos dessas crianças $(86,7 \%)$ tinha um bom funcionamento social, baseado em dados normativos. Para Cuskelly \& Gunn (2003), irmãos de crianças deficientes são mais tolerantes com o próximo, mais empáticos, menos grosseiros e apresentavam laços familiares mais estreitos, quando comparados a irmãos de crianças com desenvolvimento típico.

Verte et al. (2003) investigaram a incidência de problemas de comportamento em irmãos de crianças com Síndrome de Asperger e de crianças com desenvolvimento típico, associando medidas diretas (autorrelato dos irmãos) e indiretas (relato dos pais), e observaram que irmãos de crianças com a síndrome tinham mais problemas de comportamentos, quando comparados às crianças do grupo controle. Por outro lado, os irmãos dos indivíduos com a síndrome apresentaram um autoconceito mais positivo e atribuíam alta competência social a eles mesmos em relação aos irmãos de crianças com desenvolvimento normal.

Kaminsky \& Dewey (2001) objetivaram conhecer o relacionamento entre irmãos de crianças e adolescentes com idade entre oito e 18 anos, que foram divididos em três grupos de 30: (1) indivíduos que tinham um irmão com diagnóstico de TEA, (2) indivíduos com um irmão com Síndrome de Down (SD) e (3) indivíduos que tinham 
irmãos sem nenhuma deficiência. Observaram que os irmãos de indivíduos com TEA demonstraram menos intimidade, menos cuidado e menos comportamentos socialmente habilidosos para com seus irmãos de referência em relação aos irmãos de indivíduos com $\mathrm{SD}$ e aos irmãos de crianças com desenvolvimento típico. Em trabalho posterior, Kaminsky \& Dewey (2002) investigaram ajustamento social de irmãos de crianças com TEA, comparando com irmãos de crianças com SD e com desenvolvimento típico, e os resultados não indicaram maior risco para problemas de ajustamento e solidão em irmãos de crianças com TEA, o que as autoras atribuem à participação dos pais em grupos de apoio.

O comportamento socialmente habilidoso tem um valor fundamental para o desenvolvimento humano saudável, mas ainda são poucos os estudos que investigam se esse comportamento está presentes em irmãos de indivíduos com alguma deficiência diagnosticada. O campo das habilidades sociais conta com um conjunto de métodos de avaliação e intervenção que inclui vários instrumentos e procedimentos (entrevistas, observação direta, escalas avaliativas etc.) e por meio de diferentes informantes: pais, professores, amigos ou a própria criança (Morais et al., 2001).

Para Caballo (1996), as habilidades sociais abrangem relações interpessoais, incluindo assertividade e habilidades de comunicação, resolução de problemas imediatos e diminuição da probabilidade de problemas futuros, entre outros comportamentos que ajudam na interação social. Esses desempenhos são caracterizados por componentes comportamentais, afetivos e fisiológicos que, quando adequadamente articulados entre si e ao contexto ambiental, revelam-se altamente funcionais para: 1) manutenção ou aprimoramento das relações pessoais; 2) manutenção ou melhoria da autoestima; 3) manutenção ou aumento dos valores humanos socialmente estabelecidos. Essa funcionalidade determina a competência social do indivíduo no meio em que ele vive (Del Prette \& Del Prette, 1999).

Déficits em habilidades sociais resultam na queda da qualidade de vida, principalmente devido às intercorrências ocasionadas pelas dificuldades interpessoais. Não obstante, déficits em habilidades so- 
ciais podem propiciar o surgimento de diversos transtornos psicológicos, como depressão, timidez, fobias sociais, abuso de substâncias, problemas de aprendizagem, entre outros (Kaminsky \& Dewey, 2002; Bolsoni-Silva \& Marturano, 2002; Hastings, 2003). O indivíduo socialmente competente acaba sendo autorreforçado, o que resulta em boa autoestima e bom senso de autoeficácia, servindo para habilitá-lo a enfrentar as dificuldades e os eventos estressantes, e os contextos que mais influenciam no desenvolvimento dessas habilidades são a família, a escola e o grupo de amigos (Lucca, 2004).

A família é o primeiro grupo social de que o indivíduo faz parte, por isso oferece modelos de comportamento e modela a conduta social por meio de práticas disciplinares e do simples convívio diário (Bolsoni-Silva \& Marturano, 2002). Os pais e os irmãos costumam funcionar como modelos, uma vez que passam boa parte do tempo juntos, e por serem pessoas significativas na vida das crianças, a influência acaba sendo inevitável. Os irmãos desempenham papéis importantes à criança, pois possibilitam modelos de comportamentos diferenciados que em outros contextos poderiam ser impróprios e, ainda, favorecem o autoconhecimento e o treino de novas habilidades, além daquelas já aprendidas. Segundo Snyder (2002), o contato entre irmãos provê um contexto adicional, único e poderoso que proporciona o surgimento de diferenças individuais durante o desenvolvimento social da criança.

Portanto, para se viver com qualidade é preciso saber desempenhar com esmero diversos papéis, muitos deles essencialmente sociais, que podem ser ensinados, treinados e perfeitamente executados, proporcionando a harmonização da pessoa consigo e com o mundo que a rodeia. Esses pressupostos aplicam-se a inúmeras situações e muitas dessas questões podem relacionar-se com os TEAs, haja vista que as habilidades sociais são carências apresentadas pelas pessoas com esse tipo de problemática, sendo imprescindível investigar se os membros familiares também podem apresentar déficits nessa área.

Diante do fato de que os autistas apresentam uma incapacidade acentuada em desenvolver e manter relações interpessoais, o que pode resultar em pouca interação com os irmãos (Carlier \& 
Roubertoux, 1979), o presente trabalho questiona se há diferenças no repertório de habilidades sociais de crianças que têm um irmão com TEA quando comparado ao de crianças que têm irmãos com desenvolvimento típico. Nossa hipótese é que irmãos de indivíduos com TEA apresentam menos comportamentos socialmente habilidosos do que irmãos de indivíduos com desenvolvimento típico, em decorrência, principalmente, da pobre interação entre eles.

O objetivo deste estudo descritivo foi investigar as habilidades sociais de crianças que possuem um irmão com TEA, comparando com as habilidades sociais de crianças com irmãos com desenvolvimento típico.

\section{Método}

Esta pesquisa respeitou todos os aspectos éticos e foi realizada mediante parecer favorável de um comitê de ética local. Assim, os participantes e seus familiares foram esclarecidos quanto aos objetivos, aos procedimentos metodológicos e ao anonimato garantido e assinaram termo livre de consentimento esclarecido.

\section{Participantes}

O estudo foi realizado com dez crianças com idades entre sete e 12 anos, de ambos os sexos, as quais foram divididas em dois grupos: Grupo 1: Grupo Descritivo, composto por indivíduos com desenvolvimento típico que tinham somente um irmão com TEA, diagnosticado por um especialista. Grupo 2: Grupo Controle, composto por indivíduos com desenvolvimento típico que tinham irmãos sem nenhuma deficiência diagnosticada. Esses dados foram obtidos a partir do Formulário de Informações da Família e possibilitou a caracterização da amostra estudada, conforme apresentado na Tabela 1. Do total de crianças, $60 \%$ dos participantes dos grupos 1 e 2 são do sexo feminino, com idade média de 9,8 anos. Das crianças de ambos os grupos, a maior parte frequentava a $4^{\mathrm{a}}$ série. 
Tabela 1 - Caracterização dos participantes dos grupos 1 e 2 .

\begin{tabular}{|c|c|c|c|c|c|c|c|}
\hline \multicolumn{8}{|c|}{ Grupo 1} \\
\hline & Participante & Sexo & Idade & Série & $\begin{array}{l}\text { Mais } \\
\text { novo }\end{array}$ & $\begin{array}{l}\text { Mais } \\
\text { velho }\end{array}$ & $\begin{array}{c}\text { Diferença de idade } \\
\text { entre os irmãos }\end{array}$ \\
\hline 1 & STS & $\mathrm{F}$ & 12 & $6^{\mathrm{a}}$ & Sim & Não & Quatro anos \\
\hline 2 & ERS & $\mathrm{M}$ & 10 & $4^{\mathrm{a}}$ & $\operatorname{Sim}$ & Não & Dois anos \\
\hline 3 & BRS & $\mathrm{M}$ & 10 & $4^{\mathrm{a}}$ & $\operatorname{Sim}$ & Não & Dois anos \\
\hline 4 & TEFS & $\mathrm{F}$ & 9 & $3^{\mathrm{a}}$ & Sim & Não & Um ano \\
\hline 5 & ZCS & $\mathrm{F}$ & 8 & $2^{\mathrm{a}}$ & Sim & Não & Nove anos \\
\hline \multicolumn{8}{|c|}{ Grupo 2} \\
\hline 1 & EISR & $\mathrm{F}$ & 12 & $6^{\mathrm{a}}$ & $\operatorname{Sim}$ & Não & Dez anos \\
\hline 2 & VHLFV & $\mathrm{M}$ & 10 & $4^{\mathrm{a}}$ & Sim & Não & Cinco anos \\
\hline 3 & YRF & M & 10 & $4^{\mathrm{a}}$ & Não & $\operatorname{Sim}$ & Quatro anos \\
\hline 4 & TMS & $\mathrm{F}$ & 9 & $3^{\mathrm{a}}$ & Não & Sim & Três anos \\
\hline 5 & PBFD & $\mathrm{F}$ & 8 & $2^{\mathrm{a}}$ & São & Não & Quatro anos \\
\hline
\end{tabular}


Todos os participantes do Grupo 1 eram mais novos do que os demais irmãos, sendo inclusive mais novos do que o irmão com TEA, ou seja, são os últimos filhos do casal. Dessa amostra, a diferença média de idade entre as crianças participantes e o irmão com TEA foi de 3,6 anos, mostrando que o irmão de referência (com TEA) e o irmão participante não tinham uma diferença de idade muito grande, o que aumenta a chance de influenciar o outro devido à proximidade de idade entre ambos. Os participantes 2 e 3 do Grupo 1 eram gêmeos, portanto, tinham as mesmas características familiares, e o irmão com TEA era, evidentemente, o mesmo para os dois. No Grupo 2, 60\% das crianças eram mais novas que os irmãos de referência e a média de diferença de idade entre eles foi de 5,2 anos. Com isso, a amostra do Grupo 1 apresentou uma diferença de idade menor entre os irmãos do que a amostragem do Grupo 2, ressaltando que neste existem participantes que são mais velhos que os irmãos de referência, o que não aconteceu no Grupo 1.

Entre as crianças diagnosticadas com TEA, quatro eram do sexo masculino, uma era do sexo feminino e elas tinham entre dez e 17 anos (média de 13,4 anos). Em todas as famílias ( $\mathrm{n}=5$ ) o indivíduo com TEA era o filho mais velho, sendo que os participantes eram o segundo filho (com exceção dos gêmeos). As demais crianças tinham apenas o irmão com TEA.

\section{Materiais}

Utilizou-se o Formulário de Informações sobre a Família, que permitiu obter dados gerais para a caracterização dos participantes, e o Inventário Multimídia de Habilidades Sociais de Crianças - Del Prette - IMHSC (Del Prette \& Del Prette, 2005), que é composto por um conjunto de instrumentos e materiais para avaliação de habilidades sociais de crianças de sete a 12 anos.

As 21 situações do IMHSC, constantes no caderno de aplicação, retratam vários contextos do cotidiano de crianças das séries iniciais do Ensino Fundamental em suas interações com outras crianças e 
com adultos. Segundo definição dos autores, cada situação expõe uma circunstância em que determinada habilidade social é requerida e três possibilidades de reações são apresentadas: uma habilidosa (conforme definição de habilidade social), uma não habilidosa ativa e uma não habilidosa passiva. Embora as reações apresentadas como respostas à situação considerada não contemplem todas as possibilidades do repertório social da criança, as situações retratadas no IMHSC - Del Prette permitem obter uma amostragem de habilidades exigidas nas áreas socioafetivas (empatia, civilidade, expressão de sentimentos, comportamentos pró-sociais e cooperação, assertividade e autocontrole), as quais têm sido consideradas na literatura como fundamentais para a qualidade das relações das crianças com os colegas e professores e, a médio e longo prazo, para o bom desenvolvimento socioemocional desses indivíduos. Nesse instrumento, as crianças respondem qual das três possibilidades corresponderia à atitude que elas tomariam naquela situação apresentada. Em seguida, analisam o grau de dificuldade que encontrariam ao agir daquela maneira e, ainda, julgam a adequação de cada uma das três reações apresentadas pelo teste, bem como a frequência em que se comportariam em cada uma das três maneiras. O Inventário permite identificar quatro subescalas: Empatia e civilidade; Assertividade e enfrentamento; Autocontrole e Participação. As situações avaliadas pelo IMHSC - Del Prette produzem indicadores do repertório social das crianças nas dimensões Comportamental: frequência de cada reação; Cognitiva: adequação conferida a cada reação; e Afetiva: dificuldade avaliada para emitir a reação habilidosa.

\section{Procedimento}

\section{a) Identificação dos participantes}

As famílias desse grupo foram recrutadas antes das famílias do Grupo 2 (irmãos sem deficiência), para que fosse possível efetuar o emparelhamento adequado. Para identificar qual irmão participava do estudo - visto que as famílias poderiam ter outros filhos que não 
somente os dois: o diagnosticado com TEA e o outro com desenvolvimento típico, este foi identificado como "irmão participante", enquanto que o(s) outro(s), "irmão(s) de referência”. No Grupo 1, os participantes foram aqueles que tinham a idade exigida e não possuíam deficiência (IP-G1). No Grupo 2, os participantes foram aqueles que possuíam as mesmas características do participante correspondente do Grupo 1 (IP-G2), atendendo o emparelhamento adequado entre grupos. Nesse caso, os irmãos de referência do Grupo 2 também não podiam apresentar qualquer tipo de deficiência.

O Grupo 1 e o Grupo 2 foram pareados para facilitar a comparação entre grupos, garantindo-se a estabilidade entre as variáveis idade, sexo, série dos participantes, número de filhos do casal, estado civil dos pais e nível socioeconômico da família. As famílias do Grupo 2 foram selecionadas em uma escola da rede pública que atendia alunos de $1^{\mathrm{a}}$ a $5^{\mathrm{a}}$ série em uma cidade do interior do estado de São Paulo, baseando-se nas características apresentadas pelos irmãos dos indivíduos com TEA (Grupo 1), que deveriam ser as mesmas, como já foi comentado. A etapa seguinte ocorreu de maneira semelhante à do Grupo 1.

\section{b) Aplicação dos instrumentos}

A coleta de dados contemplou as seguintes etapas para os dois grupos: aplicação do Formulário de Informações sobre a Família, com um dos pais, e aplicação do Inventário Multimídia de Habilidades Sociais de Crianças - IMHSC (Del Prette \& Del Prette, 2005), com os irmãos. Foi necessário apenas um encontro com cada criança, sendo que o tempo total das coletas variou entre cinquenta minutos e uma hora e vinte minutos. Todos os instrumentos foram preenchidos pela pesquisadora para garantir o preenchimento correto. A coleta de dados com o irmão participante foi feita individualmente, a fim de evitar-se a inibição de respostas caso estivesse presente alguma outra pessoa. Aos pais garantiu-se o direito de terem acesso aos resultados obtidos pelos seus filhos nos diferentes instrumentos aplicados, o que foi feito ao final do trabalho. 


\section{c) Análise dos dados}

Os dados do IMHSC foram obtidos por meio da versão impressa do material e as respostas das crianças foram registradas na Ficha de Autoavaliação Individual C, para posteriormente serem processadas pelo MPD (Módulo de Processamento de Dados). Trata-se de um recurso do próprio material (IMHSC), organizado em um CD-ROM, com formato, funcionamento e conteúdos equivalentes ao IMHSC Del Prette. O MPD permite a inserção de todos os dados das crianças em planilhas do Excel, os quais são processados pelo programa que, em seguida, gera gráficos, tabelas e o protocolo final de cada criança, com base nas subescalas e nos itens avaliados pelo instrumento. Os resultados também foram analisados interindividualmente, situando-os em relação ao grupo de referência e comparando-os entre grupos, utilizando análises estatísticas.

\section{Resultados e discussão}

No perfil geral das crianças, observou-se que o escore médio dos irmãos participantes do Grupo 1 em relação às reações habilidosas foi de $82,85 \%$. Nas reações não habilidosas ativas (NH Ativas) e nas não habilidosas passivas (NH Passivas), a média foi a mesma: 8,57\%. Com isso, percebe-se uma prevalência das reações habilidosas sobre as demais (NH Ativas e Passivas). Entretanto, mesmo que em pequeno número, estas não deixaram de aparecer, e as crianças desse grupo reagem na mesma proporção no que se refere aos comportamentos não habilidosos ativos e passivos, conforme apresentado na Tabela 2 . 
Tabela 2 - Perfil geral dos participantes dos grupos 1 e 2, em porcentagem, no que se refere aos tipos de reações avaliadas.

\section{Perfil geral}

Participantes

Tipos de reações

\section{Habilidosas NH Ativas NH Passivas}

\section{Grupo 1}

STS

ERS

BRS

TEFS

ZCS

Média

Grupo 2

EISR
VHLFV
YRF
TMS
PBFD

Média

80,95
95,24
85,71
52,38
100

82,85

8,57

19,05

0
4,76

4,76

4,76

28,57

0

8,57

$\begin{array}{cc}0 & 4,76 \\ 9,52 & 4,76 \\ 9,05 & 28,57 \\ 0 & 0\end{array}$

0,00

4,76

9,52

0

4,76

0

95,24

4,76

4,76

0

95

4,76

0,95

Para o Grupo 2, a média dos resultados das crianças dessa amostra foi superior à do Grupo 1 em relação às reações habilidosas e inferior no que se refere às reações não habilidosas ativas e passivas. Essa afirmação pode ser constatada tendo em vista os escores médios dos irmãos desse grupo, cujos resultados revelaram 94,24\% de reações habilidosas, 4,76\% de reações não habilidosas ativas e 0,95\% de reações não habilidosas passivas. Percebe-se que os participantes desse grupo, quando se comportam de maneira não habilidosa, mostram maior tendência aos comportamentos externalizantes do que aos internalizantes. 
A análise estatística demonstrou que não há diferença significativa para os resultados dos dois grupos em relação aos tipos de reações, o que possibilita a inferência de que tanto o Grupo 1 quanto o Grupo 2 são habilidosos socialmente, isto é, o Grupo 1 (Descritivo) não apresentou prejuízos em relação a habilidades sociais, o que faz supor que o fato de terem um irmão com TEA não interfere na aquisição de respostas socialmente habilidosas, o que vai ao encontro de outras pesquisas que avaliaram habilidades sociais em irmãos de indivíduos com TEA, nas quais igualmente não foram encontradas pontuações clínicas ou diferenças significativas em relação ao grupo controle (Pilowsky et al., 2004; Verte et al., 2003).

Tais resultados são favoráveis para o desenvolvimento dessas crianças, ainda que tenham um irmão com deficiência, pois, conforme ressaltam Patterson et al. (1992), as interações sociais satisfatórias contribuem para a instalação de repertórios comportamentais necessários para a aprendizagem, uma vez que facilitam o acesso da criança a novas contingências de reforçamento.

Com base nos dados do IMHSC - Del Prette, foi possível obter os valores atribuídos pelas crianças aos diferentes tipos de reações (habilidosa - Hab, não habilidosa passiva - NHP e não habilidosa ativa - NHA) e aos diferentes indicadores avaliados (frequência, adequação e dificuldade), os quais variavam de zero a dois. A Tabela 3 mostra os escores dos participantes do Grupo 1 e do Grupo 2 no que diz respeito a esses indicadores e reações.

Em termos de frequência, os participantes do Grupo 1 alcançaram uma média de 1,464 nas reações habilidosas; 0,466 nas reações não habilidosas passivas e 0,166 nas reações não habilidosas ativas. Os irmãos do Grupo 2 obtiveram uma média um pouco acima daquela atingida pelos participantes do Grupo 1 em relação às reações habilidosas. Nesse quesito, a média do Grupo 2 foi de 1,76, indicando que essas crianças comportam-se mais frequentemente de maneira habilidosa do que as crianças do Grupo 1. Ainda com relação ao Grupo 2, no que diz respeito às reações não habilidosas passivas, as crianças dessa amostra apresentaram um escore de 0,65 , valor que se situa acima do encontrado no Grupo 1, o que revela que, embora 
Tabela 3 - Escores nos diferentes indicadores e reações dos participantes do Grupo 1 e do Grupo 2.

Média

1,76

0,65

0,164

1,846

0,846

0,118

0,134 
as crianças do Grupo 2 referem que se comportariam com maior frequência de maneira habilidosa, estas, em contrapartida, também utilizam com maior frequência reações não habilidosas passivas, quando comparadas às do Grupo 1.

No entanto, se forem confrontados os resultados das reações habilidosas e das reações não habilidosas passivas e não habilidosas ativas, constata-se o valor elevado das reações habilidosas, sendo que as demais se encontram no intervalo de zero a um, enquanto que as habilidosas estão mais próximas do valor máximo (=2). No que se refere às reações não habilidosas ativas, as crianças do Grupo 2 atingiram uma média de 0,164, apontando que raramente agiriam desse modo. Todavia, quando tratados estatisticamente, os resultados de ambos os grupos mostraram-se iguais, ou seja, não houve diferenças significativas nos resultados dos grupos 1 e 2, em que pesem as diferenças dos resultados brutos. Assim, nota-se que tanto o Grupo 1 quanto o 2 comportam-se mais frequentemente de maneira habilidosa, preferindo como segunda opção as reações não habilidosas passivas e preterindo as reações não habilidosas ativas. Relacionando-se esses valores (Grupo 1 e Grupo 2) com os valores médios da amostra de referência do IMHSC da população em geral, nota-se que os escores das crianças do Grupo 1 estão na média da população geral dessa idade (média de frequência da população $=1,44),{ }^{4}$ ou seja, o que é esperado para a faixa etária em que se encontram. Entretanto, os resultados apresentados pelas crianças do Grupo 2 encontram-se acima dessa média, indicando que os irmãos dessa amostra possuem repertório social acima do esperado. Esses resultados mostraram-se contrários aos achados de Dimov (2006) e Kaminsky \& Dewey (2001), cujos trabalhos apontaram que irmãos de autistas apresentam mais problemas de comportamento e baixos índices de competência social quando comparados ao grupo controle.

Por outro lado, muitos estudos, assim como a presente pesquisa, demonstraram que ter um irmão com uma incapacidade não impli-

4 Del Prette \& Del Prette (2005). 
ca necessariamente no aparecimento de vulnerabilidades e de dificuldades para a vida do irmão com desenvolvimento típico (Verte et al., 2003; Pilowsky et al., 2004). Verte et al. (2003) concluíram que os irmãos dos indivíduos com a síndrome apresentaram um autoconceito mais positivo e atribuíram alta competência social a eles mesmos.

Kaminsky \& Dewey (2002), em trabalho posterior, também não encontraram maior risco de problemas de ajustamento e solidão em irmãos de crianças com TEA. Uma razão apontada pelas autoras a respeito dessas constatações estava relacionada ao fato de a maior parte das famílias participantes frequentar grupos de apoio que trazem benefícios para os usuários, implicando em melhoras nas condições de vida. Pais assíduos em grupos de apoio podem ter mais privilégios por obterem informações sobre a condição e o prognóstico do irmão deficiente e por terem maior possibilidade de interagir com outras famílias que enfrentam a mesma condição (Kaminsky \& Dewey, 2002). O fato de os irmãos do presente estudo também terem apresentado bons repertórios em habilidades sociais pode estar associado ao fato de as mães acompanharem o trabalho desenvolvido pela escola especial na vida do filho com TEA.

No que concerne à adequação, a média dos irmãos participantes do Grupo 1 em relação às reações socialmente habilidosas perfez um total de 1,666, enquanto que a média do Grupo 2 nesse mesmo fator foi de 1,846. Apesar de o escore de avaliação da adequação dos comportamentos socialmente habilidosos do Grupo 2 ser um pouco maior do que o escore apresentado pelo Grupo 1, ambos encontramse acima da média da população geral $(=1,03),{ }^{5}$ isto é, essas crianças consideram mais adequadas as reações habilidosas, situando-se em segundo lugar as não habilidosas passivas e em terceiro as não habilidosas ativas. O Grupo 1, a respeito das não habilidosas passivas, apresentou uma média de 0,506, e o Grupo 2, uma média de 0,846. Assim, observa-se que a avaliação média sobre adequação do Gru-

5 Del Prette \& Del Prette (2005). 
po 2, no que se refere às reações não habilidosas passivas, é maior do que a avaliação média do Grupo 1. Isso revela que a amostra deste grupo indica que utilizaria menos comportamentos passivos do que a amostra do outro grupo. Com relação à adequação das reações não habilidosas ativas, o Grupo 1 apresentou uma média de 0,174, enquanto que o Grupo 2 atingiu uma média de 0,118. Apesar de o resultado médio do Grupo 1 ser maior do que o Grupo 2 - o que indica que este afirma que fariam uso de menos reações não habilidosas ativas -, os escores de ambos os grupos são próximos e encontram-se bem abaixo da média da população geral $(=0,65)$.

Em relação às dificuldades apontadas para comportarem-se nas reações socialmente habilidosas, a média do Grupo 1, nesse aspecto, foi de 0,172, e a do Grupo 2 foi de 0,134. Com base nesses resultados, percebe-se que o Grupo 1 considera um pouco mais difícil do que o Grupo 2 apresentar comportamentos socialmente habilidosos, embora essa diferença de resultados seja pequena (ver Tabela 3 , já apresentada). Não obstante, os escores de ambos os grupos encontram-se muito abaixo da média da população geral nesse quesito $(=0,71),{ }^{6}$ ou seja, essas crianças relatam que se comportariam de maneira socialmente habilidosa com menor dificuldade do que as outras crianças de mesma idade da amostra de referência, que representa a população em geral.

Tais resultados são indicativos de que as crianças participantes, por serem socialmente habilidosas, acabam sendo autorreforçadas e, segundo Lucca (2004), isso resulta em uma autoestima elevada, por terem um bom senso de eficácia. Essas capacidades demonstradas por essas crianças servem para habilitá-las a enfrentar as dificuldades e os eventos estressantes, inclusive os que estão relacionados ao advento de terem um irmão com TEA.

Entretanto, é válido ressaltar que o fato de os irmãos de indivíduos com TEA terem obtido bons resultados no Inventário, não significa que, na prática, eles apresentem esses índices de habilidades sociais.

6 Del Prette \& Del Prette (2005). 
Essas considerações podem ser comentadas à luz dos apontamentos de Costa (2005), os quais informam que uma pessoa pode ter um amplo repertório de habilidades sociais, mas não ser capaz de utilizá-lo de modo a alcançar seu objetivo na interação social. Desse modo, segundo o autor, muitas vezes uma pessoa pode saber teoricamente qual seria a melhor forma de agir em uma determinada situação, mas não o faz, o que pode ocorrer em função de diferentes variáveis, e isso mostra que a existência de um vasto repertório de habilidades sociais não garante que o indivíduo seja socialmente competente.

Sendo assim, os irmãos de indivíduos com TEA, quando questionados sobre como reagiriam em determinadas circunstâncias, relatam, na maior parte das vezes, que se comportariam de maneira habilidosa, mas não necessariamente agem assim quando se deparam na prática com essas situações. Por isso, estudos que fazem uso de observações diretas podem servir para complementar os achados do presente trabalho.

\section{Considerações finais}

A análise estatística, ainda que limitada ao contexto das pequenas amostras deste estudo, focou a rede de relações familiares de irmãos de indivíduos autistas e suas habilidades sociais por meio do IMHSC - Del Prette. Demonstrou que não houve diferença significativa entre os resultados de ambos os grupos nas dimensões e elementos estudados, aceitando-se, portanto, a igualdade entre os resultados das duas amostras.

Com base nessas considerações, a hipótese de que irmãos de indivíduos com TEA apresentam menos comportamentos socialmente habilidosos do que irmãos de indivíduos com desenvolvimento típico, em decorrência, principalmente, do risco ambiental e da pobre interação entre os irmãos, foi refutada.

Verte et al. (2003) associam a presença de problemas de comportamento em irmãos de crianças com TEA à baixa qualidade dos relacionamentos estabelecidos entre essas crianças, seus pais e seus ir- 
mãos. Entretanto, o presente estudo encontrou que irmãos de autistas relatam agir de maneira socialmente habilidosa em diversas circunstâncias da vida. Assim também o fazem os irmãos de indivíduos com desenvolvimento típico.

Interações de fatores mais complexos não foram encontradas neste estudo devido ao tamanho pequeno da amostra, o que limita nossas conclusões. Assim, pesquisas com maior número de participantes que avaliem a relação entre habilidades sociais e relacionamentos familiares em irmãos de crianças com TEA são indicadas, ou, ainda, novos estudos que utilizem tanto instrumentos de medidas diretas (observações) quanto indiretas, a fim de verificar se o que as crianças dizem que fazem está de acordo realmente com o que elas fazem.

Em função dos resultados obtidos, evidenciou-se a necessidade de se divulgarem estudos e intervenções, realizados com essa e outras populações, que enfatizem a importância da formação de relações familiares sólidas e satisfatórias, que contribuem para o aprendizado de diferentes habilidades na infância, fundamentais para um desenvolvimento social saudável.

\section{Referências bibliográficas}

AJURIAGUERRA, J. A criança e a família. In: AJURIAGUERRA, J. Manual de psiquiatria infantil. 2.ed. rev. e amp. Rio de Janeiro: Masson, 1990, p.757-802.

BOLSONI-SILVA, A. T.; MARTURANO, E. M. Práticas educativas e problemas de comportamento: uma análise à luz das habilidades sociais. Estudos de Psicologia. v.7, n.2, p.227-235, 2002.

CABALLO, V. E. O treinamento em habilidades sociais. In: CABALLO, V. E. (Org.). Manual de técnicas de terapia e modificação de comportamento. São Paulo: Santos, 1996, p.361-98.

CABALLO, V. E. El papel de las habilidades sociales em el desarrollo de las relaciones interpersonales. In: ZAMIGNANI, D. R. (Org.), Sobre comportamento e cognição. v.3. São Paulo: ARBytes, 1997, p.229-33. 
CARLIER, M.; ROUBERTOUX, P. Psychoses à manifestations precoces et psychoses à manifestations tardives: apport de l'analyse génétique. Psychiatrie de l'enfant. v.22, n.2, p.473-502, 1979.

CID-10. Classificação estatística internacional de doenças e problemas relacionados à saúde. 10.ed., v. 1. São Paulo: Universidade de São Paulo, 1997.

COSTA, C. S. L. Um estudo de caso com uma criança cega e uma vidente (gêmeas idênticas): habilidades sociais das crianças, crenças e práticas educativas da mãe. Dissertação (mestrado). Programa de pósgraduação em Educação Especial. Universidade Federal de São Carlos, São Carlos, 2005.

CUSKELLY, M.; GUNN, P. Sibling relationships of children with Down Syndrome: perspectives of mothers, fathers and siblings. American Journal of Mental Retardation. v.108, n.4, p.234-244, 2003.

DEL PRETTE, Z. A. P.; DEL PRETTE, A. Psicologia das habilidades sociais: terapia e educação. Rio de Janeiro: Vozes, 1999.

; Inventário Multimídia de Habilidades Sociais em Crianças (IMHSC - Del Prette). São Paulo: Casa do Psicólogo, 2005.

DIMOV, T. Irmãos de crianças autistas: problemas de comportamento, competência social e relacionamentos intra e extrafamiliares. Dissertação (mestrado). Programa de pós-graduação em Educação Especial. Universidade Federal de São Carlos, São Carlos, 2006.

GADIA, C.; TUCHMAN, R.; ROTTA, N. T. Autismo e doenças invasivas de desenvolvimento. Jornal de Pediatria. v.80, n.2, p.8394, 2004.

GOMES, V. F.; BOSA, C. Estresse e relações familiares na perspectiva de irmãos de indivíduos com Transtornos Globais do Desenvolvimento. Estudos de Psicologia. v.9, n.3, p.553-61, 2004.

HASTINGS, R. P. Brief report: behavioral adjustment of siblings of children with autism. Journal of Autism and Developmental Disorders. v.33, n.1, p.99-104, 2003.

HEWARD, W. L. Exceptional children: an introduction to special education. New Jersey: Pearson Merrill Prentice Hall, 2003.

KAMINSKY, L.; DEWEY, D. Siblings relationships of children with autism. Journal of Autism and Developmental Disorders. v.31, n.4, p.339-410, 2001. 
Psychosocial adjustment in siblings of children with autism. Journal of Child Psychology and Psychiatry. v.43, n.2, p.22535, 2002.

LEBOYER, M. Autismo infantil: fatos e modelos. 4.ed. Campinas: Papirus, 2003.

LUCCA, E. Habilidade social: uma questão de qualidade de vida. Disponível em: www.psicologia.com.pt. Acesso em: 3 fev. 2006.

MANUAL DE DIAGNÓSTICO E ESTATÍSTICA DE DISTÚRBIOS MENTAIS (DSM-IV-TR). Texto traduzido, 5.ed. Porto Alegre: Artes Médicas, 2002.

MARCIANO, A. R. F.; SCHEUER, C. I. Qualidade de vida em irmãos de autistas. Revista Brasileira de Psiquiatria. v.27, n.1, p.67-9, 2005.

MORAIS, M. L. S., OTTA, E.; SCALLA, C. T. Status sociométrico e avaliação de característica comportamental: um estudo de competência social em pré-escolares. Psicologia: Reflexão e Crítica. v.14, p.119-31, 2001.

MULVANY, J. Disability, impairment or illness? The relevance of the social model of disability to the study of mental disorder. Sociology of Health $\mathcal{E}$ Illness. v.22, n.5, p.582-601, 2000.

PATTERSON, G. R.; REID, J. B.; DISHION, T. J. Antisocial boys. Eugene, OR: Castalia, 1992.

PEREIRA-SILVA, N. L.; DESSEN, M. A. Deficiência mental e família: implicações para o desenvolvimento da criança. Psicologia: Teoria e Pesquisa. v.17, n.2, p.133-41, 2001.

PILOWSKY, T. et al. Social and emotional adjustment of siblings of children with autism. Journal of Child Psychology and Psychiatry. v.45, n.4, p.855-65, 2004.

POWELL, T. H.; OGLE, P. A. Irmãos especiais: técnicas de orientação e apoio para o relacionamento com o deficiente. São Paulo: Maltese, 1992.

RIVERS, J. W.; STONEMAN, Z. Sibling relationship when a child has autism: marital stress and support coping. Journal of Autism and Developmental Disorders. v.33, n.4, p.383-94, 2003.

ROSSITER, M. A.; SHARPE, D. The siblings of individuals with mental retardation: a quantitative integration of the literature. Journal of Child and Family Studies. v.10, n.1, p.65-84, 2001. 
SCHWARTZMAN, J. S. Autismo infantil. São Paulo: Memnon, 2003. SNYDER, J. Reinforcement and coercion mechanisms in the development of antisocial behavior: peer relationships. In: REID, J. B.; PATTERSON, G. R.; SNYDER, J. (Eds.). Antisocial behavior in children and adolescents: a developmental analysis and model for intervention. Washington: American Psychological Association, 2002, p.101-122.

VERTE, S.; ROYERS, H.; BUYSSE, A. Behavioural problems, social competence and self-concept in siblings of children with autism. Child: Care, Health E Development. v.29, n.3, p.193-205, 2003.

WING, L. The continuum of autistic characteristics. In: SCHOPLER, E.; MESIBOV, G. B. (Orgs.). Diagnosis and assessment in autism. New York: Plenum Press, 1988. 


\section{6 \\ ESTRESSE E BULLYING EM CRIANÇAS EM CONDIÇÃO DE SOBREPESO E OBESIDADE}

Lucinéia Crepaldi de Mello ${ }^{1}$ Sandro Caramaschi ${ }^{2}$

\section{Desenvolvimento infantil e ambiente escolar}

A fase do desenvolvimento infantil entre seis e 12 anos é marcada, segundo Martí (1995), pelo período das operações concretas, fase na qual a criança não precisa mais, como o bebê, agir de maneira efetiva sobre as coisas; já é capaz de representá-las e atuar sobre a realidade com mediações de signos, símbolos e ações mentais.

Nesse período da vida, a escola constitui-se em um importante espaço para seu desenvolvimento. Conforme abordam Padilla \& González (1995), experiências vivenciadas no âmbito escolar vão constituir, para a criança, um acúmulo de experiências ricas e interessantes. No meio escolar, a criança interage com muitas pessoas e estabelece com elas relações de igualdade, submissão e liderança.

Segundo Hidalgo \& Palácios (1995), a escola constitui, juntamente com a família, a instituição que mais repercute na vida da criança. Além de ser responsável pela transmissão do saber científico orga-

1 Programa de pós-graduação em Psicologia do Desenvolvimento e da Aprendizagem da Unesp, campus de Bauru

2 Programa de pós-graduação em Psicologia do Desenvolvimento e da Aprendizagem da Unesp, campus de Bauru 
nizado culturalmente, a escola influi nos processos de socialização e individualização da criança, em suas relações afetivas, nas habilidades sociais e de comunicação, no desenvolvimento do papel sexual e de condutas pró-sociais, bem como da própria identidade pessoal (autoconceito, autoestima, autonomia).

Hidalgo \& Palácios (1995) consideram que o autoconceito existe em função da interação com os demais e de atitudes dos outros com relação à criança, no ambiente familiar e escolar. À medida que ele se define, torna-se diferenciado e organizado, adquire certa resistência à mudança, desde que não haja alterações substanciais das condições de vida do indivíduo. $\mathrm{O}$ autoconceito da criança, ainda segundo esses autores, é influenciado pelas condutas do professor e dos colegas em relação a ela. Dessa forma, altas expectativas do professor sobre o êxito de um aluno potencializam a confiança dele em si mesmo, facilitando resultados acadêmicos positivos. Ao contrário, atitudes de desconfiança e baixa expectativa do professor com relação às capacidades do aluno fomentam sua insegurança e criam sentimento de incapacidade.

\section{Questões gerais sobre o fenômeno da obesidade}

A palavra obesidade (do latim obesus, $o b=$ muito e edere $=$ comer) é definida como o aumento da quantidade de gordura corporal, constituindo-se em uma doença universal, de prevalência crescente e que tende a assumir caráter epidêmico, como o principal problema de saúde pública na sociedade moderna (Halpern \& Mancini, 1996). Ela consiste em enfermidade crônica, caracterizada por excesso de tecido gorduroso, abarcando fatores de caráter múltiplo, como genéticos, metabólicos, neuroendócrinos, dietéticos, socioculturais e psicológicos (Mattos et al., 2003).

Diversos cálculos procuram estabelecer os limites de normalidade do peso para uma determinada altura. O Índice de Massa Corpórea (IMC) é o mais utilizado na prática, o qual é obtido pela divisão do peso (em quilos) pela altura ao quadrado (em metros). O peso é classi- 
ficado em categorias, de acordo com estudos da World Health Organization - WHO (1995): desnutrição (14,5 ou menos), abaixo do peso (vinte ou menos), peso normal (vinte a 24,9), sobrepeso (25 a 29,9), obesidade (trinta a 39,9) e obesidade mórbida (maior que quarenta).

Fisberg (2005) descreve um estudo realizado com crianças obesas no qual foram observados antecedentes de obesidade familiar em 91\% dos casos. Quando os pais são obesos, o risco de a criança ser obesa é de $80 \%$; caso um dos genitores seja obeso, a probabilidade é de $50 \%$, e se os pais são magros, a probabilidade é de $9 \%$. Não se afirma, contudo, até que ponto a determinação para essas tendências familiares é genética ou ambiental.

Campos (2005) considera que há fatores ambientais de risco para o desenvolvimento da obesidade, destacando-se o excesso de ingestão alimentar, o sedentarismo, os hábitos alimentares inadequados, os aspectos socioemocionais, o consumismo, o desmame precoce, a introdução precoce de alimentos sólidos, a substituição de refeições por lanches, a prática de assistir TV por várias horas diárias e a difusão de jogos eletrônicos.

Conforme Schussel (2005), os padrões de saúde e estéticos variam conforme a época, e hoje considera-se a obesidade como um desvio da normalidade. Wolf (1992) faz menção aos padrões estéticos historicamente valorizados. A partir dos anos 1970, começou a haver a busca por um corpo magro, atlético, com formas definidas, chegando-se, para isso, a anorexias fatais na sociedade ocidental valorizadora da "magreza" e de padrões esculturais de beleza.

Muitas vezes, os indivíduos obesos são vistos como "desleixados", "preguiçosos", "não competitivos", "grotescos" e "exagerados", o que reflete o preconceito e a não aceitação social (Lemes, 2005). Considerando tal afirmação, o autor aponta que aspectos emocionais associam-se à obesidade, seja como causa ou consequência.

Nesse sentido, o atendimento a essa população deveria considerar as questões psicológicas. Viuniski (2000) e Zlochevsky (1996) defendem a necessidade do caráter multifatorial no tratamento da obesidade, que deve incluir profissionais de várias áreas, como a Medicina, a Psicologia, a Nutrição, a Pedagogia e a Educação Física. 


\section{Bullying, estresse e aspectos socioemocionais}

Autores como Campos (1993) e Hutz \& Antoniazzi (1995) conduziram investigações acerca de aspectos do funcionamento psicológico que pudessem ser identificados em crianças obesas.

Azevedo (2000) comparou resultados obtidos com a aplicação do Desenho da Figura Humana em trinta crianças obesas e trinta crianças não obesas e diagnosticou que os primeiros apresentaram mais indicadores emocionais desfavoráveis. Venturini (2000), que também aplicou o teste do Desenho da Figura Humana em 15 crianças obesas, verificou que suas produções mostraram transtornos no esquema corporal, ansiedade, insegurança, insatisfação consigo mesmas, sinais de agressividade, entre outros.

Assim como em outros "desvios" dos padrões socialmente aceitos e valorizados, a criança obesa pode ser vítima do bullying, fenômeno definido por Fante (2005) como um conjunto de atitudes agressivas, intencionais e repetitivas que ocorrem sem motivação evidente, adotado por um ou mais alunos contra outro, causando dor, angústia e sofrimento. O comportamento bullying envolve manifestações como insultos, intimidações, apelidos cruéis, gozações, acusações injustas, exclusões e danos físicos, morais e materiais.

Considera-se que vivências traumáticas de constrangimento, impregnadas de angústia e ansiedade, são características, muitas vezes, de crianças vítimas do bullying, o que pode gerar danos à identidade e aumentar o círculo retroalimentador da ansiedade, a qual constitui um dos fatores existentes na etiologia da obesidade.

Lopes Neto \& Saavedra (2003) ressaltam que a conduta bullying gera consequências negativas e nefastas a todos os envolvidos. A não superação dos traumas sofridos pela vítima pode gerar sentimentos negativos, pensamentos e práticas de vingança, baixa autoestima, dificuldades de aprendizagem, baixo rendimento escolar, transtornos mentais, psicopatologias, doenças de fundo psicossomático e dificuldades de relacionamento.

Constata-se que pessoas vítimas do bullying podem assumir comportamentos de vingança, e quando não há atitudes de prevenção e 
combate a isso, o ambiente social torna-se contaminado, e a convivência, muito difícil.

Considera-se que as consequências da obesidade quanto a questões emocionais e de identidade, principalmente em crianças e adolescentes, dependerá, em parte, de suas habilidades sociais, do montante de estresse gerado pelas cobranças sociais, pelas experiências de bullying que sofrem e da maneira como enfrentam essas experiências.

Neme et al. (2003) conceituam o estresse como um processo mediante o qual estímulos de diferentes naturezas produzem alterações psicofisiológicas, dependentes das avaliações realizadas pelo indivíduo em relação a esses estímulos ou "estressores" e das formas com as quais lida com a situação.

Lipp (2001) define que o estresse envolve sintomas físicos, psicológicos e comportamentais. Dentre os sintomas psicológicos, destacam-se a fadiga, o esgotamento, a frustração, a tensão, o nervosismo, a irritabilidade, o pânico, o pesadelo e a vontade de chorar. Dentre os sintomas físicos, destacam-se: cefaleia constante, problemas gastrintestinais, náuseas, vertigem, taquicardia, hipertensão, zumbido nos ouvidos, afonia e dores musculares. Dentre os efeitos comportamentais, destacam-se: ansiedade, pânico, angústia, insônia, dificuldades interpessoais, inabilidade para relaxar, tédio e depressão.

Remetendo-se à infância, Lipp \& Romano (1987) abordam que eventos que exijam da criança maior esforço para adaptação podem levar a mudanças psicológicas, físicas e químicas no seu organismo. As autoras descrevem que, assim como no adulto, os sintomas do estresse infantil também podem ser psicológicos, físicos ou ambos. Dentre os sintomas de ordem psicológica, destacam-se: terror noturno, choro excessivo, birra e insegurança. Dentre os sintomas físicos, destacam-se: diarreia, tiques, dores de cabeça, enurese noturna, gagueira, bruxismo e distúrbios do apetite. Segundo as autoras, o principal efeito do estresse infantil é o desenvolvimento de doenças, como asma, doenças dermatológicas, cefaleia, anorexia, úlceras e obesidade. 
Higley \& Suomi (1996) evidenciam a relação entre estresse infantil e o desenvolvimento de neuroses, como a instabilidade emocional, a baixa autoconfiança e o enfraquecimento cognitivo; e psicopatologias, como a depressão, a ansiedade e a dependência química.

O quadro do estresse foi classificado em fases por Lipp (2001), sendo estas: fase 1 - alerta (caracterizada pela presença de reações de luta ou fuga, essenciais para a preservação da vida); fase 2 - resistência (caracterizada pela exposição contínua ao estímulo estressor para tentar adaptação; há reações de desgaste e cansaço); fase 3 - exaustão (o indivíduo não consegue adaptar-se ou resistir aos estressores; surgem algumas doenças).

De acordo com Lazarus \& Folkmam (1986), o enfrentamento pode ser entendido como o conjunto de estratégias e recursos individuais que são utilizados para diminuir o estresse e resolver as situações que o geram. Os efeitos das situações de estresse, como um dos fatores importantes relacionados a várias doenças, dependem da forma como tais situações são enfrentadas e da forma como são avaliadas e valorizadas por diferentes pessoas (Neme et al., 2003).

Pode-se dizer que no ambiente escolar as crianças obesas podem sofrer situações estressantes diante de preconceito e discriminação. O estudo realizado destinou-se a caracterizar esse fenômeno e suas consequências.

\section{Objetivos}

O presente trabalho objetivou realizar uma avaliação psicossocial com crianças em condições de sobrepeso e obesidade, bem como caracterizar essas crianças quanto aos níveis de estresse e de sua percepção sobre bullying. 


\section{Método}

\section{Participantes}

O estudo foi conduzido com 15 crianças e um de seus genitores, somando trinta participantes. Quanto ao sexo das crianças, seis eram do sexo masculino, e nove, do sexo feminino, com idades variando entre nove anos e oito meses e 11 anos e quatro meses, e escolaridade entre a $3^{\mathrm{a}}$ e a $5^{\mathrm{a}}$ série do primeiro grau. Das 15 crianças participantes, 12 estavam matriculadas em escola pública, e três, em escola particular.

O peso das crianças variou entre quarenta e 78,6 quilos, e a altura, entre um $1 \mathrm{~m} 38 \mathrm{~cm}$ e $1 \mathrm{~m} 68 \mathrm{~cm}$, no início do estudo. Do total, 12 foram avaliadas em condição de sobrepeso e três em condições de obesidade, segundo padrões estabelecidos pelo Ministério da Saúde (Brasil, 2004).

\section{Local}

A pesquisa foi realizada no centro de saúde, em uma cidade do interior do estado de São Paulo, o qual conta com atendimentos clínicos em várias especialidades médicas, farmácia, vacinação, distribuição de leite, vigilância sanitária e atendimento fonoaudiológico e psicológico.

A entrevista das crianças e dos pais foi feita em uma sala que media aproximadamente três metros de comprimento por dois metros de largura. A sala era iluminada por duas luminárias. Havia janelas, através das quais o local era arejado e também iluminado naturalmente.

\section{Materiais e instrumentos}

Os instrumentos usados na pesquisa foram:

a) roteiro de entrevista semiestruturada realizada com os pais; 
b) roteiro de entrevista semiestruturada realizada com as crianças;

c) Escala de Stress Infantil (ESI) - Lipp \& Lucarelli (2005).

A entrevista com os pais consistia em um roteiro de questões abertas, elaboradas pela pesquisadora, com a finalidade de obtenção de informações sobre a criança acerca de sua composição familiar, sua saúde, seus hábitos alimentares, aspectos escolares, aspectos socioemocionais e concepção dos pais sobre a obesidade.

A entrevista com as crianças consistia em um roteiro de questões abertas, elaboradas pela pesquisadora, objetivando colher dados a respeito da convivência das crianças com os colegas na escola, da ocorrência do bullying, das atitudes dos professores diante do bullying, dos sentimentos e reações infantis na condição de vítima do bullying, das experiências como autores do bullying, da avaliação pessoal da condição de sobrepeso ou obesidade e da opinião sobre causas relacionadas à obesidade.

A ESI - Lipp \& Lucarelli consiste em instrumento avaliativo do nível de estresse infantil por meio da identificação de sintomatologia apresentada pela criança em reações físicas e psicológicas. A ESI possui 35 itens de zero (círculos vazios) a quatro pontos (círculos cheios), agrupados em quatro fatores, a saber: reações físicas (RF), reações psicológicas $(\mathrm{RP})$, reações psicológicas com componente depressivo (RPCD) e reações psicofisiológicas (RPF).

\section{Procedimentos de coleta e análise de dados}

Primeiramente, os pais foram agendados para a entrevista, a qual ocorreu em uma sessão e foi registrada por escrito pela pesquisadora. O Termo de Consentimento Livre e Esclarecido foi lido pelos pais e pela pesquisadora, em conjunto, após a entrevista inicial, e foram feitos esclarecimentos acerca da pesquisa relativos a objetivos e metodologia.

As crianças foram agendadas para a sessão de avaliação, a qual compreendeu a aplicação da entrevista inicial e da testagem psicológica individual por meio da ESI. 
As sessões com as crianças demoraram aproximadamente uma hora e trinta minutos, contando com um intervalo de 15 minutos entre as atividades, proposto pela pesquisadora, para evitar que a sessão se tornasse exaustiva e comprometesse a qualidade das respostas.

Os dados da pesquisa foram analisados quantitativa e qualitativamente. As respostas das entrevistas aplicadas foram registradas por escrito. Para a análise do conteúdo de tais respostas, estas foram inseridas em categorias e foram calculadas as porcentagens. Com relação aos dados obtidos com a ESI, estes foram analisados somando-se os pontos e estabelecendo a porcentagem das reações avaliadas (físicas, psicológicas, psicofisiológicas) e classificando a fase de estresse em que as crianças encontravam-se.

\section{Resultados e discussão}

Os resultados são apresentados segundo a sequência da coleta de dados e divididos em seções, de acordo com as atividades desenvolvidas.

\section{Relatos dos pais sobre hábitos sociais e saúde de seus filhos}

Para a análise dos dados da entrevista inicial com os pais, utilizou-se como base as seguintes categorias referentes à vida da criança: saúde, hábitos alimentares, aspectos escolares, aspectos socioemocionais e concepções sobre a obesidade.

Com relação à saúde, 100\% dos pais relataram que seus filhos apresentam boa saúde de maneira geral. Dessas crianças, 93\% foram submetidas a algum tipo de exame nos últimos meses (sangue, cardíaco). Segundo relato dos pais, 16\% das crianças apresentaram normalidade nos exames e 51\% apresentarem resultados alterados, sendo $26 \%$ na taxa de triglicerídeos, $13 \%$ na taxa de colesterol, $6 \%$ na taxa hormonal e $6 \%$ na pressão arterial. Os resultados dos exames, por ainda não terem sido concluídos, não são conhecidos por $26 \%$ 
dos pais que submeteram os filhos a exames laboratoriais. Esses dados corroboram a afirmação de Fisberg (2005) de que a obesidade na infância aumenta as chances de elevação dos triglicerídeos e do colesterol, além de provocar alterações na pressão arterial, entre outros problemas, sendo importante sua detecção precoce. Segundo o autor, a chance de uma criança obesa chegar à vida adulta na mesma condição é de aproximadamente 16,5\%. Já Oliveira (2000) estima que de $40 \%$ a $80 \%$ das crianças obesas serão adultos obesos.

Quanto aos hábitos alimentares, os dados mostram que 67\% das crianças participantes têm preferência por alimentos considerados altamente calóricos (como doces e gordurosos) e 33\% têm preferência por alimentos considerados variados. Dos pais entrevistados, $60 \%$ afirmaram que a criança tem livre acesso às guloseimas de alto valor calórico e 40\% disseram que há restrições nesse acesso.

No âmbito escolar, $53 \%$ dos pais afirmaram que o filho apresenta bom rendimento, $27 \%$ disseram que o rendimento é regular e $20 \%$, que o rendimento é baixo. Dos pais entrevistados, 93\% têm conhecimento de que seu filho é vítima de bullying, envolvendo ou não a questão da obesidade. Essa alta porcentagem relatada confirma a afirmação de Fante (2005) acerca da incidência crescente do fenômeno bullying nas escolas brasileiras, constatada por recentes estudos. Segundo informações dos pais, diante do bullying, 20\% dos filhos apresentavam reação agressiva física, 20\% apresentavam reação agressiva verbal, $20 \%$ nada revelaram aos pais sobre o assunto, 13\% negaram-se a falar, $7 \%$ pediram ajuda aos pais e $7 \%$ sofriam ameaças de agressão física. Os 13\% restantes referem-se a outras categorias apresentadas em proporção muito pequena.

Referindo-se aos aspectos socioemocionais, 93\% dos pais admitiram que o filho tem características de ansiedade, as quais, segundo eles, revelam-se na véspera de provas escolares ou de situações novas, como uma viagem, pela insistência em ter seus desejos satisfeitos rapidamente ou pela não conclusão de uma atividade por vez; $20 \%$ dos pais relataram resistência do filho para a aceitação dos limites impostos no lar; $20 \%$ relataram que o filho come em maior quantidade quando ansioso; e 6\% apontaram características de medo e 
preguiça. Campos (1993) destaca as características psicológicas das crianças obesas, sendo uma destas a dificuldade do adiamento das satisfações.

Na categoria concepções sobre a obesidade, investigou-se a opinião dos pais sobre as desvantagens da obesidade e sobre suas causas. Com relação às desvantagens, 100\% dos pais afirmaram que a obesidade infantil traz desvantagens, entre as quais: problemas de saúde, desânimo, lentidão física, vitimização pelo bullying, preconceitos e problemas com a estética e com a autoestima.

Observou-se que a maior desvantagem da obesidade, na opinião dos pais dos meninos, foi lentidão física, e, em segundo lugar, os problemas de saúde. Já os pais das meninas consideraram a maior desvantagem da obesidade infantil os problemas com a estética, seguidos de problemas com a autoestima. A cultura atual considera a "magreza" como símbolo de beleza, sendo a exigência quanto a isso maior para as mulheres. O símbolo da virilidade masculina parece ser a exposição de um corpo atlético, voltado principalmente à força e à agilidade física (Wolf, 1992) .

As respostas dos pais no quesito causas da obesidade foram: excesso de comida (80\%), vida sedentária (33\%), ingestão de guloseimas $(20 \%)$, ansiedade $(13 \%)$, problemas hormonais (13\%), tendência familiar $(6 \%)$ e isolamento social (6\%).

Parece haver consenso sobre as causas da obesidade entre vários autores que estudam esse tema, enfatizando-se a interligação entre fatores orgânicos, ambientais e psíquicos na determinação da obesidade, o que impossibilita o estabelecimento linear de causa-efeito.

\section{Relatos das crianças sobre bullying e estar acima do peso}

Para a análise dos dados da entrevista foram utilizadas as seguintes categorias: predileção por colegas, ocorrência do bullying, atitudes da professora diante do bullying, sentimentos e reações das vítimas do bullying, experiências como autores do bullying, avaliação 
pessoal diante da situação de estar acima do peso e avaliação das causas da obesidade.

A primeira categoria revela que a predileção por certos colegas é determinada em geral pela boa receptividade destes, pela identificação na maneira de pensar, pela proximidade física (moradia) e pela iniciativa de brincar. Já os colegas preteridos, assim o são por motivos como: comportamento agressivo verbal e físico, de transgressão às regras impostas na escola, como falar palavrões, colocar apelidos, ou por desprezo às brincadeiras e por comportamento de competição sexual (disputa por paquera).

Quanto à ocorrência do bullying no contexto escolar, 73\% afirmaram que o fenômeno ocorre envolvendo, no geral, condutas como apelidar, pegar objetos alheios e atirá-los no ventilador, fazer piadinhas, puxar os cabelos.

As atitudes da professora diante da ocorrência do bullying foram registradas como sendo de advertência, risos, ameaça de levar os autores do bullying à diretoria, pedido de contenção das ações agressivas, colocação de apelidos, intervenção verbal, expressando que não é necessário fazer o que estão fazendo para chamar a atenção dos colegas.

Fante (2005) argumenta que o bullying ocorre, com maior ou menor incidência, em todas as escolas do mundo, independente das características culturais, econômicas e sociais dos alunos, e enfatiza o despreparo dos educadores em geral para lidar com esse fenômeno, de modo a colaborar para sua supressão ou erradicação, como observado no presente estudo.

A quarta categoria de análise (sentimentos e reações das vítimas do bullying) mostra que as crianças vítimas do bullying relataram que se sentem bravas, tristes, iradas, constrangidas, chateadas, deprimidas, indiferentes. Suas reações diante do bullying foram registradas como sendo: ficar quieta tentando expressar indiferença, sair de perto no momento da ocorrência, ser agressiva fisicamente, fingir não escutar as provocações e apelidar também.

Essas constatações estão de acordo com o que Saavedra (2003) e Fante (2005) discutem a respeito das consequências das situações 
traumatizantes vivenciadas pelas vítimas do bullying, que, quando não superadas, podem gerar baixa autoestima, baixo rendimento escolar, dificuldades de relacionamento, comportamentos agressivos, entre outros. Fante (2005) alerta para a gravidade do fenômeno bullying, visto seu poder desencadeador de transtornos psíquicos e até de tragédia social motivada por comportamentos de vingança das vítimas.

Quanto à questão da autoria do bullying, a entrevista com as crianças revelou que a minoria (26\%) relatou experiência como autores do bullying com os colegas na escola.

Na categoria de análise acerca da avaliação pessoal diante da situação de estar acima do peso, mais da metade (66\%) considerou a existência de desvantagens em estar acima do peso, sendo estas: a condição de ser alvo de apelidos, a rejeição social, as brincadeirinhas pejorativas, o cansaço físico, a vergonha do próprio corpo e a dificuldade para encontrar roupas que lhes sirvam. Esses dados corroboram as afirmações de Lemes (2005) sobre a discriminação social de que as crianças obesas são vítimas, o que pode gerar fobia social, insegurança, timidez, sentimentos depressivos e autoimagem negativa.

$\mathrm{Na}$ avaliação das causas da obesidade, a maior parte das crianças a atribuiu ao fato de comerem em demasia (86\%); algumas especificando os tipos de alimentos calóricos, como fritura, chocolate, doces em geral. Seis por cento das crianças atribuiram a condição de excesso de peso à ansiedade, e 6\%, a doenças, sem especificá-las. Dois por cento referem-se a outras respostas.

\section{Avaliação da Escala de Stress Infantil (ESI)}

Os resultados da aplicação da ESI nas crianças participantes revelaram que a maioria delas encontrava-se em fase normal ou em fase de alerta, de acordo com as normas de apuração dos resultados (ver Tabela 1 a seguir).

Os maiores índices de normalidade foram apresentados no item que avaliava as reações físicas (73\%) e as psicológicas com compo- 
nente depressivo (67\%). Os maiores índices de crianças avaliadas em fase de alerta apresentaram-se nos itens reações psicofisiológicas (53\%) e psicológicas (33\%).

Tabela 1 - Porcentagem das respostas infantis apresentadas na ESI para as reações físicas $(R F)$, reações psicológicas $(R P)$, reações psicológicas com componente depressivo (RPCD) e reações psicofisiológicas (RPF) denotando as fases de estresse.

\begin{tabular}{ccccc}
\hline Fase & $\begin{array}{c}\text { Reações } \\
\text { RF }\end{array}$ & RP & RPCD & RPF \\
\hline Normal & $73 \%$ & $53 \%$ & $67 \%$ & $33 \%$ \\
Alerta & $27 \%$ & $33 \%$ & $27 \%$ & $53 \%$ \\
Resistência & $0 \%$ & $14 \%$ & $6 \%$ & $7 \%$ \\
Estresse & $0 \%$ & $0 \%$ & $0 \%$ & $7 \%$ \\
\hline
\end{tabular}

Algumas crianças apresentaram-se na fase de resistência, como C5 (no fator reações psicológicas com componente depressivo), C8 (no fator reações psicofisiológicas), C10 e C12 (no fator reações psicológicas). A C12 foi a única criança que se apresentou na fase de estresse (no fator reações psicofisiológicas). As crianças C3, C11 e C13 apresentaram normalidade em todos os fatores. A C4 apresentou-se em fase de alerta em todos os fatores. Todos os outros participantes apresentaram reações variadas entre normalidade e alerta para os fatores avaliados.

De acordo com Lazarus \& Folkman (1986), diferentes indivíduos lidam de diversas formas com situações estressantes. Tais variações dependem de fatores como sexo, idade, cultura, crenças, valores pessoais, história de vida, escolaridade, experiências anteriores de enfrentamento, variáveis de personalidade e recursos intelectuais, cognitivos, econômicos e sociais. Os autores explicitam que pequenos aborrecimentos e demandas do cotidiano podem ser potencialmente mais patogênicos do que os eventos extraordinários ocasio- 
nais, podendo relacionar-se mais diretamente ao estresse psicológico e ao surgimento de sintomas somáticos.

No presente estudo, as crianças que se apresentaram em fase de resistência e estresse para algumas reações avaliadas pela ESI demonstraram sofrimento e também dar alto grau de importância aos aspectos vivenciados no cotidiano, relacionados, por exemplo, à condição de excesso de peso e às questões envolvidas, tais como autoimagem negativa, lentidão física, vitimização por preconceito social e bullying.

\section{Considerações finais}

Os relatos das crianças refletiram um autoconceito negativo mensurado pelo peso e pela estrutura corpórea fora dos padrões culturais estéticos (segundo elas) e um desejo de "fugir" das contrariedades sociais ocorrentes em forma de zombarias e insultos, por exemplo. Pode-se dizer que já na infância e adolescência as pessoas, principalmente do sexo feminino, preocupam-se em emagrecer em função das expectativas daquelas com quem convivem e da cultura que idolatra a magreza como símbolo de beleza. Percebe-se que essa decisão muitas vezes não é fruto de análise mais detalhada dos motivos, dos prós e contras da própria condição. A impressão é que a decisão por emagrecer representa, em muitos casos, a tentativa de encaixar-se na "normalidade", no padrão do grupo e na qualidade de "eficiência" social e no símbolo de imagem positiva aos outros.

Dada a complexidade do tema obesidade infantil e suas implicações, acredita-se na necessidade de pesquisas mais amplas, que possam, por exemplo, envolver a família e a escola de maneira mais sólida em programas de prevenção e intervenção, levando-se em consideração as influências sociais (familiares e escolares) no estilo de vida da criança, inclusive em seus hábitos alimentares, evitandose situações que impliquem em sofrimento emocional das crianças que fogem ao padrão corporal e também as consequências danosas envolvidas nas situações de bullying. 


\section{Referências bibliográficas}

AZEVEDO, M. A. S. B. Obesidade na infância: visão psicológica. Anais do $8^{\circ}$ ciclo de estudo em Saúde mental. Ribeirão Preto: Pós-graduação em Saúde Mental, FMRP - USP, 2000.

BRASIL. Vigilância alimentar e nutricional: SISVAN (Série A: normas e manuais técnicos). Brasília, DF: Ministério da Saúde, 2004.

CAMPOS, A. L. R. Aspectos psicológicos da obesidade. Pediatria Moderna. v.29, n.2, p.129-30, 1993.

Aspectos psicológicos da obesidade. In: FISBERG, M. Atualização em obesidade na infância e adolescência. São Paulo: Atheneu, 2005.

FANTE, C. Fenômeno bullying. Campinas: Versus, 2005.

FISBERG, M. A. Atualização em obesidade na infância e adolescência. São Paulo: Atheneu, 2005.

HALPERN, A.; MANCINI, M. C. Obesidade: como diagnosticar e tratar. Revista Brasileira de Medicina. v.53, p.77-85, 1996.

HIDALGO, V.; PALÁCIOS, J. Desenvolvimento da personalidade dos 6 aos 12 anos. In: COLL, C.; PALÁCIOS, J.; MARCHESI, A. Desenvolvimento psicológico e educação. Porto Alegre: Artmed, 1995.

HIGLEY, J. D.; SUOMI, S. J. Effect of reactivity and social competence on individual responses severe stress in children: investigations using nonhuman primates. In: PFEFFER, C. R. (Ed.) Severe stress and mental disturbance in children. Washington: American Psychiatric Press, Inc., 1996.

HUTZ, C. S.; ANTONIAZZI, A S. O desenvolvimento do desenho da figura humana em crianças de 5 a 15 anos de idade: normas para avaliação. Psicologia: Reflexão e Crítica. v.8, p.3-18, 1995.

LAZARUS, R. S.; FOLKMAN, S. Estrés y procesos cognitivos. Barcelona: Ediciones Martinez - Rocca, 1986.

LEMES, S. O. Acompanhamento emocional da obesidade na infância e adolescência. In: FISBERG, M. Atualização em obesidade na infância e adolescência. São Paulo: Atheneu, 2005.

LIPP, M. E. N. ; ROMANO, A. S. F. O stress infantil. Estudos de Psicologia. v.4, n.2, p.42-54, 1987.

Estresse emocional: a contribuição de estressores internos e externos. Revista Psiquiatria Clinica. v.28, n.6, p.347-49, 2001. 
; LUCARELLI, M. D. M. Manual da Escala de Stress Infantil: ESI. São Paulo: Casa do Psicólogo, 2005.

LOPES NETO, A; SAAVEDRA, L. H. Diga não para o bullying: programa de redução do comportamento agressivo entre estudantes. Rio de Janeiro: Abrapia, 2003.

MARTI, E. Operações concretas. In: COLL, C.; PALÁCIOS, J.; MARCHESI, A. Desenvolvimento psicológico e educação. Porto Alegre: Artmed, 1995.

MATTOS, D. G. et al. Estudo de transtornos alimentares em pacientes com obesidade mórbida no período pré-operatório. In: NEME, C. M. B; RODRIGUES. O. M. P. (Orgs). Psicologia da saúde: perspectivas interdisciplinares. São Carlos: Rima, 2003.

NEME, C. M. B. ; SOLIVA, S. N. ; RIBEIRO, E. História prévia de eventos de stress e câncer de mama, útero e ovários. In: NEME, C. M. B.; RODRIGUES, O. M. P. (Orgs). Psicologia da saúde: perspectivas interdisciplinares. São Carlos, SP: Rima, 2003.

PADILLA, M. L. ; GONZÁLEZ, M. M. Conhecimento social e desenvolvimento moral nos anos escolares. In: COLL, C.; PALÁCIOS, J.; MARCHESI, A. Desenvolvimento psicológico e educação. Porto Alegre: Artmed, 1995.

SCHUSSEL, E. Y. Obesidade e psiquismo - possibilidades de abordagem. In: FISBERG, M. Atualização em obesidade na infância e adolescência. São Paulo: Atheneu 2005.

VENTURINI, L. P. Obesidade e família: uma caracterização de famílias de crianças obesas e a percepção dos familiares e das crianças de sua imagem corporal. Dissertação (mestrado). Universidade de São Paulo, Ribeirão Preto, 2000.

VIUNISKI, N. Prevenindo a obesidade: trabalhando com os fatores de risco. Nutrição em Pauta. v.41, p.31-4, 2000.

WOLF, N. O mito da beleza: como as imagens de beleza são usadas contra as mulheres. Rio de Janeiro: Rocco, 1992.

WORLD ORGANIZATION - WHO. Physical status: the use and interpretation of antropometry. WHO. Technical Report Series. n.854. Geneva: WHO, 1995.

ZLOCHEVSKY, E. R. M. Obesidade na infância e adolescência. Revista Paulista de Pediatria. v.14, n.3, p.124-33, 1996. 

PARTe 3

\section{ADOLESCENTES: MATERNIDADE, RISCOS E PROTEÇÃO}





\section{7 \\ GRAVIDEZ E MATERNIDADE NA ADOLESCÊNCIA ${ }^{1}$}

Mariane da Silva Fonseca ${ }^{2}$

Lígia Ebner Melchiori ${ }^{3}$

\section{Introdução}

A adolescência é um período de transição construído sócio-historicamente (Ariés, 1978), o qual, ao longo do tempo, foi modificando-se em decorrência das alterações sociais, políticas e familiares.

Diversos campos do saber auxiliaram a construção das noções que temos hoje sobre a adolescência: a Medicina e a Biologia, com os conceitos de maturação sexual, puberdade, funcionamento hormonal (Martinez, 2010; Duarte, 2010); a Sociologia e Antropologia, com as noções de grupo social, regras, anomia (Lakatos \& Marconi, 1999); e a Psicologia, que contribuiu com conhecimentos sobre identidade, desenvolvimento humano e fases do ciclo vital.

Fase do curso de vida em que ocorre a transição da infância para a idade adulta, na adolescência o jovem deve preparar-se para assu-

1 Este estudo é parte da dissertação de mestrado da primeira autora sob orientação da segunda autora. Ele foi aprovado pelo Comitê de Ética da Faculdade de Ciências da Unesp, campus de Bauru.

2 Programa de pós-graduação em Psicologia do Desenvolvimento e da Aprendizagem da Unesp - Bauru

3 Idem. 
mir papéis adultos, caracterizados pela conquista da autonomia financeira e emocional (Bee, 1997; Calligaris, 2000; Aberastury \& Knobel, 1981; Kaplan et al., 2000).

A maternidade, por sua vez, como fenômeno multidimensional, abarca inúmeras concepções biológicas, sociais e psicológicas e, assim como o conceito de adolescência, não é constituída por uma versão única. Ela pressupõe diversas alterações fisiológicas, sociais, comportamentais e psicológicas que variam em uma ampla faixa, de acordo também com expectativas socioculturais, grupo de pares e condição econômica.

A gravidez na adolescência pode gerar uma sobrecarga de necessidades fisiológicas, psicológicas e sociais, implicando em uma série de acontecimentos comprometedores para o desenvolvimento do indivíduo (Ribeiro et al., 2000). Ela é, hoje, reconhecida pelo risco psicossocial, que não se restringe aos fatores psicológicos ou sociais maternos, mas que também coloca em risco a vida do recém-nascido, principalmente nas gestações abaixo dos 15 anos, quando a adolescente geralmente não possui a estrutura óssea e muscular necessária ao parto. Segundo Varella (2006), a consequência que mais ocorre nos partos de mães adolescentes é o nascimento de um bebê com baixo peso, o que requer supervisão médica especial. Outro ponto importante diz respeito à mortalidade e à morbidade materno-infantil associada à gravidez adolescente, que, segundo Silva \& Salomão (2003), estão mais relacionados às desigualdades sociais e à pobreza do que à idade da gestante.

De uma gravidez na adolescência pode decorrer a realização de abortos clandestinos. Segundo dados da Organização Mundial de Saúde (OMS), dos quatro milhões de abortos praticados por ano no Brasil, um milhão ocorrem entre adolescentes, sendo que 20\% delas morrem por suas complicações. Alguns autores (Bueno, 2004; Cavasin et al., 2004) afirmam que estamos enfrentando atualmente uma epidemia de gravidez em adolescentes, pois o número das que engravidam entre os 12 e os 19 anos quase dobrou nos últimos dez anos. Censos do IBGE de 1997 e de 2000 registram um elevado número de partos em adolescentes (Esteves \& Menandro, 2005). 
A gravidez na adolescência ainda é tema controverso, pois entre os pesquisadores e profissionais da saúde há diferentes posições a respeito. Heilborn et al. (2002) e Santos \& Schor (2002), por exemplo, defendem que a gravidez na adolescência não pode ser considerada fator de risco em si mesma, pois fatores como o nível socioeconômico e as condições de saúde materna exercem maior influência do que a idade cronológica da gestante. Outros autores (Varella, 2006; Bigras \& Paquette, 2007) afirmam que esse fenômeno é responsável por uma série de problemas de ordem social e psicológica, e deveria ser tratado como uma epidemia a ser controlada ou erradicada. Há, ainda, outra classe de autores (Ventura \& Corrêa, 2006) que analisa o fenômeno como algo muito complexo, cujas múltiplas variáveis biopsicossociais que incidem sobre ele tornam-no não rotulável e homogêneo.

O estudo apresentado neste capítulo investigou as implicações da gravidez e da maternidade na adolescência e as mudanças advindas dessa experiência, segundo a percepção das adolescentes e de seus respectivos companheiros ou mães. São tecidas também considerações a respeito da iniciação sexual das jovens, a utilização de contraceptivos, os motivos para a ocorrência da gravidez na adolescência, as reações iniciais frente à notícia da gravidez, a experiência do nascimento do bebê e as mudanças decorrentes desse evento.

\section{Método}

\section{Participantes}

Quinze adolescentes, mães de bebês de três a sete meses de idade, nove companheiros e seis mães. As adolescentes foram selecionadas no projeto de extensão "Acompanhamento do desenvolvimento de bebês: avaliação e orientação aos pais”, na Unesp, campus de Bauru, desde 1999.

Os critérios para participar deste estudo foram: (a) ter de dez a 19 anos de idade, faixa etária estabelecida pela OMS para a adoles- 
cência; (b) ser mãe de um bebê de um a 12 meses com desenvolvimento típico; (c) o companheiro (quando coabitava) ou a mãe (quando a adolescente morava com os familiares, sem a presença do parceiro) concordar em participar do estudo. A escassez de estudos com o companheiro fez com que a prioridade fosse ele e, em sua ausência, as mães das adolescentes.

As adolescentes tinham idades entre 14 e 19 anos, seus companheiros, de 18 a 32 anos, e as mães, idade entre quarenta e cinquenta anos. Oito adolescentes frequentaram o Ensino Fundamental (seis incompleto e duas completo), e sete, o Ensino Médio (cinco de modo incompleto e duas chegaram a completá-lo). Dos nove companheiros, três não completaram o Ensino Fundamental e um completou este nível. Três deles não completaram o Ensino Médio e dois concluíram. Das mães das participantes, cinco não haviam completado o Ensino Fundamental e apenas uma possuía nível universitário.

\section{Instrumentos}

Foram utilizados dois instrumentos para a coleta dos dados:

$1^{\circ}$ ) Questionário de Caracterização do Sistema Familiar (adaptado de Dessen, 2009), cujo objetivo foi o de investigar os dados demográficos, a composição familiar, a divisão de tarefas domésticas, a idade da iniciação sexual, o uso de contraceptivos, as características da rede social de apoio, a comunicação e o apoio familiar.

$\left.2^{\circ}\right)$ Entrevista sobre Conceituação da Maternidade Adolescente (elaborada para a pesquisa,) composta por questões sobre a reação inicial frente à notícia da gravidez, as implicações do nascimento do bebê na dinâmica familiar, o desempenho de papéis familiares e a percepção sobre maternidade adolescente.

\section{Procedimento de coleta e de análise de dados}

A coleta de informações ocorreu no domicílio dos participantes, após agendamento prévio por telefone, esclarecidos os objetivos do 
estudo. O Termo de Consentimento Livre e Esclarecido foi lido e assinado pelos participantes e, quando menores de 18 anos, foi assinado pelo responsável legal. A coleta de dados consistiu primeiramente na aplicação somente às adolescentes do Questionário de Caracterização do Sistema Familiar. A própria pesquisadora lia as perguntas e registrava as respostas, evitando constrangimentos decorrentes de possíveis dificuldades de leitura por parte das adolescentes, já que a maioria possuía baixo nível de escolaridade, e esse preenchimento teve duração média de 25 minutos. Depois as entrevistas foram realizadas com todos os participantes de forma individual, gravadas e transcritas, tendo uma duração aproximada de cinquenta minutos.

$\mathrm{Na}$ análise dos dados do questionário, as respostas fechadas foram tabuladas e calculou-se a frequência absoluta e as porcentagens, e nas questões abertas foram criadas categorias para análise para posterior tabulação e cálculo de frequência absoluta e de porcentagens. Na análise de dados da Entrevista sobre Conceituação da Maternidade Adolescente, optou-se pela proposta de BiasoliAlves (1998), realizando o registro e a transcrição literal dos dados, além de sua leitura e sistematização, para a redação e interpretação.

\section{Resultados}

\section{Início da atividade sexual, utilização de métodos contraceptivos e responsabilidade da concepção}

Segundo as participantes, o início da atividade sexual ocorreu entre 11 e 18 anos de idade, sendo que sete delas tiveram sua iniciação sexual entre 13 e 14 anos de idade. A maioria delas (13) iniciou sua vida sexual dos 11 aos 16 anos. Os parceiros sexuais na época da iniciação sexual possuíam entre 14 e 29 anos, concentrando-se na faixa entre 17 e 18 anos.

A maioria das adolescentes era primigesta (11). As outras quatro haviam tido experiência de gravidez anterior, sendo que uma havia 
passado por três gestações e três haviam sofrido aborto, sendo dois espontâneos e um provocado.

Os métodos contraceptivos mais utilizados por seis adolescentes, após a gravidez, foi a pílula anticoncepcional, seguida da camisinha, escolhida por quatro delas. As demais utilizavam métodos combinados: duas optavam por pílula e preservativo, duas, pela injeção hormonal, e uma delas fazia uso esporádico de contraceptivos.

Segundo as adolescentes, a responsabilidade pelo planejamento familiar e uso de métodos contraceptivos foi apontada por onze delas como sendo do casal, como se pode ver nos relatos:

Os dois colocam no mundo. (A2)

Os dois são responsáveis. (A7)

Todavia, também argumentam que a responsabilidade da gravidez seria maior para a mulher do que para o homem:

É a mulher que vai gerar. (A8)

Mas é a mulher que fica com o filho. (A13)

Quatro jovens relatam que a responsabilidade da contracepçãoé apenas da mulher, argumentando que:

Tem que tomar a pílula na hora certa. (A1)

\section{Motivos para a ocorrência da gravidez na adolescência}

Em relação aos motivos para a ocorrência da gravidez na adolescência, as respostas foram classificadas em três categorias: 1) Queria ter filho; 2) Não se preveniu, que abrange seis subcategorias explicativas: 2a) Porque o companheiro não quis usar camisinha; 2b) Porque pensava que não ia ocorrer a gravidez; 2c) Porque o parceiro desejava a gravidez; 2d) Por falta de preservativo na hora; 2e) Por falta de orientação materna; 2f) Para manter o relacionamento com 
o namorado; e 3) Erro na utilização do método contraceptivo. A Tabela 1 apresenta a ocorrência das respostas das adolescentes, de suas mães e de seus companheiros categorizadas em relação aos motivos da ocorrência da gravidez.

O maior motivo da ocorrência de gravidez entre as adolescentes foi a falta de prevenção, justificada por diferentes apontamentos, tais como porque pensavam que a gravidez não fosse ocorrer com elas ou porque o namorado não quis usar a camisinha.

Porque eu não soube dizer não. Se eu tivesse dito: É isso e pronto, sem camisinha eu não vou transar! Não tinha acontecido. Mas, é aquela estória: Ah, não vou brigar porque eu não quero brigar com ele! Não vou falar porque eu sei que a gente vai brigar e eu não quero brigar. Foi assim, pura falta... minha mãe fala que é falta de personalidade, sabe? ... E aí, nessa história eu me deixei de lado e fiz as vontades dele, se eu tivesse me respeitado mais, não tinha acontecido. (A10)

Descuido! Nós nunca procuramos [usar pílula, camisinha], não usava nada! Não gosto, é chato usar camisinha, é ruim, é desconfortável, eu não gosto, e ela nunca foi atrás de médico fazer consulta para usar pílula. A gente acha que não vai acontecer nada... Agora, para evitar filho ela tá tomando pílula, porque eu não uso camisinha. (C3)

Para quatro mães, as filhas engravidaram porque não se preveniram, e uma dessas mães argumentou que sua filha fez isso para "segurar o namorado".

Ela engravidou porque queria, porque queria segurar o rapaz, porque ele é muito agitado, tá aqui, tá lá, ele não se contenta com uma moça, se está com ela aqui, está com outra lá, então ela quis segurar ele, mas não conseguiu por ela gostar dele e ele ser mulherengo, ela fez isso, mas não adiantou, ela achou que ela arrumava [o bebê] e que ele ia ficar com ela, mas não adiantou. (M12)

Para algumas adolescentes, alguns companheiros e uma mãe, a gravidez ocorreu intencionalmente, porque havia a vontade de que isso ocorresse. 
Tabela 1 - Motivos para a ocorrência da gravidez.

\begin{tabular}{|c|c|c|c|c|}
\hline Categorias & Subcategorias & Adolescentes & Companheiros & Mães \\
\hline \multirow{6}{*}{ Não se preveniu } & $\begin{array}{l}\text { Porque o companheiro não quis } \\
\text { usar camisinha. }\end{array}$ & 2 & 2 & 1 \\
\hline & $\begin{array}{l}\text { Porque pensava que não ia ocorrer } \\
\text { a gravidez. }\end{array}$ & 4 & 0 & 1 \\
\hline & $\begin{array}{l}\text { Porque o parceiro desejava } \\
\text { a gravidez. }\end{array}$ & 1 & 0 & 0 \\
\hline & Por falta de preservativo na hora. & 1 & 0 & 0 \\
\hline & Por falta de orientação materna. & 1 & 0 & 0 \\
\hline & Para segurar o namorado. & 1 & 1 & 1 \\
\hline Queria ter filho. & 4 & 5 & 1 & \\
\hline \multicolumn{2}{|c|}{ Erro na utilização do método contraceptivo. } & 2 & 1 & 1 \\
\hline Total & 15 & 9 & 6 & \\
\hline
\end{tabular}


Eu engravidei porque eu queria, agora tem adolescente que engravida por falta de juízo. Porque tem adolescente que sai para curtir e transa com um e com outro, que acaba nem sabendo quem é o pai, onde foi que ela ficou grávida, como que foi, tenho muitas amigas que aconteceu isso. (A15)

Eu acho que é porque ela gostava de mim, e sabia que eu queria um filho. (C7)

Acho que ela queria, quando ela pensou: eu posso arrumar um neném, eu não vou me prevenir e pronto. Para mudar a vida dela. Porque eu acho que de um modo ou de outro ela se sentia sozinha, né? Porque eu acho que ela procurava essas amizades dela porque ela não tinha ninguém! Eu saía para trabalhar, ela ficava sozinha em casa, e às vezes chegava aquele monte de meninada: Vamos para a bagunça? Se ela arrumasse um neném, ela ia ter com quem se preocupar, e hoje ela não sai, ela fica só com o neném, quer dizer, ela arrumou uma companhia 24 horas por dia para ela. (M15)

Algumas justificativas foram sobre o uso inadequado do método contraceptivo.

Porque foi um descuido meu e do pai dela [companheiro, pai do bebê], esse foi um intervalo de eu não tomar o remédio. Eu esqueci de tomar a pílula, fiquei três dias sem tomar, tinha que buscar no posto, emendou, eu não tinha dinheiro para comprar. (A11)

\section{Reações diante da gravidez: no momento da notícia, na gestação e após o nascimento}

As respostas sobre as reações iniciais frente à notícia da gravidez foram categorizadas em reações desfavoráveis, favoráveis e neutras, segundo a proposta de Silva \& Salomão (2003). Na Tabela 2 pode-se observar a classificação geral das reações iniciais das adolescentes, dos companheiros e das mães quando souberam da gravidez. 
Tabela 2 - Reações iniciais frente à notícia da gravidez.

\begin{tabular}{lcccc}
\hline Categorias & $\begin{array}{c}\text { Adolescentes } \\
\mathrm{n}\end{array}$ & $\begin{array}{c}\text { Companheiros } \\
\mathrm{n}\end{array}$ & $\begin{array}{c}\text { Mães } \\
\mathrm{n}\end{array}$ & Total \\
\hline Desfavorável & 11 & 2 & 5 & 19 \\
Favorável & 3 & 6 & 1 & 10 \\
Neutra & 1 & 1 & 0 & 2 \\
\hline
\end{tabular}

Pode-se observar que a maioria das adolescentes e das mães mostrou reação desfavorável frente à notícia da gravidez. Onze adolescentes afirmaram ter tido dificuldade em aceitar a gravidez, por julgarem que ainda eram muito novas para ser mãe e/ou por medo da reação dos pais e/ou ainda por medo das transformações corporais.

Fiquei preocupada... chorei! [...] fiquei preocupada com que minha mãe ia falar, com meu pai, achava que eles "ia" brigar, mandar eu embora, sei lá, bater. Antes eles "falava", se acontecer alguma coisa vai levar uma surra, vai embora! (A8)

Fiquei desesperada, porque eu não tava querendo. Passava pela minha cabeça como eu ia ter, como eu ia ficar, se ia estragar meu corpo, só isso que eu pensava. (A9)

Dois companheiros relataram reações desfavoráveis, no sentido de não ter sido uma gravidez planejada ou desejada e por não possuírem condições financeiras avaliadas como suficientes.

A gente não tava esperando, aconteceu de novo! Eu falei: Nossa! Outro? Agora as coisas vão ficar difíceis para levar. Um já tá meio difícil de criar, agora vindo outro... (C6)

Íche! Eu fiquei louco, hein? Pensando num monte de coisas! Como eu vou sustentar esse menino? [...] Eu tinha medo dos pais dela "brigar" comigo, não "aceitar", me "ignorar", "mandar" a gente embora, qualquer coisa acontecer... A gente tinha muito medo. (C8) 
Cinco mães expressaram reações desfavoráveis, por revelarem sentimentos como tristeza, desespero ou chateação, como pode ser verificado no relato a seguir.

Foi um choque, minha pressão subiu, ficava indo em médico todo dia, foi difícil, e mais difícil ainda quando o pai dela "pôs ela" para fora [de casa], e eu fiquei naquele desespero. (M12)

Três jovens relataram reações favoráveis, como as que revelam aceitação, alegria com a notícia.

Eu chorei e fiquei muito feliz, porque era o que eu quis durante muito tempo, planejei essa gravidez tanto que veio de surpresa. (A15)

Quanto aos companheiros, seis referiram reações categorizadas como favoráveis, no sentido de que a notícia trouxe-lhes alegria por desejarem um filho.

Eu já tava na espera de um filho, estava programado [...] eu acho que ela não estava sabendo, eu não comentei com ela que queria um filho. (C1)

Foi uma felicidade tremenda, porque era o que a gente estava querendo muito. (C4)

Apenas uma mãe revelou reação favorável, alegando felicidade com o recebimento da notícia por acreditar que a gravidez seria uma forma de a filha transformar-se.

Pra te dizer a verdade eu fiquei feliz. Ela sempre falou que ela queria [...] então eu achava que a única coisa que segurava, que ia fazer ela ficar dentro de casa, era um filho, então quando eu recebi a notícia, para mim, eu fiquei feliz. (M15)

Uma jovem e um companheiro mostraram reação neutra: 
Não estava esperando, mas também não evitava. (A12)

Após a notícia da gravidez, no período da gestação, as reações das adolescentes, dos companheiros e das mães foram classificadas em três categorias e são apresentadas na Tabela 3.

Tabela 3 - Reações após a notícia da gravidez.

\begin{tabular}{lcccc}
\hline Categorias & $\begin{array}{c}\text { Adolescentes } \\
\mathrm{n}\end{array}$ & $\begin{array}{c}\text { Companheiros } \\
\mathrm{n}\end{array}$ & $\begin{array}{c}\text { Mães } \\
\mathrm{n}\end{array}$ & Total \\
\hline $\begin{array}{l}\text { Tornar as condições } \\
\text { favoráveis à chegada } \\
\text { do bebê. }\end{array}$ & 8 & 9 & 6 & 23 \\
\hline $\begin{array}{l}\text { Impedir ou } \\
\text { desfavorecer } \\
\begin{array}{l}\text { condições à } \\
\text { chegada do bebê. }\end{array}\end{array}$ & 6 & 0 & 0 & 6 \\
\hline $\begin{array}{l}\text { Neutralidade/ } \\
\text { indiferença. }\end{array}$ & 1 & 0 & 0 & 1 \\
\hline
\end{tabular}

A totalidade das respostas dos companheiros e das mães ocorreu no sentido de tornar as condições favoráveis à chegada do bebê, e mais da metade das adolescentes respondeu o mesmo. As iniciativas foram no sentido de tentar melhorar o estado da casa, aumentando o cômodo para abrigar o bebê; arrumar um trabalho ou tentar um emprego melhor e assim dispor de dinheiro para comprar roupas e fraldas para o bebê; preparar-se para morar junto com a parceira; cuidar-se fisicamente etc. Enfim, respostas que enfatizavam o preparo do ambiente físico e emocional para a chegada do bebê por meio do fornecimento de apoio emocional e financeiro, ou, no caso das adolescentes, respostas que priorizavam os cuidados consigo mesmas e com o desenvolvimento da gestação. 
Eu pensei em ter meu filho, daí perdi o medo de tudo, de falar com minha mãe, porque eu queria ter meu filho. (A2)

Em me cuidar para poder ter o filho numa condição boa. (A4)

Os companheiros emitiram respostas como:

Eu pensei em amigar com ela, morar junto, não depender dos nossos pais, nem das nossas mães. (C1)

Pensei em agilizar as coisas, guardar dinheiro para esperar essa criança nascer, para comprar as coisinhas para ele, deixar tudo arrumadinho. (C8)

Seis mães também tiveram as respostas classificadas nessa categoria, como, por exemplo:

Eu pensei em dar todo apoio, inclusive eu dei todo o apoio para ela, porque a mãe sempre dá, eu disse: Eu apoio você, a gente cuida da criança quando nascer. (M12)

No entanto, seis jovens forneceram respostas que indicavam tentativas de esconder a gravidez ou pensar ou tentar praticar o aborto. Tais respostas foram classificadas como tornar as condições desfavoráveis à chegada do bebê, por impedirem ou restringirem a preparação do ambiente físico e emocional para a vinda do bebê.

Eu tentei tirar ela, coloquei remédio, tomei remédio, só que eu não consegui, não deu resultado, aí que eu me apavorei mais ainda, fiquei com medo de nascer defeituoso, os outros tinham falado para mim: Põe remédio, assim, assado, esse remédio não falha, aí eu coloquei duas vezes e nada, não resolveu nada. (A5)

Pensei: Vou esconder... até ela [a mãe] descobrir, ou alguém contar, porque eu não tinha coragem. (A8, que escondeu a gestação da família até os sete meses) 
Apesar das dificuldades enfrentadas e reconhecidas durante a gestação, o nascimento do bebê foi relatado como um episódio positivo, marcado por emoções de alegria, realização e felicidade por sete jovens, seis companheiros e quatro mães. Como um episódio negativo, marcado por decepção, frustração, dor ou medo, foi relatado por quatro adolescentes, um companheiro e uma mãe, sendo que os demais participantes relataram a experiência com uma descrição sem qualquer tonalidade afetiva.

Oito adolescentes tiveram parto normal. Das adolescentes que realizaram cesáreas, duas foram submetidas a esse procedimento porque estavam contaminadas pelo HPV, transmitido pelos parceiros. Doze bebês nasceram após nove meses de gestação. As três adolescentes (A4, A10 e A13) que tiveram bebês prematuros tinham de 17 a 19 anos e seus bebês nasceram entre sete e oito meses de gestação.

As principais mudanças descritas em decorrência do nascimento do bebê foram o aumento da responsabilidade e da maturidade, a privação de lazer, o isolamento social e um sentimento de maior significado para a vida.

\section{Discussão}

Algumas variáveis demográficas parecem concorrer para a gravidez na adolescência, uma delas é a escolaridade. A literatura da área (Singh, 1998; Barnet et al., 2004; Dias \& Aquino, 2006) associa os níveis de escolaridade aos índices de gravidez na adolescência. Quanto menor a escolaridade da jovem, maiores são as chances de ocorrência da gravidez na adolescência, uma relação que também é válida para casos de recorrência de gestação, sendo verificado que quanto maior é o nível de escolaridade das mães adolescentes, menores são as chances de engravidarem pela segunda vez (Leite et al., 2004). Nesta amostra, os índices de escolaridade apresentam-se baixos, tanto para as adolescentes quanto para os companheiros e as mães participantes, indo ao encontro da ideia de ciclo de pobreza: menor escolaridade, menor qualificação para o mercado de traba- 
lho, menores salários, mais exposição a situações de risco: violência, drogas e prostituição (Siqueira et al., 2002; Barnet et al., 2004; Sabroza et al., 2004)

Todavia, a maternidade pode ser um fator de proteção para a adolescente, ao que Preto (1995) refere-se quando argumenta que a gravidez na adolescência pode significar a resolução de tensões familiares em arranjos específicos. Entre as participantes, as mães M10 e M15 relataram que a gestação tornou a filha mais caseira e responsável ou afastou-a das drogas, respectivamente.

Assim como descrito por Herrman (2007), no presente estudo também pode ser observado a atividade sexual das jovens como não planejada, algumas vezes por ceder às pressões do companheiro que se recusava a usar camisinha ou por este desejar um filho. Tal comportamento reflete a inabilidade das jovens em instaurar atitudes sexualmente seguras, já que neste estudo 11 jovens eram primíparas, três haviam tido duas gestações e uma estava na terceira gestação. Dessas quatro jovens que não eram primíparas, apenas uma desejava a gravidez, as demais não planejaram nem a desejaram. Entretanto, Scappaticci (2007) ressalta que o não planejamento da gravidez foi encontrado igualmente em grupos de mulheres adolescentes e adultas, o que pressupõe a necessidade de maior atenção nas políticas de controle de natalidade e educação em saúde sexual e reprodutiva no Brasil.

Sobre a adoção de medidas contraceptivas, vemos que a responsabilidade recai sobre as jovens, fato presente no relato de dois companheiros e de todas as mães, que responsabilizaram as jovens com argumentos de que a responsabilidade da gestação é da mulher, pelo fato de os companheiros não quererem usar camisinha ou não se preocuparem com a questão, o que confirma os achados de Heilborn et al.(2002). Os autores ressaltaram a tendência de os rapazes considerarem a contracepção como uma questão relativa às parceiras, justificando o uso esporádico de preservativos, um aspecto validado pela noção da diferença de gêneros que ainda vigora em nossa cultura. Todavia, Orlandi (2006) alerta para a ineficácia ou ausência de programas educativos sexuais " um empecilho para a adequação de prá- 
ticas sexuais preventivas pelo jovem casal", que deveriam ser oferecidos a ambos os gêneros e aos familiares.

Com relação aos motivos para a ocorrência da gravidez, os dados indicaram mais companheiros desejando a gravidez do que as adolescentes, o que confirma os achados de Bradt (2001), que argumenta maior desejo do homem por filhos em detrimento das mulheres, por estas arcarem com maiores responsabilidades que seus companheiros em relação à casa e aos filhos. As participantes A4, A5, A7 e A10 afirmaram que os companheiros incentivavam a gravidez. No caso dos companheiros C1, C4, C5 e C7, eles desejavam filhos e alguns reforçavam a não utilização da pílula pelas adolescentes. Todavia, outros motivos foram apontados para a ocorrência da gravidez na adolescência, como: a adolescente querer ter filho; o companheiro não aceitar o uso da camisinha; pensar que não ia acontecer a gravidez; falta de preservativo na hora; e a utilização inadequada de métodos contraceptivos. Vários autores (Reis \& Oliveira-Monteiro, 2007; Ponte-Junior \& Ximenes Neto, 2004; Lima et al., 2004; Bueno, 2004; Catharino \& Giffin, 2002) descreveram motivos para a ocorrência da gravidez na adolescência semelhantes aos encontrados neste estudo.

Billy et al. (1994) apontam para a influência do grupo no comportamento sexual e reprodutivo dos jovens, o que neste estudo foi verificado de acordo com o relato das jovens quando afirmam que amigas, colegas, vizinhas e irmãs da mesma faixa etária já eram mães. Neste estudo, além das três mães (M10, M14 e M15) que afirmam ter tido filhos na adolescência, há história de gravidez adolescente das irmãs mais velhas de A14 e A11. Bueno (2004) e Caputo (2006), estudando as variáveis concorrentes para a gravidez adolescente, também apontam a repetição de padrões de comportamento familiar. Pesquisas na área (Cerveny, 2002; Carter \& McGoldrick, 1995) apontam a influência geracional e a possibilidade de transmissão dos padrões familiares, como da gestação na adolescência, para as gerações futuras. Porém, a educação sexual poderia quebrar essa repetição de padrões.

Dados do estudo de Reis \& Oliveira-Monteiro (2007), no fator concernente aos motivos envolvidos na gestação adolescente, como 
o sentir-se só, brigas e tristezas com a família, falta de opções na vida, vontade de ter a própria família, por exemplo, estavam também no contexto das adolescentes do presente estudo.

Seemark \& Lings (2005), em estudo realizado na Inglaterra, encontraram relatos de experiências positivas de jovens mães referindo-se à motivação para efetivar transformações progressivas em suas vidas em decorrência de seus filhos. No presente estudo, também foi verificado o relato de jovens que enfatizaram a aquisição de um objetivo e de um rumo na vida, com o bebê, em termos de agora terem um motivo para lutar (A2, A3, A5, A6, A8, A10, A15). Para uma das participantes (A5), ser mãe e desempenhar as tarefas domésticas trouxe-a para o espaço protegido do lar, onde a instabilidade antes vivida foi deixada para trás por meio de esforços do casal para manter a família unida. Para A15, a maternidade parece ter constituído o ritual de passagem necessário para o ingresso no mundo adulto, em que abandonaria todas as transgressões e seus riscos e passaria a viver com maior tranquilidade, obtendo respeito familiar e social.

Com relação ao exercício da maternidade, pode-se notar nos relatos das jovens o que apontou Aragão (2002) ao evidenciar os sentimentos contraditórios pelos quais as mulheres em geral passam em decorrência da gravidez. Folle \& Geib (2004) confirmam tais resultados concernentes ao exercício materno conflituoso ora representado pelo status de assumir um papel adulto e responsável, ora vivido com despreparo e insegurança, afetando as relações com o bebê e os familiares.

Conforme o posicionamento de Braga \& Amazonas (2005) e Kahhale (1997), embora haja uma grande diversidade de configurações e funções familiares, persistem as idealizações da maternidade e a expectativa de ampliação de sentido de vida com o nascimento do bebê em variadas faixas etárias e camadas sociais. Talvez a força do imaginário feminino, carregado das idealizações da maternidade, faça as jovens sentirem-se "alguém" em um mundo em que antes não se sentiam reconhecidas ou valorizadas. Agora podem dizer de "boca cheia" (como no depoimento de A15) que são mães, orgulhar-se de seus rebentos tão pequenos, frágeis, dependentes de seus 
cuidados e da importância que é a elas atribuída para que possam existir no mundo onde estão expostas às drogas, a doenças, à violência e ao descaso do poder público, procurando criar uma ilha de cuidados, afeição e entrega em que realizem a maternidade de si mesmas, crianças ainda que são, pedindo colo, sustento e proteção.

\section{Considerações finais}

A valorização da maternidade legitima tal desejo porque o vincula como forma de inserção social e garantia de relacionamento estável com o parceiro. Dessa forma, pode-se compreender por que, em muitos casos, a gestação e a maternidade não são vistas como um problema e sim como uma meta a ser atingida (Lima et al. 2004).

No entanto, a vulnerabilidade social das adolescentes evidenciou-se na medida em que a atividade sexual relatada foi caracterizada pela iniciação sexual sem prevenção contra a gravidez ou doenças sexualmente transmissíveis, pela prática ou tentativa de aborto e, também, pela gravidez não planejada e dificuldade de ajustar a prática sexual segura com os parceiros. Daí a necessidade de oferecerse programas de atenção e educação em saúde familiar, considerando as crenças sobre maternidade, a compreensão dos projetos e dos valores de vida dos jovens e suas condições emocionais e sociais.

Programas de educação familiar, sexual e reprodutiva podem significar o diferencial para que os jovens possam desenvolver sua vida sexual de forma responsável e saudável, ajustados à família, ao grupo de pares e à sociedade, cabendo aos estudiosos e formadores de opinião pública o desenvolvimento de pesquisas que ofereçam suporte aos programas destinados a essa população.

\section{Referências bibliográficas}

ABERASTURY, A.; KNOBEL, M. Adolescência normal. Porto Alegre: Artes Médicas, 1981. 
ARAGÃO, R. O. De mães e de filhos. Disponível em: <http:// www.estadosgerais.org >. Acesso em: 18 jun. 2006.

ARIÉS, P. História social da criança e da família. Rio de janeiro: Zahar, 1978.

BARNET, B. et al. Reduced school dropout rates among adolescent mothers receiving school-based prenatal care. Arch Pediatr Adolesc Med.v.158, p.262-8, 2004.

BEE, H. O ciclo vital. Porto Alegre: Artes Médicas, 1997.

BIASOLI-ALVES, Z. M. M. A pesquisa psicológica: análise de métodos e estratégia na construção de um conhecimento que se pretende científico. In: ROMANELLI, G. (Org.) Diálogos metodológicos sobre prática de pesquisa. Ribeirão Preto: Legis Summa, 1998, p.135-57.

BIGRAS, M.; PAQUETTE, D. Estudo pessoa-processo-contexto da qualidade das interações entre mãe adolescente e seu bebê. Ciência e Saúde Coletiva. v.12 (5), p.1167-74, 2007

BILLY, O. G.; BREWSTER, K. L. E.; GRADY, W. R. Contextual effects on the sexual behavior of adolescent women. J Marriage Fam. v.56, p.387-404, 1994.

BRADT, J. O. Tornando-se pais: famílias com filhos pequenos. In: CARTER, B.; McGOLDRICK, M. (Orgs.) As mudanças no ciclo de vida familiar: uma estrutura para a terapia familiar. Porto Alegre: Artes Médicas, 2001, p.206-22.

BRAGA, M. G. R.; AMAZONAS, M. C. L. A. Família: maternidade e procriação assistida. Psicologia em Estudo. v.10(1), p.11-8, 2005.

BUENO, G. M. Gravidez na adolescência. Dissertação (mestrado). Pontifícia Universidade Católica de Campinas, São Paulo, 2004.

CALliGARIS, C. A adolescência. São Paulo: Publifolha, 2000.

CAPUTO, V. G. Gravidez na adolescência: fatores de risco e perfil de saúde mental. Tese (doutorado em Psiquiatria e Psicologia Médica). Universidade Federal de São Paulo, São Paulo, 2006.

CARTER, B., McGOLDRICK, M. As mudanças no ciclo de vida familiar: uma estrutura para a terapia familiar. In: . (Orgs.) As mudanças no ciclo de vida familiar. Tradução de M. A. V. Veronese. Porto Alegre: Artes Médicas, 1995, p.7-27.

CATHARINO, T. R.; GIFFIN, K. Gravidez e adolescência: investigação de um problema moderno. UERJ/ Nugera. Disponível 
em: <http://www.abep.nepo.unicamp.br/docs/anais/pdf/2002/ Com_JUV_ST7_Catharino_texto.pdf>. Acesso em: 28 dez. 2007. CAVASIN, S. et al. Gravidez de adolescente entre 10 e 14 anos e vulnerabilidade social: estudo exploratório em cinco capitais brasileiras. ECOS. Comunicação em sexualidade. São Paulo. Disponível em: <www.ecos.org.br/docs/Pesquisa>. Acesso em: 23 mar. 2006.

CERVENY, C. M. O. Pensando a família sistemicamente. In: ; BERTHOUD, C. M. E. (Orgs.). Visitando a família ao longo do ciclo vital. São Paulo: Casa do Psicólogo, 2002, p.15-28

DESSEN, M. A. Questionário de caracterização familiar. In: WEBER, L.; DESSEN, M. A. (Orgs.). Pesquisando a família: instrumentos para coleta e análise de dados. Curitiba: Juruá, 2009, p.102-14.

DIAS, A. B.; AQUINO, E. M. L. Maternidade e paternidade na adolescência: algumas constatações em três cidades do Brasil. Cad. Saúde Pública. v.22 (7), p.1447-58, jul. 2006

DUARTE, M. F. S. Maturação física: uma revisão da literatura, com especial atenção à criança brasileira. Cad. Saúde Pública. Rio de Janeiro, Disponível em: <http://www.scielo.br/scielo.php?script= sci_arttext\&pid=S0102-311X1993000500008\&lng= en\&nrm=iso >. Acesso em: 11 jun. 2010.

ESTEVES, J. R.; MENANDRO, P. R. M. Trajetórias de vida: repercussões da maternidade adolescente na biografia de mulheres que viveram tal experiência. Estudos de Psicologia. v.10, n.3, p.363-70, 2005.

FOLLE, E. E.; GEIB, L.T.C. Representações sociais de primíparas adolescentes sobre o cuidado materno ao recém-nascido. Rev latino-am. Enfermagem. v.12, n.2, p.183-90, 2004.

HEILBORN, M. L. et al. Aproximações socioantropológicas sobre a gravidez na adolescência. Horizontes Antropológicos, Porto Alegre, ano 8, n.17, p.13-45, 2002.

HERRMAN, J. W. Repeat pregnancy in adolescence: intentions and decision making. Am J Matern Child Nurs. v.32, n.2, p.89-94, mar.apr. 2007

KAHHALE, E. P., et al. Desenvolvimento da sexualidade e da relação materno - filial em gestantes adolescentes. Revista de Ginecologia e Obstetrícia, v. 8, n.1, 23-29, 1997. 
KAPLAN, H. I. SADOCK, B. J.; GREBB, J. A. Compêndio de Psiquiatria. Porto Alegre: Artmed, 2002.

LAKATOS, E. M. M.; MARCONI, M. A. Sociologia geral. 7.ed. São Paulo: Atlas, 1999.

LEITE, I. C.; RODRIGUES, R. N.; FONSECA, M. C. Fatores associados com o comportamento sexual e reprodutivo entre adolescentes das regiões Sudeste e Nordeste do Brasil. Cad Saúde Pública. v.20, n.2, p.474-81, 2004.

LIMA, C. T. B. et al. Percepções e práticas de adolescentes grávidas e de familiares em relação à gestação. Rev Bras Saúde Mater Infant. v.49, n.1, p.71-83, 2004.

MARTINEZ, J. et al. Growth patterns in early childhood and the onset of menarche before age twelve. Rev. Saúde Pública. São Paulo, v.44, n.2, abr. 2010. Disponível em: <http://www.scielo.br/ s c i e lo.ph p ? s c r i p t $=$ s c i_a r t text \& p i d $=$ S0034-89102010000200004\&lng=pt\&nrm=iso >. Acesso em: 11 jun. 2010.

ORLANDI, R. Paternidade nas adolescências: investigando os sentidos atribuídos por adolescentes pais à paternidade e às práticas de cuidados dos filhos. Dissertação (mestrado em Psicologia). Universidade Federal de Santa Catarina, Santa Catarina, 2006.

PONTE-JUNIOR, G. M.; XIMENES NETO, F. R. G. Gravidez na adolescência no município de Santana do Acaraú - Ceará - Brasil: uma análise das causas e riscos. Revista Eletrônica de Enfermagem. v.6, n.1, 2004. Disponível em: <http://www.fen.ufg.br>. Acesso em: 28 dez. 2007.

PRETO, N. G. Transformações do sistema familiar na adolescência. In: Carter, B.; McGOLDRICK, M. (Orgs.). As mudanças no ciclo de vida familiar. Tradução de M. A. V. Veronese. Porto Alegre: Artes Médicas, 1995, p.248-66.

REIS, A. O. A.; OLIVEIRA-MONTEIRO, N. R. Sexualidade e procriação na ótica de jovens de periferias sociais e urbanas. Ver Brás Crescimento Desenvolv. Hum. v.17, n.2, p.54-63, 2007. Disponível em: <http://pepsic.bvs-psi.org.br/pdf/rbcdh/v17n2/07.pdf>. Acesso em: 28 dez. 2007

RIBEIRO, E. R. O. et al. Comparação entre duas coortes de mães adolescentes em município do sudeste do Brasil. Rev. Saúde Pública. v.34, n.2, p.136-42, abr. 2000. 
SABROZA A. R. et al. Algumas repercussões emocionais negativas da gravidez em adolescentes no município do Rio de Janeiro. Cad. Saúde Pública. v.20, Supl.1, p.130-7, 2004.

SANTOS, S. R.; SCHOR, N. Vivências da maternidade na adolescência precoce. Rev. Saúde Pública. v.37, n.1, p.15-23, fev. 2003.

SCAPPATICCI, A. L. Dissertação de mestrado em Psiquiatria. Universidade Federal de São Paulo. In: CASTRO, I. A. Mãe adolescente interage mais com recém-nascido. Disponível em: <http: // www.unifesp.br/comunicação/jpta/ed 144/pesqu3.htm>. Acesso em: 20 mar. 2007.

SEEMARK, C. J.; LINGS, P. Positive experiences of teenage motherhood: a qualitative study. $\mathrm{Br} J$ Gen Pract. v.55, n.510, p.53. jan. 2005.

SILVA, D. V.; SALOMÃO, N. M. R. A maternidade na perspectiva de mães adolescentes e avós maternas dos bebês. Estudos de Psicologia. v.8, n.1, p.135-45, 2003.

SINGH, S. Adolescent childbearing in developing countries: a global review. Stud Fam Plann. v.29, p.117-36, 1998.

SIQUEIRA, M. J. T. et al. Profissionais e usuárias(os) adolescentes de quatro programas públicos de atendimento pré-natal da região de grande Florianópolis: onde está o pai? Estudos de Psicologia. v.7, n.1, p.65-72, 2002.

VARELLA, D. Gravidez na adolescência. Disponível em: $<$ www.drauziovarella.com.br/entrevistas / gravidez_adolescencia12.asp>. Acesso em: 23 mar. 2006.

VENTURA, M.; CORREAA, S. Adolescência, sexualidade e reprodução: construções culturais, controvérsias normativas, alternativas interpretativas. Cad Saúde Pública. v.22, n.7, p.1505-9, jul. 2006. 


\title{
8 \\ MÃes ADOLESCENTES \\ DESENHANDO E FALANDO SOBRE SUAS INTERAÇÕES FAMILIARES
}

\author{
Verônica Lima dos Reis ${ }^{1}$ \\ Tânia Gracy Martins do Valle ${ }^{2}$ \\ Ana Claúdia Bortolozzi Maia ${ }^{3}$
}

\section{Introdução}

A gravidez na adolescência é um fenômeno que tem gerado discussões nos meios acadêmicos e nas comunidades em geral, isto porque o número de partos entre as idades de 15 e 19 anos vem aumentando, tanto no Brasil quanto em outros países de modo geral (Almeida, 2003; Atlas Racial Brasileiro, 2009; Berquió, 2003; Ministério da Saúde, 2007; Organização Pan-Americana de Saúde, 2009).

A desaprovação social à gestação na adolescência é grande, tornando-se um difícil obstáculo para a mãe adolescente e para sua família, que enfrentam diretamente o desapontamento, a vergonha, sentimentos de culpa e até mesmo a violência por meio da rejeição social (Almeida, 2003; Lourenço, 1998).

1 Programa de pós-graduação em Psicologia do Desenvolvimento e da Aprendizagem da Unesp, campus de Bauru.

2 Programa de pós-graduação em Psicologia do Desenvolvimento e da Aprendizagem da Unesp, campus de Bauru.

3 Programa de pós-graduação em Psicologia do Desenvolvimento e da Aprendizagem da Unesp, campus de Bauru. 
Aliado a isso, a ocorrência de gravidez nessa fase da vida acarreta grandes modificações no cotidiano da adolescente, exigindo novos posicionamentos em relação a si, à família, ao parceiro afetivo e aos agrupamentos sociais (Manriquez \& Le-Bert, 1994), o que pode gerar um aumento na tensão familiar.

A tensão, ou estresse, em um sistema familiar pode originar-se em quatro fontes diferentes: a) o contato de um membro com forças extrafamiliares; b) o contato de toda a família com forças extrafamiliares; c) fases de transição na família; d) problemas idiossincráticos (Benoit et al., 1988; Minuchin, 1982).

Neste estudo, enfoca-se a transição da mãe adolescente em seu sistema familiar, o que pode tornar a adaptação de sua nova condição - a de mãe - conflituosa. A adolescência por si só provoca mudanças no sistema familiar, exigindo a redefinição de seu funcionamento, bem como dos relacionamentos e das negociações dos papéis de cada subsistema (Frota, 2007; Pereira, 2005; Preto, 2001). Esse processo, vivenciado concomitantemente à maternidade, torna-se ainda mais intenso.

Vale lembrar que em um sistema familiar, segundo os fundamentos da Teoria Sistêmica, existem três subsistemas básicos: o subsistema conjugal (refere-se ao casal); o subsistema parental (refere-se à dinâmica entre pais e filhos); e o subsistema fraternal (refere-se à dinâmica entre os irmãos). As díades familiares formadas também são consideradas subsistemas, como exemplo, esposa-esposo, mãe-filho, pai-filho, avó-neto, entre outros. Assim, cada membro pertence a diferentes subsistemas, que influenciam e são influenciados pelos outros, seja na interação entre eles ou mesmo com os sistemas extrafamiliares. Entre um subsistema e outro existe a frontei$r a$, que delimita quem participa e como participa daquele subsistema. Tal fronteira deve ser clara, para que exista uma boa comunicação entre seus membros (Minuchin, 1982; Relvas, 1996; Silva \& Salomão, 2003).

Desse modo, é relevante considerar o aumento no número de possíveis relações diádicas e de subsistemas maiores na família (Férez-Carneiro, 1996) e o consequente modo de funcionamento das 
interações entre os membros do sistema familiar de mães adolescentes. Tais interações foram subdivididas em categorias por FérezCarneiro (idem), sendo que neste estudo serão utilizadas dez delas para análise: comunicação, papéis, regras, liderança, agressividade, conflito, afeição, individuação, integração e autoestima.

Para o bom funcionamento do sistema familiar, a comunicação deve ser clara, congruente e com direcionalidade, pois define a natureza das relações entre os envolvidos, além de permitir que se compartilhem informações entre eles. As regras devem ser explícitas, coerentes e flexíveis, compartilhadas por pelo menos dois membros do sistema familiar, direcionando as ações ao grupo. Os papéis devem definir as funções de cada membro dentro do sistema, clareando os limites entre os subsistemas. A liderança requer que os papéis sejam claros, portanto, não deve ser invertida, de modo que os filhos aceitem o posicionamento dos pais enquanto figuras de autoridade, e estes, por sua vez, devem fazer uso da autoridade, mas não de forma autoritária. Os conflitos são importantes para promover a busca pelo equilíbrio entre os subsistemas, devendo existir também a busca pela solução, visando o desenvolvimento construtivo do grupo. A agressividade diz respeito ao modo como os membros expressam os seus sentimentos, podendo ou não ser destrutiva; todavia, torna-se construtiva quando a família facilita e promove o crescimento uns dos outros. A afeição é importante, pois propicia o desenvolvimento do potencial afetivo dos membros, e, portanto, o desenvolvimento emocional saudável do sistema, ao mesmo tempo em que promove a formação da identidade pessoal. A individuação é importante para que cada membro da família mantenha sua identidade, de modo que haja, no sistema familiar, o respeito às diferenças e às discordâncias entre seus membros, possibilitando a manifestação de opiniões divergentes. A integração permitirá que a família aja em grupo, de acordo com uma identidade grupal, buscando soluções para os problemas e caminhos para o alcance de objetivos comuns, embora cada membro tenha sua individualidade. E, por fim, a autoestima promoverá o crescimento de cada membro, o que o 
levará a realizar-se e a valorizar os outros membros, promovendo a autoestima de todo o sistema (idem, ibidem).

De modo resumido, o Quadro 1 apresenta as dimensões interacionais e o modo de funcionamento que poderá promover uma boa dinâmica familiar.

Quadro 1 - Dimensão interacional e modo de funcionamento segundo Férez-Carneiro (1996).

Dimensão interacional Modo de funcionamento

1 Comunicação Clara; congruente; com direcionalidade.

2 Regras Explícitas; coerentes; flexíveis.

3 Papéis Claros, definindo as funções de cada membro.

4 Liderança Papéis claros; hierarquizada, ou seja, de pais para os filhos.

5 Conflitos Devem ser sanados mediante a busca por soluções.

6 Agressividade Construtiva, visando crescimento dos membros.

7 Afeição Deve existir; promove desenvolvimento saudável.

8 Individuação Necessária; com respeito a diferenças e discordâncias.

9 Integração Importante para a busca de resolução dos conflitos.

10 Autoestima Importante para promover o crescimento individual e de cada membro.

Para investigar tais dimensões interacionais junto a dez mães adolescentes, foram utilizados instrumentos de investigação como o Teste do Desenho da Família (Corman, 1979; Retondo, 2000), com adaptação de Valle (2000) - Teste de Desenho em Cores da Família (TDCF), e um questionário complementar ao teste, sendo que a abordagem sistêmica subsidiou a presente investigação, auxiliando na compreensão das dimensões interacionais que regem a dinâmica familiar dessas participantes.

Estudos que focam a dinâmica familiar de mães adolescentes com o uso do TDCF são raros, mas há várias pesquisas que utilizaram esse instrumento com populações diferenciadas para buscar a compreensão das dimensões interacionais. 
Peçanha \& Lacharité (2007) testaram a validade de constructo e a validade do protocolo de Avaliação Familiar Sistêmica (AFS) com a participação de 11 crianças brasileiras com asma e 14 sem a doença. Os materiais utilizados foram o protocolo AFS, o TDCF e um roteiro de entrevista semiestruturada. Os resultados de comparações feitas entre os dois grupos de crianças mostraram que as dimensões interacionais mais afetadas nas famílias de crianças asmáticas foram individuação, conflitos, integração, coesão, papéis e liderança.

Neuber et al. (2008) objetivaram investigar os componentes emocionais e as dificuldades envolvidas na dinâmica familiar de adolescentes portadores de deficiência auditiva, para tanto utilizaram o TDCF. Participaram do estudo oito adolescentes de ambos os sexos e seus pais, somando 24 participantes. Como resultado, encontraram dificuldades em algumas das dimensões interacionais, quer sejam, comunicação, conflitos, afeição e integração.

Panosso \& Peçanha (2009) trabalharam com cinco famílias com filhos adolescentes usuários de drogas. Objetivaram investigar o papel que a drogadição desempenha no contexto familiar. Os instrumentos utilizados foram a Entrevista Familiar Estruturada (EFE), o TDCF e uma entrevista semidirigida. Os resultados mostraram que as famílias apresentavam disfuncionalidade em relação à integração, à autoestima (baixa), à definição de papéis, na integração e na explicitação das regras, sendo também evidenciadas dificuldades na expressão de conflitos e agressividade.

Vicentin \& Valle (2009) desenvolveram estudo com 15 crianças do sexo feminino com idades entre seis e dez anos e suas respectivas mães, somando trinta participantes, sendo as crianças vítimas de violência sexual praticada pelo pai. Objetivaram identificar variáveis que pudessem comprometer os processos funcionais da dinâmica de famílias permeadas por violência sexual. Os materiais utilizados foram um roteiro de entrevista (realizada com as mães) e o TDCF (realizado com as mães e as crianças). Os resultados mostraram que a dinâmica familiar é permeada por dificuldades nas seguintes $d i$ mensões interacionais: comunicação, conflitos, afeição, integração e autoestima. 
Tais estudos, embora com população diferenciada em relação a este, com problemáticas distintas, mas também desencadeadas pelo ciclo vital de cada família, que enfrentam constantes desafios ao longo da sua existência devido ao dinâmico processo do desenvolvimento de seus membros, mostram que são múltiplos os fatores que levam um grupo familiar a perder seu equilíbrio. Todo contexto familiar que é afrontado por estímulos externos a ponto de desestabilizá-lo merece ser analisado, como é o presente caso: o interesse pela investigação com a população de mães adolescentes. Este estudo qualitativo objetivou, portanto, descrever a dinâmica familiar de mães adolescentes de acordo com suas percepções, enfocando as dimensões interacionais familiares utilizando-se do instrumento TDCF.

A compreensão da dinâmica em família dessas pessoas em uma nova constituição familiar com a presença do bebê poderá facilitar o desenvolvimento de programas que visem a qualidade de vida dessa população que vivencia o fenômeno da gravidez não planejada na adolescência, primando pelo desenvolvimento saudável do bebê e da família. Facilitará também o desenvolvimento de programas de educação sexual formal que visem a prevenção da gravidez não planejada na adolescência.

\section{Método}

Para a seleção das participantes foram utilizados os seguintes critérios de inclusão: a) que a mãe adolescente fosse também participante do projeto de extensão "Mães adolescentes: projetos de vida", que ocorre nas dependências do CPA Bauru; b) ter idade entre 12 e 18 anos, caracterizando o período adolescente conforme o Estatuto da Criança e do Adolescente, Lei n 8.069, de 13 de julho de 1990, artigo $2^{\circ}$, título $1^{\circ}$. Desse modo, participaram do estudo dez mães adolescentes, cuja caracterização encontra-se no Quadro 2. 
Quadro 2-Caracterização das participantes.

\begin{tabular}{|c|c|c|c|c|c|c|}
\hline Participante & Idade & $\begin{array}{c}\text { Idade } \\
\text { do bebê }\end{array}$ & Religião & Escolaridade & $\begin{array}{c}\text { Renda } \\
\text { familiar }\end{array}$ & $\begin{array}{c}\text { Constituiu } \\
\text { nova família? }\end{array}$ \\
\hline P1 & 18 & Dois meses & Católica & $\begin{array}{l}\text { Ensino Médio, } \\
\text { cursando }\end{array}$ & $\begin{array}{c}\text { Entreum e três } \\
\text { SM }\end{array}$ & Não \\
\hline $\mathbf{P} 2$ & 18 & Quatro meses & Católica & $\begin{array}{l}\text { Ensino Médio } \\
\text { incompleto }\end{array}$ & $\begin{array}{c}\text { Entreum e três } \\
\text { SM }\end{array}$ & Sim \\
\hline P3 & 17 & Sete meses & Católica & $\begin{array}{c}\text { Ensino Médio } \\
\text { completo }\end{array}$ & $\begin{array}{c}\text { Menos deum } \\
\text { SM }\end{array}$ & Sim \\
\hline P4 & 17 & Nove meses & Evangélica & $\begin{array}{l}\text { Ensino Médio } \\
\text { completo }\end{array}$ & $\begin{array}{c}\text { Menos deum } \\
\text { SM }\end{array}$ & Sim \\
\hline P5 & 18 & Dez meses & Evangélica & $\begin{array}{l}\text { Ensino Fundamental } \\
\text { completo }\end{array}$ & $\begin{array}{c}\text { Menos deum } \\
\text { SM }\end{array}$ & Não \\
\hline P6 & 17 & Quinze dias & Evangélica & $\begin{array}{l}\text { Ensino Médio } \\
\text { incompleto }\end{array}$ & $\begin{array}{c}\text { Entreum e três } \\
\text { SM }\end{array}$ & Não \\
\hline P7 & 18 & Quarenta dias & Católica & $\begin{array}{c}\text { Ensino Médio } \\
\text { completo }\end{array}$ & $\begin{array}{c}\text { Entretrês e seis } \\
\text { SM }\end{array}$ & Não \\
\hline P8 & 15 & Quatro meses & Católica & $\begin{array}{l}\text { Ensino Fundamental } \\
\text { completo }\end{array}$ & $\begin{array}{c}\text { Entreum e três } \\
\text { SM }\end{array}$ & Não \\
\hline P9 & 17 & Dois meses & Sem religião & $\begin{array}{l}\text { Ensino Médio } \\
\text { incompleto }\end{array}$ & $\begin{array}{c}\text { Entreum e três } \\
\text { SM }\end{array}$ & Não \\
\hline P10 & 15 & 43 dias & Evangélica & $\begin{array}{l}\text { Ensino Fundamental } \\
\text { incompleto }\end{array}$ & $\begin{array}{c}\text { Entreum e três } \\
\text { SM }\end{array}$ & Sim \\
\hline
\end{tabular}


Como já descrito, para a investigação das dimensões interacionais junto às dez mães adolescentes, foram utilizados como instrumentos: a) o Teste do Desenho da Família (Corman, 1979; Retondo, 2000), com adaptação de Valle (2000) - TDCF; b) um questionário complementar ao teste. A abordagem sistêmica auxiliou na compreensão das dimensões interacionais que regem a dinâmica familiar dessas participantes.

O instrumento TDCF subdivide-se na aplicação do desenho e de um questionário, um complementando o outro, e será descrito a seguir.

a) O Teste do Desenho da Família (Corman, 1979; Retondo, 2000), com adaptação de Valle (2000), é uma técnica projetiva que inclui o uso de cores para a pintura das figuras realizadas -TDCF. Foi aplicado individualmente, sendo disponibilizados à participante: folha em branco (tipo A4), lápis preto, borracha e 12 lápis coloridos.

b) O questionário com questões a respeito da dinâmica familiar é fundamentado na Teoria Sistêmica (Minuchin, 1982) e é composto por 24 perguntas a respeito das interações familiares vivenciadas pela participante. Tais questões visam auxiliar a verbalização dos relacionamentos e das interações familiares.

Para a coleta de dados, as participantes foram convidadas a participar do estudo, recebendo inicialmente todos os esclarecimentos que a ética em pesquisa exige e contidos no Termo de Consentimento Esclarecido. Vale ressaltar que a proposta deste estudo foi encaminhada ao Comitê de Ética em Pesquisa da Faculdade de Ciências da Unesp, campus de Bauru - SP, em respeito às normas do Conselho Nacional de Saúde, que visa autorização para o estudo com seres humanos, recebendo parecer favorável sob processo $n^{\circ}$ 953/46/01/09.

A coleta de dados ocorreu nas dependências do Centro de Psicologia Aplicada (CPA) da Unesp - Bauru. A aplicação dos instrumentos ocorreu de forma individual, cumprindo a mesma ordem de aplicação: TDCF e o questionário.

Para a análise dos dados, obedeceu-se aos parâmetros de avaliação do referido teste psicológico com base em pesquisadores específicos (Corman, 1979; Cunha, 2000; Hammer, 1991; Ocampo, 
1995; Retondo, 2000). Em relação aos dados obtidos com as respostas dadas ao questionário, estes foram analisados com base nos fundamentos da Abordagem Sistêmica, especialmente pelos conteúdos contidos nas dez categorias interacionais propostas por Férez-Carneiro (1996) e pelas análises propostas por Peçanha (1997) e Valle (2000).

\section{Resultados}

\section{Caracterização das mães adolescentes}

Os resultados mostram que a população estudada tem média de idade de 17 anos, com bebês de 123,8 dias de média de idade, ou seja, quatro meses e 13 dias. A religião é a católica ou a evangélica, tendo como escolaridade predominante o Ensino Médio completo e o incompleto. A renda familiar compreende a faixa entre um e três salários mínimos, sendo que seis das dez participantes não constituíram nova família, continuando agregadas, portanto, às suas famílias de origem.

\section{Análise das dimensões interacionais da família}

Em relação às dimensões interacionais da família, o Quadro 3 apresenta, de modo geral, os resultados encontrados. Em seguida é apresentada separadamente cada dimensão investigada.

Quadro 3 - Frequência absoluta das dimensões interacionais da família.

Dimensões interacionais da família

Comunicação
Inadequada

Sem problemas
Frequência absoluta 
164 TÂNIA GRACY MARTINS DO VALLE E LÍGIA EBNER MELCHIORI (ORGS.)

Continuação

\begin{tabular}{|c|c|c|c|}
\hline \multicolumn{3}{|c|}{ Dimensões interacionais da família } & $\begin{array}{c}\begin{array}{c}\text { Frequência } \\
\text { absoluta }\end{array} \\
2\end{array}$ \\
\hline Regras & $\begin{array}{l}\text { Autoritária } \\
\text { Omissas } \\
\text { Sem problemas }\end{array}$ & & $\begin{array}{l}2 \\
1 \\
7\end{array}$ \\
\hline Papéis & $\begin{array}{l}\text { Indiferenciados } \\
\text { Sem problemas }\end{array}$ & & $\begin{array}{l}4 \\
6\end{array}$ \\
\hline Liderança & $\begin{array}{l}\text { Casal } \\
\text { Ego } \\
\text { Companheiro } \\
\text { Mãe } \\
\text { Pai } \\
\text { Bebê }\end{array}$ & & $\begin{array}{l}2 \\
2 \\
1 \\
2 \\
2 \\
1\end{array}$ \\
\hline Conflitos & $\begin{array}{l}\text { Sem busca de sol } \\
\text { Com busca de sol }\end{array}$ & & $\begin{array}{l}7 \\
3\end{array}$ \\
\hline Agressividade & $\begin{array}{l}\text { Destrutiva } \\
\text { Sem problemas }\end{array}$ & & $\begin{array}{l}1 \\
9\end{array}$ \\
\hline Afeição & $\begin{array}{l}\text { Figura preferida } \\
\text { Figura rejeitada }\end{array}$ & $\begin{array}{l}\text { Companheiro } \\
\text { Mãe } \\
\text { Bebê } \\
\text { Ego } \\
\text { Companheiro } \\
\text { Mãe } \\
\text { Pai } \\
\text { Outros }\end{array}$ & $\begin{array}{l}2 \\
2 \\
9 \\
2 \\
2 \\
1 \\
3 \\
2\end{array}$ \\
\hline Individuação & $\begin{array}{l}\text { Presente } \\
\text { Dificultada }\end{array}$ & & $\begin{array}{l}7 \\
3\end{array}$ \\
\hline Integração & $\begin{array}{l}\text { Não gratificante } \\
\text { Gratificante }\end{array}$ & & $\begin{array}{l}5 \\
5\end{array}$ \\
\hline Autoestima & $\begin{array}{l}\text { Baixa } \\
\text { Alta }\end{array}$ & & $\begin{array}{l}5 \\
5\end{array}$ \\
\hline
\end{tabular}




\section{Análise das categorias investigadas}

\section{Comunicação}

A comunicação mostrou-se inadequada para sete das participantes (P1, P2, P4, P6, P7, P8 e P9). Duas delas constituíram nova família (P2 e P4), demonstrando que a busca pela reestruturação familiar pode estar gerando dificuldades na comunicação. As participantes P3, P5 e P10 mostraram que não têm problemas na comunicação dentro do sistema familiar, sendo que uma delas não constituiu nova família (P5).

\section{Regras}

As regras mostram-se sem problemas para sete das participantes (P1, P2, P4, P5, P7, P9 e P10), omissas para P3 e autoritárias para P6 e P8, sendo que ambas não constituíram novas famílias, continuaram agregadas às suas famílias de origem. Para P6, a figura materna é quem dita as regras no sistema familiar, e para P8 é a figura paterna.

\section{Papéis}

A distribuição de papéis é indiferenciada para P2, P6, P7 e P8, sendo que o conflito entre ser filha e mãe aparece como um dificultador na distribuição dos novos papéis e na formação de novas fronteiras, muitas vezes a avó assumindo o bebê como se fosse mãe, havendo, portanto, a confusão no papel de mãe para a participante. Por outro lado, seis das participantes (P1, P3, P4, P5, P9 e P10) demonstram que a distribuição dos papéis ocorre sem problemas.

\section{Liderança}

Os membros familiares distribuem-se nessa função, sendo que até mesmo o bebê aparece como líder do sistema familiar (P1). Outros 
membros também aparecem como líderes no sistema familiar, tais como o companheiro (P2), o casal (P3 e P10), a figura do Ego (P4 e $\mathrm{P} 5)$, a mãe (P6 e P7) e o pai (P8 e P9). Veja a figura 1.

\section{Conflitos}

Os conflitos estão presentes e denotam a falta de busca por soluções para sete das dez participantes (P1, P2, P4, P5, P6, P8 e P9). Para $\mathrm{P} 2$, os conflitos relacionam-se mais diretamente na relação com o bebê, e P4 expressa conflitos em sua nova constituição familiar. Outros conflitos aparecem, todavia, o sistema familiar parece buscar a solução para as dificuldades (P3, P7 e P10).

\section{Agressividade}

Esta dimensão interacional apareceu somente para uma das participantes (P8), que relatou "medo" em deixar o bebê com algum subsistema da família: "tenho medo que alguém bata ou judie dela" (P8). Todavia, não apareceu em seu TDCF, enquanto forma gráfica projetada, estando presente apenas na resposta ao questionário a respeito do desenho

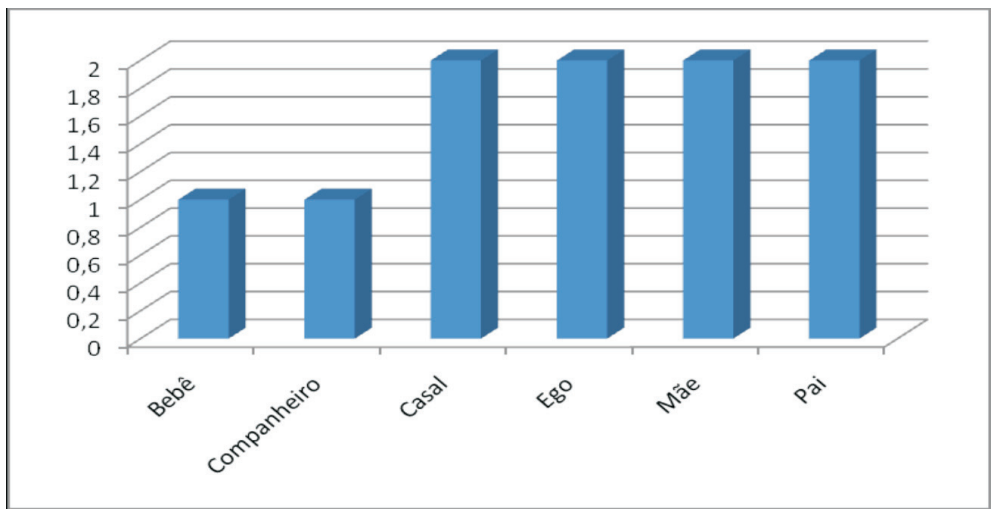

Figura 1 -Dimensão interacional: Liderança. 


\section{Afeição}

De modo geral, a afeição da mãe adolescente está voltada para o novo membro da família, ou seja, o bebê. Somente as participantes $\mathrm{P} 3$ e $\mathrm{P} 5$ acrescentam como figura preferida o companheiro. Para P7, a mãe é sua figura preferida, relatando sobre o bebê que "eu amo ela, gosto muito dela, mas ainda é novidade. Mas a minha mãe, [temos] a vida juntas, é diferente". Como figura rejeitada, portanto, com menos afeição por parte da figura do Ego, aparecem a própria mãe adolescente (P3 e P4), o pai e a mãe (P6), o pai (P8 e P9) e o companheiro (P8 e P10). Veja a figura 2.

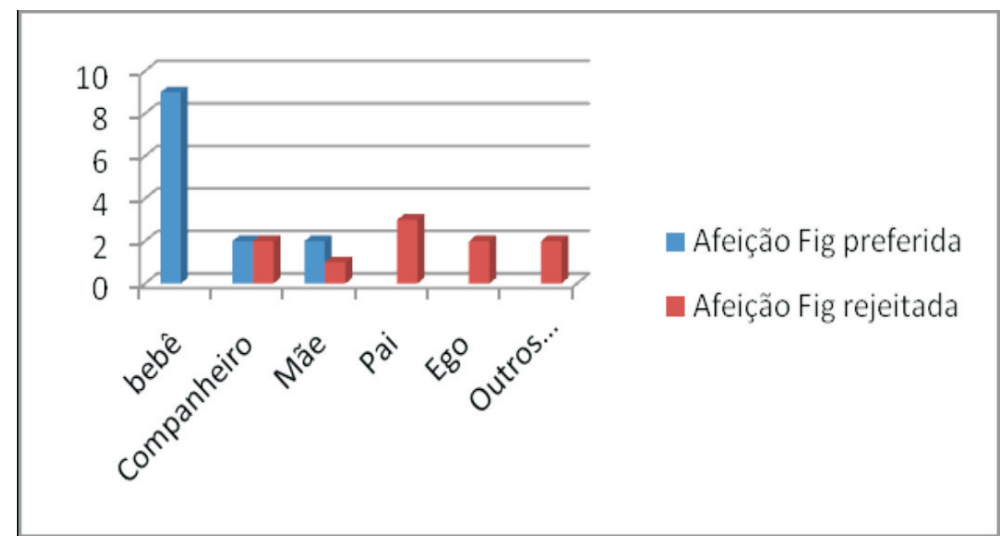

Figura 2-Dimensão interacional: Afeição.

\section{Individuação}

A individuação está presente para sete das dez participantes (P1, P2, P3, P4, P5, P9 e P10), contudo aparece dificultada para P6, P7 e P8.

\section{Integração}

A integração aparece como não gratificante, em especial para as mães adolescentes que continuaram agregadas à sua família de ori- 
gem (P1, P6, P8, e P9). Para P4, a integração também não é gratificante, sendo gratificante para P2, P3, P5, P7 e P10.

\section{Autoestima}

A autoestima é baixa para metade das participantes (P2, P4, P5, P7 e P9) e alta para a outra metade (P1, P3, P6, P8 e P10).

Resumidamente, os resultados mostram a seguinte dinâmica familiar entre essas dez mães adolescentes, descrita no quadro 4.

Quadro 4 - Situação da dinâmica interacional das participantes mães adolescentes.

\begin{tabular}{ll}
\hline Dinâmica interacional & Situação desta dinâmica \\
\hline Comunicação & Inadequada \\
\hline Regras & $\begin{array}{l}\text { Autoritárias para a mãe adolescente que não } \\
\text { constituiu nova família }\end{array}$ \\
\hline Papéis & Indiferenciada \\
\hline Liderança & Varia entre os diferentes membros \\
\hline Conflitos & Presentes e sem busca de solução \\
\hline Afeição & Voltada para o bebê \\
\hline Integração & Dificultada \\
\hline Autoestima & Variando entre baixa e alta \\
\hline
\end{tabular}

\section{Discussão}

Os resultados mostram a dificuldade das mães adolescentes em posicionar-se na nova estrutura familiar. Agregadas às suas famílias de origem, onde a estrutura familiar já está estabelecida, torna-se difícil no subsistema parental a entrada de novo membro com a for- 
mação de novo subsistema (mãe-bebê) em que a mãe adolescente já não é somente filha, mas também mãe.

A adolescência em si, por ser um período de grandes mudanças, sejam fisiológicas, em decorrência da puberdade, ou mesmo emocionais, em decorrência de fatores sociais e culturais (Frota, 2007; Heilborn et al., 2006; Kahhale, 2001; Maia, 2009; Pereira, 2005; Preto, 2001; Rangel, 1999), provoca dificuldades para o funcionamento familiar, trazendo conflitos que requerem novo posicionamento de seus membros e novo funcionamento de todo o sistema (Benoit et al., 1988; Lourenço, 1998; Minuchin, 1982). Quando a ela, como fase de transição na família (Benoit et al., 1988; Minuchin, 1982), é agregada a maternidade, também uma fase de transição, as dificuldades tornam-se maiores e demandam maior energia de todos os envolvidos no sistema familiar, em especial quando a adolescente não constitui nova família e o bebê torna-se um novo membro. Isto posto, formam-se outros subsistemas familiares, seja: mãe-bebê, avó-neto, avô-neto, irmão-bebê, entre outros (Minuchin, 1982; Relvas, 1996; Silva \& Salomão, 2003).

A ocorrência da gravidez não planejada altera a dinâmica familiar e provoca, muitas vezes, conflitos com os quais as famílias nem sempre sabem lidar (Lourenço, 1998; Minuchin, 1982; Santos \& Schor, 2003; Zeck et al., 2007). Nesse aspecto, observando as dimensões interacionais, os resultados podem confirmar tal informação.

De modo geral, a comunicação é inadequada. As regras são autoritárias somente quando a mãe adolescente não constituiu nova família e ainda tem o agravante da comunicação dificultada. A distribuição de papéis é indiferenciada, sendo que o conflito entre o subsistema parental e a nova função da maternidade mostra-se como um entrave para a reestruturação familiar. A liderança varia entre os diferentes membros, sendo que até mesmo o bebê aparece como líder, em uma função invertida, mas compreendida na fase que a família vivência, ou seja, um novo membro adentrando o grupo familiar e que exige uma redistribuição nos papéis e na função de cada um, em especial quando a participante não constituiu nova família. Os conflitos estão presentes e denotam a falta de busca por soluções, 
em especial, também, para as mães adolescentes que não constituíram nova família, sendo que os conflitos ocorrem na relação familiar com os outros subsistemas que coabitam, ou seja, com os pais, irmãos e sobrinhos. A agressividade mostrou-se presente somente para uma das participantes, em uma dinâmica familiar em que o pai é relatado como muito autoritário. A afeição da mãe adolescente está voltada para o novo membro da família, ou seja, o bebê. Outras figuras rejeitadas aparecem em outros membros familiares (pai, companheiro, Ego, mãe e outros). A integração aparece dificultada, novamente, para as participantes que não constituíram nova família, e a autoestima é baixa para a metade das participantes, independente de ter ou não constituído nova família.

Vale ressaltar a importância, apontada por Férez-Carneiro (1996), de estas dimensões estarem congruentes para um bom funcionamento do sistema familiar, em que a comunicação deve ser clara; as regras, explícitas; os papéis, bem definidos; a liderança, exercida pela figura de autoridade, buscando uma integração que vise a resolução de conflitos, permeada pela afeição entre os membros, deste modo, resultando na promoção de alta autoestima para todos os membros do sistema familiar.

As dimensões interacionais mostram o funcionamento da estrutura familiar, a dinâmica que ocorre dentro do sistema. Assim, são preocupantes as interações que são apresentadas pelas participantes deste estudo, pois mostram que a família está encontrando dificuldades em reorganiza-se a partir da chegada do bebê, filho de mães adolescentes.

Não foram encontrados estudos que utilizaram os métodos de investigação junto à mesma população de mães adolescentes para a comparação dos dados obtidos. Todavia, os estudos de Peçanha \& Lacharité (2007), Neuber et al. (2008), Panosso \& Peçanha (2009) e Vicentin \& Valle (2009) mostraram famílias com características diferenciadas (crianças com asma, adolescentes com deficiência auditiva, adolescentes usuários de drogas e crianças que sofreram violência sexual) que, embora apresentem disfunções em relação às dimensões de interação, não mostraram como resultado oito das di- 
mensões com disfunção. Este resultado é bastante preocupante: à medida que mais uma pessoa ingressa no sistema familiar (o bebê), já vivenciará o desenvolvimento dentro de um contexto que apresenta disfunções.

Assim, refletir como a mãe adolescente poderá subsidiar o desenvolvimento saudável de seu bebê é relevante, uma vez que ela encontra-se, muitas vezes, sem parâmetros para assumir o seu papel como mãe, seja em uma família constituída, ou mesmo naquela à qual continuou agregada. A ocorrência da gravidez não planejada requer novos posicionamentos por parte de todos os envolvimentos, pois gera um aumento na tensão familiar na busca por um novo funcionamento, devendo ser consideradas as várias relações entre os subsistemas formados (Manriquez \& Le-Bert, 1994; Minuchin, 1982; Motta et al., 2004; Pereira \& Piccinini, 2007; Preto, 2001; Vasconcellos, 2002), em especial quando existe uma coesão muito grande entre mãe e filha, que poderá dificultar a formação da nova díade mãe-bebê, visto que o papel de mãe parece confundir-se com o papel de filha, assim como o de avó parece confundir-se com o de mãe (Fonseca, 2008; Reis, 2009).

\section{Considerações finais}

A dinâmica familiar das mães adolescentes participantes deste estudo apresenta conflitos na relação com o bebê, dificuldades em assumir a maternidade devido às interferências de outros membros na relação mãe-bebê, relacionamento conflituoso com o companheiro para aquelas que constituíram novo sistema familiar e, ainda, dificuldades em agregar novos papéis à sua nova condição de mãe.

Em relação às dimensões interacionais, as participantes expressam que a comunicação é inadequada; as regras são autoritárias para a mãe adolescente que não constituiu nova família e que tem como agravantes as dificuldades na comunicação; a distribuição dos papéis é indiferenciada; a liderança é exercida por diferentes membros; os conflitos estão presentes e caracterizam-se pela não busca de solu- 
ções; a afeição é voltada para o bebê; a integração encontra-se dificultada; e a autoestima varia entre baixa e alta.

A vivência da maternidade não planejada na adolescência agrava a reestruturação familiar necessária para uma nova etapa da vida, que é a adolescência. As famílias encontram dificuldades para o enfrentamento de duas fases de transição concomitantes (adolescência e maternidade), resultando em uma dinâmica familiar conflituosa.

O desenvolvimento de programas de apoio às famílias que vivenciam tal fenômeno mostra-se necessário, o que poderia construir parâmetros norteadores para facilitar a reestruturação familiar e a definição de papéis dos membros envolvidos, construindo fronteiras claras de relacionamento, bem como para auxiliar na formação da nova díade mãe-bebê.

Enfim, a ocorrência da gravidez na adolescência, seja planejada ou não, requer o desenvolvimento de programas que visem a qualidade de vida na adaptação dessas famílias, oportunizando o desenvolvimento saudável do bebê e de todo o sistema familiar. Ressaltase a necessidade de outras pesquisas que poderiam elucidar melhor tais achados, como aquelas que tenham como população mães adolescentes com filhos mais velhos; comparação estatística, portanto com maior amostra, entre mães adolescentes que constituíram novo sistema familiar e entre aquelas que não constituíram; e comparação entre famílias com mães adolescentes e famílias com mães adultas, ambas com bebês, visando verificar as dimensões interacionais de uma e de outra.

\section{Referências bibliográficas}

ALMEIDA, J. M. R. Adolescência e maternidade. Lisboa: Fundação Calouste Gulbenkian, 2003.

ATLAS RACIAL BRASILEIRO. 2004. Organização Panamericana de Saúde. Disponível em: <www.opas.org.br/familia>. Acesso em: 13 jul. 2009.

BENOIT, J. C. et al. Dictionnaire clinique des Thérapies Familiales Systémiques. Paris: ESF, 1988. 
BERQUIÓ, E. Sexo Ė vida: panorama da saúde reprodutiva no Brasil. Campinas: Unicamp, 2003.

CORMAN, L. O Teste do Desenho da Família. São Paulo: Mestre Jou, 1979.

CUNHA, J. A. Psicodiagnóstico. 5.ed. rev. Porto Alegre: Artes Médicas Sul, 2000.

FÉREZ-CARNEIRO, T. O papel da família na promoção da saúde mental. Revista de Psicologia Hospitalar. v.12, n.2, p.4-9, 1996.

FONSECA, M. S. Mães adolescentes: estrutura e funcionamento familiar. Dissertação (mestrado em Psicologia do Desenvolvimento e Aprendizagem). Faculdade de Ciências da Unesp, Bauru, 2008. $180 f$.

FROTA, A. M. M. C. Diferentes concepções da infância e da adolescência: a importância da historicidade para a sua construção. Estudos e Pesquisas Em Psicologia. UERJ-RJ. v.7, n.1, ${ }^{\circ}$ sem. 2007.

HAMMER, E. F. Aplicações clínicas dos desenhos projetivos. São Paulo: Casa do Psicólogo, 1991.

HEILBORN, M. L. et al. O aprendizado da sexualidade: reprodução e trajetórias sociais de jovens brasileiros. Rio de Janeiro: Garamond, 2006.

KAHHALE, E. M. P. Subsídeos para reflexão sobre sexualidade na adolescência. In: BOCK, A. M. B.; FURTADO, O.; TEIXEIRA, M. L. T. Psicologia sócio-histórica: uma perspectiva crítica em psicologia. São Paulo: Cortez, 2001, p.179-91.

LOURENÇO, M. M. C. Textos e contextos da gravidez na adolescência: a adolescente, a família e a escola. Lisboa: Fim de Século, 1998.

MAIA, A. C. B. Reflexões sobre sexualidade na adolescência. Revista Psicopedagogia Educação e Saúde Mental. Disponível em: $<\mathrm{w} w \mathrm{w}$. p s i copedagogia.com.br/a r tigos / artigo.asp?entrID=947\&or=bol_280507>. Acesso em: 04 set. 2007.

MANRIQUEZ, I. P.; LE-BERT, C. Q. Respostas à gravidez entre adolescentes chilenas de estratos populares. In: COSTA, A. O.; AMADO, T. Alternativas escassas: saúde, sexualidade e reprodução na América Latina. Rio de Janeiro: Editora 34; Fundação Carlos Chagas, 1994, p.11-46.

MINISTÉRIO DA SAÚDE. Secretária de Políticas de Saúde. Departamento de atenção Básica. Parâmetros para programação das ações 
básicas de saúde. 2001. Disponível em: <www.opas.org.br/servico/ arquivos/Sala5406.pdf>. Acesso em: 25 abr. 2007.

MINUCHIN, S. Familias: funcionamento e tratamento. Porto Alegre: Artes Médicas, 1982.

MOTTA, M.G.C. et al. Vivências da mãe adolescente e sua família. Acta Scientiarum. Health Sciences. Maringá, v.26, n.1, p.249-56, 2004.

NEUBER, L. M. B.; VALLE, T. G. M.; PALAMIN, M. E. G. O adolescente e a deficiência auditiva: as relações familiares retratadas no teste do desenho em cores da família. Rev. bras. crescimento desenvolv. hum. São Paulo, v.18, n.3, p.321-38, dez. 2008.

OCAMPO, M. L. S. et al. O processo psicodiagnóstico e as técnicas projetivas. São Paulo: Martins Fontes, 1995.

ORGANIZAÇÃO PAN-AMERICA DE SAÚDE. OPAS/OMS. Saúde integral do adolescente e do jovem. Disponível em: $<$ www.opas.org.br/familia/temas.cfm?id=72\&area=Conceito $>$. Acesso em: 25 abr. 2007.

1998. A saúde no Brasil. Disponível em: <www.opas.org.br/ sistema/arquivos/SAUDEBR.PDF>. Acesso em: 25 abr. 2007.

PANOSSO, I. R.; PEÇANHA, D. L. A dinâmica familiar do adolescente usuário de drogas (Resumo expandido). Ufscar, S/D. Disponível em: <www.ufscar.br/ bdsepsi/dor_pec_res_8.pdf > . Acesso em: 06 nov. 2009.

PEÇANHA, D. L. A reciprocidade de desenvolvimento entre a criança com asma e sua família. Tese (doutorado). Instituto de Psicologia. Universidade de São Paulo, São Paulo, 1997.

; LACHARITE, C. The systemic family assessment system: its validity with asthmatic children and their families. Psicol. estud. [online].v.12, n.3, p.503-12, 2007. Disponível em: <www.scielo.br/ scielo.php? pid=S1413-73722007000300007\&script $=$ sci_abstract\&tlng=pt>. Acesso em: 06 nov. 2009.

PEREIRA, A. C. A. O adolescente em desenvolvimento. São Paulo: Marbra, 2005.

PEREIRA, C. R.; PICCININI, C. A. O impacto da gestação do segundo filho na dinâmica familiar. Estud. psicol., Campinas, v.24, n.3, set. 2007. Disponível em: <www.scielo.br/scielo.php?script= sci_arttext\&pid=S0103-166X2007000300010\&lng= pt\&nrm=iso>. Acesso em: 24 mar. 2009. 
PRETO, N. G. Transformação do sistema familiar na adolescência. In: CARTER, B.; McGOLDRICK, M. (Orgs.). As mudanças no ciclo de vida familiar: uma estrutura para a terapia familiar. Porto Alegre: Artmed, 2001.

RANGEL, L. H. Da infância ao amadurecimento: uma reflexão sobre rituais de iniciação. Revista Interface - Comunicação, saúde e Educação. v.5, p.147-52, ago. 1999.

REIS, V. L. Aspectos psicossociais da gravidez na adolescência: relatos de mães adolescentes. Dissertação (mestrado em Psicologia do Desenvolvimento e da Aprendizagem). Faculdade de Ciências da Unesp, Bauru, 2009.

RELVAS, A. P. O ciclo vital da família: perspectiva sistêmica. Porto Alegre: Edições Afrontamento, 1996.

RETONDO, M. F. N. G. Manual prático de avaliação do HTP (casaárvore-pessoa) e família. São Paulo: Casa do Psicólogo, 2000.

SANTOS, S. R.; SCHOR, N. Vivências da maternidade na adolescência precoce. Rev. Saúde Pública. v.37, n.1, p.15-23, fev. 2003. Disponível em: <www.scielosp.org/ scielo.php? script=sci_abstract \& pid=S 0034 89102003000100005\&nrm=iso\&tlng=pt>. Acesso em: 09 set. 2008.

SILVA, D. V.; SALOMAO, N. M. R. A maternidade na perspectiva de mães adolescentes e avós maternas dos bebês. Estud. psicol., Natal, v.8, n.1, p.135-45, 2003.

VALLE, T. G. M. Reciprocidade socioafetiva da criança com fissura lábio-palatal e sua família. Tese (doutorado). Instituto de Psicologia da Universidade de São Paulo, São Paulo, 2000.

VASCONCELLOS, M. J. E. Acompanhando as transformações do paradigma da ciência. In: Pensamento sistêmico: o novo paradigma da ciência. Campinas: Papirus, 2002, p.67-99.

VICENTIN, S. C.; VALLE, T. G. M. Relações familiares permeadas por violência sexual do pai contra a filha. In: VALLE, T. G. M. (Org.). Aprendizagem e desenvolvimento humano: avaliações e intervenções. São Paulo: Cultura Acadêmica, 2009.

ZECK, W. et al. Impact of adolescent pregnancy on the future life of young mothers in terms of social, familial, and educational changes. J Adolesc Health. v.41, n.4, p.380-8, oct. 2007. 



\title{
9 \\ FATORES DE RISCO E \\ MECANISMOS DE PROTEÇÃO EM \\ ADOLESCENTES DO SEXO FEMININO COM TRANSTORNO MENTAL ${ }^{1}$
}

\author{
Cristiane Araújo Dameto \\ Carmen Maria Bueno Neme ${ }^{3}$
}

\section{Introdução}

As condições de saúde do ser humano relacionam-se às circunstâncias de seu desenvolvimento, desde a gestação até as fases posteriores: crescimento pré-natal, condições da mãe e da criança no momento do parto, alimentação, higiene, estimulação do desenvolvimento psicomotor e cognitivo e suas relações afetivas e sociais.

A ciência do desenvolvimento busca compreender os padrões de normalidade do desenvolvimento humano, mostrando que quando as diferenças nas trajetórias são conhecidas, podem revelar o momento no qual as desordens biológicas, psicológicas ou sociais passam a interferir prejudicialmente sobre o desenvolvimento do indivíduo. O conhecimento dessas trajetórias possibilita a criação de ações preventivas no combate à instalação de patologias crônicas (Aspesi et al., 2005).

1 Este trabalho é parte de dissertação de mestrado pela faculdade de Psicologia do Desenvolvimento e da Aprendizagem da Unesp, campus de Bauru.

2 Pós-graduação em Psicologia do Desenvolvimento e da Aprendizagem da Unesp, campus de Bauru.

3 Pós-graduação em Psicologia do Desenvolvimento e da Aprendizagem da Unesp, campus de Bauru. 
Ao abordar questões polêmicas no desenvolvimento humano, tais como o conceito de normal e patológico, Aspesi et al. (idem) discutem sobre o conceito de crise ou risco. Segundo os autores, os estudos consideram condições de crise ou risco aquelas situações que desencadeiam eventos que podem prejudicar a saúde do indivíduo em relação ao ajustamento no contexto, comprometendo seu bemestar e desempenho social.

No enfrentamento de situações geradoras de alto nível de tensão, de crise ou de rupturas em seus padrões relacionais no curso da vida, o indivíduo pode expressar diferentes tipos e níveis de vulnerabilidades. Se apresentadas nos momentos de crise, tais vulnerabilidades aumentam a predisposição do indivíduo para interagir de forma menos adequada, ou disfuncional, em seu contexto. Neme (2005) aponta que a maneira como o indivíduo lida com o estresse, situações de risco ou adversidades relaciona-se positivamente ao potencial de dano desses eventos à saúde de cada um. Nesse sentido, para que as situações de risco não acarretem grande vulnerabilidade ao indivíduo, este deve desenvolver mecanismos de proteção para responder adequadamente a essas situações.

O desenvolvimento humano é permeado por diferentes situações que podem configurar-se como de crise ou risco e, segundo Knobel (1981), a adolescência é uma das mais reconhecidas e estudadas crises normativas do desenvolvimento. Knobel (idem) considera a adolescência uma síndrome normal do desenvolvimento, destacando o aspecto de contradição ao associar os conceitos de síndrome (entidade clínica) e de normalidade (fora da patologia). Ao ampliar seu conceito, em uma concepção psicodinâmica, assinala que a adolescência é vista como etapa aparentemente seminormal e semipatológica pelo fato de que as normas de conduta estão sendo, ainda, estabelecidas, manejadas e regidas pelos adultos, e sob o ponto de vista da intercorrelação das gerações é que a adolescência deve ser entendida.

$\mathrm{Na}$ adolescência, o amadurecimento físico e os conflitos emocionais associados às diferentes tarefas psicossociais levam à necessidade de reorganização da personalidade em busca de um novo equilíbrio. Nessa fase, o indivíduo vive uma situação de vulnerabilidade e 
crise, e, dependendo das condições familiares e biopsicossociais presentes, bem como da existência ou não de mecanismos de proteção, um transtorno mental pode manifestar-se. A literatura sobre os fatores de risco aponta várias experiências consideradas estressantes no desenvolvimento infantil e adolescente. Segundo Teles (2005), entre as mais citadas estão o divórcio dos pais, as perdas de entes próximos, o abuso físico e sexual, a pobreza, além das catástrofes naturais, das guerras e de outras formas de trauma.

Os fatores de risco relacionam-se a todos os eventos de vida que, quando presentes, aumentam a probabilidade de o indivíduo apresentar problemas físicos, sociais ou emocionais. Os riscos psicológicos podem mudar de acordo com o momento de vida, assim como suas consequências, não sendo possível estabelecer uma relação de causa-efeito, pois é preciso identificar os mecanismos interferentes, ligando o fator de risco à consequência, em determinado ponto da história individual. O que se destaca na resposta do indivíduo às situações que enfrenta são os níveis de exposição e os limites individuais, ou seja, sua visão subjetiva, sua percepção, sua interpretação e o sentido atribuído ao evento estressor, o que o classifica ou não como condição de risco. Sendo assim, o que para um pode ser um perigo, para outro pode ser apenas um desafio (Yunes \& Skymanski, 2001).

Ao abordar os fatores de risco no desenvolvimento, Gauy \& Costa-Júnior (2005) citam pesquisadores como Bronfenbrenner \& Ceci (1994); Oliveira (1998); Rutter et al. (1999) e Plomin (2000), indicando três grandes grupos de fatores de risco: sociais, denominados distais, que se referem a condições contextuais básicas de nutrição, moradia, lazer, escola, bem como a experiências de privação, violência e religiosidade, entre outras; familiares, denominados meioproximais, referentes a condições de interação familiar, como nível de autoridade parental, existência de transtornos mentais e/ou problemas físicos entre membros familiares e sistemas de punição/coerção física; pessoais, denominados proximais, que se referem às características do indivíduo, tais como temperamento, personalidade, percepção, habilidades cognitivas e estratégias de manejo frente a situações adversas. Os fatores de risco ambientais podem estar as- 
sociados a diversos contextos da interação indivíduo-ambiente, influenciando o funcionamento humano e os resultados comportamentais do desenvolvimento.

Para Sapienza \& Pedromônico(2005), outros fatores podem tornar o indivíduo vulnerável, como prematuridade, desnutrição, baixo peso, lesões cerebrais, atraso no desenvolvimento, desestrutura familiar, minoria social, desemprego, pobreza e dificuldade de acesso à saúde e à educação. Crianças com desvantagens socioeconômicas cujas mães sejam também jovens, solteiras e pobres ou que tenham vindo de famílias desorganizadas (riscos psicossociais), ou, ainda, crianças que tenham pais com desordens afetivas, esquizofrenia, desordens antissociais, hiperatividade, déficit de atenção e isolamento (riscos genéticos) são potencialmente vulneráveis aos eventos estressores e são consideradas crianças com risco de problemas de desenvolvimento.

Segundo Rutter (1981), as pesquisas enfatizam a importância da família, tanto na redução como no aumento dos riscos. O processo de risco envolve um funcionamento familiar complicado e tende a ocorrer em ambientes menos adequados. A interação entre vários fatores de risco no desenvolvimento da criança e as diferenças individuais pode aumentar a suscetibilidade à situação de risco.

Um estudo brasileiro sobre resiliência em adolescentes, realizado por Trombeta \& Guzzo (2002), reúne vários conceitos e contribuições de diferentes autores sobre fatores de risco e mecanismos de proteção, ressaltando as contribuições de Rutter (1987) e de Winfield (1995), que citam a pobreza crônica associada a condições de gestação e parto e a falta de acesso à escola e emprego como importantes fatores de risco. Rutter (1987) também aponta características do temperamento individual como fatores de risco, tais como baixa tolerância à frustração, mau humor, passividade, senso de inferioridade, comportamento destrutivo, baixa autoestima, hostilidade, pobre habilidade de comunicação, depressão, tentativa de suicídio, abuso de álcool ou drogas e ego frágil, inseguro e instável.

Segundo Pesce et al. (2004), os mecanismos de proteção são pontos chave para o restabelecimento do equilíbrio e para a demonstra- 
ção da presença de competências para o manejo de situações adversas ou geradoras de desequilíbrio, uma vez que defendem que há uma relação entre fatores de risco e proteção, considerando o desenvolvimento de crianças e os comportamentos resilientes na idade adulta. Quanto maior a quantidade de desvantagens e estresse acumulados ao longo da vida, maior a necessidade de fatores de proteção durante a infância e a juventude. Os adultos resilientes são mais afetuosos, ativos, de boa índole e fáceis de lidar na primeira infância, e, quando adolescentes, têm uma tendência a apresentar melhor autoconceito, maior autocontrole, mais facilidade em interagir com amigos e professores e facilidade de inserir-se em grupos.

Os mecanismos de proteção foram definidos por Rutter (1981) como sendo as influências que modificam, melhoram ou alteram respostas pessoais a determinados riscos ou desadaptação. A característica essencial desses fatores é a modificação catalítica da resposta do indivíduo à situação de risco. Esses fatores podem não apresentar efeitos na ausência de um estressor, pois seu papel é o de modificar a resposta do indivíduo em situações adversas, mais do que favorecer o desenvolvimento normal. Esse autor aponta como mecanismos de proteção as diferenças individuais geradas por fatores constitucionais e pela experiência, as experiências positivas fora de casa, a construção da autoestima, a existência de oportunidades, o nível apropriado de controle e a estrutura do meio ambiente, a aquisição de habilidades para lidar com diferentes situações e a existência de relações interpessoais positivas.

Os recursos financeiros também são ressaltados por Winfield (1995) como possível mecanismo de proteção, argumentando que sua falta é, muitas vezes, o motivo da saída da escola e da perda de outras oportunidades sociais. Rutter (1971) e Garmezy (1987)apontam como mecanismos de proteção ligados à escola a possibilidade de estabelecer relações estáveis com um adulto, as condições oferecidas para favorecer a aquisição de competências cognitivas e sociais por meio de técnicas efetivas em sala de aula, o planejamento de atividades, oportunidades para que aluno assuma responsabilidades e a manutenção de uma atmosfera pró-social. 
De acordo com Trombeta \& Guzzo (2002), a maioria dos pesquisadores divide os mecanismos de proteção em três grandes grupos de condições: individuais, familiares e ambientais. As características individuais mais citadas são: autoestima positiva; temperamento fácil e maleável ou flexibilidade; controle interno; habilidades pró-sociais e habilidades para lidar com as próprias emoções. Os mecanismos de proteção ligados às condições familiares são, de acordo com Garmezy (1991), a coesão, a estabilidade, a flexibilidade, a adaptabilidade, a consistência, a independência, a identidade própria, o respeito e ainda o fato de todos os membros compartilharem dos mesmos objetivos, expectativas, valores e crenças. Com relação às características dos pais, menciona que pais amorosos e competentes, que fazem elogios, são interessados e preocupados, participam da vida escolar dos filhos, têm expectativa positiva para o futuro dos filhos, possuem autoestima positiva e estão satisfeitos com a vida favorecem o desenvolvimento de mecanismos de proteção. Esses pais tendem a estabelecer uma boa comunicação com os filhos e a criar um clima familiar facilitador.

As condições socioambientais gerais também podem representar importantes mecanismos de proteção, e Trombeta \& Guzzo (2002) citam aspectos como comunicação aberta, oferecimento de limites definidos e realistas, tolerância aos conflitos, garantia de privacidade, demonstração de respeito, reconhecimento, aceitação, busca de reconciliação, receptividade a novas ideias e oferecimento de oportunidade de experiências de sucesso, além da possibilidade de conviver com um círculo de amigos bem estabelecidos em que o contato humano e empático acontecesse com pelo menos um adulto significativo.

Ampliando o conjunto de aspectos pesquisados sobre o desenvolvimento de mecanismos de proteção, Trombeta \& Guzzo (idem) apontam outras características que aparecem frequentemente na literatura, tais como expectativa de sucesso no futuro, senso de humor, otimismo, entusiasmo, mente aberta e receptiva a novas ideias e experiências, disciplina pessoal e responsabilidade, reconhecimento e desenvolvimento dos próprios talentos, identificação com mode- 
los positivos, busca de autonomia, capacidade de comunicar sentimentos de forma adequada, estabilidade emocional, engajamento em diferentes atividades e comportamento direcionado a metas.

Considerando que o desenvolvimento humano é um processo de aquisição cumulativa de competências cada vez mais complexas, as quais buscam atender as necessidades do organismo e as exigências do ambiente, tais competências constituem o principal resultado de um processo dinâmico de adaptação. Dada sua importância no desenvolvimento saudável, o conceito de adaptação foi escolhido por Simon (2005) para avaliar indivíduos e estabelecer diagnósticos e prognósticos, em uma proposta clinica preventiva. Por adaptação Simon (1989) entende um conjunto de respostas de um organismo vivo a situações que o modificam, permitindo a manutenção de sua organização (por mínima que seja) compatível com a vida, de tal forma que a adaptação é condição para a sobrevivência. Enquanto há vida, infere-se que há algum modo de adaptação em ação. Para ser adequada, a adaptação deve levar a novas respostas para situações sempre novas, já que na vida nada se repete.

O conjunto de condições internas e externas utilizado pelo indivíduo para lidar adaptativamente com situações de estresse ou crises normativas do desenvolvimento diminui sua vulnerabilidade a doenças físicas e mentais e, ao mesmo tempo, incrementa sua capacidade adaptativa. Ao discutir o conceito de normalidade, Knobel (1981) menciona que esse conceito está pautado na adaptação ao meio, o que não significa submissão a este, mas mostra a capacidade do indivíduo em utilizar os recursos existentes para alcançar suas satisfações básicas, em uma interação permanente que busca modificar o desagradável ou inútil e, ao mesmo tempo, encontrar substituições para o indivíduo e a comunidade.

A consulta à literatura indica escassez de estudos epidemiológicos sobre transtornos mentais na infância e na adolescência. De acordo com Kernberg et al. (2003), a pesquisa epidemiológica indica alta prevalência de transtornos de personalidade entre indivíduos na faixa etária de nove a 19 anos, embora não se encontre investigações sobre o desenvolvimento desses transtornos em jovens. Em adultos, os 
transtornos de personalidade têm sido apontados como responsáveis por profundo e contínuo impacto na vida do indivíduo.

Segundo Kernberg et al. (idem), todos os resultados de pesquisas e os achados clínicos enfatizam fatores evolutivos iniciais no desenvolvimento desses transtornos. Em função de concordâncias e discordâncias na literatura sobre o desenvolvimento de psicopatologias em crianças e adolescentes, os autores sugerem a necessidade de estudos sistemáticos em uma perspectiva evolutiva, visando identificar relações entre aspectos de personalidade e diferentes fases do desenvolvimento.

Considerando a epidemiologia de transtornos psiquiátricos por gênero e por etapa de desenvolvimento, a consulta à literatura indicou a escassez de estudos epidemiológicos sobre adolescentes. Pesquisas com adolescentes e crianças, comentadas por Andrade et al. (2006), demonstram que a maior diferença entre os gêneros na incidência da depressão manifesta-se primeiramente entre os 11 e os 14 anos, assim mantendo-se no decorrer da vida adulta, sugerindo papel importante dos hormônios sexuais, considerando que outras variações hormonais também são associadas ao humor depressivo, como no período pré-menstrual, no puerpério, na menopausa, no uso de contraceptivos orais e em terapias de reposição hormonal. Os autores apontam algumas possíveis causas relacionadas à maior incidência da depressão em mulheres, tais como pressões sociais, estresse crônico e baixo nível de satisfação associados ao desempenho de papéis tradicionalmente femininos ou devido à forma diferencial entre os gêneros de lidar com problemas e buscar soluções. As mulheres também teriam maior facilidade para identificar sintomas, admitir a depressão e buscar ajuda, comparativamente aos homens.

Em um estudo epidemiológico sobre transtornos mentais em mulheres adultas, Andrade et al. (2006) relataram que nessa etapa do desenvolvimento emergem grandes diferenças entre os gêneros com relação aos transtornos mentais. A mulher apresenta vulnerabilidade marcante a sintomas ansiosos e depressivos, especialmente associados ao período reprodutivo. A depressão é, comprovadamente, a doença que mais incapacita mulheres (duas mulheres para cada 
homem), tanto em países desenvolvidos como naqueles em desenvolvimento, sendo que o suicídio é a segunda causa de morte mundial entre mulheres na faixa etária de 15 a 44 anos de idade.

Fatores de risco associados à depressão incluem história familiar, adversidades na infância, aspectos associados à personalidade, isolamento social e exposição a experiências estressantes (idem, ibidem). Para os autores, outro quadro comum em mulheres mais jovens é a depressão atípica, caracterizada principalmente por sintomas vegetativos reversos, como hipersonia e hiperfagia. Os transtornos de ansiedade também aparecem nos estudos epidemiológicos como de maior prevalência em mulheres, e os transtornos alimentares, particularmente a anorexia e a bulimia nervosa, são causas importantes de morbidade e mortalidade em adolescentes do sexo feminino e em mulheres jovens. Esses transtornos estão associados a consequências clínicas e psicológicas devastadoras, incluindo retardo no crescimento e no desenvolvimento, infertilidade, osteoporose e morte. Tais transtornos são prevalentes em adolescentes e em adultos jovens, pertencentes a todos os grupos étnicos, sendo aproximadamente dez vezes mais comuns em mulheres do que em homens.

Tendo em vista a necessária utilização dos resultados de pesquisas sobre saúde e desenvolvimento no que se refere à possibilidade de prevenir-se doenças ou seu agravamento, considera-se relevante o conhecimento das condições que podem representar risco ao desenvolvimento, bem como a identificação das condições que podem proteger o indivíduo de tais riscos.

Dadas as possíveis relações entre fatores de risco e mecanismos de proteção e o adoecimento, a escassez de estudos sobre os transtornos mentais no desenvolvimento em adolescentes, bem como a prevalência de alguns tipos de transtornos em mulheres, o presente estudo visou investigar os possíveis fatores de risco e os mecanismos de proteção na história de vida de adolescentes do sexo feminino com diagnóstico de transtornos mentais, assim como possíveis mecanismos de proteção por elas desenvolvidos. 


\section{Método}

Nesta pesquisa qualitativa, optou-se pelo estudo de caso, considerando-se a inexistência de instrumentos destinados a esse tipo de investigação. Foram incluídos dados considerados relevantes, tais como os de identificação da família e demográficos, referentes aos transtornos mentais e aos tipos de tratamentos atuais realizados, configurando-se um conjunto de informações destinadas a revelar o mais completamente possível a condição total das participantes. Segundo Martins \& Bicudo (1989), a pesquisa qualitativa não se preocupa com generalizações, princípios e leis. A generalização é secundária e o foco da atenção é centralizado no específico, no peculiar, no individual, almejando sempre a compreensão e não a explicação dos fenômenos estudados.

A pesquisa foi realizada na cidade de Bauru, região centro-oeste do estado de São Paulo, Brasil. Foram entrevistadas 16 adolescentes do sexo feminino, na faixa etária de 14 a 18 anos, solteiras, com algum tipo de transtorno mental, realizando tratamento em um ambulatório público de saúde mental. O número de adolescentes entrevistadas que correspondiam aos critérios da pesquisa representou $80 \%$ do total de adolescentes em atendimento no Centro de Atenção Psicossocial Infantil (CAPSi) da Secretaria de Saúde do Município de Bauru, no período de setembro a outubro de 2006.

Considerou-se a faixa etária de 14 a 18 anos, de acordo com a organização de atendimentos por faixa etária do CAPSi. O critério de estado civil "solteira" foi estabelecido por avaliar-se que as experiências atuais de adolescentes casadas poderiam ser bastante diferentes das experiências das adolescentes solteiras com relação ao tema pesquisado. Foram selecionados prontuários de adolescentes solteiras, na faixa etária pretendida, com quaisquer tipos de diagnóstico de transtorno mental, em tratamento no CAPSi. Vinte pacientes preenchiam os requisitos exigidos e já estavam agendadas para consultas na instituição, sendo que 16 concordaram voluntariamente em participar. As adolescentes e seus pais assinaram Termo de Consentimento Esclarecido, conforme normas éticas em pesquisas com seres humanos. 
As entrevistas foram realizadas individualmente, com duração média de uma hora, nas dependências do ambulatório, de acordo com roteiro de entrevista elaborado para o estudo, e as respostas foram anotadas pelas entrevistadoras na presença das entrevistadas. Três auxiliares de pesquisa treinadas ${ }^{4}$ participaram da coleta de dados.

\section{Instrumentos de coleta de dados}

a) Ficha de dados do prontuário: ${ }^{\circ}$ de identificação, ano e mês de nascimento, filhos, escolaridade, profissão e ocupação atual. Dados referentes aos pais: pai (nome), idade, escolaridade, profissão e ocupação atual; mãe (nome), idade, escolaridade, profissão e ocupação atual. Dados do tratamento: início, tipo de tratamento atual, início do tratamento na instituição, medicamentos atuais. Breve histórico da doença: início (quando/como/sintomas), tratamentos já realizados (onde, quando, resultados).

b) Roteiro de entrevista clínica sobre os temas: evolução do tratamento; constituição, funcionamento e relações familiares; condições familiares no período de gestação e nascimento da paciente (o que sabe ou lembra); condições da mãe no puerpério (o que sabe ou lembra); o que sabe ou lembra sobre seus primeiros dois anos de vida; o que lembra ou sabe de sua infância dos dois aos sete anos de vida; processo de escolarização; eventos mais significativos, negativos e positivos (individuais, escolares e familiares) dos sete anos à idade atual; autodescrição (como se avalia quanto a: humor, otimismo/ pessimismo, flexibilidade/receptividade a mudanças ou ao novo, modo de enfrentar as dificuldades, interesse por atividades variadas, capacidade de reconhecer seus próprios sentimentos - raiva, medo, tristeza, afeto positivo - e comunicá-los aos outros, capacidade de estabelecer metas e cumpri-las, autoestima, autoconceito).

4 Agradecimentos especiais às auxiliares de pesquisa Fabiana Neme Nogueira Ramos, Monica Garroti Cury e Raquel Tenório dos Santos. 
Os dados anotados, obtidos nas entrevistas, foram lidos, categorizados e analisados de acordo com os conceitos de risco e de mecanismos de proteção estabelecidos por Rutter (1971, 1979, 1981, 1987, 1999), conforme os objetivos propostos. Foram quantificados os dados demográficos referentes às adolescentes, às suas famílias e ao seu históricos de vida, além dos dados relacionados aos transtornos mentais diagnosticados por profissionais do CAPSi e aos tratamentos atuais em realização pelas participantes.

\section{Resultados e discussão}

Dados demográficos:

Quanto aos dados demográficos, encontrou-se: das 16 entrevistadas, três $(18,75 \%)$ encontravam-se na faixa etária entre 14 e 15 anos (casos 6, 9, 16); dez (62,5\%), entre 15 anos e sete meses e 17 anos e seis meses (casos 2, 3, 4, 5, 7, 11, 12, 13, 14, 15); e três (18,75\%) na faixa etária entre 17 anos e sete meses e 18 anos (casos 1, 8, 10). Uma das adolescentes tinha o Ensino Fundamental completo (caso 6), e uma, o Ensino Fundamental incompleto (caso 9); 11 (68,75\%) tinham o Ensino Médio incompleto (casos 2, 3, 4, 5, 7, 11, 12, 13, 14, $15,16)$ e três $(18,75 \%)$ tinham o Ensino Médio completo (casos 1, 8, 10). Apenas três adolescentes (18,75\%) trabalhavam e estudavam (casos 6, 7, 8), e $13(81,25 \%)$ não trabalhavam, apenas estudavam (casos 1, 2, 3, 4, 5, 9, 10, 11, 12, 13, 14, 15, 16).

A faixa etária dos genitores masculinos variou de 37 a 69 anos. Um dos genitores era falecido e cerca de 50\% deles tinham de 37 a 47 anos. Sobre a escolaridade desses genitores, quatro adolescentes (25\%) não souberam informar ( $\operatorname{casos} 3,5,8,11)$, e entre os 12 restantes, a escolaridade variou de Ensino Superior (caso 7) a nenhuma escolaridade (caso 14). Um dos pais era aposentado e 50\% deles tinham ocupação de nível técnico.

A idade das mães variou de trinta a 56 anos, com cerca de metade das mães na faixa etária de trinta a quarenta anos. A escolaridade das genitoras variou do Ensino Fundamental incompleto a Ensino 
Médio completo. Cerca de 50\% das mães tinham o Ensino Médio completo e dez (62,5\%) eram "do lar".

Quanto aos diagnósticos, diferentes tipos de transtornos mentais foram encontrados, tais como esquizofrenia paranoide (casos 1 e 10), transtornos depressivos leves (casos 7, 8, 12, 13 e 15) e moderados (casos 3, 9 e 11), transtornos de ansiedade, como fobia social (caso 14), fóbico-ansiosos (caso 16) e transtorno obsessivo compulsivo (caso 5), transtornos alimentares, como a bulimia (caso 4) e anorexia nervosa (caso 2), e transtorno do estresse pós-traumático (caso 6).

Segundo estudos epidemiológicos sobre os transtornos mentais em mulheres realizado por Andrade et al. (2006), os transtornos de ansiedade e depressivos apresentam maiores taxas de prevalência em mulheres. No presente estudo, os sintomas depressivos e ansiosos atingiram mais de $50 \%$ das adolescentes. Alguns fatores de risco na história do indivíduo foram associados por Andrade et al. (idem) ao desenvolvimento da depressão. Tais fatores foram constatados nos relatos das adolescentes participantes como adversidades na infância, aspectos de personalidade, isolamento social e exposição a experiências estressantes. Neste estudo não houve a preocupação em realizar uma investigação diagnóstica nem em comparar os relatos das pacientes quanto aos motivos pelos quais buscaram esse tratamento com os diagnósticos formulados na instituição. Os diagnósticos não foram utilizados como critério para a seleção das participantes.

Com relação ao tratamento, entre as 16 entrevistadas, 12 (62,5\%) iniciaram o tratamento no CPASi e as demais (25\%) já haviam feito outros tratamentos médico-psicológicos, indicando que a maior parte das adolescentes buscou tratamento no CAPSi desde a primeira crise. As adolescentes estavam inseridas em diferentes tipos de tratamento, sendo que seis faziam apenas psicoterapia de grupo e as demais faziam psicoterapia de grupo associada ao tratamento medicamentoso e a oficinas terapêuticas.

Os fatores de risco e os mecanismos de proteção apresentados no Quadro 1 foram identificados por meio do relato da história de vida das participantes. 
Quadro 1 - Fatores de risco e os mecanismos de proteção identificados.

Casos Fatores de risco Mecanismos de proteção

01 Doença mental da mãe; pri- Relações interpessoais posivação materna; adversida- tivas; bom aproveitamento des; ego frágil, inseguro e dos recursos escolares. instável.

\begin{tabular}{|c|c|c|}
\hline 02 & $\begin{array}{l}\text { Privação materna parcial; } \\
\text { vitimização por bullying na } \\
\text { idade escolar. }\end{array}$ & $\begin{array}{l}\text { Relação familiar positiva; } \\
\text { otimismo; busca de autono- } \\
\text { mia; autoestima; receptivi- } \\
\text { dade a mudanças; capacida- } \\
\text { de de cumprir metas. }\end{array}$ \\
\hline 03 & $\begin{array}{l}\text { Privação paterna; perda de } \\
\text { irmão jovem; baixa tolerân- } \\
\text { cia a frustrações; ideação } \\
\text { suicida; sentimento de não } \\
\text { ser amada; agressividade e } \\
\text { tristeza. }\end{array}$ & $\begin{array}{l}\text { Estabilidade familiar; rela- } \\
\text { ções interpessoais positivas; } \\
\text { aproveitamento escolar; oti- } \\
\text { mismo; receptividade a } \\
\text { mudanças; capacidade de } \\
\text { reconhecer e comunicar } \\
\text { sentimentos. }\end{array}$ \\
\hline 04 & $\begin{array}{l}\text { Bulimia; "autoritarismo" } \\
\text { do pai e baixa autoestima. }\end{array}$ & $\begin{array}{l}\text { Relações interpessoais posi- } \\
\text { tivas; sociabilização; recur- } \\
\text { sos escolares; otimismo; ca- } \\
\text { pacidade para estabelecer e } \\
\text { cumprir metas. }\end{array}$ \\
\hline 05 & $\begin{array}{l}\text { Conflitos familiares; pri- } \\
\text { vação paterna; repetidas } \\
\text { hospitalizações; anemia; } \\
\text { humor deprimido; dificul- } \\
\text { dade em cumprir metas; } \\
\text { condições financeiras e } \\
\text { ambientais desfavoráveis. }\end{array}$ & $\begin{array}{l}\text { Bom aproveitamento dos re- } \\
\text { cursos escolares; boa autoes- } \\
\text { tima; otimismo e capacidade } \\
\text { para comunicar e reconhecer } \\
\text { sentimentos. }\end{array}$ \\
\hline
\end{tabular}


Continuação

Casos Fatores de risco

06 Separação dos pais; doença e morte do pai; timidez; dificuldades em relações sociais e em comunicar sentimentos e desânimo.

07 Separação dos pais; confli- Apoio familiar; habilidades tos com a mãe; agressão so- sociais e cognitivas; capacifrida por uma professora; dade de pedir ajuda; autoesaspectos pessoais como tima; capacidade de comuni"mau humor, inflexibilida- car sentimentos e estabelecer de e depressão". e cumprir metas.

08 Problemas emocionais ma- Relações interpessoais; diáternos (gestação e puerpé- logo familiar; recursos escorio); ausência do pai; con- lares; capacidade de estabeflitos com a mãe; humor lecer e cumprir metas; bom oscilante; dificuldade com humor e receptividade a musentimentos; hiperativida- danças. de e pouca flexibilidade.

09 Alcoolismo do pai; crise Estabilidade e bom relaciodepressiva e dificuldade em namento familiar; recursos adaptar-se a mudanças. escolares; autoestima; habilidades sociocognitivas; expressão de sentimentos.

10 Depressão; ausência pater- Apoio familiar; capacidade na; desadaptação a mudan- de pedir ajuda; participa de ças; temperamento explosi- diferentes atividades; habilivo; desinteresse pela dadescognitivas e paracumprópria história de vida. prir metas. 
Continuação

\section{Casos Fatores de risco}

11 Alcoolismo eagressividade Recursos escolares, sociais e do pai; conflitos com a mãe; cognitivos; participação em mau humor; dificuldade de diferentes atividades; excumprir metas.

\section{Mecanismos de proteção} pressão de sentimentos; autoestima.

12 Crises convulsivas na in- Estabilidade e apoio famifância; conflitos familiares; liar; recursos escolares; bom descontrole emocional; humor; otimismo; capacidaperfeccionismo; apego exa- de de cumprir metas; habiligerado à mãe. dades sociais e cognitivas; autoestima.

13 Privação materna; irritabi- Boa relação dos pais; apoio lidade; dificuldade em fa- familiar; recursos escolares; zer amigos e em lidar com habilidades cognitivas; boas situações novas. relações interpessoais; flexibilidade.

14 Hospitalizações no primei- Estabilidade familiar; relaro ano de vida; conflitos fa- ções interpessoais; recursos miliares; bullying; dificul- escolares; flexibilidade; cadades financeiras e para pacidade de comunicar senenfrentar situações novas. timentos.

15 Derrame sofrido pela mãe Estabilidade e diálogo famihá dois anos; medo de per- liar; receptividade a mudander os pais e ficar sozinha; ças; capacidade de estabeledificuldade para fazer ami- cer e cumprir metas, gos; humor deprimido e in- comunicar sentimentos e pesônia. dir ajuda.

16 Falta de diálogo com a mãe; Apoio familiar; relações inpais autoritários; dificuldade terpessoais e habilidades sopara fazer amigos e timidez. ciais; busca de autonomia. 
Em cinco casos (1, 2, 5, 8 e 14) a privação materna total ou parcial no primeiro ano de vida foi importante fator de risco encontrado. Para Winnicott (2001), tal privação é reconhecida como um dos principais fatores para o surgimento de graves comprometimentos na saúde mental, visto que a frustração desmedida da criança ainda muito pequena pode limitar o desenvolvimento de sua espontaneidade. Winnicott (idem) ressalta que a presença da mãe é precondição para o desenvolvimento do autocontrole, da moralidade e da capacidade de preocupar-se com o outro.

O papel da escola destacou-se como fundamental na formação de mecanismos de proteção. A maioria das adolescentes $(87,5 \%)$ relatou que as relações de amizades com colegas e professores, festas e outros relacionamentos sociais em geral foram os principais fatores ou situações positivas que vivenciaram, assim como o aprendizado e o conhecimento. Esse resultado confirma os dados encontrados na literatura. Rutter (1979) e Garmezy (1987) destacam a escola e as atribuições ligadas a ela como facilitadores no desenvolvimento de mecanismos de proteção.

A resposta positiva ao tratamento no CAPSi também foi apontado como importante para a superação de crises e situações adversas, consistindo em mecanismo de proteção para a prevenção de agravamentos e/ou emergência de outros transtornos mentais.

Entre as características autoatribuídas relatadas pelas adolescentes, destacaram-se importantes fatores de risco, além de mecanismos pessoais de proteção. Considerando o apontado por Rutter (1987) e Winfield (1995), foram identificadas características pessoais, apontadas pelas entrevistadas, indicativas de fatores de riscos, tais como baixa tolerância à frustração, mau humor, passividade, comportamento destrutivo, baixa autoestima, ego frágil, inseguro e instável, cinismo e hostilidade, pobre habilidade de comunicação, depressão, tentativa de suicídio e abuso de álcool e drogas. Características relatadas pelas adolescentes e consideradas mecanismos de proteção pessoal, segundo Trombeta \& Guzzo (2002), também foram encontradas: autoestima positiva, flexibilidade, otimismo, mente aberta e receptiva a mudanças e a novas experiências, disciplina 
pessoal e responsabilidade, busca de autonomia, engajamento em diferentes atividades e comportamento direcionado a metas.

Os relatos de mais de $80 \%$ das adolescentes sugerem famílias estruturadas e atentas às necessidades de saúde, de socialização e educacionais dos filhos, com predomínio de relações mais positivas do que negativas e tendo o diálogo como principal ação educativa. No que se refere à escola, a maioria das adolescentes não apontou dificuldades relevantes, não teve reprovação escolar e pôde dedicar-se apenas aos estudos, sem necessidade de trabalhar. Estes resultados são sugestivos de condições favorecedoras ao desenvolvimento de mecanismos de proteção, de acordo com a literatura pesquisada (Rutter, 1987).

\section{Considerações finais}

Foram realizados 16 estudos de caso, representando $80 \%$ do total de adolescentes em tratamento no CAPSi na época da coleta de dados para o estudo. Os dados demográficos referentes à amostra revelaram condições familiares, econômicas, de escolaridade e relações sociais indicativas de estruturas relativamente mais favoráveis e estáveis do que desfavoráveis ou instáveis: acesso e frequência à escola e emprego; um dos genitores ou ambos empregados, verificando-se que as adolescentes vivem com a família nuclear, têm boas condições gerais de saúde física, entre outros fatores positivos.

Foi possível identificar os fatores de risco e os mecanismos de proteção na história de desenvolvimento relatada pelas adolescentes entrevistadas, considerados nas categorias familiar, social e pessoal, os quais são similares aos encontrados na literatura.

Quantitativamente, os fatores de risco superaram os mecanismos de proteção encontrados nas histórias de vida relatadas. Porém, o conjunto de condições familiares, econômicas e socioemocionais do contexto das entrevistadas e o destacado papel da escola possivelmente atuaram na proteção das adolescentes frente aos fatores de risco identificados em seu desenvolvimento. 
Embora as adolescentes estivessem em tratamento médico e psicológico em uma instituição de saúde metal, com diagnósticos de diferentes tipos de transtornos mentais, na maior parte dos casos, identificou-se uma condição atual mais favorável do que seria esperado em função de seus diagnósticos. Esses resultados também expressam o desenvolvimento de alguns aspectos psicológicos pessoais positivos, possivelmente decorrentes de ganhos biopsicossociais gerais e específicos decorrentes da atenção e de tratamentos em realização na instituição.

\section{Referências bibliográficas}

ANDRADE, L. H. S. G.; VIANA, M. C.; SILVEIRA, C. M. Epidemiologia dos transtornos psiquiátricos na mulher. Revista de Psiquiatria Clínica. v.33, n.2, p.43-54, 2006.

ASPESI, C. C; DESSEN, M. A; CHAGAS, J. F. A ciência do desenvolvimento humano: uma perspectiva interdiciplinar. In: DESSEN, M. A.; COSTA-JUNIOR, A. L. A ciência do desenvolvimento humano: tendências atuais e perspectivas futuras. Porto Alegre: Artmed, 2005.

GARMEZY, N. Stress, competence and development: continuities in the study of schizophrenic adults, children vulnerable to psychopathology, and the search for stress resistant children. American Journal of Orthopsychiatry. 1987.

GAUY, F. V.; COSTA-JUNIOR, A. L. A natureza do desenvolvimento humano: contribuições das teorias biológicas. In: DESSEN, M. A.; COSTA-JUNIOR, A. L. A ciência do desenvolvimento humano: tendências atuais e perspectivas futuras. Porto Alegre: Artmed, 2005. KERNBERG, F. P; WEINER,S. A; BARDENSTEIN, K. K. Transtornos da personalidade em crianças e adolescentes. Porto Alegre: Artmed, 2003.

KNOBEL M. A síndrome da adolescência normal. In: ABERASTURY, A.; KNOBEL, M. Adolescência normal. Porto Alegre: Artmed, 1981. 
NEME, C. M. B. Stress, enfrentamento e resiliência na história de mulheres com e sem câncer. Campinas: Pontifícia Universidade Católica, 2005.

PESCE, P. R. et al. Risco e proteção em busca de um equilíbrio promotor de resiliência. Psicologia: teoria e pesquisa. Brasília, v.20, n.2, mai.-ago. 2004.

RUTTER, M. Parent-child separation: psychological effects on the children. Journal of Child Psychology and Psychiatry. n.12, p.23360, 1971.

Protective factors in children's responses to stress and disadvantage. In: KENT, M. W.; ROLF, J. (Eds.). Primary prevention of psychopathology. v.3. Hanover: University Press of New England, 1979.

Stress, coping and development: some issues and some questions. Journal of Child Psychology and Psychiatry. v.22, n.4, p.323-56, 1981.

Psychosocial resilience and protective mechanisms. American Journal of Orthopsychiatry. v.67, p.316-31, 1987.

Resilience concepts and findings: implications for family therapy. Journal of Familiy Therapy. v.21, p.119-44, 1999.

SAPIENZA, G; PEDROMÔNICO, M. R. M. Risco, proteção e resiliência no desenvolvimento da criança e do adolescente. Psicologia em estudo. Maringá, v.10, n.2, maio 2005.

TELES, S. S. Câncer infantil e resiliência: investigação fenomenológica dos mecanismos de proteção na díade mãe-criança. Ribeirão Preto: Universidade de São Paulo, 2005.

TROMBETA, L. H. A. P.; GUZZO, R. S. L. Enfrentando o cotidiano adverso: estudos sobre resiliência em adolescentes. Campinas: Alínea, 2002.

WINFIELD, L. The knowledge base on resilience in african american adolescents. In: CROCKETT, L. J.; CROUTER, A. C. (Eds.). Pathways through adolescence. New Jersey: Lawrence Erlbaum Associates, 1995.

WINNICOTT, D. W. A família e o desenvolvimento individual. São Paulo: Martins Fontes, 2001.

YUNES, M. A. M.; SKYMANSKI, H. Resiliência: noção, conceitos afins e considerações criticas. In: TAVARES, J. C. (Org.). Resiliência e educação. São Paulo: Cortez, 2001, p.13-42. 
Parte 4

\section{MANEJO DE ESTRESSE E OUTROS FATORES EM DIFERENTES POPULAÇÕES ADULTAS}





\title{
10 \\ ESTRESSE, HABILIDADES SOCIAIS E DESORDENS TEMPOROMANDIBULARES EM UNIVERSITÁRIOS
}

\author{
Tânia Gracy Martins do Valle ${ }^{1}$ \\ Rui Mateus Joaquim ${ }^{2}$ \\ Alessandra Turini Bolsoni-Silva ${ }^{3}$
}

\section{Introdução}

Desordens temporomandibulares (DTM) constituem uma heterogênea coleção de disfunções caracterizada pela dor orofacial que envolve, em muitos casos, deslocamento de disco, desordens musculares ou mudanças disfuncionais na articulação temporomandibular. Durante a década de 1960 e 1970 foi proposto um modelo psicofisiológico para explicar a etiologia da DTM(Kight et al., 1999). Tal modelo compreendia que estressores no contexto de vida levavam o indivíduo a desenvolver hábitos orais parafuncionais tais como o apertamento dental, o que, por sua vez, gerava uma tensão muscular que criava uma contração muscular crônica e dor facial (McCready et al., 1991).

As DTM têm sido estudadas amplamente quanto aos aspectos relacionados à incidência, à etiologia e ao tratamento (Venâncio \&

1 Programa de pós-graduação em Psicologia do Desenvolvimento e da Aprendizagem da Unesp, campus de Bauru.

2 Programa de pós-graduação em Psicologia do Desenvolvimento e da Aprendizagem da Unesp, campus de Bauru.

3 Programa de pós-graduação em Psicologia do Desenvolvimento e da Aprendizagem da Unesp, campus de Bauru. 
Camparis, 2002). Descrevem, geralmente, uma sensação dolorosa que afeta principalmente os músculos faciais e as articulações da mandíbula e representam a maioria das queixas de dores crônicas orofaciais estudadas por cirurgiões-dentistas (Alencar Junior, 2005). DTM afetam, de modo geral, músculos das regiões da face, da cabeça, do pescoço, da articulação temporomandibular, do periodonto e das estruturas dentais, caracterizando-se como sinais e sintomas as dores faciais, as cervicais, cefaleias, limitações nos movimentos mandibulares, fadiga muscular, sensibilidade, desgastes dentais e ruídos articulares.

Pesquisadores, como Greene(1982), apresentaram evidências de que fatores psicológicos são relevantes na etiologia, na progressão e no tratamento das DTM. Fatores psicossociais estão implicados e possuem funções na dinâmica das DTM (Rollman \& Gillespie, 2000), o que demanda ênfase na investigação multidisciplinar.

Dificuldades emocionais e psicológicas presentes em pacientes com DTM podem constituir elementos fundamentais para diagnóstico e tratamento adequados. Por meio dos trabalhos de Moulton (1955) surgiram as primeiras associações entre as DTM e os fatores psicológicos. Dentre esses fatores psicológicos, foram relacionados os comportamentais, os cognitivos e os emocionais ou afetivos, como a ansiedade, o estresse e a depressão. Segundo Okeson (1992), não há dados precisos sobre o número de pessoas acometidas por DTM, mas segundo estudos norte-americanos, cerca de $75 \%$ da população têm ao menos um sintoma de disfunção articular e 33\% têm de alguma disfunção muscular. As DTM podem ocorrer em qualquer idade e a literatura aponta que as diferenças encontradas em estudos epidemiológicos entre homens e mulheres apresentam proporções de mulheres-homens de 3:1 a 9:1 entre os indivíduos que procuram o tratamento para DTM (Okeson, 1998; Steenks \& Wijer, 1996). Nicolas (2001) tenta relacionar essa alta incidência de mulheres envolvidas em tal problemática ao fato de a mulher estar mais exposta ao estresse emocional e às mudanças hormonais durante o ciclo menstrual, além da gravidez e das alterações anatômicas que produziriam uma má relação do côndilo com o disco articular. 
Um estudo realizado por Martins \& cols. (2007) verificou a associação da classe econômica e do estresse com a ocorrência de disfunção temporomandibular. A população desse estudo constituiu-se de uma amostra de 354 indivíduos, de ambos os sexos, pertencentes a diferentes classes econômicas da zona urbana do município de Piacatu, São Paulo, Brasil. Os autores utilizaram o Critério de Classificação Econômica Brasil (CCEB) para a estratificação econômica da população. Retiraram uma amostra de cada estrato, na qual se aplicou questionário para verificar o grau de DTM, e a Escala de Reajustamento Social (SRRS) para verificar o grau de estresse. De acordo com os resultados obtidos, a classe econômica não influencia na ocorrência de DTM, mas existe associação direta entre aquela e esta.

A literatura tem mostrado que deficiências em habilidades sociais podem contribuir para o desenvolvimento do estresse. Furtado \& cols. (2003) avaliaram as fontes de estresse existentes no curso de graduação em Medicina, assim como a relação entre os níveis de estresse e as habilidades dos estudantes de seu estudo. A amostra constituiu-se de 178 alunos (105 mulheres e 73 homens) do primeiro ao sexto ano do curso de medicina. Utilizaram para a avaliação de estressores o Inventário de Sintomas de Stress para Adultos de Lipp (ISSL), e para verificar as habilidades sociais, o Inventário de Habilidades Sociais (IHS). Os resultados mostraram que estudantes de Medicina, durante sua formação acadêmica, ficam expostos a diversas situações geradoras de estresse. A falta de habilidade para enfrentar tais situações pode influenciar seu desempenho acadêmico, sua saúde e seu bem-estar psicossocial.

A perda da saúde e do bem-estar, bem como a procura por atendimento, aparece associada a uma das principais queixas relacionadas à problemática das DTM: a questão da dor. Glaros et al. (2005) afirmam que comportamentos parafuncionais relacionam-se com tensões musculares e que certos estados emocionais constituem bons indicadores na compreensão de dores mandibulares.

Diversos autores (Turk \& Gatchel, 1996; Angelotti, 1999; 2001; Fortes, 2002) descrevem conceituações e modelos que estão envolvidos na manutenção da dor, o que pode auxiliar na com- 
preensão de como fatores psicológicos podem influenciar a problemática da dor.

O modelo da aprendizagem social (Bandura, 1969) entende que os comportamentos de dor podem ser adquiridos por meio de modelação, que é a aprendizagem decorrente da observação de um modelo.

O contexto social e cultural no qual o indivíduo está inserido influencia a percepção e a interpretação de seus sintomas, o que pode determinar o modo de comportar-se do indivíduo no processo de adoecer.

O modelo de condicionamento, de acordo seus princípios, entende que, se o comportamento (neste caso, a dor ou o hábito parafuncional) for seguido de consequências reforçadoras, positivas ou negativas, aquele irá aumentar ao longo do tempo.

O modelo cognitivo-comportamental, segundo Rangé(2001), afirma que as emoções e o comportamento das pessoas são influenciados pela maneira como estas interpretam sua percepção dos eventos. O modelo cognitivo-comportamental pontua que os principais aspectos para a compreensão de dores crônicas são:

a) A dor não inclui apenas sensações físicas, mas também emoções, pensamentos e comportamentos a ela ligados.

b) $\mathrm{O}$ indivíduo pode ter crenças, pensamentos negativos e não realistas a respeito de sua dor, de si, dos outros e do mundo em relação ao futuro.

c) Esses pensamentos negativos e irrealistas sobre a dor e outros eventos da vida têm consequências significativas sobre a percepção da dor.

d) Existem distorções quanto à maneira de pensar, que podem ser identificadas (distorções cognitivas) e afetam negativamente a experiência dolorosa.

Pacientes que possuem expectativas negativas quanto a suas habilidades para enfrentar e controlar a dor se veem como impotentes diante desta.

Penido (2004) buscou investigar o repertório de habilidades sociais de pacientes fibromiálgicas (pacientes com dor crônica). $\mathrm{Na}$ 
revisão de literatura realizada para esta pesquisa não foi encontrado nenhum estudo investigando déficits de habilidades sociais em pacientes com dor crônica, mas alguns estudos incluem treino assertivo e treino de habilidades de comunicação no tratamento de pacientes com dor crônica (Cowan \& Lovasike, 1991; Corbin et al., 1988; Philips, 1998; Caudill, 1998; Winterowd et al., 2003).

Os estudos de Del Prette \& Del Prette (2006) a partir da noção de habilidades sociais, elaborado sob as bases de teóricos da aprendizagem como Skinner \& Bandura, têm fornecido subsídios sólidos e instrumentos eficientes para o desenvolvimento de variados estudos. O conceito de habilidades sociais tem suas origens na psicologia clínica e na psicologia do trabalho e define como habilidades sociais distintas classes de comportamentos sociais que compõem o repertório de um indivíduo.

Del Prette \& Del Prette (2006) pontuam, ainda, que o conjunto de habilidades sociais relevantes pode ser organizado em classes e subclasses de maior ou menor abrangência. Entre as principais classes destacam-se as habilidades de comunicação (fazer e responder perguntas, dar e pedir feedback, elogiar, iniciar, manter e encerrar conversação), as habilidades de civilidade (dizer "por favor", agradecer, apresentar-se, cumprimentar), as habilidades assertivas de enfrentamento ou de defesa de direito e de cidadania (expressar opinião, discordar, fazer e recusar pedidos, interagir com autoridades, lidar com críticas, expressar desagrado, lidar com a raiva do outro, pedir uma mudança de comportamento etc.), as habilidades empáticas e de expressão de sentimento positivo e outras duas mais abrangentes, nomeadas de habilidades profissionais ou de trabalho (coordenação de grupo, falar em público), e as habilidades sociais educativas de pais, professores e outros agentes envolvidos na educação ou treinamento. $\mathrm{Na}$ base de qualquer desempenho socialmente competente, destacase a automonitoria enquanto habilidade geral de observar, descrever, interpretar e regular pensamentos, sentimentos e comportamentos em situações sociais.

As habilidades sociais referem-se também à capacidade do indivíduo de organizar seus pensamentos, formulando critérios coeren- 
tes de compreensão e avaliação de situações. As habilidades sociais são aprendidas e dependem das dimensões pessoal, situacional e cultural para sua configuração (idem, 1999), e elas podem ser desenvolvidas por meio de treinamento sistemático em contextos estruturados por meio de estratégias grupais. Tal treinamento tem sido aplicado nos contextos de psicologia clínica e da saúde, no tratamento e na prevenção de transtornos correlatos com déficits de habilidades ou competências sociais. O Treinamento de Habilidades Sociais (THS) tem sido utilizado como método para combater transtornos que envolvem primariamente problemas de relacionamento social, como os depressivos, de ansiedade e de fobia social, (idem, 2006). Segundo Penido (2004), ao identificar deficiências de habilidades sociais em uma determinada população, é possível criar formas de desenvolvimento para essas habilidades que têm como objetivo a melhora na qualidade de vida.

Rangé (2001) afirma que há uma necessidade de as atuais abordagens psicoterápicas buscarem metodologias de tratamento baseadas em métodos e descobertas científicas. A necessidade e a importância de novos estudos e pesquisas se dão em razão de que estes expandem e refinam as metodologias de intervenção existentes.

Na busca por tais ampliações metodológicas para o presente tema, este estudo teve por objetivo analisar a correlação entre o índice de estresse e as habilidades sociais de universitários, considerando a diferença de gêneros, com e sem diagnóstico de DTM, contribuindo na investigação de elementos importantes para seu diagnóstico e tratamento.

\section{Material e método}

\section{Aspectos éticos da pesquisa}

Como determina o Conselho Nacional de Saúde, este estudo foi submetido ao Comitê de Ética de Pesquisa das instituições envolvidas e o trabalho iniciou após sua aprovação. 


\section{Participantes}

Foram avaliados 57 universitários na faixa etária entre 18 e trinta anos, alunos do $4^{\circ}$ ano da Faculdade de Odontologia de Araçatuba (FOA, Unesp), que receberam diagnóstico de DTM. Todos os participantes responderam ao Índice de Fonseca, elaborado para avaliação e diagnóstico de DTM.

\section{Instrumentos}

Para dimensionar a condição de estresse e relacioná-lo ao conjunto de habilidades sociais dos participantes, foram aplicados dois inventários: o Inventário de Sintomas de Stress Lipp (ISSL) e o Inventário de Habilidades Sociais (IHS).

\section{ISSL}

O ISSL tem como objetivo identificar se o indivíduo possui sintomas de estresse, qual o tipo de sintoma predominante e em que fase do estresse tal indivíduo encontra-se. Segundo Selye (1952), o estresse desencadeia-se em três fases: alerta, resistência e exaustão. A fase de alerta é aquela na qual o organismo prepara-se para lutar ou fugir; a fase de resistência é aquela em que o organismo tenta uma adaptação. Lipp, no processo de desenvolvimento de seu instrumento (ISSL), identificou uma quarta fase, chamada "quase-exaustão". Essa nova fase fica entre a fase de resistência e a da exaustão e caracteriza-se pelo enfraquecimento da pessoa, que não mais está conseguindo adaptar-se ou resistir ao estressor. É nessa fase de vulnerabilidade que surge a possibilidade do desencadeamento de doenças. Contudo, nesta fase, a pessoa ainda consegue "funcionar" socialmente com limitações. Na fase de exaustão a pessoa para de "funcionar" adequadamente, comprometendo seu trabalho e sua vida social (Lipp, 2000). A aplicação do ISSL leva acerca cerca de dez minutos e tem 37 itens, dos quais 19 são somáticos e 18, psicológicos. 


\section{IHS}

O IHS, de autoria de Del Prette \& Del Prette (2001), foi validado, a princípio, junto a uma população universitária com grupo de amostra de 472 respondentes entre 17 e 25 anos, mas já tem sido utilizado na avaliação de adultos com formação no ensino médio. Trata-se de um instrumento de autorrelato que confere o repertório de habilidades sociais requerido usualmente em uma série de situações interpessoais cotidianas. Para cada situação deve-se marcar a frequência com que o desempenho da pessoa coincide com o descrito na situação. O questionário contém 38 itens que devem ser considerados do seguinte modo: A - Nunca, raramente se, em cada dez situações desse tipo, reajo dessa forma no máximo duas vezes; B Com pouca frequência se, em cada dez situações desse tipo, reajo dessa forma de três a quatro vezes; C - Com regular frequência se, em cada dez situações desse tipo, reajo dessa forma de cinco a seis vezes; D - Muito frequentemente se, em cada dez situações desse tipo, reajo dessa forma de sete a oito vezes; E - Sempre ou quase sempre se, em cada dez situações desse tipo, reajo dessa forma de nove a dez vezes.

\section{Procedimento de coleta de dados}

Em sala de aula, os alunos foram instruídos e receberam os instrumentos: o ISSL e em seguida o IHS. Estes foram respondidos e entregues ao pesquisador. As respostas obtidas nos instrumentos foram corrigidas de acordo com seus respectivos manuais.

\section{Procedimento de tratamento e análise dos dados}

Com o resultado dos instrumentos, os participantes foram divididos para análise em dois modos: o primeiro, comparando "grupo com DTM" e "grupo sem DTM", e o segundo, comparando as diferenças de gênero. Para a análise estatística dos dados foi utilizado 
o software SPSS, versão 14.0. Realizaram-se comparações de grupos por meio do teste Mann-Whitney.

\section{Resultados}

Foram encontradas diferenças entre o índice de estresse e as habilidades sociais. Todo o grupo livre do diagnóstico de DTM apresentou um repertório mais positivo de habilidades sociais do que o grupo com DTM.

O grupo livre de DTM apresentou-se mais habilidoso nos seguintes itens doIHS: 17 - "Encerrar conversação"; 19 - "Abordar autoridade". O resultado total da comparação homens x mulheres indica que os homens mostraram-se socialmente mais habilidosos do que as mulheres. Especificamente, os homens apresentaram-se mais habilidosos nos seguintes itens do IHS: 8 - "Participação de conversação", 17 - "Encerrar conversação", 19 - "Abordar autoridade". As diferenças de habilidades sociais entre os grupos com e sem DTM, bem como entre homens e mulheres, estão descritas na Tabela 1.

Referente ao estresse, comparando o grupo com e sem DTM, verificou-se que o grupo com DTM mostrou-se mais afetado por sintomas de estresse em relação ao grupo sem DTM. Em todos os quadros de sintomas, o estresse apresentou-se como fator emocional com significância estatística. Comparando as diferenças nos sintomas de estresse entre homens e mulheres, estas se mostraram mais afetadas em todos os quadros de sintomas F1, F2, P3, todos estes com significância estatística.

As diferenças nos sintomas de estresse entre o grupo com e sem DTM, bem como entre homens e mulheres, estão dispostas na Tabela 2 . 
Tabela 1 - Comparações entre universitários com e sem diagnóstico de DTM e entre homens e mulheres para o IHS (Del Prette), organizadas por grupos. Média, desvio padrão e valor de $t$ são apresentados para os itens com diferença estatística. * = Índice de significância; A) * p d•0,01; B) ** p d•0,05.

\begin{tabular}{|c|c|c|c|c|}
\hline Itens & DTM x sem DTM & $\mathrm{t}$ & Homens x mulheres & $\mathrm{t}$ \\
\hline 8 - Participar de conversação & $3,03(1,20) \times 3,28(1,02)$ & - & $3,65(1) \times 2,93(1,12)$ & $2,41^{*}$ \\
\hline 16 - Discordar do grupo & $2,43(1,01) \times 3,04(0,97)$ & - & $2,94(0,9) \times 2,6(1,08)$ & - \\
\hline 17 - Encerrar conversação & $2,71(1,30) \times 3,08(1,11)$ & - & $3,35(0,7) \times 2,6(1,35)$ & $-2,49 *$ \\
\hline 19 - Abordar autoridade & $1,71(, 99) \times 2,40(1,19)$ & $2,3^{*}$ & $2,47(1,12) \times 0,83(1,13)$ & $0,5^{*}$ \\
\hline $\begin{array}{l}23 \text { - Fazer pergunta } \\
\text { a desconhecido }\end{array}$ & $1,71(1,17) \times 2,64(1,25)$ & $2,83 * *$ & $2,41(1,54) \times 2(1,15)$ & - \\
\hline Total & $88.94(12,44)$ x 98,2(13,83) & $2,63 * *$ & $98,5(13,37) \times 90,6(13,4)$ & $-2,03^{*}$ \\
\hline
\end{tabular}


Tabela 2 - Comparações entre universitários com e sem diagnóstico de DTM e entre homens e mulheres para o ISSL, organizados por grupos. Média, desvio padrão e valor de $t$ são apresentados para os itens com diferença estatística. * = Índice de significância; A) * p d•0,01; B) ** p d•0,05.

\begin{tabular}{|c|c|c|c|c|}
\hline Itens & DTM x sem DTM & $\mathrm{t}$ & Homens x mulheres & $\mathrm{t}$ \\
\hline $\begin{array}{l}\text { F1 Quadro de sintomas } \\
\text { físicos I }\end{array}$ & $2,28(1,57) \times 1,4(1,26)$ & $-2,35^{*}$ & $0,94(1,39) \times 2,22(1,73)$ & $-2,95 *$ \\
\hline $\begin{array}{l}\text { F2 Quadro de sintomas } \\
\text { físicos de estresse II }\end{array}$ & $2,28(1,81) \times 1,28(1,45)$ & $-2,30 *$ & $0,94(1,39) \times 2,22(1,73)$ & $2,95 *$ \\
\hline $\begin{array}{l}\text { P3 Quadro de sintomas } \\
\text { psicológicos de estresse III }\end{array}$ & $4,12(2,77) \times 1,84(1,57)$ & $-3,91 *$ & $1,88(1,90) \times 3,65(2,66)$ & $2,83^{* * *}$ \\
\hline Total F2 & $4,12(2,91) \times 2,64(2,25)$ & $-2,16 *$ & $2,23(2,33) \times 4(2,73)$ & $2,47 *$ \\
\hline Total P3 & $4,12(2,77) \times 1,84(1,45)$ & $-3,91 *$ & $1,88(1,9)$ x $3,65(2,66)$ & $2,83^{*}$ \\
\hline
\end{tabular}




\section{Discussão}

As dificuldades presentes durante a formação no curso de odontologia podem configurar situações geradoras de estresse na vida acadêmica e no bem-estar físico e psicossocial do estudante. O estresse presente na vida acadêmica tem sido objeto de estudo e de pesquisas em vários países (Furtado, 2003). A autora pôde demonstrar que os alunos do curso de Medicina de uma das mais importantes faculdades do estado do Rio de Janeiro também estão em contato com uma série de dificuldades que se tornam, para muitos, verdadeiras fontes de estresse.

A etiologia multifatorial da DTM está relacionada a problemas psicológicos, especialmente ao estresse (Seger \& cols, 1998; Venâncio \& Camparis, 2002). Fatores estressores da vida relacionam-se a hábitos orais disfuncionais (que envolvem a hiperativa ação muscular da mandíbula)e, por conseguinte, à dor. É provável que pessoas em tal situação tenham sua capacidade de interagir socialmente alterada e, com isto, suas competências situacionais poderão sofrer interferências, diminuindo suas habilidades sociais e seus recursos de enfrentamento em contextos diferenciados.

Os resultados, aqui, apontam que os jovens universitários participantes desse estudo apresentam indicadores de estresse, o que, de acordo com literatura, encontra respaldo em diferentes estudos que afirmam que existem evidências de que o estresse e fatores psicológicos são muito relevantes na etiologia, na progressão e no tratamento das DTM (Greene, 1982; Molina, 1996; Rollman \& Gillespie, 2000; Martins \& cols., 2007). Nicolas (2001), comparando a presença de sintomas de estresse na comparação entre os sexos, apontou que as mulheres mostraram-se mais afetadas em todos os quadros de sintomas de desse mal. A análise da pontuação total obtida no questionário para avaliação do nível de estresse levando em consideração o gênero mostrou que as mulheres percebem os estressores de forma mais intensa que os homens. Tais resultados confirmam estudos anteriores que indicam serem as mulheres mais suscetíveis às fontes de estresse (Caruana \& cols., 1999). 
Pode-se observar que o grupo sem diagnóstico de DTM obteve resultados mais positivos, quando comparado aos demais, no referente à habilidade social. Estudo realizado por Furtado \& cols. (2003) com população similar, ou seja, com universitários da área da saúde, já tinha chegado a paralelos similares a este, indicando que a falta de habilidade de sujeitos universitários para enfrentar situações estressantes pode influenciar seu desempenho acadêmico, sua saúde e seu bem-estar psicossocial.

As habilidades sociais desenvolvidas e adequadas para as diferentes situações de enfrentamento no cotidiano das pessoas são de grande valia para seu equilíbrio biopsicossocial, considerando que elas referem-se, segundo Del Prette \& Del Prette (2006), à capacidade do indivíduo de organizar seus pensamentos, formulando critérios coerentes de compreensão e avaliação de situações sociais. Neste estudo, quando os grupos são comparados no que se refere a habilidades sociais, o grupo de universitários sem DTM manifestou um repertório mais adaptativo. Os universitários do sexo masculino mostraram resultados mais positivos em habilidades sociais do que as jovens do sexo feminino. Tal resultado diverge de estudos que apontam mulheres como mais habilidosas do que os homens (idem, ibidem).

Dados como estes indicam a necessidade de realização de novas investigações com o mesmo objetivo de estudo, para que se possam melhor compreender tais fenômenos.

\section{Conclusão}

Após a análise dos questionários, observou-se que o estresse, na comparação dos grupos, teve maior incidência sobre o grupo com DTM $(4,12)$ do que em relação ao grupo sem DTM $(1,84)$. Comparando mulheres e homens, a prevalência de sintomas de estresse foi maior nas mulheres $(3,65)$ do que nos homens $(1,88)$.

Na comparação dos grupos, no quesito habilidades sociais, o grupo de universitários sem DTM $(98,2)$ apresentou um repertório mais 
positivo de habilidades sociais em relação ao grupo $\operatorname{com} \operatorname{DTM}(88,9)$. Os homens $(98,5)$ mostraram resultados mais positivos em habilidades sociais do que as mulheres $(90,6)$. Quanto a relação entre habilidades sociais, estresse e a possibilidade do desenvolvimento da DTM, os presentes resultados sugerem a necessidade de realização de outras pesquisas, visando à sistematização de resultados das descobertas e o desenvolvimento e amadurecimento desta área de estudo.

\section{Referências bibliográficas}

ALENCAR JUNIOR, F. G. P. O et al. Oclusão, dores orofaciais e cefaleia. São Paulo: Livraria Santos, 2005.

ALLBERG, J. et al. Reported bruxism and biopsychosocial symptoms: a longitudinal study. Community Dent Oral Epidmiol. Copenhagem v.32, p.307-11, 2004.

ANGELOTTI G. Fibromialgia: análise de componentes emocionais, cognitivos e comportamentais. Dissertação (mestrado). Instituto de Psicologia da PUC, Campinas, 1999.

Tratamento de dor crônica. In: RANGE, B. P. (Org.).

Psicoterapias Cognitivo-comportamentais: um diálogo com a psiquiatria. Porto Alegre: Artmed, 2001.

BANDEIRA, M. C. M. N.; DEL PRETTE, Z. A. P.; DEL PRETTE,

A. Qualidades psicométricas do Inventário de Habilidades Sociais (IHS): estudo de estabilidade temporal e a validade concomitante. Estudos de psicologia. Natal, v.5, n.2, p.401-9, 2000.

BANDURA, A. Principles of behavior modification. New York: Hoct, Rinehant and Winston Inc., 1969.

BOLSONI-SILVA, A. T. DEL PRETTE, Z. A. P. et al. Habilidades sociais no Brasil: uma análise de estudos em periódicos. In: BANDEIRA, Z. A. P. M.; DEL PRETTE, Z. A. P.; DEL PRETTE, A. (Orgs.). Estudos sobre habilidades sociais e relacionamento interpessoal São Paulo: Casa do Psicólogo, s. d., p.17-45.

BUENAVER, L. F.; McGUIRE, L.; HAYTHORNTHWAITE, J. A. Cognitive-behavioral self-help for chronic pain. J Clin Psychol. New York, v.62, n.11, p.1389-96, nov. 2006. 
CARUANA, A. et al. Evaluación del estrés en estudiantes de medicina. Ansiedad y estrés. v.5, n.1, p.79-97, 1999.

CAUDILL M. A. Controle a dor antes que ela assuma o controle: um programa clinicamente comprovado. São Paulo: Summus, 1998.

CELIC, R.; PANDURIC, J.; DULCIC, N. Psychologic status in pacients with temporomandibular disorders. Int J Prosthodont. Lombard, v.19, n.1, p.28-9, 2006.

COOPER, B. C.; KLEINBERG, I. Examination of a large patient population for the presence of symptoms and signs of temporomandibular disorders. Journal of Craniomandibular Practice. v.25, n.2, p.114-25, 2007.

CORBIN, A. et al. Attentional functioning in fibromyalgia, rheumatoid arthritis, and musculoskeletal pain patients. Arthritis $\mathcal{E}$ Rheumatism. v.47, n.6, p.639-44, 1998.

COWAN, P.; LOVASIK, D. A. American chronic pain association: strategies for surviving chronic pain. Orthopaedic Nursing. v.9, n.4, p.47-9, 1991.

DEL PRETE, A.; DL PRETTE Z. A. P. Psicologia das relações interpessoais e habilidades sociais: vivências para o trabalho em grupo. Petrópolis: Vozes, 2001.

Relações interpessoais e habilidades sociais na saúde e na clínica. Disponível em: <www.rihs.ufscar.br>. Acesso em: 19 jan. 2008.

Habilidades sociais: conceitos e campo teórico prático. Disponível em: <www.rihs.ufscar.br>. Acesso em: 19 jan. 2008. ; MEYER, S. B. Psicoterapia com crianças ou adultos: expectativas e habilidades sociais de graduandos em psicologia. Estudos de psicologia (Pucccamp). Disponível em: <www.rihs.ufscar.br>. Acesso em: 19 jan. 2008.

FORDYCE, W. E. et al. Operant condiotining in the treatment of chronic pain. Aarchives of Phisica Medicine and rheabilitational. v.54, p.399-408, 1973.

FORTES, S. O paciente com dor. In. BOTEGA, N. (Org.). Prática psiquiátrica em hospital: interconsulta e emergência. Porto Alegre: Artmed, 2002a, p.338-351.

Somatização In: N. BOTEGA, N. (Org.). Prática psiquiátrica em hospital: interconsulta e emergência. Porto Alegre: Artmed, 2002b, p.268-284. 
FREITAS, M. G.; DEL PRETTE, Z. A. P.; DEL PRETTE, A. Melhorando habilidades sociais de crianças com deficiência visual: um programa de intervenção para mães. s. n. Benjamim Constant. v.13, n.37, p.17-7, 2007.

FURTADO, E. S.; FALCONE, E. M. O.; CLARK, C. Avaliação do estresse e das habilidades sociais na experiência acadêmica de estudantes de medicina de universidade do Rio de Janeiro. Interação psicologia. v.7, n.2, p.43-51, jun.-dez. 2003.

GLAROS, A. G. Emotional factors in temporomandibular joint disorders. J Indiana Dent Assoc. Indianápolis, v.79, n.4, p.20-3, 2001. ; WILLIAMS, K., LAUSTEN, L. The role parafunctions emotions and stress in predicting facial pain. J Am Dent Assoc. Chicago, v.136, p.451-8, 2005.

GOLDEN, B. A. A multidisciplinary approach to nonpharmacologic pain management. The J Am Ostheopathic Assoc. Chicago, v.105, n.9, p. 51-5, 2002.

GREENE, C. S.. Psychological factors in etiology, progression and treatment of MPD syndrome. J Am Dent Assoc. Chicago, v.105, p.443-8, s. d.

KIGHT, M., GATCHEL, R. J.; WESLEY, L. V. Temporomandibular disorders and stress-associated syndromes. Oral Surg Oral Med Oral Pathol Med. Compenhagem, v.31, n.10, p.615-9, nov. 2002.

KORSZUN, A. The relashionship between temporomandibular disorders and stress-associated syndromes. Oral Surg Oral Med Oral Pathol Radiol Endod. St. Lowis, v.86, n.4, p.416-20, 1998.

MAIA, E. A. V.; VASCONCELOS, L. M. R.; SILVA, A. S. Prevalência das desordens tempormandibulares: uma abordagem sobre a influência do stress. ABO Nac. v.9, n.4, p.228- 32, ago.-set. 2001.

MARTINS, R. J. et al. Associação entre classe econômica e estresse na ocorrência da disfunção temporomandibular. Rev. bras. epidemiol. v.10, n.2, jun. 2007.

MOLINA, O. M. Estresse no cotidiano. São Paulo: Pancast, 1996.

MOODY, P. M. et. al. Stress-pain relationship in MPD syndrome patients and non-MPD syndrome patients. J Prosthet Dent. St. Louis, v.45, p.84-8, 1988.

MYAZAKI. M. C. O. S.; AMARAL, V. L. A. R. (1995) Instituições de saúde. In. RANGÉ, B. Psicoterapia comportamental e cognitiva. 
Pesquisa, Prática, aplicações e problemas. Campinas: Psy II, 1995, p.235-244.

OKESON, J. P. Dor orofacial. São Paulo: Quintessence, 1998a. Dores bucofaciais de Bell. São Paulo: Quintessence, 1998b.

PHILIPS, H. C. The psychological management of chronic pain: a treatment manual. 2ed. New York: Springer Publishers, 1998.

RANGÉ, B. Psicoterapias cognitivo-comportamentais: um diálogo com a psiquiatria. Porto Alegre: Artmed, 2001.

ROBERT, J. G. et al. Efficacy of an early intervention for patients with acute temporomandibular disorder-related pain. J Am Dent Assoc. Chicago, v.137, n.3, p.339-47, 2006.

ROLLMAN, G. B, GILLESPIE, J. M. The role of psychosocial factors in temporomandibular disorders. Curr Rev Pain. Philadhelphia, v.4, n.1, p.71-81, 2000.

SEGER, L. et al. Psicologia e odontologia: uma abordagem integradora. 3ed. São Paulo: Santos, 1998.

STEENKS, M. H.; WIJER, A. Disfunção da articulação temporomandibular do ponto de vista da fisioterapia e da odontologia. São Paulo: Santos, 1996.

TOWNSEND C. O. et al. The role of mental health professionals in multidisciplinary pain rehabilitations program. J Clin Psychol. New York, v.62, n.11, p.1433-43, 2006.

TURK, C. D. \& GATCHEL J. R. (1996). Psychological approaches to pain manegement a practioners handbook. New York: The Guilford Press.

VENÂNCIO, R. A.; CAMPARIS, C. M. Estudo da relação entre fatores psicossociais e desordens temporomandibulares. RBO. v.59, n.3, p.152-4, maio-jun. 2002.

WINTEROWD, C; BECK, A. T.; GRUENER, D. (2003). Cognitive therapy with chronic pain patients. New York: Springer Publishing Company, 2003. 



\section{1 \\ MANejo de estresse, COPING E RESILIÊNCIA EM MOTORISTAS DE ÔNIBUS URBANO}

Luciana Silva Zanelato $^{1}$

Sandra Leal Calais ${ }^{2}$

\section{Introdução}

O estresse ocupacional em motoristas de ônibus urbano tem sido discutido devido aos inúmeros estressores presentes na profissão, tais como condições de trabalho, das vias, do veículo, do relacionamento com os passageiros e com a empresa. Esses estressores parecem resultar na expansão do absenteísmo, de licenças-saúde, assim como em baixa produtividade, comportamento inadequado no trânsito e envolvimento em acidentes com ou sem vítimas. Isso evidencia como os motoristas envolvem-se com sua atividade laboral, afetando sua saúde e impossibilitando-lhes uma vida saudável.

Para Lipp (2003), o estresse é definido como uma reação psicofisiológica muito complexa que tem, em sua gênese, a necessidade de o organismo modificar-se frente a algo que ameace sua homeostase interna. Isso pode ocorrer quando a pessoa confronta-se com uma situação tanto positiva quanto negativa.

1 Programa de pós-graduação em Psicologia do Desenvolvimento e da Aprendizagem da Unesp - Bauru.

2 Idem. 
Selye (1956), médico austríaco, foi um dos pioneiros nos estudos sobre o estresse para designar uma síndrome produzida por vários agentes nocivos. Na década de 1920, observou em seus pacientes alguns sintomas comuns para doenças diferentes, que estavam relacionados à condição geral de estar enfermo, que ele denominou Síndrome de Adaptação Geral.

Lipp (2003) descreve as fases do estresse iniciando com a fase de alerta, quando a pessoa defronta-se com uma situação estressora. $\mathrm{O}$ organismo prepara-se para lutar ou fugir, gerando um estado de prontidão, caracterizado por taquicardia, alteração da pressão arterial, sudorese, boca seca, mãos e pés frios, mudanças de apetite, diarreia passageira, entre outros.

$\mathrm{Na}$ segunda fase, a resistência, o organismo tenta restabelecer o equilíbrio interno, utilizando toda a energia adaptativa. Pode, assim, apresentar cansaço injustificado, problemas com a memória, sensação de desgaste e irritabilidade (idem, ibidem).

De acordo com Lipp (idem), a fase de quase-exaustão é caracterizada pelo início do processo de adoecimento, pois há um enfraquecimento do sistema imunológico e as defesas do organismo começam a ceder, dando início à quarta fase do estresse, a exaustão. Esta última é considerada a mais patológica, pois há uma quebra total da resistência, ocasionando exaustão psicológica em forma de depressão, exaustão física e doenças como úlceras, aumento da pressão arterial, problemas cardíacos, dermatológicos, sexuais, câncer, e, ainda, pode levar o indivíduo à morte.

A literatura aponta que categorias profissionais como a dos bombeiros (Calais, 2002), dos enfermeiros (Gil-Monte, 2002), dos juízes (Lipp \& Tanganelli, 2002) e dos professores vêm sendo avaliadas como estressoras, devido às situações laborais adversas. $\mathrm{O}$ trabalho do motorista de ônibus urbano também inclui-se nessa categoria.

A atividade de dirigir não é um ato mecânico, mas envolve uma série de requisitos tais como demonstrar percepção de profundidade, orientação espacial, rapidez de reflexos, senso de responsabilidade, atenção, discriminar ruídos, além de demandar um bom es- 
tado de saúde e equilíbrio emocional (Ministério do Trabalho e Emprego, 2009).

Zanelato \& Oliveira (2004) entrevistaram 204 motoristas e identificaram estressores laborais relacionados com: a) condições do trabalho - carga horária elevada, exposição a assaltos, falta de sanitários, movimentos repetitivos e mecânicos, ruídos e vibrações do motor, baixo reconhecimento social, conflitos com passageiros, pressão para cumprir horário e excesso de paradas durante as viagens; b) condições das vias - asfalto irregular, alagamento, congestionamento e travessia inadequada, tanto de pedestres como de condutores; c) condições climáticas - calor excessivo, incidência de raios solares e chuva; e d) condições do veículo - falhas nos equipamentos e falta de manutenção.

É importante salientar que a persistência de tais condições adversas de trabalho pode contribuir para o aparecimento de estresse, doenças ocupacionais, comportamentos inadequados ou de risco e de probabilidade de acidentes de trânsito (Souza \& Silva, 1998; Neri et al., 2005). No entanto, o efeito nocivo dos estímulos estressores também pode estar associado às avaliações realizadas pelo indivíduo, à intensidade do estímulo, ao tempo de duração, à vulnerabilidade da pessoa, à habilidade em administrá-los (Neme et al., 2003) e ao tipo de estratégia de enfrentamento (coping).

Lazarus \& Folkman (1986) consideram que qualquer esforço em lidar com o estressor é uma resposta de coping. Segundo eles, há dois tipos principais de estratégias, ou seja, duas grandes funções do coping. Um deles é centrado no problema, ou seja, atua diretamente no o que causa, com o objetivo de mudar ou eliminar o agente estressor. Geralmente, são situações que podem ser modificadas. O tipo centrado na emoção tem como função reduzir as sensações físicas ocasionadas pelas situações estressoras presentes nas situações que não se pode mudar.

As estratégias de enfrentamento podem ter consequências positivas ou negativas. Por exemplo, um motorista que está ansioso no trânsito pode tanto fumar um cigarro como fazer um treino respiratório. Ambos reduzem a ansiedade, porém só o último está voltado 
para estratégias saudáveis, o que faz parte de uma das características pessoais do indivíduo resiliente.

Outro processo que também pode ser desencadeado frente a estressores é a resiliência. Esta pode ser compreendida como a capacidade do ser humano de superar as adversidades, desenvolvendo, na presença de risco, habilidades de enfrentar e responder de forma assertiva e positiva, ativando recursos pessoais e ambientais que atenuam as consequências negativas, convertendo-se assim em bemestar psicofisiológico, crescimento pessoal e aprendizagem.

Os fatores de risco e de proteção podem ser considerados como variáveis que interferem na resposta da pessoa a uma situação adversa, sendo que o primeiro aumenta a probabilidade do estresse. No caso do motorista, os fatores de risco seriam: o contexto de trabalho estressante; a possibilidade de acidente, morte e assalto; conflitos no relacionamento entre motorista e passageiro. Os fatores de proteção seriam estratégias de enfrentamento eficazes, recursos pessoais, apoio social e familiar, reconhecimento e valorização da profissão e relações positivas com os usuários do transporte.

É importante ressaltar que o conceito de resiliência encontra-se em fase de construção e debate, por tratar-se de um conceito relativamente novo no campo da Psicologia. Esse termo originou-se da Física e refere-se à capacidade de um material absorver energia sem sofrer deformação plástica ou permanente (Yunes, 2003). Do ponto de vista psicológico, Tavares (2001) define resiliência como a capacidade de as pessoas superarem situações adversas, como guerras, assaltos, mortes, maus-tratos físico e psicológico, sem perder seu equilíbrio inicial. Ou seja, o indivíduo é capaz de acomodar-se e reequilibrar-se constantemente.

Em algumas pesquisas que envolvem motoristas de ônibus, como as de Almeida (2002), Barduco (2006), Gianasi (2004), Souza \& Silva (1998) e Zanelato \& Oliveira (2004), nota-se a preocupação com as condições de trabalho e suas consequências para a saúde do trabalhador, com ênfase na doença e nos fatores de risco. No entanto, parece haver uma lacuna quanto a estudos voltados para o desenvolvimento de programas interventivos no ma- 
nejo do estresse com enfoque na promoção da saúde e nos fatores protetores.

Ao desenvolver um programa eficaz de intervenção no manejo ao estresse, questiona-se se haveria implicações quanto ao coping e à resiliência, ou seja, se alterando estas duas variáveis, seria modificado também o nível de estresse. Presume-se que indivíduos menos estressados podem possuir um maior repertório de comportamentos resilientes e melhores formas de lidar com estressores. Dentro dessa perspectiva, o presente estudo teve como propósito analisar a eficácia de um programa de intervenção de manejo do estresse relacionado ao coping e à resiliência em motoristas de ônibus urbano.

Trata-se de uma pesquisa com delineamento quase experimental. Segundo Cozby (2003), esse delineamento foi desenvolvido para atender a uma necessidade de realizar pesquisas aplicadas em situações em que não é possível atingir o mesmo grau de controle que no delineamento experimental e é empregado em contexto de pesquisas de avaliação de programas cujo propósito é atingir algum efeito positivo sobre um grupo de indivíduos. Também é característica desse tipo de pesquisa a formação de um grupo experimental e um de controle, bem como a aplicação de pré e pós-teste.

A amostra foi composta por 38 motoristas de transporte urbano, todos do sexo masculino, sendo divididos em dois grupos: Experimental (GE) e Controle (GC). O maior nível de escolaridade era Ensino Fundamental e quase todos eram casados.

Para a realização da pesquisa foram utilizados cinco instrumentos, a saber:

a) Questionário sociodemográfico dos participantes: elaborado com o objetivo de registrar informações sobre idade, sexo, estado civil, escolaridade, tempo de trabalho como motorista e estado de saúde.

b) Inventário de Sintomas de Stress para Adultos de Lipp (ISSL), validado em 1994 por Lipp \& Guevara e padronizado por Lipp em 2000. Esse instrumento permite avaliar se a pessoa tem estresse, em qual fase encontra-se e qual a área de maior manifestação dos sintomas, se físicos ou psicológicos. 
c) Questionário do índice de resiliência: adultos (Reivich \& Shatté/ Barbosa), elaborado por Reivich \& Shatté em 2002, validado e adaptado para a população brasileira em 2006 por Barbosa. O instrumento possui 56 itens, com respostas tipo likert variando entre (1) nunca, (2) algumas vezes, (3) quase sempre e (4) sempre, que avaliam indicadores de resiliência. Barbosa (2006) define esses indicadores como: administração das emoções, controle dos impulsos, otimismo, análise do ambiente, empatia, autoeficácia e alcançar pessoas.

d) Inventário de estratégias de coping (Folkman \& Lazarus/ Savóia), desenvolvido por Folkman \& Lazarus e adaptado por Savóia (1996). Contém 66 possibilidades de comportamentos e pensamentos emitidos diante de uma situação de vida problemática, com respostas tipo likert variando entre (0) não usei esta estratégia, (1) usei um pouco, (2) usei bastante a (3) usei em grande quantidade. Avalia os fatores: confronto, afastamento, autocontrole, suporte social, aceitação da responsabilidade, fuga e esquiva, resolução de problema e reavaliação positiva.

Em relação aos procedimentos adotados, o programa de estresse foi divulgado por meio de cartazes informativos na empresa de ônibus e por contato pessoal com os motoristas. Depois do prazo final para a inscrição, foram organizados dois grupos experimentais com aproximadamente 13 motoristas em cada grupo. Houve algumas desistências do programa por diversos motivos: problemas de saúde, mudança na escala de trabalho, férias, demissões e desinteresse. Foram, então, organizados os grupos experimentais com 19 motoristas, sendo que dez deles participaram do grupo A e nove participaram do grupo B.

O GC foi formado por 19 motoristas que faziam o mesmo horário e itinerário dos que estavam participando do grupo experimental. Em algumas linhas isso não foi possível, mas houve substituição por motoristas que mais aproximaram-se do grupo experimental no que se refere ao horário de trabalho e ao itinerário.

Foram elaborados dois termos de consentimento, um para o $\mathrm{GE}$ e o outro para o GC, conforme orientava a Resolução MS 196/96 do Conselho Nacional de Saúde. 
Para o GE, na primeira e na última sessão foram aplicados o ISSL e o questionário de indicadores de resiliência, e na segunda e na penúltima sessão foi aplicado o inventário de estratégias de enfrentamento (pré e pós-teste). Os participantes do GE receberam uma intervenção psicológica para controle e prevenção do estresse com oito sessões de aproximadamente duas horas por semana.

As sessões foram desenvolvidas a partir de discussões teóricas e de atividades práticas que abordavam temas como fatores estressantes, conceito e fases do estresse, sintomas físicos e psicológicos, Síndrome de Burnout, técnicas de manejos do estresse (relaxamento, treino respiratório, exercício físico e alimentação), estratégias de enfrentamento (coping), comportamento assertivo, não assertivo e agressivo, rede de apoio familiar e social, e conceito e aplicabilidade da resiliência.

$\mathrm{O}$ GC foi submetido às mesmas avaliações que o GE. Este não recebeu nenhuma intervenção durante a realização do treino de manejo do estresse, o que teve por objetivo verificar somente o efeito da passagem do tempo e depois fazer uma comparação. Foram aplicados os mesmos instrumentos para o GE, antes e depois da intervenção, em datas próximas à aplicação para o GC, exceto no pós-teste, quando houve algumas variações devido a outros compromissos assumidos pelos motoristas.

Para a análise estatística intragrupal e intergrupal foram aplicados o teste qui-quadrado (não paramétrico) somente na variável estresse (presença ou ausência), para verificar se havia associação estatística. Quanto às outras variáveis do ISSL - que são: fase e porcentagem da fase e dos sintomas - foi utilizado o teste não paramétrico de Wilcoxom para análise intragrupal. Foi empregado o teste de coeficiente de concordância (Kappa) no GE e no GC, com o propósito de avaliar a eficácia do programa de manejo de estresse. Para a análise intergrupal foi aplicado o teste de MannWhitney para duas amostras independentes, ou seja, pré-teste do GE e do GC e pós-teste de ambos. Também usou-se o mesmo procedimento para o inventário de estratégias de coping e para o questionário de resiliência, sendo que para todos os testes estatísticos o nível de significância considerado foi de 5\%. 


\section{Resultados e discussão}

De modo geral, o GE e o GC foram similares quanto às variáveis sociodemográficas, sendo que a maioria dos participantes estava na faixa etária entre quarenta e 49 anos (47,4\%), tendo o Ensino Fundamental como maior nível de escolaridade (45\%) e sendo casados (95\%). Em relação à religião, houve predomínio da católica (58\%). O maior tempo de empresa é de cinco anos (45\%) e a maior tempo atuando na profissão é de dez anos (29\%).

Grande parte dos participantes (78\%) mencionou não ter problemas de saúde, porém $1 / 3$ deles já esteve afastado do trabalho por problemas de saúde como diabetes, hipertensão arterial e depressão. Poucos motoristas (10\%) relataram possuir o hábito de fumar, ingerir bebida alcoólica, com resposta nunca ou raramente $(60 \%)$, e praticar exercícios físicos (24\%), entretanto a maioria consome café (85\%). O GE apresentava maior incidência na variável envolver-se em acidente de trânsito (74\%), e com vítimas (32\%).

\section{Estresse}

Na aplicação do pré-teste foi constatado que dos 19 motoristas pertencentes ao GE, seis $(31,58 \%)$ não possuíam estresse e 13 $(68,42 \%)$ possuíam, sendo 11 na fase de resistência e dois na de quase-exaustão, com porcentagens que variam de $8 \%$ a $75 \%$.

A fase de resistência teve frequência maior (85\%). Isso pode ser visto como preocupante, uma vez que os estressores são constantes e muitos deles não estão sob controle, o que possibilitaria levar esses motoristas a evoluir para outras fases do estresse mais patológicas, como a quase-exaustão ou a exaustão. Houve predominância dos sintomas psicológicos, presentes em seis participantes. Dos demais, quatro apresentaram sintomas físicos, e três, físicos e psicológicos.

Após a intervenção, a presença de estresse foi identificada em apenas quatro motoristas, sendo que o participante 1 reduziu a porcentagem da fase resistência de $17 \%$ para $8 \%$, porém foram modificados os 
sintomas de físicos para psicológicos. $\mathrm{O}$ motorista 2 permaneceu igual ao pré-teste, enquanto que o motorista 3 , da fase de quaseexaustão mudou para a de resistência. Apenas o motorista 4 acentuou a porcentagem da fase de resistência e dos sintomas psicológicos.

Os dados apresentados na Tabela 1 demonstraram-se estatisticamente significativos na redução dos itens do ISSL para o GE quanto ao pré e pós teste, mostrando que a intervenção para manejo do estresse apresentou significância quanto à redução deste, (NcNemar $=7,11$ e p = 0,003), verificado também pelo teste estatístico Kappa.

Tabela 1 - Análise estatística intragrupal dos dados do ISSL em motoristas - GE.

\begin{tabular}{lccc}
\hline Fatores & $\begin{array}{c}\text { Média } \\
\text { (pré-teste) }\end{array}$ & $\begin{array}{c}\text { Média } \\
\text { (pós-teste) }\end{array}$ & $\begin{array}{c}\text { Significância } \\
\text { Probabilidade }<\text { 0,05 }\end{array}$ \\
\hline Estresse & 0,69 & 0,21 & $\downarrow(\mathrm{p}=0,001)$ \\
Fase do estresse & 1,48 & 0,42 & $\downarrow(\mathrm{p}=0,0009)$ \\
Porcentagem da fase & 17,26 & 6,58 & $\downarrow(\mathrm{p}=0,013)$ \\
Porcentagem dos sintomas & 37,37 & 7,79 & $\downarrow(\mathrm{p}=0,0004)$ \\
\hline
\end{tabular}

*Teste Wilcoxom

Os resultados do GC mostraram que no pré-teste apenas quatro motoristas (21\%) foram identificados como estressados, estando dois na fase de alerta e dois na fase de resistência, com porcentagens entre $8 \%$ e $33 \%$ e predominância de sintomas psicológicos. No pósteste houve um aumento da quantidade de motoristas com estresse, totalizando dez motoristas (53\%), sendo que dos quatro participantes do pré-teste, dois motoristas avançaram na fase de estresse e os outros dois aumentaram a porcentagem da fase de resistência. Seis motoristas encontravam-se na fase de resistência e com predominância de sintomas psicológicos. Isso coincide com o estudo de Vilela (2004), no qual se obteve redução nos sintomas de estresse dos casais que participaram do GE, enquanto que no GC aqueles permaneceram iguais ou até aumentaram. 
A Tabela 2 informa sobre a análise estatística intragrupal do GC, a qual apontou significância estatística quanto aos itens estresse, sintomas e porcentagens de sintomas $(p=0,03)$; fase $(p=0,007)$. Apenas a porcentagem da fase do estresse não apresentou significância $(\mathrm{p}=0,07)$. Para verificar se houve alteração no nível de estresse no GC, comparou-se o resultado do pré e do pós-teste e obtiveram-se dados significativos quanto ao aumento do estresse $(\mathrm{NcNemar}=$ $8,62$ e $\mathrm{p}=0,003)$.

Tabela 2 - Análise estatística intragrupal dos dados do ISSL em motoristas - GC.

\begin{tabular}{lccc}
\hline Fatores & $\begin{array}{c}\text { Média } \\
\text { (pré-teste) }\end{array}$ & $\begin{array}{c}\text { Média } \\
\text { (pós-teste) }\end{array}$ & $\begin{array}{c}\text { Significância } \\
\text { Probabilidade }<0,05\end{array}$ \\
\hline Estresse & 0,21 & 0,53 & $\downarrow(\mathrm{p}=0,03)$ \\
Fase do estresse & 0,32 & 1,16 & $\downarrow(\mathrm{p}=0,007)$ \\
Porcentagem da fase & 4,21 & 8,95 & $\downarrow(\mathrm{p}=0,07)$ \\
Sintomas & 0,42 & 1,05 & $\downarrow(\mathrm{p}=0,03)$ \\
Porcentagem dos sintomas & 1,63 & 21,26 & $\downarrow(\mathrm{p}=0,03)$ \\
\hline
\end{tabular}

*TesteWilcoxom

A comparação dos resultados intergrupais quanto à variável estresse verificados na Tabela 3 mostrou dados estatisticamente significativos em todos os itens do pré-teste, escores do estresse ( $\mathrm{p}=$ $0,003)$, da fase ( $p=0,0009)$, a porcentagem da fase $(p=0,005)$ e a porcentagem da sintomatologia $(\mathrm{p}=0,007)$. No pós-teste, só não houve diferença quanto à porcentagem da fase $(0,10)$, e os outros resultados mantiveram-se significativos. Verifica-se, que, de modo geral, nas variáveis estresse, fase e porcentagens do pré-teste, o GE apresentou maior nível de estresse, enquanto que no pós-teste houve uma redução deste no GE e aumento no GC. 
Tabela 3 - Análise estatística intergrupal dos dados do ISSL em motoristas.

Intergrupal - Manejo do estresse

Fatores

*Estresse

**Fase do estresse

*** Porcentagem da fase

***orcentagem dos sintomas
GE e GC (pré-teste)

$$
\begin{array}{ll}
(\mathrm{p}=0,003) & (\mathrm{p}=0,04) \\
(\mathrm{p}=0,0009) & (\mathrm{p}=0,04) \\
(\mathrm{p}=0,005) & (\mathrm{p}=0,10) \\
(\mathrm{p}=0,007) & (\mathrm{p}=0,05)
\end{array}
$$

GE e GC (pós-teste)

* Teste de associação qui-quadrado (respostas sim ou não)

*** Teste de Mann-Whitney (escores)

Portanto, comparando-se o pré e pós-teste de cada grupo, verifica-se que o GE teve redução dos níveis, das fases e dos sintomas de estresse, enquanto que o contrário acorreu no GC, com exceção da porcentagem da fase.

\section{Estratégias de enfrentamento (coping)}

No que se refere às respostas ao inventário de estratégias de enfrentamento (coping) apresentadas na Tabela 4, observou-se que houve significância na análise intragrupal do GE, ou seja, aumento de respostas de enfrentamento, comparando pré e pós-teste, quanto a quatro fatores: autocontrole, suporte social, aceitação da responsabilidade e reavaliação positiva. Nos itens afastamento, fuga e esquiva houve redução de respostas. Não houve alteração nas variáveis confronto e resolução de problemas, que, segundo Lazarus \& Folkman (1986), pertencem às estratégias de enfrentamento focadas no problema, as quais possibilitam alterar as relações indivíduoambiente, controlando a situação geradora de tensão.

A Tabela 4 também aponta os resultados da análise intragrupal dos grupos, sendo que no GC verifica-se que apenas a variável reavaliação positiva diminuiu de forma significativa $(\mathrm{p}=0,05)$, do pré para o pós-teste, enquanto os outros itens não se mostraram signi- 
Tabela 4 - Análise estatística intragrupal - GE e GC (coping).

\begin{tabular}{|c|c|c|c|c|c|c|}
\hline \multicolumn{4}{|c|}{ Análise estatística intragrupal (GE) } & \multicolumn{3}{|c|}{ Análise estatística intragrupal (GC) } \\
\hline Estratégias & $\begin{array}{c}\text { Média } \\
\text { (pré-teste) }\end{array}$ & $\begin{array}{c}\text { Média } \\
\text { (pós-teste) }\end{array}$ & $\begin{array}{l}\text { Significância } \\
\mathrm{P}<0,05\end{array}$ & $\begin{array}{c}\text { Média } \\
\text { (pré-teste) }\end{array}$ & $\begin{array}{c}\text { Média } \\
\text { (pós-teste) }\end{array}$ & $\begin{array}{c}\text { Significância } \\
\mathrm{P}<0,05\end{array}$ \\
\hline Confronto & 1,68 & 1,79 & $(\mathrm{p}=0,68)$ & 1,21 & 1,37 & $(p=0,25)$ \\
\hline Afastamento & 2,05 & 1,58 & $\downarrow(\mathrm{p}=0,003)$ & 1,53 & 1,53 & $(\mathrm{p}=1)$ \\
\hline Autocontrole & 2,37 & 2,95 & $\downarrow(\mathrm{p}=0,013)$ & 2,10 & 2,26 & $(\mathrm{p}=0,46)$ \\
\hline Suporte social & 2,89 & 3,32 & $\downarrow(\mathrm{p}=0,027)$ & 2,42 & 2,32 & $(\mathrm{p}=0,62)$ \\
\hline $\begin{array}{l}\text { Aceitação da } \\
\text { responsabilidade }\end{array}$ & 2,37 & 2,89 & $\downarrow(\mathrm{p}=0,003)$ & 2,32 & 2,16 & $(\mathrm{p}=0,57)$ \\
\hline Fuga e esquiva & 2,37 & 1,79 & $\downarrow(\mathrm{p}=0,009)$ & 1,89 & 2,05 & $(p=0,42)$ \\
\hline $\begin{array}{l}\text { Resolução de } \\
\text { problemas }\end{array}$ & 2,79 & 3,05 & $(p=0,19)$ & 2,47 & 2,42 & $(\mathrm{p}=0,84)$ \\
\hline $\begin{array}{l}\text { Reavaliação } \\
\text { positiva }\end{array}$ & 2,68 & 3,16 & $\downarrow(\mathrm{p}=0,013)$ & 2,74 & 2,37 & $\downarrow(\mathrm{p}=0,05)$ \\
\hline
\end{tabular}


ficativos. A diminuição dessa estratégia poderia servir de hipótese para o aumento de estresse, como também para o afastamento ser maior no pré-teste do GE (análise intergrupal), pois o problema não é eliminado à medida que se afasta dele. Apesar de os motoristas enfrentarem os estressores utilizando recursos emocionais, que, segundo Zakir (2003), objetivam modificar situações emocionais momentâneas, os resultados deste estudo apontaram relação entre estresse e coping, sendo que a presença ou a ausência de algumas estratégias de enfrentamento provocou redução no nível de estresse do GE.

De acordo com Dell'Aglio (2003), as funções de coping centrado na emoção ou no problema podem efetivar-se por meio de diferentes estratégias de enfrentamento que são utilizadas pelas pessoas em condições estressantes. $\mathrm{O}$ uso do coping centrado na emoção pode ser explicado, uma vez que a maioria dos estressores presentes no cotidiano dos motoristas não está sob seu controle. Assim, fica inviabilizado o uso das estratégias de confronto e de resolução de problemas em dificuldades como congestionamento, vias com buracos, árvores que atrapalham o acostamento nos pontos de embarque e desembarque e situações que interferem também no cumprimento de horário. Por mais que os motoristas possam ter ações indiretas, como a de informar aos órgãos competentes sobre as dificuldades que encontram ao dirigir no trânsito, não cabe a eles, e sim aos órgãos públicos ou privados, tomar as devidas providências em prol da melhoria do tráfego.

Comparando-se os dois grupos na análise intergrupal, conforme Tabela 5, constata-se que no pré-teste só houve diferença significativa quanto ao item afastamento, sendo maior no GE. No entanto, no pós-teste averigua-se um aumento das respostas de enfrentamento no GE quanto às variáveis autocontrole, suporte social, aceitação da responsabilidade, resolução de problemas e reavaliação positiva. Não houve significância nas estratégias de confronto, afastamento, fuga e esquiva. 


\begin{tabular}{lcccccc}
\hline & \multicolumn{3}{c}{ Análise estatística intragrupal } & \multicolumn{3}{c}{ Análise estatística intragrupal } \\
\hline Estratégias & $\begin{array}{c}\text { Média GE } \\
\text { (pré-teste) }\end{array}$ & $\begin{array}{c}\text { Média GC } \\
\text { (pré-teste) }\end{array}$ & $\begin{array}{c}\text { Significância } \\
\mathbf{P}<\mathbf{0 , 0 5}\end{array}$ & $\begin{array}{c}\text { Média GE } \\
\text { (pós-teste) }\end{array}$ & $\begin{array}{c}\text { Média GC } \\
\text { (pós-teste) }\end{array}$ & $\begin{array}{c}\text { Significância } \\
\mathbf{P}>\mathbf{0 , 0 5}\end{array}$ \\
\hline Confronto & 1,68 & 1,21 & $(\mathrm{p}=0,61)$ & 1,79 & 1,37 & $(\mathrm{p}=0,13)$ \\
Afastamento & 2,05 & 1,53 & $\uparrow \mathrm{GE}(\mathrm{p}=0,01)$ & 1,58 & 1,53 & $(\mathrm{p}=0,98)$ \\
Autocontrole & 2,37 & 2,10 & $(\mathrm{p}=0,15)$ & 2,95 & 2,26 & $\uparrow \mathrm{GE}(\mathrm{p}=0,02)$ \\
$\begin{array}{l}\text { Suporte social } \\
\text { Aceitação da }\end{array}$ & 2,89 & 2,42 & $(\mathrm{p}=0,09)$ & 3,32 & 2,32 & $\uparrow \mathrm{GE}(\mathrm{p}=0,003)$ \\
responsabilidade & 2,37 & 2,32 & $(\mathrm{p}=0,86)$ & 2,89 & 2,16 & $\uparrow \mathrm{GE}(\mathrm{p}=0,005)$ \\
$\begin{array}{l}\text { Fuga e esquiva } \\
\text { Resolução de }\end{array}$ & 2,37 & 1,89 & $(\mathrm{p}=0,12)$ & 1,79 & 2,05 & $(\mathrm{p}=0,33)$ \\
$\begin{array}{l}\text { problemas } \\
\text { Reavaliação }\end{array}$ & 2,79 & 2,47 & $(\mathrm{p}=0,21)$ & 3,05 & 2,42 & $\uparrow \mathrm{GE}(\mathrm{p}=0,01)$ \\
positiva & 2,68 & 2,74 & $(\mathrm{p}=0,92)$ & 3,16 & 2,37 & $\uparrow \mathrm{GE}(\mathrm{p}=0,001)$ \\
\hline
\end{tabular}


O relato verbal dos motoristas (GE) parece exibir mudanças quanto às estratégias de enfrentamento por suporte social, com busca de apoio no próprio grupo, maior envolvimento entre os participantes, sendo levado também para o ambiente familiar, criando espaços de lazer e maior compreensão com filhos e esposa. Quanto às variáveis autocontrole e reavaliação positiva, os participantes mencionaram que adquiriram habilidade de identificar o fator estressor e de lidar com ele por intermédio do controle da irritabilidade, da reavaliação do evento de forma positiva, bem como da adesão às técnicas de manejo do estresse.

Outro dado apresentado é a estratégia de resolução de problema e aceitação da responsabilidade. Os motoristas refletiram e relataram que poderiam solicitar à empresa um cobrador para auxiliá-los; em caso de reclamação de passageiro, deveriam responder a ele educadamente; sentiram a necessidade de ser mais conscientes e criteriosos na eleição do sindicato, além de desenvolver a assertividade. Todas essas ações mostraram-se diretamente relacionadas com a diminuição do estresse. Portanto, os relatos verbais dos motoristas também pareceram indicar que o programa de manejo de estresse teve implicações nas estratégias de enfrentamento.

\section{Resiliência}

Ao analisar estatisticamente intra e intergrupo, não houve diferença significativa nos indicadores de resiliência, exceto a empatia no GC (pós-teste), podendo inferir-se que não houve relação entre estresse e resiliência. Este dado aproxima-se aos do estudo de Belancieri (2007), que investigou a possibilidade de promover o processo de resiliência em enfermeiras de um hospital universitário por meio de intervenção grupal. Em contrapartida, Mota et al. (2006) constataram que pessoas que apresentavam sintomas de doenças de Chagas obtiveram níveis mais elevados de sintomas psicológicos e físicos de estresse e menores de resiliência.

O número de participantes, a falta de controle das variáveis, o foco maior nas técnicas de manejo do estresse, o próprio conceito de 
resiliência compreendida como um processo que se desenvolve no decorrer da vida por meio de características pessoais, todos podem ser algumas das limitações deste estudo, como também o curto espaço de tempo para desenvolver a intervenção. Outra suposição para que o indivíduo desenvolva a resiliência é a presença de fatores de risco, isto é, momentos críticos e de adversidade, que estimulam o aumento da resiliência. E durante a aplicação de um programa não é possível controlar todas as variáveis, dificultando a descrição das relações contingenciais.

De acordo com Assis et al. (2006), o termo enfrentar tem conotação restrita a agir frente ao problema, não dando indicativos sobre o modo de atuação da pessoa. Superar refere-se à resolução do problema, ao encaminhamento ou à adaptação positiva.

Assim, tem-se a hipótese de que o coping possui caráter situacional e está ligado diretamente à resposta aos agentes estressores, pois desde a fase de alerta do estresse ele é acionado, ao emitir-se comportamento de enfrentamento ou fuga. A resiliência, no entanto, parece ter aspecto mais desenvolvimentista, no sentido que é construída nas interações ambientais associadas à história de vida e às variáveis individuais, construídas em longo prazo. Partindo-se desse entendimento, ao colocar em ação estratégias de enfrentamento positivo diante de situações estressoras, poderia supor-se que o processo de resiliência estaria sendo desenvolvido.

\section{Considerações finais}

O objetivo maior desta pesquisa foi proporcionar aos motoristas atitudes mais eficazes para enfrentar o estresse, voltadas para ações que beneficiem a saúde. Nos estudos encontrados nesta área, a ênfase era, em sua maioria, nas questões aversivas do trabalho e direcionadas para a doença ocupacional.

O programa de intervenção pareceu propiciar redução do nível de estresse e desenvolvimento de estratégias de enfrentamento mais positivas, pois à medida que se alteram as estratégias de enfrenta- 
mento, verificam-se também mudanças no nível de estresse. Um dos objetos de enfoque da pesquisa, a comparação dos escores de resiliência antes e depois do manejo de estresse, não apresentou alterações, mas trouxe uma hipótese a ser mais bem investigada: o caráter processual da resiliência.

Quanto ao procedimento, devido à maioria dos motoristas possuir somente Ensino Fundamental, sugere-se que a aplicação não seja coletiva, para dar maior suporte a dúvidas e dificuldades de compreensão do texto. $\mathrm{O}$ grande número de perguntas contidas nos instrumentos pode levá-los a dar respostas menos refletidas.

Este estudo, no entanto, não esgota o assunto, mas levanta alguns pontos de reflexão, ampliando as discussões sobre a relação dos processos adaptativos ocupacionais: estresse, coping e resiliência. Sugere-se que novas pesquisas sejam feitas com amostra maior e com maior tempo de duração; introduzir estudos de follow-up para acompanhar as mudanças ocorridas e percebidas pelos participantes, e sugere-se o estudo de aspectos das empresas de transporte urbano que podem contribuir para o desencadeamento do estresse ou para a promoção da resiliência.

Considerando-se as condições estudadas neste trabalho como importantes na qualidade de vida do trabalhador, estratégias de prevenção deveriam ser empregadas para aquele, estratégias estas que devem voltar-se ao nível individual e ao coletivo. No primeiro, envolver uma ação integrada por meio de uma equipe multiprofissional em prol da redução dos sintomas físicos e psicológicos do indivíduo ocasionados pelos estressores. No nível coletivo, focar o contexto organizacional com mudanças na cultura da empresa, propiciando melhores condições de serviço e interferindo de maneira positiva na relação entre indivíduo e trabalho.

Entende-se, por fim, serem necessárias ações de caráter contínuo, pois à medida que se altera o ambiente, altera-se o indivíduo, e vice-versa, o que contribui para uma melhor qualidade de vida dos motoristas, para a melhoria dos serviços prestados aos passageiros e para a prevenção de possíveis acidentes de trânsito e doenças ocupacionais. 


\section{Referências bibliográficas}

ALMEIDA, N. D. V. Contemporaneidade x trânsito: reflexão psicossocial do trabalho dos motoristas de coletivo urbano. Psicologia: ciência e profissão. v.1, n.3, p.62-9, 2002.

ASSIS, S. G. et al. Superação de dificuldades na infância e adolescência: conversando com profissionais de saúde sobre resiliência e promoção da saúde. Rio de Janeiro: Fiocruz; ENSP; Claves; CNPQ, 2006. BARBOSA, G. S. Resiliência em professores do Ensino Fundamental de $5^{a}$ a $8^{a}$ série: validação e aplicação do Questionário de índice de resiliência: adultos Reivich-Shatté/Barbosa. Tese (Doutorado). Pontifícia Universidade Católica de São Paulo,São Paulo, 2006.

BARDUCO, R. C. Motorista de ônibus urbano: insatisfação e desconforto com a poltrona. Dissertação (Mestrado, Desenho Industrial). Faculdade de Arquitetura, Artes e Comunicação. Universidade Estadual Paulista Júlio de Mesquita Filho, Bauru, 2006.

BELANCIERI, M. F. Promoção do processo de resiliência em enfermeiras: uma possibilidade? Tese. Pontifícia Universidade Católica de São Paulo, São Paulo, 2007.

CALAIS, S. L. Stress pós-traumático: intervenção clínica em vítimas secundárias. Tese (Doutorado). Pontifícia Universidade Católica de Campinas, Campinas, 2002.

COZBY, P. C. Delineamentos quase experimentais, delineamentos com sujeito único e delineamentos de pesquisa sobre desenvolvimento. In: _. Métodos de pesquisa em ciências do comportamento. São Paulo: Atlas, 2003, p.237-56.

DELL'AGLIO, D. D. O processo de coping em crianças e adolescentes: adaptação e desenvolvimento. Temas em Psicologia da SBP. v.11, n.1, p.38-45, 2003.

GIANASI, L. B. S. As fontes de desgaste físico e emocional e a Síndrome de Burnout no setor de transporte coletivo urbano de Natal. Dissertação (Mestrado). Universidade Federal do Rio Grande do Norte, Rio Grande do Norte, 2004.

GIL-MONTE, P. Influencia del género sobre el proceso de desarrollo del síndrome de quemarse por el trabajo (burnout) em profesionales de enfermaría. Revista Psicologia em Estudo. v.7, n.1, p.3-10, 2002.

LAZARUS, R. S.; FOLKMAN, S. Estrés y procesos cognitivos. Tradução de M. Zaplana. Barcelona: Martinez Roca, 1986. 
LIPP, M. E. N. Manual do Inventário de Sintomas de Stress para adultos de Lipp (ISSL). 2.ed. São Paulo: Casa do Psicólogo, 2000.

O modelo quadrifásico do stress. In: (Org.). Mecanismos neuropsicofisiológicos do stress: teoria e aplicações clínicas. São Paulo: Casa do Psicólogo, 2003, p.17-21.

; TANGANELLI, M. S. Stress e qualidade de vida em magistrados da Justiça do Trabalho: diferenças entre homens e mulheres. Psicologia Reflexão e Crítica. Rio Grande do Sul, v.15, n.3, p.537548, 2002.

MENDES, A. L. A. Situação de trabalho e estresse ocupacional: um estudo de caso com os motoristas de transporte urbano por ônibus. Dissertação (Administração Comportamento Humano nas Organizações). Universidade Federal de Minas Gerais. Minas Gerais, 2000.

MINISTÉRIO DO TRABALHO E EMPREGO. Classificação brasileira de ocupações. Brasília. Disponível em: <http:// www.mtecbo.gov.br/busca/descricao.asp? codigo $=7824>$. Acessoem : 13 maio 2009.

MOTA, D. C. G. A et. al. Estresse e resiliência em doenças de chagas. Revista Aletheia. n.24, p.57-68, 2006.

NEME, C. M. B; SOLIVA, S. N.; RIBEIRO, E. J. História prévia de eventos de estresse e câncer de mama, útero e ovários. In: Psicologia da saúde: perspectivas interdisciplinares. São Carlos: Rima, 2003, p.95-124.

NERI, M.; SOARES, W. L.; SOARES, C. Condições de saúde no setor de transporte rodoviário de cargas e passageiros: um estudo baseado na pesquisa nacional por amostra de domicílios. Revista Caderno Saúde Pública. v.21, n.14, p.1107-23, 2005.

REIVICH, K.; SHATTÉ, A. The resilience factor: 7 essential skills for overcoming life's inevitable obstacles. New York: Broadway Books; Random House, 2002.

SAVOIA, M. G. Escalas de eventos vitais e de estratégias de enfrentamento (coping). Revista Psiquiatria Clínica. v.2, n.26, p 57- 67, 1999.

SELYE, H. The stress of life. New York: McGraw-Hil, 1956.

SOUZA, A. F. M.; SILVA, G. R. Risco de distúrbios psiquiátricos menores em áreas metropolitanas na região Sudeste do Brasil. Revista de Saúde Pública. São Paulo, v.32, n.1, p.50-8, 1998. 
TAVARES, J. (Org.). Resiliência e educação. São Paulo: Cortez, 2001. VILELA, M. V. Stress no relacionamento conjugal. In: LIPP, M. E. N. O stress no Brasil: pesquisas avançadas. Campinas: Papirus, 2004, p.51-160.

YUNES, M. A. M.; SZIMANSKI, H. Resiliência: noção, conceitos afins e considerações críticas. In: TAVARES, J. (org.). Resiliência e educação. São Paulo: Cortez, 2001, p.13-42.

ZAKIR, N. S. Mecanismos de coping. In: LIPP, M. E. N. (Org.). Mecanismos neuropsicofisiológicos do stress: teoria e aplicações clínicas. São Paulo: Casa do Psicólogo, 2003.

ZANELATO, L. S.; OLIVEIRA, L. C. Fatores estressantes presentes no cotidiano dos motoristas de ônibus urbano. In: II Seminário Internacional de Pesquisas e Estudos Qualitativos: a pesquisa qualitativa em debate, 2004, Bauru. ANAIS. Disponível em: <.http:// www.sepq.org.br>. Acesso em: 25 jun. 2010. 


\title{
12 \\ PACIENTES COM LÍOUEN PLANO ORAL: AVALIAÇÃO DE EFICÁCIA ADAPTATIVA EM ESTUDO LONGITUDINAL ${ }^{1}$
}

\author{
Mirella Martins Justi \\ Carmen Maria Bueno Neme
}

\section{Introdução}

O Líquen Plano (LP) é uma desordem mucocutânea, com evidências de associação a uma resposta imune celular mediada, que pode apresentar manifestações em pele, em mucosa ou em ambos (Miguel et al., 2003). Segundo Neville et al. (2004), essa patologia foi inicialmente descrita pelo médico britânico Erasmus Wilson, em 1869, que possivelmente associou a aparência das lesões a liquens crescendo em rochas. Sua etiologia é ainda desconhecida, e seu diagnóstico, controverso, embora seja atualmente considerada uma das doenças dermatológicas da cavidade bucal mais comuns, com prevalência de $1 \%$ a $2 \%$ na população geral. Sua manifestação bucal e/ ou cutânea apresenta um variado espectro de características clínicas, com surgimento de manchas ou placas opacas em rede ou ramificadas (estrias de Wickham), de coloração branco-acinzentada e localizadas mais frequentemente nas bochechas, na língua, no lábio, no palato e na gengiva (Monti et al, 2006). Como consequência,

1 Este trabalho é parte de dissertação de mestrado em Psicologia do Desenvolvimento e da Aprendizagem, FC-Unesp, campus de Bauru. 
os pacientes acometidos acabam por procurar cuidados tanto dos dermatologistas como dos dentistas, tornando indispensável a integração entre essas duas especialidades (Dorta et al., 2000).

Ao descrever suas manifestações, Neville et al. (2004) apontam que o LP pode apresentar-se de variadas formas: reticular, papular, placa, atrófico, erosivo e bolhoso. Em algumas classificações, as lesões são distribuídas em dois grandes grupos: pacientes sintomáticos e pacientes assintomáticos.

A partir da década de 1960, foi sugerida possível natureza prémaligna do Líquen Plano Oral (LPO). Desde então, a literatura tem confirmado esse possível caráter pré-maligno (Colombini, 1987; Tommasi, 1988; Marcussi, 1997; Rodrigues, 1999), e a Organização Mundial da Saúde (OMS) o define como uma condição cancerizável, a despeito de controvérsias quanto ao seu potencial de malignização. Pesquisadores, como Dorta et al. (2000), sugerem a necessidade de estabelecer-se critérios diagnósticos que permitam a realização de estudos de longa duração e com protocolos bem definidos, permitindo maior segurança quanto à natureza cancerizável do LPO.

Para o diagnóstico diferencial e a indicação da terapêutica adequada, o paciente com LPO deve ser submetido a uma entrevista de anamnese cuidadosa (Prado et al., 1994). Fatores etiológicos, como íons mercuriais provenientes de restaurações de amálgama e drogas como antiinflamatórios não esteroides, entre outras substâncias, podem induzir a lesões chamadas reações liquenoides. Tanto o diagnóstico de LPO quanto o diagnóstico diferencial entre LPO e as reações liquenoides são estabelecidos por meio de biópsia. Confirmado o diagnóstico, o tratamento tem como objetivo o alívio dos sintomas, pois a cura nem sempre é possível. Segundo Regezi \& Sciubba (2000), os corticoesteroides são os medicamentos de escolha no tratamento do LP, o que se deve à sua capacidade de modular a resposta inflamatória e imunológica.

Entre as causas sugeridas do LPO incluem-se traumatismos, má nutrição e infecções. O curso da doença é longo, de meses a vários anos, passando com frequência por períodos de remissão seguidos 
de exacerbações que, muitas vezes, correspondem a períodos de perturbações emocionais, estresse ou alguma forma de tensão mental (Shafer, 1985). Sugerman et al. (2002) acreditam que mecanismos imunológicos específicos e não específicos podem estar envolvidos em sua etiopatogenia e que a cronicidade da doença pode ser explicada, em parte, por uma deficiência nos mecanismos de imunossupressão, embora os fatores que levam ao início desse processo ainda não sejam totalmente esclarecidos.

Nos últimos anos, certas condições psicológicas, como níveis exacerbados de estresse e ansiedade, têm sido fortemente associadas ao LP (Vallejo et al., 2001; Chaudhary, 2004; Monti et al., 2006; Hoffmann et al., 2005). Embora tal associação seja conhecida há décadas, a dificuldade em mensurar-se de modo objetivo tais variáveis fez com que só recentemente a importância da ansiedade e do estresse na etiopatogenia do LP passasse a ser amplamente reconhecida, tornando-os alvo de novas pesquisas (Sousa \& Rosa, 2008).

Associações entre patologias físicas e psíquicas têm sido confirmadas por estudos, buscando preencher lacunas que expliquem as interações entre os fenômenos psicossociais e importantes patologias humanas, como as doenças autoagressivas, infecciosas, neoplásicas e alérgicas. Entretanto, ainda não se conhecem os mecanismos pelos quais o organismo estabelece "adequada" ou "má" resposta diante do estresse.

Segundo Neme (1999), a visão sistêmica do funcionamento biopsicossocial, clarificada por pesquisas no campo da psiconeuroimunologia, apontou o papel de variáveis cognitivo-afetivas em diversas condições e doenças, e a necessidade de intervenções interdisciplinares e mais abrangentes, não limitadas à dimensão biológica do adoecimento. Considerando os postulados de Solomon (1999) sobre as interações entre o sistema imunológico e o sistema nervoso, pode-se indicar diversas possibilidades de relações de influência entre fatores psicológicos e o funcionamento imunológico. O estresse, tanto experimental (Solomon, 1969) como natural (Kiecolt-Glaser et al., 1987), está associado à imunossupressão. Acontecimentos que produzem uma ativação específica, conhecida como estresse agudo, 
induzem a elevação da função imunológica, enquanto o estresse crônico induz a diminuição da competência imunológica (Dhabhar \& McEwen, 1996; Naliboff et al.,1991).

Os efeitos do estresse também podem ser verificados em estudos que, utilizando intervenções psicológicas e outros recursos paralelos para seu manejo e redução, mostram o retorno do organismo aos níveis homeostáticos anteriores à ação dos estressores. Ulla \& Remor (2002) e Sardá Junior et al. (2004) citam estudos que utilizam técnicas de relaxamento como recurso efetivo para a redução do estresse. Ao lado de observações e estudos clínicos em psicologia, nos quais as técnicas de relaxamento são utilizadas junto a outras intervenções, encontra-se na literatura psicológica brasileira vasto trabalho desenvolvido por Lipp \& cols., demonstrando a eficácia do uso dessas técnicas como parte essencial de programas de controle do estresse em pacientes com diferentes tipos de patologias e em pessoas de diversas categorias profissionais (Lipp, 1996; 2003; Lipp \& Rocha, 1996; Lipp et al., 2007).

No campo da Psicologia, de acordo com Neme (1999), os interrelacionados fenômenos do estresse, enfrentamento e adaptação têm sido estudados com base em suas principais correntes teóricas, destacando-se as perspectivas psicanalítica e cognitiva, sobretudo a partir de 1960. Pesquisas sobre o estresse e o enfrentamento mostram as diferenças individuais no modo de lidar com o estresse, superando-o ou não. Essas variações dependem de múltiplos fatores, como sexo, idade, cultura, valores pessoais, história de vida, experiências anteriores de enfrentamento e variáveis de personalidade, além de recursos intelectuais, cognitivos e sociais (Lazarus \& Folkman, 1986; Mello Filho, 1992; Neme, 1999; 2005; Neme et al., 2003).

Ulla \& Remor (2002) citam diversas pesquisas realizadas com o objetivo de identificar relações entre estilos de enfrentamento e alterações na imunocompetência, assim como formas de enfrentamento mais adaptativas, que não reduziram a incompetência imune. Para Freitas \& Oliveira (2006), o indivíduo, visto como um ser biopsicossocial, possui mecanismos adaptativos inatos e adquiridos, os quais lhe permite adaptar-se a mudanças, sejam internas ou ex- 
ternas. A adaptação é influenciada pelo desenvolvimento de sistemas de enfrentamento reguladores (transmissores químicos, neurais e endócrinos) e cognoscentes (cerebrais superiores de percepção, julgamento e emoção).

Adaptação, para Simon (1989), é o conjunto de respostas de um organismo vivo, apresentado em diferentes momentos, frente a situações que o modificam, permitindo a manutenção de sua organização compatível com a vida. Para o autor, a capacidade de adaptação permite-nos separar os organismos vivos dos não vivos.

O desenvolvimento de habilidades adaptativas está relacionado à experiência de situações de crise, as quais são necessárias para a emergência de recursos adaptativos. Em uma concepção psicodinâmica, Dameto (2007) ressalta que a própria consciência que temos da realidade é, por si, geradora de angústia, e esta predispõe o ego ao dispêndio de energia para enfrentar os dissabores e manter a adaptação estável por um prazo maior.

Constata-se, assim, a complexidade e a interdependência dos fenômenos do estresse, do enfrentamento e da adaptação, bem como a necessidade de que tais conceitos sejam entendidos no contexto de tal interdependência. As relações de influência entre estresse, alterações psicoimunológicas e o aparecimento de várias doenças, incluindo o LPO, apontadas por diferentes estudos, fundamentam a necessidade de que o profissional de saúde desenvolva métodos e técnicas capazes de melhor diagnosticar e intervir, auxiliando os indivíduos a lidar com suas fontes de estresse e a desenvolver adaptações não patológicas. A literatura aponta a relevância da realização de estudos interdisciplinares que busquem abarcar a complexidade dos fenômenos biopsicossociais implicados na gênese de diferentes doenças, bem como colaborar para o controle ou cura dessas doenças.

O trabalho interdisciplinar é valorizado em diferentes pesquisas e apontado como aspecto de relevância científica. De acordo com Vasconcellos (2000), a interface entre campos do conhecimento humano é fundamental para a área da saúde, especialmente para as próximas décadas. Sem o exercício da interdisciplinaridade, segundo o autor, tornaremo-nos fomentadores de uma profunda iatrogenia e 
responsáveis pelo descrédito e malefício não apenas no atendimento dos pacientes, mas também em nossas profissões.

Considerando a escassez de estudos sobre o LPO, suas relações com o estresse e o funcionamento imune, e a necessidade de desenvolver-se avaliações e intervenções psicológicas que se mostrem efetivas para a melhoria da capacidade adaptativa e para a redução de danos orgânicos induzidos por estresse, principalmente de modo longitudinal, realizou-se este estudo, na interface entre a Psicologia e a Odontologia. O objetivo foi o de realizar estudo longitudinal de dez pacientes que em 2003 foram diagnosticados com LPO, passaram por avaliação odontológica e psicológica e por psicoterapia breve grupal, foram reavaliados após a psicoterapia e, em 2008, foram novamente avaliados com relação às lesões do LPO e à eficácia adaptativa. Foram também investigadas as condições de saúde e a ocorrência de eventos de estresse no período de cinco anos entre as avaliações, de acordo com o relato dos participantes, comparando-se essas variáveis.

\section{Método}

O estudo focalizou dez casos clínicos submetidos a avaliações odontológicas e psicológicas e a intervenções psicoterápicas em três momentos distintos: antes da psicoterapia, após a psicoterapia e cinco anos após seu término. A avaliação psicológica consistiu na identificação e análise da eficácia adaptativa dos participantes, realizada por meio da EDAO-R (Escala Diagnóstica Adaptativa Operacionalizada - Redefinida). A técnica psicoterápica utilizada foi a Psicoterapia Breve Operacionalizada (PBO), com base nas propostas de Simon (2005), adaptada pela pesquisadora para a forma grupal.

A EDAO foi considerada adequada para este estudo por ter sido desenvolvida para avaliar a eficácia da adaptação, ou seja, a capacidade dos indivíduos de responder adequadamente a situações-problema da vida. Na versão atual - Redefinida (EDAO-R) - são quantificados o setor Afetivo-Relacional (A-R) e o da Produtivida- 
de $(\mathrm{Pr})$, sendo que os demais, Sociocultural (S-C) e Orgânico (Or) são objeto de avaliação qualitativa, instrumentalizando a Psicoterapia Breve Operacionalizada (PBO).

A PBO, modelo de psicoterapia breve também criado por Ryad Simon, é focalizada nas situações-problema atuais e em suas interações com os setores adaptativos (A-R, Pr, S-Ce Or), detectados por meio da EDAO-R. A PBO visa levar o paciente a compreender as razões de suas soluções pouco adequadas e, consequentemente, reformular as soluções pouco ou pouquíssimo adequadas nos quatro setores adaptativos (Alves, 2001).

Para a coleta de dados do estudo, além da EDAO-R, foram utilizados os instrumentos: relatórios de sessões da $\mathrm{PBO}$; medidas de lesões de LPO, realizadas por odontólogo colaborador nas duas avaliações; roteiro de entrevista sobre estresse, enfrentamento e saúde, elaborado apenas para a segunda avaliação e composto por itens sobre os temas "ocorrências de doenças no período de 2003 a 2008", "ocorrências de lesões de LP oral ou não no período de 2003 a 2008" e "eventos de estresse no período de 2003 a 2008 nas áreas da saúde, social, do trabalho, das relações familiares e afetivo-sexuais, e outras"; mudanças observadas em diferentes áreas da vida, percebidas como ganhos obtidos na psicoterapia realizada em 2003; e opinião do participante sobre ter ou não alguma lesão de LPO no presente e qual motivo dessa opinião.

A coleta de dados, em ambas as avaliações, ocorreu no PromoVi (Centro de Promoção da Qualidade de Vida), unidade vinculada à Faculdade de Odontologia de Araçatuba - FOA/Unesp.

Participaram do estudo nove mulheres e apenas um homem, visto que a maioria dos pacientes em tratamento na instituição na qual os dados foram coletados era de mulheres, de modo concordante com a literatura sobre LPO, doença que ocorre em cerca de 1\% a 2\% da população geral, aparecendo com maior frequência entre mulheres (Monti et al., 2006; Sousa \& Rosa, 2008).

Com relação à faixa etária, a literatura mostra prevalência do LPO em pessoas de meia-idade (Araya et al., 2004; Seoane et al., 2004), o que se evidenciou na amostra deste estudo, em que a faixa etária dos 
portadores variou da quarta à sexta década de vida, com média de 65,5 anos.

Todos os participantes apresentavam ao menos uma lesão de LPO na primeira avaliação e nenhum deles tomou medicação ou fez tratamento para LPO nos cinco anos de intervalo entre as duas avaliações.

\section{Primeira avaliação}

Após aprovação pelo Comitê de Ética em Pesquisa da Faculdade de Odontologia da Unesp de Araçatuba, 76 pacientes foram identificados junto ao setor de triagem do Laboratório de Patologia da instituição, listados e contatados por meio de cartas-convocação. Compareceram nos dias agendados para o primeiro contato 32 pacientes, que foram individualmente informados sobre a pesquisa e optaram por participar ou não desta. Dez sujeitos aceitaram participar da pesquisa e assinaram o Termo de Consentimento Pós-Esclarecido; dois pacientes não apresentavam mais a lesão e foram dispensados; seis utilizavam medicação para LPO (corticoides) e foram excluídos; e 15 não se dispuseram ou alegaram não poder participar da psicoterapia e do estudo. Os dez pacientes que aceitaram participar compuseram a amostra e foram submetidos a exames histopatológicos (biópsias) para a confirmação do LPO. Então, foram entrevistados individualmente, de acordo com a EDAO-R, e passaram por consulta com os odontólogos colaboradores (Faculdade de Odontologia da Unesp, campus de Araçatuba) para a mensuração das lesões de LPO. Depois das avaliações, participaram de 12 sessões grupais de PBO, conduzidas pela psicóloga pesquisadora e por outra psicóloga coterapeuta, que registrou as sessões.

A PBO teve como foco a sintomatologia e a adaptação dos participantes frente às situações-problema enfrentadas, consideradas crises ou fontes de estresse, com base nos informes obtidos nas entrevistas prévias (EDAO-R) e no que emergia durante as sessões. Também ocorreram, ao final das sessões, práticas da Técnica de 
Relaxamento Progressivo de Jacobson (Sarda Júnior et al., 2004). A PBO ocorreu nos moldes propostos por Simon (1989), incorporando-se o recurso do relaxamento progressivo, dado o potencial dessa técnica em reduzir os efeitos do estresse e, consequentemente, auxiliar no tratamento de doenças orgânicas a ele associadas.

Ao final das 12 sessões de psicoterapia, os participantes realizaram novas entrevistas individuais (EDAO-R) e novas mensurações de lesões de LPO, encerrando a primeira avaliação.

\section{Segunda avaliação}

Os dez pacientes que participaram dos procedimentos em 2003 foram contatados por telefone e convidados novamente a participar do estudo. Após a obtenção do consentimento, as entrevistas foram realizadas (EDAO-R e Roteiro de Entrevista sobre Estresse, Enfrentamento e Saúde) e, em seguida, as medidas de lesão de LPO foram tomadas. As entrevistas foram gravadas em áudio e posteriormente transcritas. Essa avaliação (realizada em 2008) visou verificar se os ganhos obtidos pelos pacientes quanto à capacidade de lidar com o estresse e de realizar adaptações eficazes, obtidos em 2003, foram ou não mantidos, além da mensuração das lesões atuais de LPO, dado o caráter inconstante que essas lesões podem apresentar.

A faixa etária dos participantes ficou entre 58 e 74 anos, com uma média de 65,2 anos (desvio padrão de 5,09), sendo que na primeira avaliação a faixa etária era de 53 a 69 anos de idade (média de 60,2 e mesmo desvio padrão). Na segunda avaliação, cinco participantes estavam aposentados (participantes 1, 4, 5, 7 e 9), sendo que o único homem ainda trabalhava após a aposentadoria. Dentre as demais, uma (participante 10) trabalhava como empregada doméstica e quatro (participantes 2, 3, 6 e 8) descreveram-se como "do lar". Oito participantes declararam-se casados, uma participante ficou viúva há cerca de um ano e outra era solteira.

Foram tomados todos os cuidados éticos e realizados todos os procedimentos éticos exigidos para a realização de pesquisas com 
seres humanos, incluindo esclarecimentos aos participantes antes e após cada avaliação.

A Tabela 1 apresenta os dados demográficos dessa amostra.

Tabela 1 - Dados demográficos da amostra.

\begin{tabular}{ccccc}
\hline Participante & Sexo & Profissão/ocupação & Idade & Estado civil \\
\hline 1 & Feminino & Aposentada & 74 & Casada \\
2 & Feminino & Do lar & 70 & Casada \\
3 & Feminino & Do lar & 66 & Viúva \\
4 & Feminino & Aposentada & 60 & Casada \\
5 & Feminino & Aposentada & 58 & Casada \\
6 & Feminino & Do lar & 58 & Casada \\
7 & Feminino & Aposentada & 65 & Solteira \\
8 & Feminino & Do lar & 68 & Casada \\
9 & Masculino & Aposentado & 68 & Casado \\
10 & Feminino & Empregada doméstica & 65 & Casada \\
\hline
\end{tabular}

\section{Resultados e discussão}

Quanto à eficácia adaptativa dos participantes obtida na primeira avaliação (antes e após a PBO), constatou-se importante melhora adaptativa, de acordo com a EDAO-R, em cinco dos dez casos. Nos demais ocorreu a permanência no mesmo nível adaptativo anterior à $\mathrm{PBO}$, sendo que um paciente saiu da situação de crise em que se encontrava, mas permaneceu com a mesma classificação diagnóstica, não ocorrendo qualquer caso de piora adaptativa após a PBO. Nenhum dos casos apresentou indicativo de estar em crise nos diagnósticos adaptativos após a PBO.

Quanto às mensurações das lesões bucais realizadas antes e após a psicoterapia, os resultados demonstraram a melhora do LPO, constatada pela diminuição das lesões em nove dos dez casos, com um deles apresentando remissão total. Em seis dos dez casos houve concordância entre os resultados da EDAO-R e das medidas de lesão de 
LPO, observando-se diminuição das lesões bucais e melhora na eficácia adaptativa. Em um dos casos ocorreu remissão total das lesões de LPO e o paciente saiu da crise psicológica anterior à psicoterapia.

Os resultados da primeira avaliação indicaram melhora em todas as lesões de LPO e melhora da eficácia adaptativa em seis dos dez casos após a psicoterapia, sugerindo que a $\mathrm{PBO}$ possivelmente teve influência na melhora verificada nesses participantes quanto ao manejo do estresse e de adaptações eficazes, bem como na diminuição das lesões do LPO.

Para a análise dos dados foram considerados como melhora os resultados da EDAO-R que apontaram evolução positiva em comparação ao resultado anterior e também os casos que na avaliação de 2008 mantiveram o diagnóstico adaptativo positivo obtido após a $\mathrm{PBO}$. O caso que apresentou resultados iguais nas três avaliações foi considerado como em manutenção e os casos que apresentaram resultados piores com relação aos anteriores foram chamados de piora.

Com base nos resultados obtidos quanto à eficácia adaptativa em 2003, antes e após a PBO, constatou-se evolução positiva nos diagnósticos adaptativos. Logo após a PBO, 60\% (seis) dos participantes apresentaram melhora e 40\% (quatro) indicaram manutenção nos diagnósticos adaptativos. Cinco anos após a PBO, 40\% (quatro) tiveram melhora no diagnóstico adaptativo, 30\% (três) mantiveram a mesma avaliação e 30\% (três) tiveram evolução negativa (piora) nos diagnósticos adaptativos obtidos.

A respeito da ocorrência de lesões de LPO entre 2003 e 2008, de acordo com os relatos dos participantes, nenhum referiu ter percebido a ocorrência de nova lesão de LP na cavidade bucal ou em outro local do corpo e também não realizou tratamento para LP. As mensurações de lesão de LPO realizadas cinco anos depois da psicoterapia indicaram que quatro participantes ainda eram portadores de lesões e seis não apresentavam lesões de LP.

Com a finalidade de facilitar a análise dos resultados das mensurações, optou-se por definir como melhora os casos em que ocorreu diminuição e/ou remissão das lesões de LPO quando comparadas com o resultado anterior; como manutenção os casos em que não hou- 
ve alteração das dimensões das lesões de LPO e como piora os casos em que constatou-se aumento das dimensões das lesões e/ou surgimento de novas lesões.

Ao comparar os resultados obtidos das mensurações das lesões de LPO, constata-se que depois da PBO, em 2003, houve melhora nas dimensões de todas as lesões apresentadas na primeira mensuração. Cinco anos após a PBO, verificou-se seis casos de melhora (60\%), um caso de manutenção das mesmas medidas (10\%) e três casos (30\%) de piora quanto ao tamanho das lesões de LPO. Destaca-se, portanto, que todos os pacientes tiveram melhora das lesões de LPO após a psicoterapia e que após cinco anos do tratamento psicoterápico, seis pacientes apresentaram remissão total das lesões e um foi avaliado como tendo mantido a melhora obtida após a PBO. Entre os três casos que tiveram aumento das lesões de LPO, tal aumento foi considerado importante, já que em todos os casos as lesões aumentaram mais que o dobro do tamanho que tinham em 2003.

Além da EDAO-R e da mensuração das lesões de LPO, na avaliação em 2008 os pacientes foram questionados sobre suas condições de saúde nos cinco anos entre as avaliações, bem como sobre eventos de estresse ocorridos no período.

Entre os dez participantes, quatro relataram ter passado por problemas de saúde, como gastrite hipertensão e hipotiroidismo, hérpes zoster, retração de gengiva e sintomas de "nervosismo". Tais sintomas também relacionam-se a fatores de estresse, conforme encontrado na literatura (Mello Filho \& Moreira, 1992).

Ao estudar as condições de saúde de pacientes com LPO, Femiano et al. (2004) e Monti et al. (2006) encontraram doenças sistêmicas, como o diabetes e a hipertensão, como as mais frequentes. Sabe-se que essas doenças, comuns na população brasileira, relacionam-se a desequilíbrios físicos e psicológicos. Além disso, os pacientes entrevistados no estudo mencionado declararam que o surgimento ou a piora das lesões de LPO ligavam-se a experiências de aborrecimentos, nervosismo, ansiedade e situações estressantes, fortalecendo a constatação das condições emocionais na etiologia do LPO. 
Com relação aos eventos de estresse ocorridos no período entre as avaliações, todos os participantes referiram ter passado ao menos por pequenos aborrecimentos comuns do cotidiano, como discordâncias com o cônjuge ou com familiares, insatisfações financeiras e eventos similares, os quais podem ser potencialmente mais geradores de patologias do que os grandes estressores (Lazarus \& Folkman, 1986; Neme, 1999). Dos dez participantes, sete relataram eventos de estresse significativo no período entre as duas avaliações e foram indagados sobre como reagiram a eles e os enfrentaram, considerando as importantes relações entre estresse e enfrentamento. Estes referiram maior número de situações de estresse na área das relações familiares, seguida da área da saúde e do trabalho, o que é concordante com o encontrado por Neme (2005) e por Neme et al. (2003) com pacientes oncológicos.

Quanto aos ganhos obtidos com a PBO realizada em 2003, os relatos revelaram que todos os participantes têm uma visão positiva acerca da influência da psicoterapia em suas vidas. De modo geral, os participantes fizeram referência à importância de práticas saudáveis e às técnicas de respiração diafragmática e de relaxamento muscular progressivo aprendidas e discutidas durante a psicoterapia. Também disseram que se sentem mais tranquilos, seguros e confiantes, conscientes quanto ao que falam e fazem, compreensivos e com maior controle da ansiedade e do nervosismo. Ressalta-se, portanto, que após a $\mathrm{PBO}$, todos os participantes obtiveram avaliações adaptativas melhores do que as apresentadas antes da psicoterapia e que todos obtiveram melhoras nas lesões de LPO, ocorrendo um caso de remissão total. Tais resultados sugerem que a psicoterapia pode ter contribuído para a significativa melhora das lesões de LPO logo após sua realização, em 2003, e que pode ter sido importante fator em sete dos casos estudados, em que se observou melhora ou manutenção das lesões de LPO após cinco anos da PBO, conforme depoimentos dos participantes. Decorridos cinco anos do tratamento psicoterápico realizado, seis casos apresentavam remissão total das lesões de LPO, um dos casos teve redução das lesões e apenas três casos tiveram aumento daquelas. Quanto às avaliações da eficácia 
adaptativa, os resultados mostraram que seis casos tiveram melhor avaliação, três mantiveram a mesma avaliação e apenas um caso apresentou pior avaliação de eficácia adaptativa.

A literatura aponta que as psicoterapias são mais eficientes em gerar mudanças positivas quanto às queixas ou aos problemas dos pacientes do que a simples passagem do tempo. Tais melhoras podem ser gerais (na qualidade de vida, nas relações com outros, no funcionamento global do paciente, entre outras) ou específicas (mudanças positivas diretamente relacionadas às queixas ou dificuldades tratadas na psicoterapia). Importantes aspectos referentes à avaliação de ganhos terapêuticos com a psicoterapia são discutidos por Cordioli (1993). Neme (2005) avaliou ganhos terapêuticos específicos e inespecíficos com a psicoterapia breve em 130 pacientes oncológicos atendidos em psicoterapia breve em hospital geral, constatando que a maioria significativa dos pacientes teve ganhos inespecíficos e que mais da metade da amostra obteve ganhos específicos.

Apresentam-se os resultados comparativos, quanto às variáveis estudadas, em termos de melhora, piora ou manutenção da eficácia adaptativa e das lesões de LPO, presença ou ausência de estresse relatado e estratégias e recursos de enfrentamento utilizadas frente ao estresse ao longo dos cinco anos de intervalo entre as avaliações.

Tabela 2 - Comparação das variáveis estudadas.

\begin{tabular}{cccll}
\hline Participante & $\begin{array}{c}\text { Evolução } \\
\text { adaptativa } \\
2 \text { (cinco } \\
\text { anos depois } \\
\text { da PBO) }\end{array}$ & $\begin{array}{c}\text { Evolução } \\
\text { LPO 2 } \\
\text { (cinco anos } \\
\text { depois da } \\
\text { PBO) }\end{array}$ & $\begin{array}{c}\text { Eventos de } \\
\text { estresse } \\
\text { relatados } \\
\text { como } \\
\text { significativos }\end{array}$ & $\begin{array}{c}\text { Recursos e estratégias de } \\
\text { enfrentamento }\end{array}$ \\
\hline 1 & Melhora & Melhora & NÃO & \\
\hline 2 & Melhora & Piora & $\begin{array}{l}\text { SIM } \\
\text { (família; } \\
\text { situação } \\
\text { econômica) }\end{array}$ & $\begin{array}{l}\text { Estratégias dirigidas à } \\
\text { resolução do problema è̀s } \\
\text { emoços }\end{array}$ \\
\hline
\end{tabular}


continuação

\begin{tabular}{|c|c|c|c|c|}
\hline Participante & $\begin{array}{l}\text { Evolução } \\
\text { adaptativa } \\
2 \text { (cinco } \\
\text { anos depois } \\
\text { da PBO) }\end{array}$ & $\begin{array}{l}\text { Evolução } \\
\text { LPO 2 } \\
\text { (cinco anos } \\
\text { depois da } \\
\text { PBO) }\end{array}$ & $\begin{array}{l}\text { Eventos de } \\
\text { estresse } \\
\text { relatados } \\
\text { como } \\
\text { significativos }\end{array}$ & $\begin{array}{l}\text { Recursos e estratégias de } \\
\text { enfrentamento }\end{array}$ \\
\hline 3 & Manut. & Piora & $\begin{array}{l}\text { SIM } \\
\text { (família; } \\
\text { morte do } \\
\text { marido) }\end{array}$ & $\begin{array}{l}\text { Fé como recurso de } \\
\text { enfrentamento e mudança } \\
\text { cognitiva }\end{array}$ \\
\hline 4 & Melhora & Piora & $\begin{array}{l}\text { SIM } \\
\text { (saúde) }\end{array}$ & $\begin{array}{l}\text { Fé como recurso de } \\
\text { enfrentamento e mudança } \\
\text { cognitiva }\end{array}$ \\
\hline 5 & Melhora & Melhora & NÃO & \\
\hline \multirow[t]{2}{*}{6} & \multirow[t]{2}{*}{ Manut. } & \multirow[t]{2}{*}{ Melhora } & $\begin{array}{l}\text { SIM } \\
\text { (saúde) }\end{array}$ & $\begin{array}{l}\text { Fé como recurso de } \\
\text { enfrentamento e estratégias } \\
\text { dirigidas à solução do } \\
\text { problema }\end{array}$ \\
\hline & & & $\begin{array}{l}\text { SIM } \\
\text { (família; } \\
\text { conflitos) }\end{array}$ & $\begin{array}{l}\text { Estratégias dirigidas à } \\
\text { emoção }\end{array}$ \\
\hline 7 & Melhora & Melhora & $\begin{array}{l}\text { SIM } \\
\text { (família; } \\
\text { morte do } \\
\text { irmão) }\end{array}$ & $\begin{array}{l}\text { Fé como recurso de } \\
\text { enfrentamento e estratégias } \\
\text { dirigidas às cognições e } \\
\text { emoções }\end{array}$ \\
\hline 8 & Piora & Melhora & NÃO & \\
\hline \multirow[t]{2}{*}{9} & \multirow[t]{2}{*}{ Melhora } & \multirow[t]{2}{*}{ Melhora } & $\begin{array}{l}\text { SIM } \\
\text { (famíla; } \\
\text { conflitos) }\end{array}$ & $\begin{array}{l}\text { Estratégias dirigidas à } \\
\text { emoção }\end{array}$ \\
\hline & & & $\begin{array}{l}\text { SIM } \\
\text { (trabalho; } \\
\text { perdas) }\end{array}$ & $\begin{array}{l}\text { Estratégias dirigidas ao } \\
\text { problema }\end{array}$ \\
\hline \multirow[t]{3}{*}{10} & \multirow[t]{3}{*}{ Manut. } & \multirow[t]{3}{*}{ Melhora } & $\begin{array}{l}\text { SIM } \\
\text { (trabalho; } \\
\text { conflitos) }\end{array}$ & $\begin{array}{l}\text { Estratégias dirigidas à } \\
\text { emoção }\end{array}$ \\
\hline & & & $\begin{array}{l}\text { SIM } \\
\text { (família; } \\
\text { morte da } \\
\text { sobrinha) }\end{array}$ & $\begin{array}{l}\text { Fé como recurso de } \\
\text { enfrentamento e estratégias } \\
\text { dirigidas à emoção }\end{array}$ \\
\hline & & & $\begin{array}{l}\text { SIM } \\
\text { (família; } \\
\text { saúde) }\end{array}$ & $\begin{array}{l}\text { Estratégia dirigida à } \\
\text { resolução do problema }\end{array}$ \\
\hline
\end{tabular}


A PBO auxiliou no desenvolvimento ou no fortalecimento de modos de enfrentamento mais efetivos das situações estressantes e, dessa forma, contribuiu para a redução ou remissão das lesões de LPO, avaliadas após o término da psicoterapia, o que é corroborado pelos depoimentos dos participantes na avaliação de 2003, durante as sessões de psicoterapia e na entrevista de 2008. A psicoterapia mostrou-se como efetiva forma de tratamento, único ou coadjuvante, em casos de doenças orgânicas que ainda não dispõem de tratamentos médico-medicamentosos efetivos e para quadros orgânicos que demonstrem melhoras com o auxílio da psicoterapia. Femiano et al. (2004) utilizaram e relataram a eficácia da psicoterapia psicanalítica na Síndrome da Ardência Bucal, enfatizando que esse método poderia ser estendido a outras enfermidades.

Os resultados obtidos e os encontrados na literatura em psicossomática e psicoimunologia são indicativos da integração psicofisiológica na saúde e na doença, fortalecendo a utilização de técnicas e de recursos psicológicos e psicoterapêuticos na prevenção e no tratamento de moléstias orgânicas.

\section{Considerações finais}

Este estudo longitudinal permitiu constatar a relevância da colaboração entre odontólogos e psicólogos, tanto na investigação científica de fenômenos de interesse para ambas as áreas, como na intervenção junto a portadores de patologias como o LPO, cuja gênese indica a junção de fatores biopsicossociais e cujo tratamento médico, odontológico e medicamentoso não é curativo, não se dispondo ainda de condutas médico-odontológicas totalmente satisfatórias.

O modelo de psicoterapia breve utilizado demonstrou eficácia em auxiliar os participantes a obter melhoras em sua capacidade adaptativa, podendo-se sugerir que esses ganhos colaboraram para a redução de suas lesões de LPO. A PBO possivelmente auxiliou os participantes a lidar de forma mais efetiva com situações de estresse, permitindo a manutenção de melhoras nas lesões de LPO, mes- 
mo após cinco anos decorridos entre o témino da psicoterapia e a avaliação realizada em 2008. Os ganhos terapêuticos também foram observados nos partipantes que melhoraram ou mantiveram sua eficácia adaptativa no decorrer dos cinco anos entre as avaliações realizadas no estudo, já que nenhum dos participantes realizou qualquer tipo de tratamento para o LPO ou outros tratamentos psicológicos nesse período.

O método longitudinal foi fundamental para a averiguação dos possíveis benefícios obtidos com a psicoterapia, decorridos cinco anos entre sua realização e a última avaliação, revelando a eficácia da aprendizagem de recursos terapêuticos como o relaxamento e outras orientações terapêuticas, conforme relato dos participantes.

Sugere-se que a psicoterapia seja oferecida em serviços médicos e odontológicos, especialmente para pacientes com doenças relacionadas ao funcionamento psicoimunológico e que, como o LPO, podem evoluir para manifestações mais graves, como o câncer. Sugere-se, também, que outros estudos longitudinais sejam realizados em diferentes interfaces entre a Psicologia e outras especialidades em saúde, aprimorando e aprofundando os conhecimentos já disponíveis sobre o imbricamento de variáveis biológicas e psicológicas no aparecimento e no tratamento de diversas patologias. Tais estudos, assim como o presente trabalho, podem beneficiar-se de mensurações objetivas e de avaliações qualitativas, fortalecendo os resultados obtidos.

\section{Referências bibliográficas}

ALVES, H. Psicoterapia breve operacionalizada-PBO com adolescentes da rede pública escolar da cidade de Santos-SP: uma contribuição à psicologia clínica preventiva. Tese. (Doutorado). Psicologia. Instituto de Psicologia da USP, São Paulo, 2001.

ARAYA, M. S. et al. Asociacion entre alteraciones psicológicas y la presencia de Líquen plano oral, Síndrome boca urente y Estomatitis aftosa recidivante. Méd Oral. EUA, v.9, p.1-7, 2004. 
CHAUDHARY, S. Psychosocial stressors in oral lichen planus. Aust. Dent. Journal. Murad-Nagar, Ghaziabad, India, v.49, n.4, p.192-5, 2004.

COLOMBINI, N. E. P. Lesões pré-cancerizaveis. Rev. Odontologia Moderna. Curitiba, v.14, n.3, p.36-46, ago. 1987.

CORDIOLI, A. V. (Org). Psicoterapias: abordagens atuais. Porto Alegre: Artes Médicas, 1993.

DAMETO, C. A. Adolescentes do sexo feminino com transtornos mentais: fatores de risco, mecanismos de proteção e eficácia adaptativa. 2007. Dissertação (Mestrado). Psicologia do Desenvolvimento e da Aprendizagem. Faculdade de Ciências da Unesp, Bauru, 2007.

DHABHAR, F. S.; McEWEN, B. S. Stress-induced enhancement of antigen-specific cell mediated immunity. Journal of Immunology. Bethesda, EUA, v.156, p.2608-15, 1996.

DORTA, R. G. et al. Conduta médica em pacientes com líquen plano cutâneo e bucal. Rev. FOB. Bauru, v.8, n.3/4, p.23-8, jul.-dez. 2000.

FEMIANO, F; GOMBOS, F.; SCULlY, C. Síndrome de boca ardiente. Estúdio de la psicoterapia, medicación com ácido alfalipoico y combinación de terapias. Med Oral. EUA, v.9, p.8-13, 2004.

FREITAS, M. C.; OLIVEIRA, M. F. Assistência de enfermagem a idosos que realizam cateterismo cardíaco: uma proposta a partir do modelo de adaptação de Calista Roy. Rev. Bras. Enfermagem, Brasília, v.59, n.5, set.-out. 2006. Disponível em: <http://www.scielo.br/ scielo.php? script $=$ sci_arttext $\&$ pid $=\& \operatorname{lng}=\& \mathrm{nrm}=\mathrm{iso}>$. Acesso em: 28 out. 2008.

HOFFMANN, F. S. et al. A integração mente e corpo em psicodermatologia. Psicologia: Teoria e Prática. São Paulo, v.7, n.1, p.51-60, 2005.

KIECOLT-GLASER, J. K. et al. Marital quality, marital disruption, and immune function. Psychosomatic Medicine. Inverness, EUA, v.49, p.13-8, 1987.

LAZARUS, R. S.; FOLKMAN, S. Estrés y procesos cognitivos. México: Martinez Roca, 1986.

LIPP, M. E. N. (Org). Pesquisas sobre stress no Brasil: saúde ocupações e grupos de risco. Campinas: Papirus, 1996. O stress está dentro de você. São Paulo: Contexto, 2003. 
; ROCHA, J. C. Stress, hipertensão arterial e qualidade de vida. Campinas: Papirus, 1996.

; MALAGRIS, L. E. N.; NOVAIS, L. E. Stress ao longo da vida. São Paulo: Ícone, 2007.

MARCUSSI, G. Lesões cancerizáveis da mucosa bucal. Rev. Paul. Odontologia. São Paulo, v.19, n.2, p.22-7, jun.-jul. 1997.

MELLO FILHO, J. Psicossomática hoje. Porto Alegre: Artes Médicas, 1992.

; MOREIRA, M. D. Psicoimunologia hoje. In: . Psicossomática hoje. Porto Alegre: Artes Médicas, 1992, p.119-51.

MIGUEL, M. C. C.; PINTO, L. P.; SOUZA, L. B. de. Líquen plano oral: relato de caso em criança. Rev. Bras. Patologia Oral. Natal, v.2, n.3, p.14-7, jul.-set. 2003.

MONTI, L. M. et al. Avaliação da condição psicológica e de saúde de pacientes portadores de líquen plano. Revista Odontológica de Araçatuba. Araçatuba, v.27, n.2, p.123-28, 2006.

NALIBOFF, B. D. et al. Psychological, psychophysiological and immunological changes in young and old subjects during brief laboratory stress. Psychosomatic Medicine. Inverness, EUA, v.53, p.121-32, 1991.

NEME, C. M. B. Abandono prematuro da psicoterapia: um estudo exploratório comparando motivos alegados por pacientes que abandonaram ou não a psicoterapia. Dissertação (Mestrado). Psicologia Clínica. Pontifícia Universidade Católica, Campinas, 1991.

Enfrentamento do câncer: ganhos terapêuticos com psicoterapia num serviço de Psico-oncologia em Hospital Geral. 1999. Tese (Doutorado). Psicologia Clínica. Pontifícia Universidade Católica, São Paulo,1999.

Ganhos terapêuticos em psicoterapia breve em serviço de psico-oncologia hospitalar. In: SIMON, C. P.; MELO-SILVA, L. L.; SANTOS, M. A. (Orgs.). Formação em Psicologia: desafios da diversidade na pesquisa e na prática. São Paulo: Vetor, 2005, p.39-66.

; SOLIVA, S. N.; RIBEIRO, E. J. História prévia de eventos de estresse e câncer de mama, útero e ovários. In: ; RODRIGUES, O. M. P. R. (Orgs.). Psicologia da saúde: perspectivas interdisciplinares. São Carlos: Rima, 2003, p.95-124. 
NEVILLE, B. W. et al. Patologia oral \& maxilofacial. Rio de Janeiro: Guanabara Koogan, 2004.

PRADO, M. C. P. et al. Reações liquenoides da mucosa bucal. Rev. Odontol. Univ. Säo Paulo. São Paulo, v.8, n.3, p.221-4, 1994.

REGEZI, J. A.; SCIUBBA, J. J. Patologia bucal: correlações clínicopatológicas. Rio de Janeiro: Guanabara Koogan, 2000.

RODRIGUES, M. Análise crítica do possível potencial de transformação malígna do líquen plano. Dissertação (Mestrado). Patologia Bucal. USP, São Paulo, 1999.

SARDÁ JUNIOR, J. J.; LEGAL, E. J.; JABLONSKI JUNIOR, S. J. Estresse: conceitos, métodos, medidas e possibilidades de intervenção. São Paulo: Casa do Psicólogo, 2004.

SEOANE, J. et al. Oral lichen planus: a clinical and morphometric study of oral lesions in relation to clinical presentation. Braz Dent J. São Paulo, v.5, n.1, p.9-12, 2004.

SHAFER, W. G. Tratado de patologia bucal. Rio de Janeiro: Interamericana, 1985.

SIMON, R. Psicologia clínica e preventiva: novos fundamentos. São Paulo: E.P.U., 1989.

Psicoterapia breve operacionalizada: teoria e técnica. São Paulo: Casa do Psicólogo, 2005.

SOLOMON, G. F. Stress and antibody response in rats. International Archives of Allergy. Viena, Áustria, v.35, p.97-104, 1969.

Immune and nervous system interactions: an analytic bibliography supporting postulates on communication links, similarities and implications. The Fund for Psychoneuroimmunology. Los Angeles, EUA, 1999.

SOUSA, F. A. C. G.; ROSA, L. E. B. Líquen plano bucal: considerações clínicas e histopatológicas. Rev Bras Otorrinolaringologia. São Paulo, v.74, n.2, p.65-72, mar.-abr. 2008.

SUGERMAN, P. B. et al. The pathogenesis of oral lichen planus. Crit. Rev. Oral Biol. Med. EUA, v.13, n.4, p.350-65, 2002.

TOMMASI, A. F. Diagnóstico em patologia bucal. São Paulo: Artes Médicas, 1988.

ULLA, S.; REMOR, E. A. Psiconeuroimunologia e infecção por HIV: realidade ou ficção? Psicol. Reflexão e Crítica. Porto Alegre, v.15, n.1, 2002. 
VALLEJO, M. J. et al. Anxiety and depression as risk factors for oral lichen planus. Dermatology. Oviedo, Espanha, v.203, n.4, p.303-7, 2001.

VASCONCELLOS, E. G. Psiconeuroimunologia: uma história para o futuro. In: ANGERAMI-CAMON, V. A. (Org.). Psicologia da saúde: um novo significado para a prática clínica. São Paulo: Pioneira, 2000, p.23-41. 
SOBRE O LIVRO

Formato: $14 \times 21 \mathrm{~cm}$

Mancha: $23,7 \times 42,5$ paicas

Tipologia: Horley Old Style 10,5/14

1a edição: 2010

\section{EQUIPE DE REALIZAÇÃO}

Coordenação Geral

Marcos Keith Takahashi 